VICTOR KENITI SAKANO

METODOLOGIA PARA AQUISIÇÃO DE SINAL ELÉTRICO E TRATAMENTO DE DADOS EM REÔMETROS SERVO CONTROLADOS

SÃO PAULO

2016 


\section{METODOLOGIA PARA AQUISIÇÃO DE SINAL ELÉTRICO E TRATAMENTO DE DADOS EM REÔMETROS SERVO CONTROLADOS}

Dissertação apresentada à Escola Politécnica da Universidade de São Paulo para obtenção do título de Mestre em Engenharia

Área de concentração: Engenharia de Construção Civil e Urbana

Orientador: Prof. Dr. Rafael Giuliano Pileggi 
Autorizo a reprodução e divulgação total ou pacial deste trabalho, por qualquer meio convencional ou eletrônico, para fins de estudo e pesquisa, desde que citada a fonte.

Este exemplar foi revisado e corrigido em relação à versão original, sob responsabilidade única do autor e com a anuência de seu orientador.

São Paulo, 06 de__unho de 2016

Assinatura do autor:

Assinatura do orientador:

Catalogação-na-publicação

Sakano, Victor Keniti

Metodologia para aquisição de sinal elétrico e tratamento de dados em reômetros servo controlados / V. K. Sakano -- versão corr. -- São Paulo, 2016. $136 \mathrm{p}$.

Dissertação (Mestrado) - Escola Politécnica da Universidade de São Paulo. Departamento de Engenharia de Construção Civil.

1.Reologia 2.Reômetro 3.Filtro digital 4.Sinal analógico 5.Software de pós tratamento I.Universidade de São Paulo. Escola Politécnica. Departamento de Engenharia de Construção Civil II.t. 


\section{AGRADECIMENTOS}

Aos meus pais Milton e Célia, à minha irmã Yumi e minha namorada Gabriela pelo apoio e incentivo ao desenvolvimento do mestrado.

Ao Prof. Rafael Pileggi pela orientação e confiança para o desenvolvimento deste trabalho. Especialmente pelos ensinamentos profissionais e pessoais.

Ao Prof. Gustavo Rehder, sempre paciente, pelo esclarecimento dos princípios elétricos envolvidos no reômetro servo controlado e disponibilidade do uso do laboratório para realização de testes.

Ao Prof. Magno da Silva pela cordialidade em ensinar os princípios envolvidos no processamento do sinal elétrico e também auxiliar no desenvolvimento do filtro digital.

À Prof. Lucia Filgueiras pelo incentivo à realização do mestrado e pelo auxílio no desenvolvimento do software.

À Engracia Bartuciotti por estar sempre disposta em auxiliar todos os tramites administrativos.

Ao Mário Takeashi, técnico do laboratório, pela boa vontade em todos os momentos e pelas fotografias realizadas.

À Wandrea Dantas pela prontidão em sempre auxiliar a resolver problemas burocráticos da pós-graduação.

Aos colegas de laboratório (Cesar, Fábio, Marco, Liz, Markus, Marylinda, Winnie, Franco, Marcel, Juliana e Heitor) pela convivência diária, pelas discussões e auxilio nos ensaios.

À CAPES pelo apoio financeiro 
"Se tiver o hábito de fazer as coisas com alegria, raramente encontrará situações difíceis"

Baden Powell 


\section{RESUMO}

A ciência na qual se estuda a deformação de um fluido no qual é aplicada uma tensão de cisalhamento é conhecida como reologia e o equipamento utilizado para a realização dos ensaios é chamado de reômetro. Devido a impraticabilidade de uso de reômetros comerciais, diversos pesquisadores desenvolveram reômetros capazes de analisar suspensões de macropartículas, baseados nos mesmos princípios de funcionamento dos equipamentos já existentes. Em alguns casos, a medição do torque do motor é realizada pela aquisição da tensão, uma vez que esta é proporcional ao torque. Entretanto, para melhor compreensão do resultado e para evitar a possibilidade de conclusões precipitadas, vê-se necessária correta interpretação do sinal elétrico, precisando avaliar qual frequência do sinal é relevante para o ensaio e, também, qual a melhor taxa de amostragem. Além da aquisição, para que o ensaio reológico seja realizado com precisão, é indispensável ótimo controle da taxa ou tensão do motor e uma alternativa é a utilização de um servomotor e um servoconversor. No caso desse ser comercial é essencial saber configurá-lo. Para facilitar o usuário leigo, alguns pesquisadores desenvolveram softwares para controle do equipamento e análise dos dados. Assim, o presente trabalho tem como objetivo propor uma metodologia para compreender o sinal aquisitado de um reômetro servo controlado e desenvolvimento do software de análise para o tratamento dos dados obtidos a partir de ensaios reológicos. Verificou-se a melhor configuração do servocontrolador, a melhor taxa de amostragem, de no mínimo 20 amostras/segundo, e, também, desenvolveu-se um filtro digital passa-baixa do tipo FIR para remover a frequência indesejada. Além disso, foi desenvolvido um software utilizando uma rotina em Matlab e uma interface gráfica do usuário (Graphical User Interface - GUI), para o pós-processamento dos dados para auxiliar o usuário leigo no tratamento e interpretação do resultado, que se mostrou eficaz.

Palavras-chaves: Reologia; Reômetro; Filtro digital; Sinal analógico; Software de pós-tratamento. 


\section{ABSTRACT}

Rheology is the study of the behavior of material in fluid state. Rheometer is the equipment used to perform rheological measurements. Because of the impracticability of commercial rheometer, many researchers have developed rheometer able to analyze macro particles suspension, based on the principle of operation of the existing equipment. In some cases, measurement of the motor torque is performed by acquiring voltage signal, since is proportional to torque. However, for better understanding of the rheological results, it is necessary to understand the electrical signal, evaluating which signal frequency is relevant and what is the best sample rate. In addition, for an accurate rheological testing, it is essential a precise control of the shear rate or shear stress of the motor and a good alternative is the use of a servomotor and a drive. In the case of the drive being commercial, it is essential to know how to configure it. To turn rheometer user-friendly, some researchers have developed software to control the equipment and to analyze data. Thus, this dissertation propose a methodology to understand the electrical signal of a servo controlled rheometer and development of analysis software to process the data obtained from rheological tests. It has been found the best configuration of the servo drive, minimum sampling rate of 20 samples/second, and development of a low pass digital filter to remove unwanted frequency. In addition, was developed a software using a Matlab routine and a Graphical User Interface (GUI) to assist the user in the processing and interpretation of the result.

Keywords: Rheology; Rheometer; Digital filter; Analog signal; pos-processing software. 


\section{SUMÁRIO}

1 INTRODUÇÃO

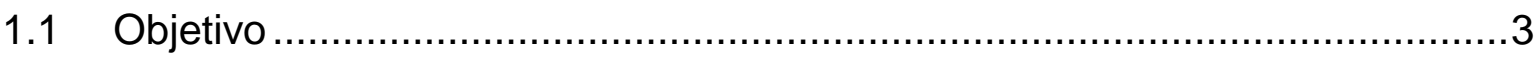

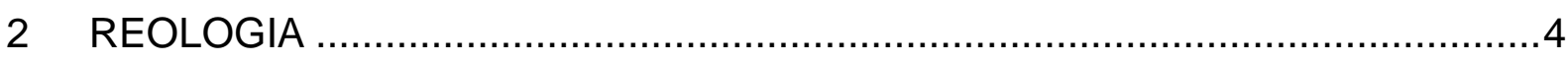

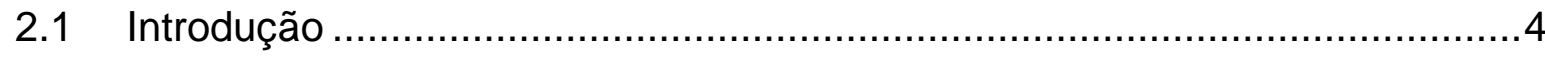

2.2 Conceito de viscosidade e tensão de escoamento …………......................

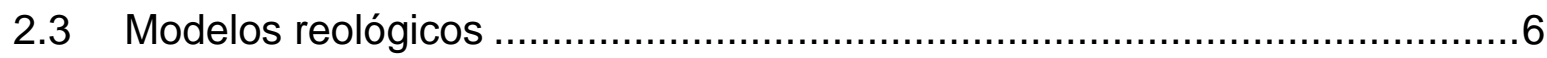

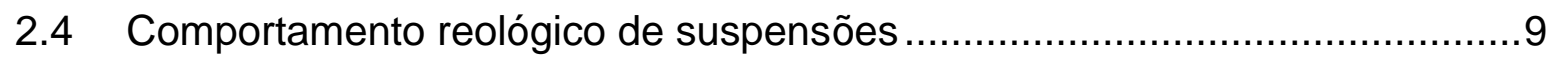

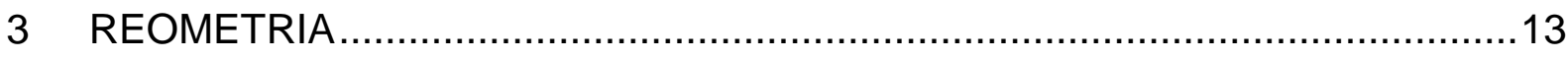

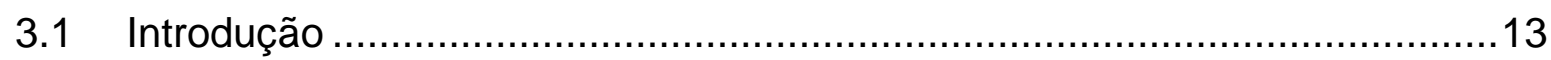

3.2 Tipos de reômetros e métodos de controle ..............................................14

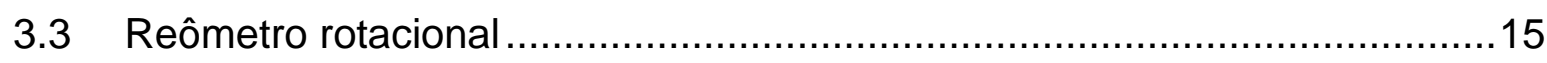

3.4 Modelos de reômetros para concretos e argamassa ………………….......17

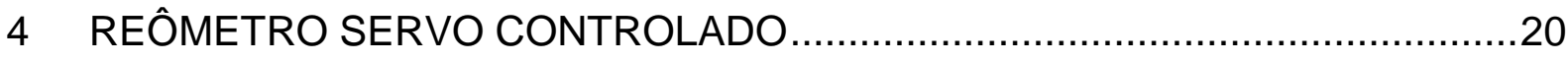

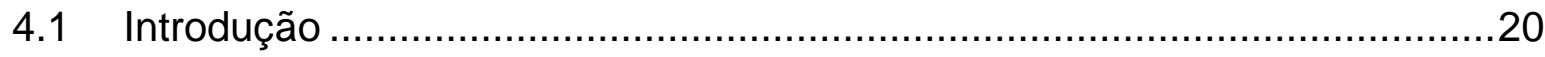

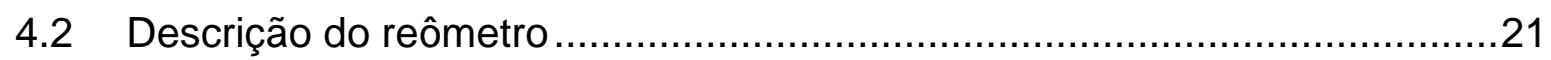

4.3 Potencial uso do reômetro servo controlado ............................................22

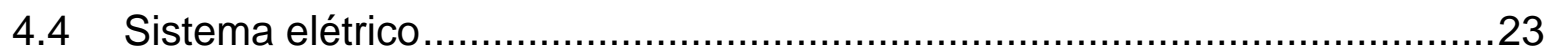

4.4.1 Definição de um servoconversor ....................................................24

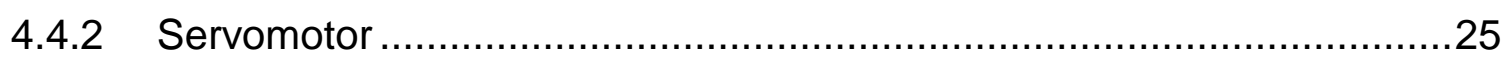

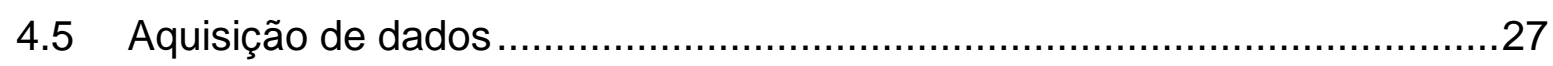

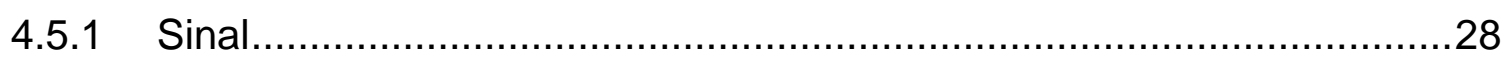

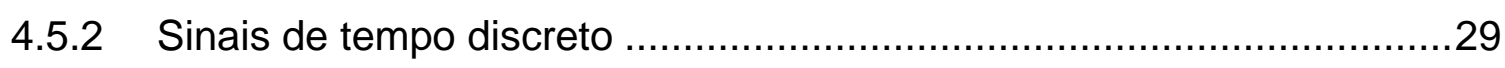

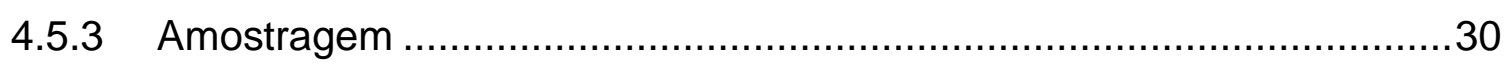

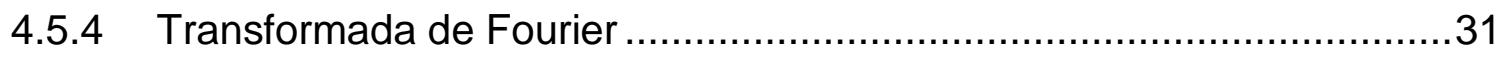

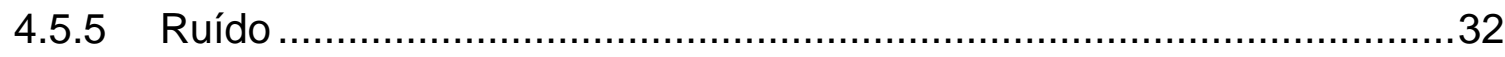

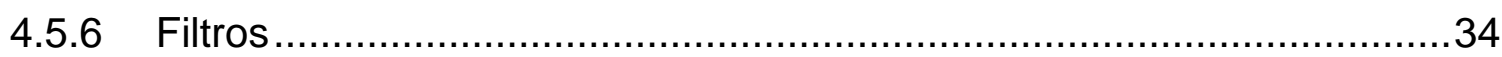




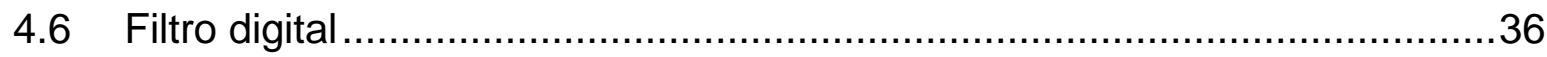

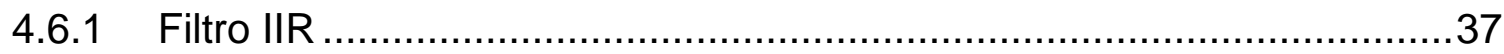

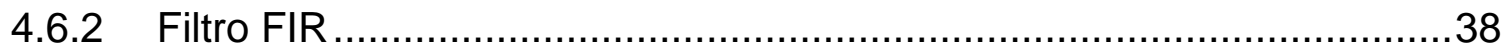

4.6.3 Comentários sobre os filtros FIR e IIR …….........................................43

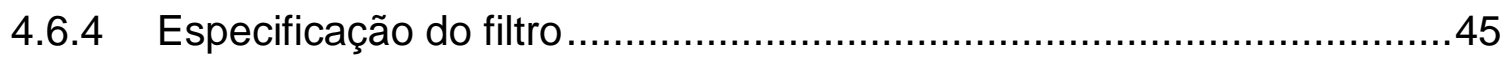

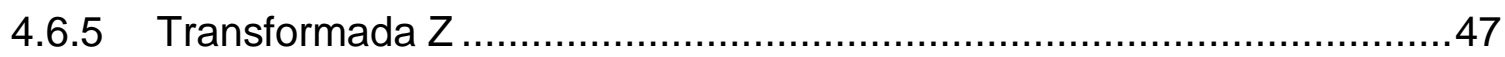

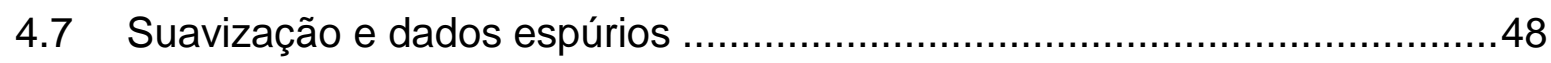

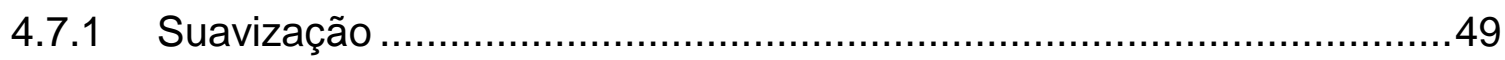

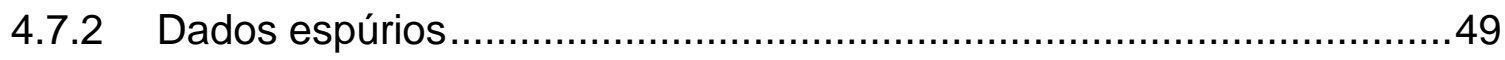

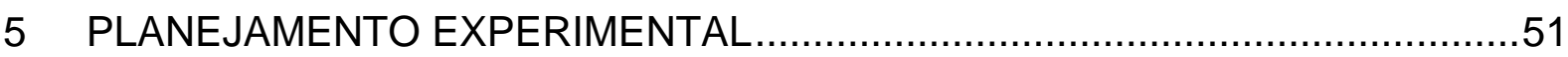

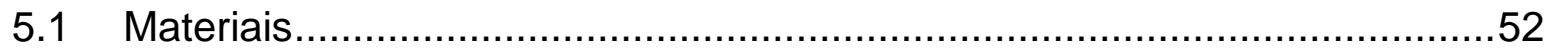

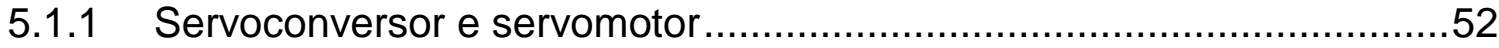

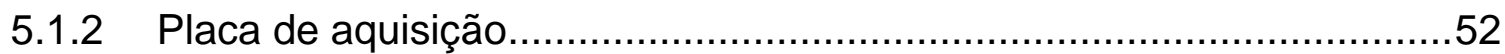

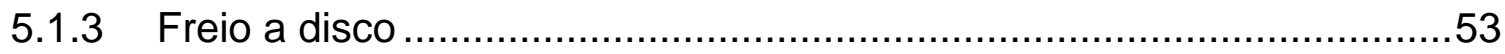

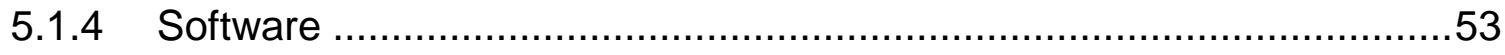

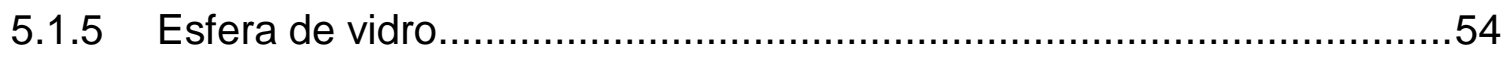

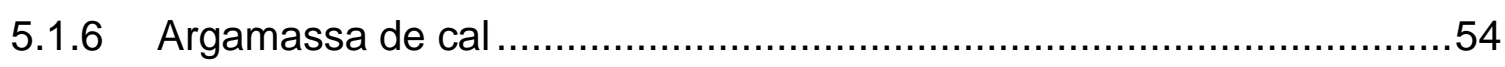

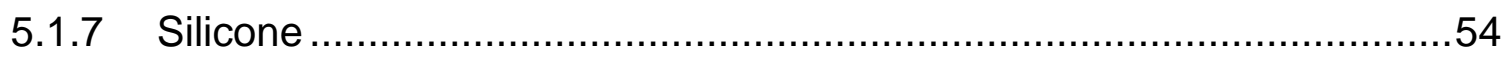

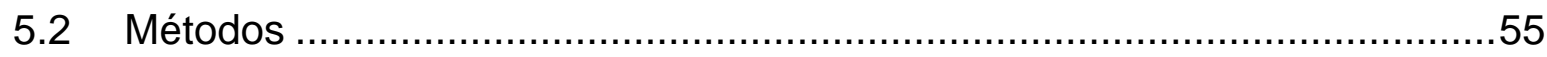

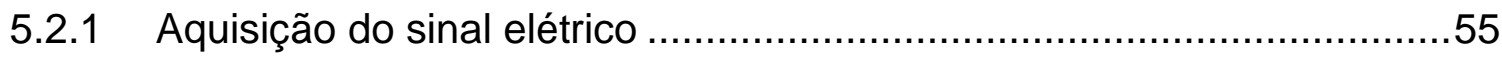

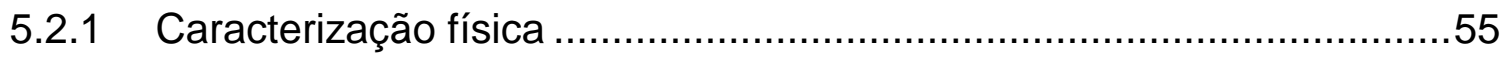

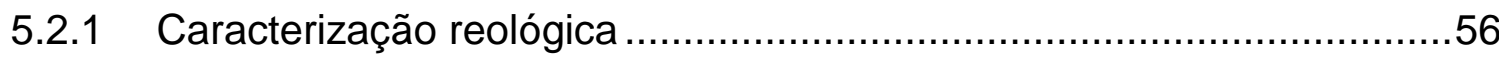

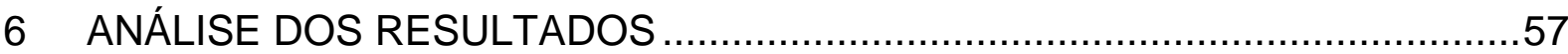

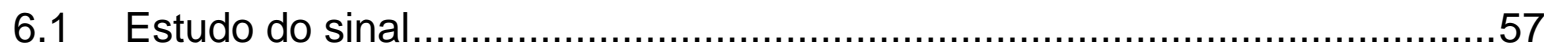

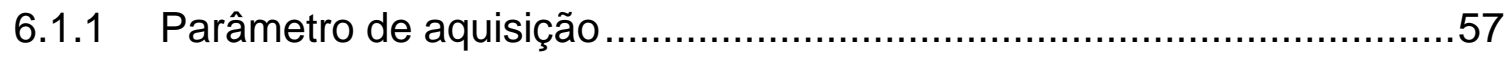

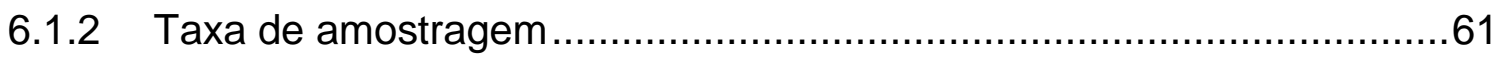

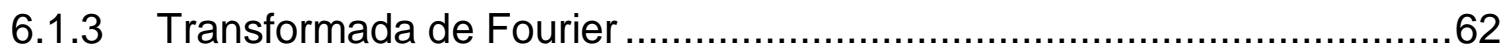


6.1.4 Comparação entre as placas de aquisição ........................................63

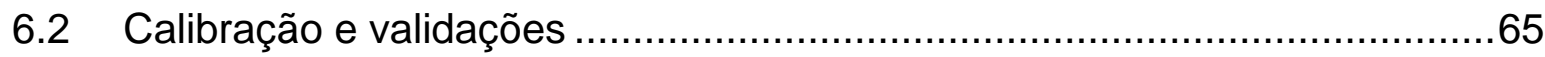

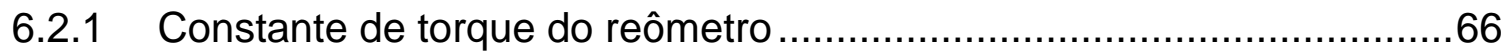

6.2.2 Linha base e repetibilidade do ensaio .................................................68

6.2.3 Teste de volume da amostra .......................................................

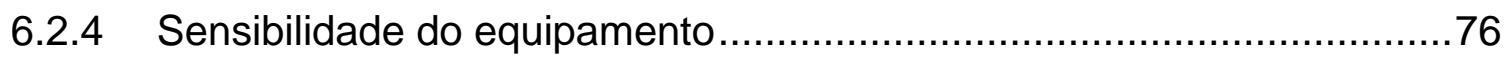

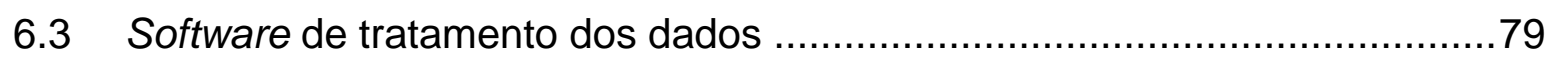

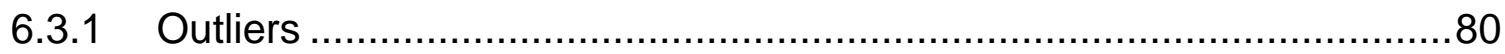

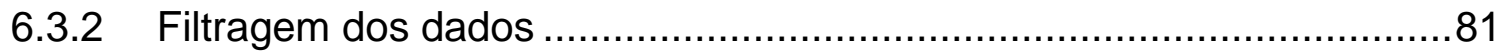

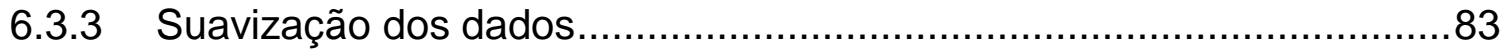

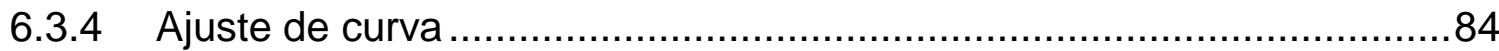

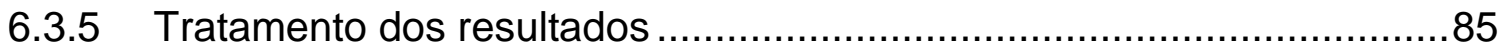

6.4 Comportamento reológico de suspensões com esferas rígidas com extensão

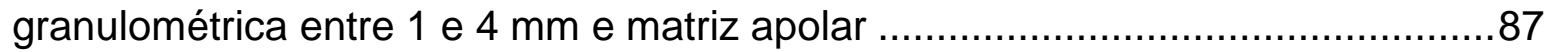

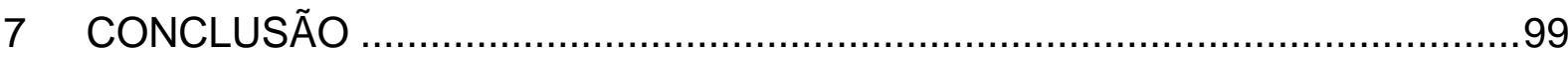

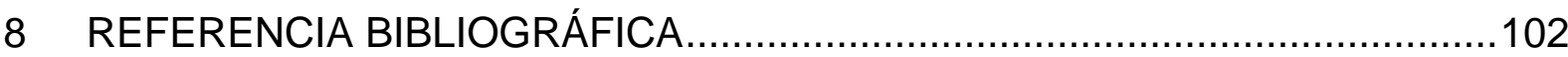

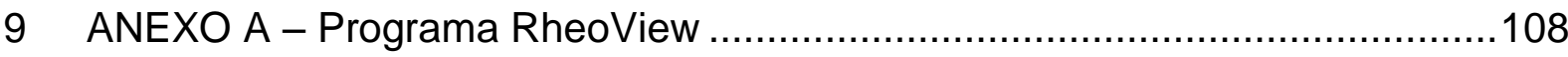

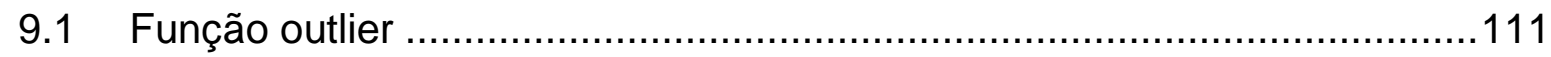

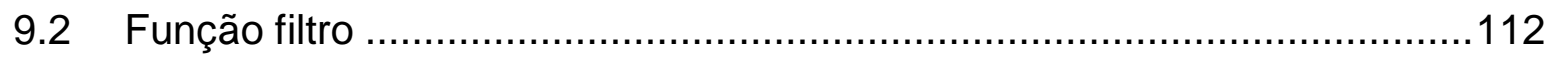

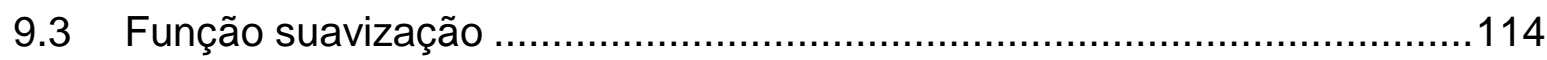

9.3.1 Média móvel .............................................................................114

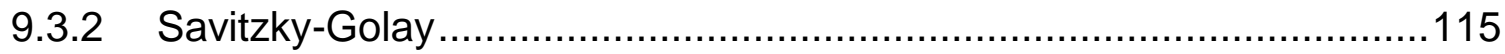

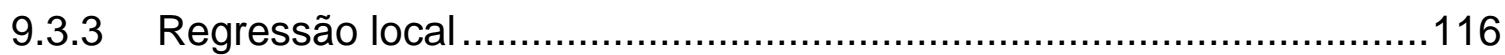

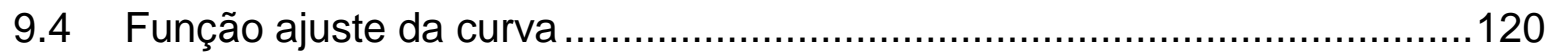

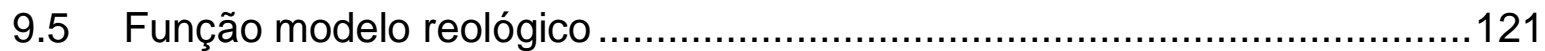

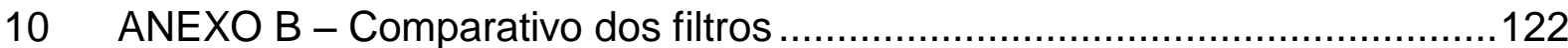




\section{INTRODUÇÃO}

O estudo da viscosidade de materiais surgiu com Newton através do experimento de placas paralelas (BARNES; HUTTON; WALTERS, 1989). Desencadeou pesquisas para compreensão, controle e previsão do comportamento dos materiais no estado fluido frente a solicitações externas, dando início ao ramo da reologia. Com essa ciência, surgiu a reometria, que responde pelas medições experimentais, sendo reômetro o equipamento de análise.

O reômetro possibilita quantificar grandezas reológicas como tensão de escoamento e viscosidade através da aplicação de uma taxa ou tensão cisalhante no material analisdo. Atualmente, diversas empresas comercializam reômetros, dimensionados para sistemas homogêneos, com geometrias adequadas para pequenos volumes e para partículas menores que $100 \mu \mathrm{m}$ (MACOSKO, 1994; STEFFE, 1996). No entanto, não se adequam a materiais como concretos e argamassas. Primeiro, por atuarem em faixa restrita de torque (MACOSKO, 1994; SCHRAMM, 2006). Segundo, por problemas causados pelo efeito parede devido à dimensão das macropartículas que compõem a suspensão (BANFILL, 2003). E terceiro, a representatividade da suspensão é afetada pelo reduzido volume requerido (TEUBERT, 1969).

Por conta dessa impraticabilidade, no ramo de materiais de construção civil, reômetros foram desenvolvidos para análise de suspensões de macropartículas, baseados nos princípios de funcionamento dos comerciais. O primeiro protótipo para caracterização reológica de concretos foi desenvolvido por Powers e Wiler (1941). Ainda viu-se necessário melhorar a mecânica e controle do equipamento e aquisição dos dados (KOEHLER; FOWLER, 2004). Consequentemente, outros pesquisadores desenvolveram reômetros utilizando novos mecanismos para melhorar a robustez, o controle e a aquisição de dados do equipamento (BANFILL et al., 2000; $\mathrm{HU}$ et al., 1996; KOEHLER; FOWLER, 2004; PILEGGI, 2001; WALLEVIK; GJORV, 1990).

Para cada reômetro, optou-se por uma técnica de aquisição do torque, por exemplo, célula de torque rotativa (KOEHLER; FOWLER, 2004) ou aquisição do sinal elétrico do motor (HU et al., 1996; PILEGGI, 2001; WALLEVIK; GJORV, 1990). Neste segundo caso, embora a tensão gerada no motor seja proporcional ao torque (CENG, 2000), a reconstrução do sinal elétrico depende tanto da taxa de amostragem quanto da 
interpretação do sinal para avaliação da frequência relevante para o ensaio, ambas feitas pelo usuário, podendo ocasionar em conclusões precipitadas (OPPENHEIM; SCHAFER, 2009).

Para que o ensaio reológico seja executado de forma precisa é necessário ter ótimo controle da taxa ou da tensão de cisalhamento (MACOSKO, 1994; SCHRAMM, 2006). Para tal, é primordial o controle preciso do motor, sendo a utilização de um servoconversor e um servomotor uma boa alternativa (ELLIS, 2004).

No caso do servoconversor para controle do servomotor ser comercial, é de primordial importância saber configurá-lo, diferenciando e atribuindo valores aos parâmetros de ajustes essenciais. Há diversas informações, como número de voltas e tensão, que podem ser aquisitadas no servoconversor pela saída analógica e/ou digital, dessa forma, deve-se entender qual sinal elétrico do motor corresponde ao ensaio.

Qualquer sinal contínuo é aquisitado em tempo discreto, ou seja, em instantes de tempo igualmente espaçados. Entretanto é preciso se atentar ao valor adotado da frequência de amostragem, para garantir a reconstrução posteriori do sinal. O sinal elétrico pode ser utilizado para transmissão de dados entre humanos e máquinas e, no caso do reômetro, transmite informações sobre o torque do motor. Provavelmente, o sinal apresentará uma fração indesejada, ou seja, um ruído (HOLMAN, 2012). O ruído é uma adição ao sinal de informação original que pode alterar seu conteúdo e, na maioria das vezes, dificultar a compreensão do resultado. Por isso, é importante verificar quais frequências do sinal são relevantes para o resultado (HOLMAN, 2012; OPPENHEIM; SCHAFER, 2009), sendo o filtro seletivo de frequência uma alternativa para atenuação do ruído.

Como os sinais elétricos podem ser representados de várias formas, em todos os casos a informação está contida em variações de algum padrão, que, normalmente, são representados matematicamente como funções de uma ou mais variáveis independentes. E por isso, sua manipulação é facilitada. Diversos pesquisadores criaram funções e algoritmos para o desenvolvimento de filtros digitais para remoção de sinais indesejados (OPPENHEIM; SCHAFER, 2009). No desenvolvimento de um filtro, precisam ser verificados diversos fatores como estabilidade, complexidade e resposta. 
Embora muitas conclusões sobre comportamento reológico de concreto e argamassas foram realizadas em reômetros, mostrando resultados satisfatórios, como queda do torque com o aumento de dispersante (BANFILL, 2003), sensibilidade quanto ao tipo de agregado (VALENCIA et al., 2015) ou utilização de incorporador de ar (TORRES et al., 2014), não foram encontradas em literatura referências a respeito da investigação do sinal elétrico usado para interpretação do torque medido do motor. Por isso, vê-se necessária metodologia de investigação do sinal elétrico obtido a partir de servoconversor de forma a garantir que o sinal represente fielmente o ensaio.

A maioria dos pesquisadores, juntamente com o reômetro, desenvolveu software para controle do equipamento e análise dos dados, a fim de facilitar e agilizar a utilização do equipamento e interpretação dos resultados por um usuário leigo (HU et al., 1996; KOEHLER; FOWLER, 2004; WALLEVIK; GJORV, 1990).

No grau de desenvolvimento em que se encontra o reômetro de Pileggi et al. (2015), percebe-se a possibilidade de evolução justamente quanto à investigação e à interpretação do sinal elétrico, a fim de refinar as informações analisadas e possibilitar um leque maior de exploração de outras famílias de suspensões. Embora este estudo se concentre em um reômetro específico servo controlado, entende-se que é simplesmente um caso aplicado, logo a metodologia pode ser aplicada para outros equipamentos dependentes da análise de sinal elétrico.

\subsection{Objetivo}

O presente trabalho tem como objetivo propor uma metodologia para compreender o sinal aquisitado de um reômetro servo controlado e desenvolvimento do software de análise para o tratamento dos dados obtidos a partir de ensaios reológicos. 


\section{REOLOGIA}

\subsection{Introdução}

Suspensões são formadas por uma fase sólida e uma fase líquida e/ou gasosa. O comportamento reológico é influenciado pela microestrutura das partículas. A microestrutura é uma função das ligações físico-químicas e as interações inter/intramolecular, que afeta fundamentalmente o fluxo característico do material, alterando os parâmetros reológicos, como por exemplo, viscosidade e tensão de escoamento. Estes parâmetros são medidos nos reômetros, no entanto é necessário compreender os fatores que afetam o comportamento reológico para compreender os resultados obtidos.

Reologia é a ciência que estuda o fluxo e a deformação dos materiais, avaliando as relações entre a tensão de cisalhamento aplicada e a deformação em determinado período de tempo, ou vice-versa (CHEREMISINOFF, 1986; MESCHYAN, 1995). Ela ocupa um vasto domínio entre a teoria da elasticidade clássica e a hidrodinâmica. Embora a reologia esteja relacionada com o fluxo e a deformação de matéria, incluindo líquidos, sólidos e gases, o termo reologia é principalmente usado para se referir ao estudo de fluidos.

Os objetos de estudo em reologia são materiais que apresentam propriedades reológicas, ou seja, elasticidade, plasticidade, viscosidade, relaxação e redução da resistência em longo prazo, que são características presentes em todos os corpos reais. As propriedades reológicas de cada material são manifestadas em diferentes maneiras e dependem do estado de tensão e deformação em que o corpo já se encontra, das suas características físicas e químicas, e de fatores como tensão, tempo, temperatura e pressão.

A compreensão do comportamento reológico no estado fluido possui forte relevância tecnológica, tanto em processo de fabricação (moldagem cerâmica, produtos cimentíceos, etc.) quanto nos produtos (cosméticos, alimentos, etc.). Sendo então, o domínio da natureza reológica dos distintos materiais no estado fluido de suma importância para os diferentes setores da sociedade. No caso da construção civil, os materiais como argamassa e concreto, são suspensões aquosas que despertam 
grande interesse, principalmente devido ao seu elevado consumo. A compreensão do comportamento reológico destes materiais é complexa, sobretudo na presença de partículas reativas como o cimento, as quais alteram as características dos sistemas a cada instante.

Neste capítulo são apresentados os conceitos fundamentais da reologia e os principais fatores que afetam o comportamento reológico de uma suspensão.

\subsection{Conceito de viscosidade e tensão de escoamento}

Para compreender viscosidade, é válida a distinção entre um material sólido elástico e líquido viscoso. Se o material apresenta comportamento elástico, o mesmo segue a lei de Hooke, que estabelece que sua deformação varie linearmente com a tensão aplicada. Se for aplicada uma tensão constante sobre este material, ele sofrerá deformação e quando a carga for removida a deformação será totalmente recuperada, desde que esteja dentro do regime elástico. Em contraste ao sólido elástico, um líquido viscoso deforma continuamente devido uma tensão cisalhante e sua deformação não será recuperada uma vez que a carga for removida. O caso bidimensional para o fluxo de um líquido viscoso entre duas placas paralelas de um comprimento suficiente de modo que os efeitos das extremidades possam ser ignorados foi estudada por Newton.

Newton apud Barnes, Hutton, Walters (1989), em 1687 definiu o parâmetro de viscosidade através da experiência de placas paralelas, conforme ilustrada na Figura 2.1. Segundo este modelo, duas placas paralelas de área (A) são separadas a com uma distância infinitesimal (dy) que se movem na mesma direção, mas com velocidades distintas $\left(\mathrm{V}_{1}>\mathrm{V}_{2}\right)$ sob a ação de uma força externa $(\mathrm{F})$.

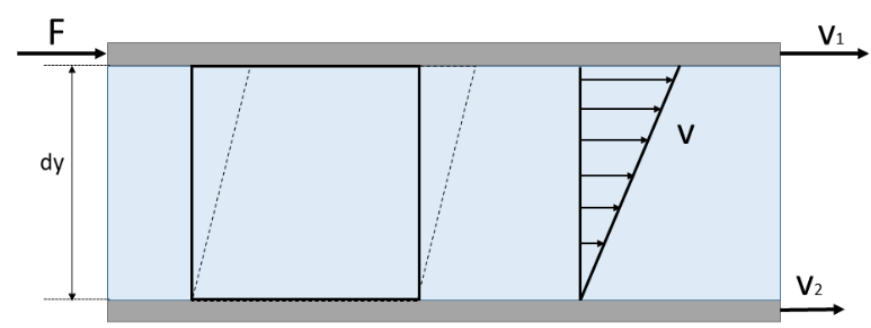

Figura 2.1: Modelo de Newton para definir o conceito de viscosidade. 
Devido à diferença de velocidade (dv), o fluido entre as placas é submetido a um cisalhamento simples. A taxa de cisalhamento $(\dot{\gamma})$ equivale ao gradiente de velocidade ao longo da distância entre as placas (dy), como expresso na Equação 2.1.

$$
\dot{\gamma}=\frac{d v}{d x}
$$

A viscosidade é uma propriedade do fluido que se caracteriza pela medida da resistência ao escoamento que este oferece quando se encontra sujeito a um esforço tangencial. Além disso, depende da temperatura e da pressão, de forma menos significativa.

Utilizando o modelo, Newton verificou que a viscosidade de um fluido ( $\eta$ ) é uma constante de proporcionalidade de primeira ordem que relaciona a taxa de cisalhamento $(\dot{\gamma})$ com a tensão de cisalhamento $(\tau)$ conforme a Equação 2.2.

$$
\tau=\frac{F}{A}=\eta \frac{d v}{d x}=\eta \dot{\gamma}
$$

Os fluidos cujo comportamento reológico segue a Equação 2.2 são chamados de fluidos newtonianos. Quando o fluido não apresenta uma linearidade entre a tensão e a taxa de cisalhamento, conforme apontada por Newton, o fluido é chamado de não newtoniano.

Outro importante parâmetro é a tensão de escoamento, correspondente a tensão mínima para que o escoamento de suspensões ou de fluidos se inicie. Quando submetidos a tensões menores que essa, os materiais se comportam como sólidos elásticos. A tensão de escoamento, na suspensão, é originada pela aglomeração das partículas, de modo a formar uma estrutura espacial rígida de partículas por toda suspensão (CHENG, 1986). A tensão de escoamento das suspensões corresponde àquela necessária para romper essa estrutura tridimensional de partículas.

\subsection{Modelos reológicos}

As propriedades de fluxo são normalmente representadas por curvas de tensão de cisalhamento $(\tau)$ em função da taxa de cisalhamento $(\dot{\gamma})$, conforme Figura $2.2(\mathrm{a})$. 


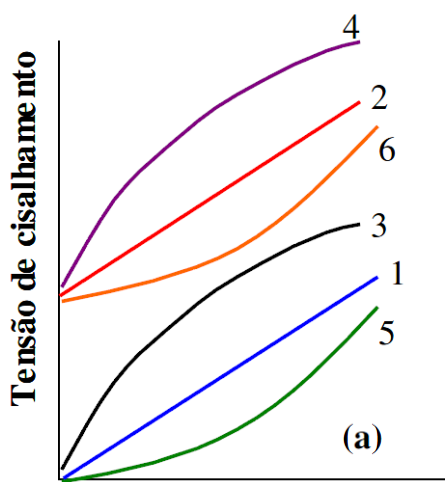

Taxa de cisalhamento

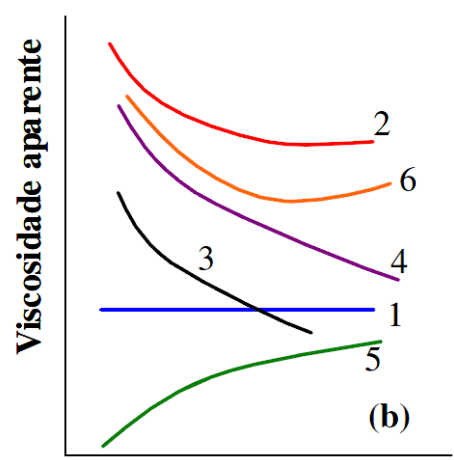

Taxa de cisalhame nto

Figura 2.2: Comportamento reológico dos fluidos: (1) newtoniano; (2) de Bingham; (3) pseudoplástico; (4) pseudoplástico com tensão de escoamento; (5) dilatante; (6) dilatante com tensão de escoamento (PILEGGI, 2001).

O comportamento dos fluidos se divide em dois grandes grupos, os newtonianos e os não newtonianos. O modelo newtoniano assume que a relação entre a tensão e taxa de cisalhamento é linear e que intercepta a origem do eixo da tensão de cisalhamento e taxa de cisalhamento, conforme a curva 1 na Figura 2.2 (a). Além disso, indica que a viscosidade é uma característica intrínseca e constante do material, independentemente da taxa de cisalhamento aplicada e do tempo a qual está submetido em uma dada temperatura e pressão, sendo representado pela curva 1 na Figura 2.2 (b). Na realidade, a maioria dos fluidos não apresenta este comportamento linear, e em muitos casos, apresentam uma tensão de escoamento, ou seja, é necessário superar esta tensão para iniciar o fluxo.

Os fluidos que possuem comportamento independente do tempo e dependem somente da taxa de cisalhamento, dado outros parâmetros constantes, dividem-se em dois grupos principais, que são representados na Figura 2.2: pseudoplástico (curva 3) e dilatante (curva 5). O comportamento dilatante ocorre quando a viscosidade aparente aumenta ao se elevar a taxa ou a tensão de cisalhamento. Já o comportamento pseudoplástico é caracterizado pela diminuição da viscosidade aparente com aumento da taxa ou da tensão de cisalhamento (BARNES, 1989).

A equação de estado reológico que descreve tal comportamento é conhecida como Lei de Potência, conforme a Equação 2.3. Na equação, $k$ é uma constate e $\mathrm{n}$ é um índice de comportamento do fluido. Se o expoente $\mathrm{n}$ for menor que 1 , será o caso do comportamento pseudoplástico e se $\mathrm{n}$ for maior que 1 , será o caso do comportamento dilatante. 


$$
\tau=k(\dot{\gamma})^{n}
$$

Os demais tipos de fluidos, representados pelas curvas 2, 4 e 6 da Figura 2.2, apresentam as mesmas propriedades gerais que caracterizam respectivamente os comportamentos newtoniano, pseudoplástico e dilatante, com a particularidade de exigirem a aplicação de uma tensão mínima de cisalhamento para o início do escoamento, denominada de tensão de escoamento.

Os fluidos que apresentam tensão de escoamento (Figura 2.2 (a)) são classificados como fluido de Bingham (curva 2), pseudoplástico com tensão de escoamento (curva 4) e dilatante com tensão de escoamento (curva 6).

Bingham desenvolveu, em 1916, um modelo (Equação 2.4), apresentando, pela primeira vez, o conceito de tensão de escoamento $\left(\tau_{0}\right)$ e a viscosidade plástica $(\mu)$ (BARNES, 1999).

$$
\tau=\tau_{0}+\mu \dot{\gamma}
$$

Entretanto, a maior parte dos fluidos que apresentam tensão de escoamento, é caracterizada por comportamentos reológicos mais complexos do que o descrito pela equação de Bingham (Equação 2.4). Por isso, outras equações de estado reológico têm sido apresentadas para descrever o comportamento desses fluidos.

Uma delas é o modelo de Herschel-Bulkley (Equação 2.5), que combina a equação de Bingham (Equação 2.4) e a Lei de Potência (Equação 2.3), no qual esta apresenta tensão de escoamento e uma não linearidade do fluxo.

$$
\tau=\tau_{y}+k(\dot{\gamma})^{p}
$$

Onde $\tau_{y}$ é a tensão de escoamento de Herschel-Bulkley, k é uma constante e p é um índice de consistência do fluido obtido a partir do ajuste dos dados experimentais de $\tau_{y}$ e $\dot{\gamma}$.

Outra maneira de representar uma não-linearidade do fluxo de um fluido com tensão de escoamento é através do modelo de Casson (Equação 2.6). 


$$
\tau^{1 / 2}=\tau_{c}{ }^{1 / 2}+\mu_{c}{ }^{1 / 2} \dot{\gamma}^{1 / 2}
$$

Onde $\tau_{c}$ é a tensão de escoamento de Casson e $\mu_{c}$ é a viscosidade de Casson.

Já os fluidos que dependem da taxa de cisalhamento e do tempo de aplicação da mesma são classificados em dois grupos: tixotrópico e reopéxico, dependendo da história de cisalhamento e do tempo de aplicação do cisalhamento (OLIVEIRA et al., 2000).

Tixotropia é definida como a redução da viscosidade aparente quando o fluido é submetido a uma taxa (ou tensão) de cisalhamento constante (HACKLEY; FERRARIS, 2001). Este fenômeno é reversível, isto é, interrompido o cisalhamento, e após um tempo de repouso suficiente, a viscosidade aumenta, retornando à viscosidade inicial. Já a reopexia ou tixotropia negativa representa o fenômeno reológico inverso, sendo caracterizado pelo aumento da viscosidade aparente em função do tempo em suspensões submetidas a uma taxa (ou tensão) de cisalhamento constante (HACKLEY; FERRARIS, 2001).

Um dos métodos utilizados na prática para avaliar o comportamento destes materiais é a obtenção de ciclo de cisalhamento, ou seja, aceleração e desaceleração da taxa de cisalhamento. Para todos os materiais com comportamento tixotrópico, a curva de aceleração ficará acima da de desaceleração, enquanto que para os materiais com comportamento reopéxico, a curva de aceleração ficará abaixo da de desaceleração. A área entre as curvas corresponde ao grau de tixotropia do material, denominada de área de histerese.

A aplicação de uma taxa de cisalhamento fixa superior favorece a quebra dos aglomerados e a redução da viscosidade aparente do material (CYR, 1999; OLIVEIRA et al., 2000). A orientação preferencial de partículas em função da taxa de cisalhamento é um fator que, também, depende do tempo e pode originar o comportamento tixotrópico.

\subsection{Comportamento reológico de suspensões}

A presença de partículas e/ou aglomerados em um meio líquido modifica o seu perfil de escoamento e também o seu comportamento reológico (Figura 2.3) (OLIVEIRA et al., 2000). 


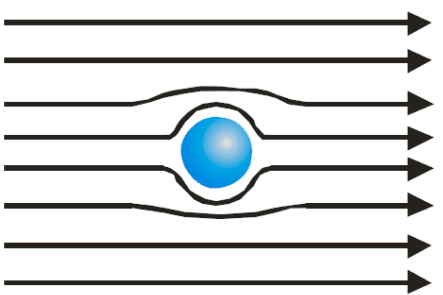

(a)

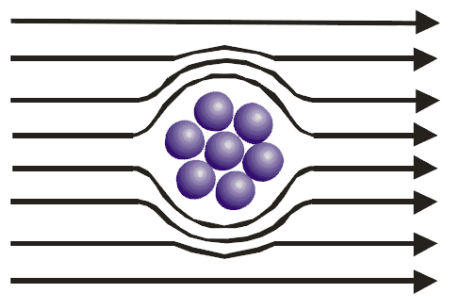

(b)

Figura 2.3: Representação esquemática da perturbação causada pela presença de unidades móveis (partículas e/ou aglomerados) imersas no líquido sob cisalhamento: (a) perturbação causada pela presença de uma partícula com pequeno diâmetro e (b) perturbação causada por um aglomerado de pequenas partículas (PILEGGI, 2001).

Pileggi (2001) apontou que a viscosidade é uma medida da resistência do fluido ao escoamento. A viscosidade do fluido aumenta devido à dificuldade ao fluxo imposta pelas partículas sólidas dispersas. Sendo assim, quanto maior a perturbação das partículas sólidas, maior será a viscosidade do sistema. Portanto, os principais fatores que afetam a viscosidade de uma suspensão são: concentração volumétrica de sólidos, características do meio líquido (viscosidade, densidade, etc.) e temperatura.

Por exemplo, quando uma suspensão apresenta uma concentração volumétrica de sólidos inferiores a $5 \%$, ela não altera o seu comportamento reológico devido à baixa frequência de colisões entre as partículas. Com o aumento da concentração de sólidos, a distância interparticular diminui e as partículas passam a interagir entre si. Em altas taxas de cisalhamento a probabilidade de colisões aumenta, intensificando as forças de atrito e de aglomeração entre as partículas, favorecendo o comportamento dilatante. Neste caso, outros fatores passam a influenciar a viscosidade da suspensão, além dos mencionados a cima (CHANDER, 1998): características físicas das partículas (tamanho, distribuição granulométrica, densidade, formato, área superficial específica, rugosidade superficial, etc.) e tipo de interação entre as partículas.

Partículas com morfologia irregular (maior rugosidade) afetam o empacotamento. Quanto mais afastada do formato esférico, menor tende a ser a densidade de empacotamento devido ao contato direto das superfícies irregulares das partículas e quanto menor a partícula, maior é esse efeito. Além disso, o aumento da área superficial específica devido às irregularidades pode resultar em maior quantidade de água necessária para molhar a superfície, restando menos água para afastar as partículas. Dessa forma, o comportamento reológico é afetado, favorecendo 
comportamento dilatante ou necessitando de mais água para atingir a mesma consistência (PILEGGI, 2001).

Fica evidente, portanto, a importância da interação entre as partículas sólidas de uma suspensão para as características reológicas desta. Considerando que as partículas estejam devidamente dispersas, essa influência tem grande dependência da concentração. Para que seja possível quantificá-la, utiliza-se o conceito de distância de separação entre partículas, do inglês Inter-Particle Spacing (IPS), que indica a quantidade de fluido, em média, que separa as partículas sólidas umas das outras, facilitando a movimentação da suspensão (OLIVEIRA et al., 2000).

O modelo denominado Maximum Paste Thickness (MPT) utiliza a hipótese de que, a partir do sistema somente com as partículas sólidas, o fluido inicialmente preenche os poros deixados por este sistema, recobrindo a superfície das partículas para, finalmente, começar a separar as partículas umas das outras (POWERS, 1968) que pode ser calculado de forma similar ao IPS, considerando o sistema particulado composto apenas pelas partículas grossas e o fluido composto pela matriz, de acordo com a Equação 2.7 .

$$
M P T=\frac{2}{V S A_{g}} \times\left[\frac{1}{V_{s g}}-\left(\frac{1}{1-P_{\text {ofg }}}\right)\right]
$$

No qual MPT é a máxima espessura de pasta $(\mu \mathrm{m}), \mathrm{VSA}_{\mathrm{g}}$ é a área superficial volumétrica das partículas grossas $\left(\mathrm{m}^{2} / \mathrm{cm}^{3}\right)$, Vsg é o teor de sólidos grossos da suspensão e $\mathrm{P}_{\text {ofg }}$ e a porosidade residual do sistema de partículas grossas.

Desta forma, caso o volume de fluido seja menor do que o volume dos poros, podese afirmar, segundo esta hipótese, que as partículas sólidas estão em contato e o sistema não apresenta fluidez.

Existe também outros fatores que podem afetar a viscosidade da suspensão, como as forças de interação entre as partículas. Existem três forças que atuam sobre as partículas, sendo elas: forças de superfície, força Browniana e força viscosa (BARNES; HUTTON; WALTERS, 1989; OLIVEIRA et al., 2003). Podem-se destacar como principais forças superficiais existentes entre as partículas, a força de van der Waals e as forças eletrostáticas (OLIVEIRA et al., 2003). Além disso, existem outras forças, como capilaridade, solvatação e adsorção de água (CYR, 1999). 
As forças de interação que agem sobre as partículas são resultantes da atração ou repulsão entre as partículas. As forças de atração ocorrem devido as forças de van der Waals e as forças de repulsão pode ser causada por cargas eletrostáticas opostas. Estas forças existem de forma simultânea, resultando em um comportamento complexo. Devido à elevada área superficial específica, partículas com dimensões menores que $100 \mu \mathrm{m}$, forças de superfície prevalecem em relação às forças mássicas, controlando a forma com que as partículas interagem e, consequentemente, seu comportamento reológico. Caso as cargas atrativas sejam superiores às repulsivas, existirá uma tendência de aglomeração, favorecendo o aumento da viscosidade. Com o aumento das forças repulsivas as partículas se afastam uma das outras, resultando em um sistema disperso e, consequentemente, redução da viscosidade(OLIVEIRA et al., 2000).

O movimento Browniano é resultado da aleatoriedade da distribuição e da orientação espacial das partículas gerado a partir do movimento do líquido. As forças brownianas influenciam fortemente partículas menores que $1 \mu \mathrm{m}$.

Forças viscosas são proporcionais à diferença entre a diferença de velocidade entre as partículas e o fluido, dessa forma, a alteração na viscosidade do meio líquido resulta em uma mudança na viscosidade da suspensão total. 


\section{REOMETRIA}

\subsection{Introdução}

No capítulo anterior, foi apresentado a importância da reologia, os conceitos fundamentais e os principais fatores que afetam o comportamento reológico de uma suspensão. Neste capítulo será apresentado a reometria, que é o ramo da reologia que se ocupa da medição experimental das características reológicas dos materiais como, por exemplo, a viscosidade e tensão de escoamento. Reômetro é o equipamento utilizado para quantificação dos parâmetros reológicos. Vale a pena ressaltar a diferença entre um viscosímetro e um reômetro. O primeiro é um equipamento para medir a viscosidade dos fluidos sob uma única condição de fluxo, enquanto o segundo é utilizado para medir a viscosidade dos líquidos que variam ou não de acordo com as condições de fluxo.

Os ensaios reológicos permitem aferir ao longo do tempo valores de tensão e deformação de um material. Enquanto as propriedades reológicas de um fluido newtoniano são completamente caracterizadas através de uma só medição, permitindo definir a viscosidade, no estudo de fluidos não newtonianos é preciso identificar a dependência entre a tensão e a taxa de deformação e, no caso de materiais viscoelásticos ou viscoplásticos, que exibem efeitos memória é, também, necessário observar o comportamento ao longo de certo período de tempo.

O reômetro deve provocar preferencialmente uma deformação de tal forma que possa ser quantificada com precisão através da resolução das equações de balanço (MACOSKO, 1994; STEFFE, 1996). Caso contrário, a solução aproximada corresponde a um erro que deverá necessariamente ser aceitável para que os resultados sejam aceitos. Por este motivo, as medições reológicas são geralmente efetuadas em regimes simples de deformação em que só existe uma componente de velocidade, em apenas uma direção.

Neste capítulo é apresentado o princípio de funcionamento dos reômetros convencionais e suas geometrias clássicas. Além disso, será apresentado os principais reômetros desenvolvidos por outros pesquisadores. 


\subsection{Tipos de reômetros e métodos de controle}

Os ensaios de reometria são aqueles nos quais as propriedades reológicas são determinadas, sendo que existem diversas técnicas experimentais disponíveis que variam de acordo com o material a ser ensaiado. Steffe (1996) apresentou os instrumentos mais comuns utilizados para medir propriedades reológicas fundamentais na indústria alimentícia, reproduzido na Figura 2.8.

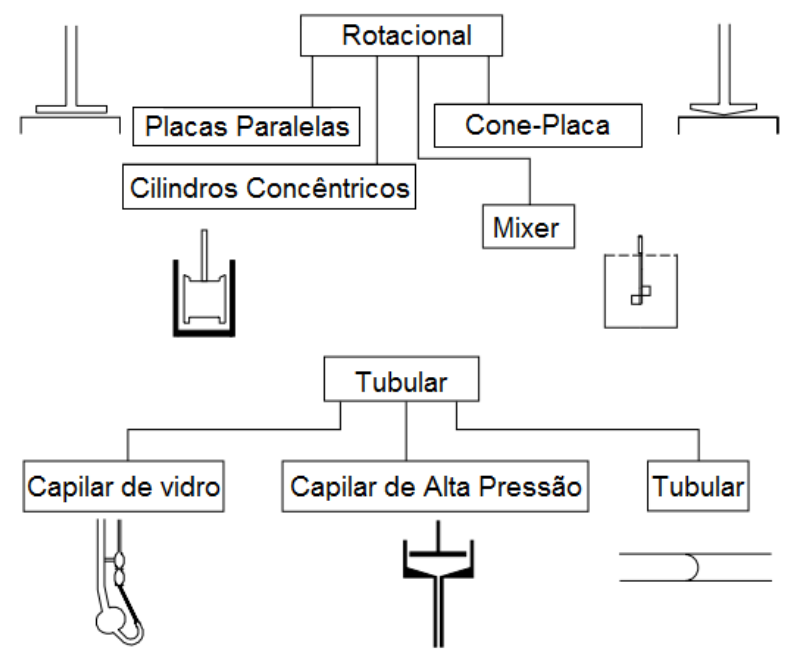

Figura 3.1: Conceito de reômetros (STEFFE, 1996).

Os reômetros do tipo rotacional geram tensões cisalhantes a partir do movimento entre duas superfícies com uma determinada velocidade relativa. Já o tipo tubo, as tensões cisalhantes são geradas por um diferencial de pressão ao longo de um canal. Além disso, existe o reômetro do tipo compressiva (squeeze flow), que gera as tensões cisalhantes através da compressão do material.

De acordo com Hackley e Ferraris (2001), os reômetros do tipo rotacionais são, geralmente, a melhor opção para ensaiar as suspensões, emulsões e géis, mesmo que os ensaios em tubos capilares tendam a ser mais precisos para medir a viscosidade. Os reômetros rotacionais apresentam como vantagem a capacidade de cisalhar a amostra e monitorar as alterações ao longo do tempo. Para fluidos não newtonianos, a distribuição da tensão e taxa de cisalhamento é normalmente melhor definida em um reômetro do tipo rotacional do que em um capilar. $O$ aumento da temperatura devido ao cisalhamento pode ser um dos problemas em reômetros rotacionais. Os reômetros tubulares são, normalmente, mais barato e mais simples do que reômetros rotacionais (WHORLOW, 1980). 
Para o desenvolvimento desta pesquisa, focou-se nos reômetros do tipo rotacional.

\subsection{Reômetro rotacional}

O princípio dos reômetros rotacionais aliado aos sistemas de medição permite o desenvolvimento e fabricação de reômetros absolutos que apresentem excelência e versatilidade (SCHRAMM, 2006). Existem duas alternativas básicas que transformam as geometrias (cone-placa, placas paralelas e cilindro concêntricos) em reômetros absolutos (SCHRAMM, 2006):

- Reômetros de tensão de cisalhamento controlada (Controlled Stress Rheometer) ou Reômetros CS: possui um controlador da tensão de cisalhamento e determina a taxa de cisalhamento resultante;

- Reômetro de taxa controlada (Controlled Rate Rheometer) ou Reômetros CR: possui um controlador da taxa de cisalhamento e determina a tensão de cisalhamento resultante.

Alguns reômetros têm a possibilidade de trabalhar com ambos os modos. Além disso, existem diferença quanto ao elemento cisalhante.

O termo Couette (Figura 3.2-a) significa que o rotor, que controla a velocidade, atua no copo externo enquanto que o torque relacionado à viscosidade é medido na haste do cilindro interno. Já o termo Searle (Figura 3.2-b) indica que o controle da velocidade e a medida do torque é realizada no eixo interno (MACOSKO, 1994; SCHRAMM, 2006). Os sensores são projetados de tal forma que os dados do torque possam ser transformados matematicamente em tensão de cisalhamento e a velocidade do rotor em taxa de cisalhamento.

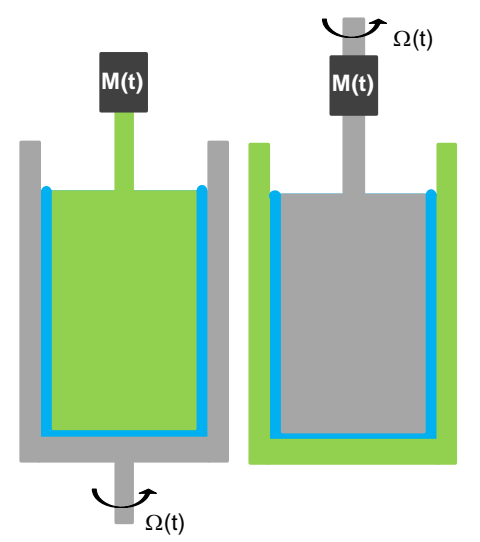

(a) (b)

Figura 3.2: Sistema de medição: (a) tipo Couette; (b) tipo Searle. 
Reômetros rotacionais são capazes de aplicar tensão de cisalhamento a uma única amostra de material de forma contínua. Por medição de uma série de combinações de tensão e taxa de cisalhamento, uma curva de escoamento pode ser determinada. É possível impor uma série de taxas de cisalhamento e determinar as tensões de cisalhamento resultantes (Reômetro $\mathrm{CR}$ ) ou impor uma série de tensões de cisalhamento e medir as taxas de cisalhamento resultantes (Reômetro CS). Comparado a um reômetro de taxa controlada, um reômetro de tensão de cisalhamento controlada normalmente tem maior sensibilidade, principalmente em taxas de cisalhamento muito baixas, e podem diferenciar melhor fluidos altamente não-newtonianos (SCHRAMM, 2006). As geometrias mais utilizadas para este equipamento são: cilindro concêntricos, cone/placa e placas paralelas.

Cada geometria apresenta certa distribuição do fluxo de velocidade e, a partir das dimensões das geometrias, é possível desenvolver equações analíticas relativas ao torque e à velocidade de rotação medidos pelo reômetro com os parâmetros específicos de uma dada equação constitutiva.

Nos reômetros rotacionais é possível realizar ensaios de fluxo, oscilatório, entre outros. O ensaio de fluxo consiste em aplicar uma força ou deformação e medir a resistência do material a este esforço aplicado. Com a variação da taxa ou tensão de cisalhamento, pode-se traçar a curva de escoamento e, através desta ou de equações adequadas de estado reológico podem ser obtidas as propriedades reológicas viscosidade e tensão de escoamento. Além disso, é possível medir no ensaio da primeira e segunda diferença das tensões normais, $N_{1}$ e $N_{2}$ (SCHRAMM, 2006).

Já o ensaio oscilatório é um exemplo de ensaio dinâmico capaz de trabalhar em baixa deformação ou tensão, não causando a ruptura da estrutura. Consiste em aplicar uma deformação senoidal sobre a amostra e analisar a resposta desta solicitação, a tensão $(\tau)$

Com todas as geometrias apresentadas anteriormente é possível obter todos os parâmetros reológicos destacados, no entanto, é necessário escolher a geometria adequada a informação que se deseja obter do material a ser analisado. 


\subsection{Modelos de reômetros para concretos e argamassa}

Os reômetros desenvolvidos por empresas como Anton Paar, TA Physica, Brookfiels, Bohlin, etc., utilizam geometrias clássicas, como por exemplo, cilindro concêntricos, placa-placa e cone-placa. Estas geometrias são ideais para materiais homogêneos como polímeros, óleos e tintas e o volume necessário para realizar o ensaio é de até $100 \mathrm{ml}$, aproximadamente (MACOSKO, 1994; TEUBERT, 1969).

No entanto tais geometrias quando utilizadas para a análise de suspensões, como é o caso de materiais para construção civil, não se mostram muito adequadas. Segundo Teubert (1969) devido aos motivos apresentados a seguir:

1. Argamassa e concreto são suspensões heterogêneas. O diâmetro máximo do agregado é superior ao espaçamento (gap) utilizado nos reômetros comuns. Sendo necessário um espaçamento maior para evitar o efeito parede;

2. Devido às forças gravitacionais, existe a possibilidade das partículas sedimentarem ao longo do ensaio;

3. Durante a execução do ensaio, surgem forças centrípetas que tendem a segregar o material, separando o fluido das partículas sólidas. Além disso, existe a possibilidade da suspensão aderir à geometria, modificando sua configuração e afetando o ensaio.

Devido aos motivos apresentados, diversos pesquisadores desenvolveram novos reômetros para analisar concreto e argamassa no estado fresco, devido à ausência de equipamento no mercado (KOEHLER; FOWLER, 2004). Alguns destes modelos serão apresentados na Tabela 3.1. 
Tabela 3.1: Alguns modelos de reômetros desenvolvidos por diferentes pesquisadores.

\begin{tabular}{|c|c|c|c|c|c|}
\hline Nome & Modelo & Desenvolvedor & Geometria & Controle & Movimento \\
\hline $\begin{array}{c}\text { Tattersall } \\
\text { two-point } \\
\text { Rheometer }\end{array}$ & $\begin{array}{l}\text { Mk I } \\
\text { Mk II } \\
\text { Mk III }\end{array}$ & $\begin{array}{c}\text { Tattersall e } \\
\text { Banfill (1983) } \\
\text { Inglaterra }\end{array}$ & Própria & $\begin{array}{c}\text { Taxa } \\
\text { controlada }\end{array}$ & $\begin{array}{c}\text { Tipo Searle, } \\
\text { com } \\
\text { movimento } \\
\text { planetário }\end{array}$ \\
\hline $\begin{array}{c}\text { IBB } \\
\text { Rheometer }\end{array}$ & - & $\begin{array}{c}\text { Beaupré (1994) } \\
\text { Canadá }\end{array}$ & Própria & $\begin{array}{c}\text { Taxa } \\
\text { controlada }\end{array}$ & $\begin{array}{c}\text { Tipo Searle, } \\
\text { com } \\
\text { movimento } \\
\text { planetário }\end{array}$ \\
\hline $\begin{array}{c}\text { Com Tec } \\
\text { Rheometer }\end{array}$ & $\begin{array}{l}\text { Visco } 3 \\
\text { Visco } 4 \\
\text { Visco } 5 \\
\text { Visco } 6 \\
\end{array}$ & $\begin{array}{c}\text { Wallevik e Gjorv } \\
(1990) \\
\text { Noruega }\end{array}$ & $\begin{array}{c}\text { Cilindros } \\
\text { concêntricos }\end{array}$ & $\begin{array}{c}\text { Taxa } \\
\text { controlada }\end{array}$ & $\begin{array}{c}\text { Tipo } \\
\text { Couette }\end{array}$ \\
\hline BTRHEOM & - & $\begin{array}{c}\text { Hu et al. (1996) } \\
\text { França }\end{array}$ & $\begin{array}{l}\text { Placas } \\
\text { paralelas }\end{array}$ & $\begin{array}{c}\text { Taxa } \\
\text { controlada }\end{array}$ & Tipo Searle \\
\hline $\begin{array}{l}\text { CEMAGRAF- } \\
\text { IMG }\end{array}$ & - & $\begin{array}{l}\text { Hu (1995) } \\
\text { França }\end{array}$ & $\begin{array}{c}\text { Cilindros } \\
\text { concêntricos }\end{array}$ & $\begin{array}{c}\text { Taxa } \\
\text { controlada }\end{array}$ & Tipo Searle \\
\hline $\begin{array}{c}\text { UIUC } \\
\text { Concrete } \\
\text { Rheometer }\end{array}$ & - & $\begin{array}{c}\text { Szecsy (1994) } \\
\text { EUA }\end{array}$ & $\begin{array}{l}\text { Placas } \\
\text { paralelas }\end{array}$ & $\begin{array}{c}\text { Taxa } \\
\text { controlada }\end{array}$ & Tipo Searle \\
\hline $\begin{array}{c}\text { ICAR } \\
\text { Rheometer }\end{array}$ & - & $\begin{array}{c}\text { Koehler e } \\
\text { Fowler (2004) } \\
\text { EUA }\end{array}$ & Vane & $\begin{array}{c}\text { Taxa } \\
\text { controlada }\end{array}$ & Tipo Searle \\
\hline $\begin{array}{c}\text { Bertta } \\
\text { apparatus }\end{array}$ & - & $\begin{array}{c}\text { Technical } \\
\text { Research } \\
\text { Center of } \\
\text { Finland } \\
\text { Finlândia }\end{array}$ & $\begin{array}{c}\text { Cilindros } \\
\text { concêntricos }\end{array}$ & $\begin{array}{c}\text { Taxa } \\
\text { controlada }\end{array}$ & $\begin{array}{c}\text { Tipo } \\
\text { Couette }\end{array}$ \\
\hline $\begin{array}{c}\text { Ball } \\
\text { Measuring } \\
\text { System }\end{array}$ & - & $\begin{array}{c}\text { Tyrach }(2001) \\
\text { Alemanha }\end{array}$ & $\begin{array}{c}\text { Esfera } \\
\text { excêntrica }\end{array}$ & $\begin{array}{c}\text { Taxa } \\
\text { controlada }\end{array}$ & Tipo Searle \\
\hline $\begin{array}{c}\text { BT2 } \\
\text { Rheometer }\end{array}$ & - & $\begin{array}{c}\text { Schleibinger } \\
\text { GmbH } \\
\text { Alemanha }\end{array}$ & $\begin{array}{l}\text { Geometria } \\
\text { excêntrica }\end{array}$ & $\begin{array}{c}\text { Taxa } \\
\text { controlada }\end{array}$ & Tipo Searle \\
\hline Viskomat & $\begin{array}{l}\text { NT } \\
\text { XL }\end{array}$ & $\begin{array}{c}\text { Teubert (1969) } \\
\text { Alemanha }\end{array}$ & Própria & $\begin{array}{c}\text { Taxa e } \\
\text { tensão } \\
\text { controlada }\end{array}$ & $\begin{array}{c}\text { Tipo } \\
\text { Couette }\end{array}$ \\
\hline RheoCAD & $\begin{array}{l}420 \\
450 \\
500\end{array}$ & $\begin{array}{c}\text { CAD } \\
\text { Instruments } \\
\text { França }\end{array}$ & Própria & $\begin{array}{c}\text { Taxa } \\
\text { controlada }\end{array}$ & Tipo Searle \\
\hline
\end{tabular}

Todos estes reômetros apresentam o resultado tratado para o usuário, não permitindo a análise do dado bruto e permitem apenas um tipo de ensaio, conhecido como ciclo de cisalhamento, em que a geometria acelera e desacelera a amostra. Além disso, todos os reômetros apresentados na Tabela 3.1 com exceção do Tattersall two-point 
Rheometer, apresentam uma baixa taxa de amostragem, no máximo 5 amostras por segundo.

Além disso, existem outros modelos que não são reômetros, conforme a Tabela 3.2, pois trabalham apenas com uma única velocidade. No entanto, os resultados indicam que é possível correlacionar seus resultados com o ensaio de abatimento (FAY, 1982; STEINER, 1996; WONG et al., 2001).

Tabela 3.2: Modelos de equipamentos utilizados para correlacionar seu resultado com o ensaio de abatimento.

\begin{tabular}{ccccc}
\hline Nome & Modelo & Desenvolvedor & Geometria & Controle \\
\hline $\begin{array}{c}\text { Fresh } \\
\begin{array}{c}\text { Concrete } \\
\text { Tester 101 }\end{array}\end{array}$ & - & $\begin{array}{c}\text { Steiner (1996) } \\
\text { Alemanha }\end{array}$ & Própria & $\begin{array}{c}\text { Rotação } \\
\text { única }\end{array}$ \\
\hline $\begin{array}{c}\text { Ready-mix } \\
\text { truck } \\
\text { hydraulic } \\
\text { device }\end{array}$ & - & $\begin{array}{c}\text { Fay (1982) } \\
\text { EUA }\end{array}$ & - & $\begin{array}{c}\text { Rotação } \\
\text { única }\end{array}$ \\
\hline
\end{tabular}




\section{REÔMETRO SERVO CONTROLADO}

\subsection{Introdução}

Assim como os demais reômetros apresentados no capítulo anterior, o reômetro utilizado nesta pesquisa foi desenvolvido com o intuito de analisar materiais da construção civil: argamassa e concreto.

Este reômetro, provém da evolução do protótipo desenvolvido na tese de doutorado de Pileggi (2001), como uma ferramenta para o estudo e desenvolvimento de formulação de concretos refratários, conforme a Figura 4.1.

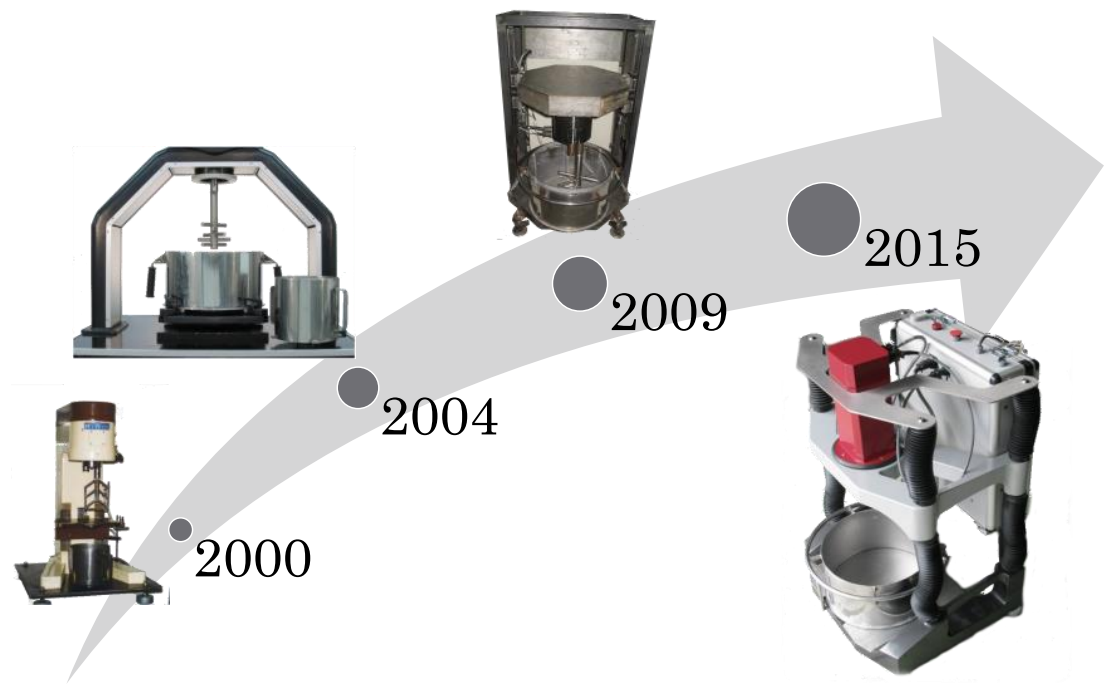

Figura 4.1: Evolução dos reômetros desenvolvidos por Pileggi.

Este reômetro foi desenvolvido porque os reômetros convencionais não permitiam a análise dos materiais de construção civil. Pileggi (2001) buscou sanar os principais problemas encontrados nos reômetros convencionais, destacados anteriormente, como aumento do torque do equipamento e capacidade do volume de amostra analisado. Por se tratar de um protótipo, sempre houve uma melhoria de uma versão para a outra. No início, a principal falha era a parte mecânica, que apresentava falhas de projeto, dimensionamento incorreto, entre outros. Conseguiu-se chegar ao conceito final que é adotado neste reômetro, o conjunto motor-redutor planetário, sanando falhas mecânicas. Por conseguinte, deve-se explorar fatores que ficaram em segundo plano, como compreensão dos parâmetros de ajuste do servoconversor, e desconhecimento das limitações do software de controle e aquisição. 
Pileggi (2001) dedicou o seu tempo e conhecimento no desenvolvimento do reômetro e compreensão dos materiais para reduzir uma defasagem que existe entre a elevada tecnologia, complexidade dos materiais e as técnicas de caracterização reológica convencionalmente empregadas, as quais se baseiam apenas no conceito de fluidez.

Neste capítulo será realizado uma breve descrição do reômetro, possíveis ensaios e, também, apresentação dos principais conceitos para compreensão do sinal elétrico.

\subsection{Descrição do reômetro}

O reômetro pode ser divido em três grandes grupos: estrutura, conjunto motor-redutor planetário e sistema elétrico.

A estrutura do reômetro é formada basicamente pela base, a plataforma e as colunas, conforme ilustrado na Figura 4.2. A base e a plataforma são de alumínio fundido. $\mathrm{O}$ conjunto motor-redutor planetário é composto pelo motor com rotação variável de 0 até $3000 \mathrm{rpm}$ no motor e as engrenagens planetárias que geram uma redução e o movimento planetário. Os componentes elétricos são compostos basicamente por um servoconversor de corrente alternada (ca) e uma placa de aquisição da Advantech.
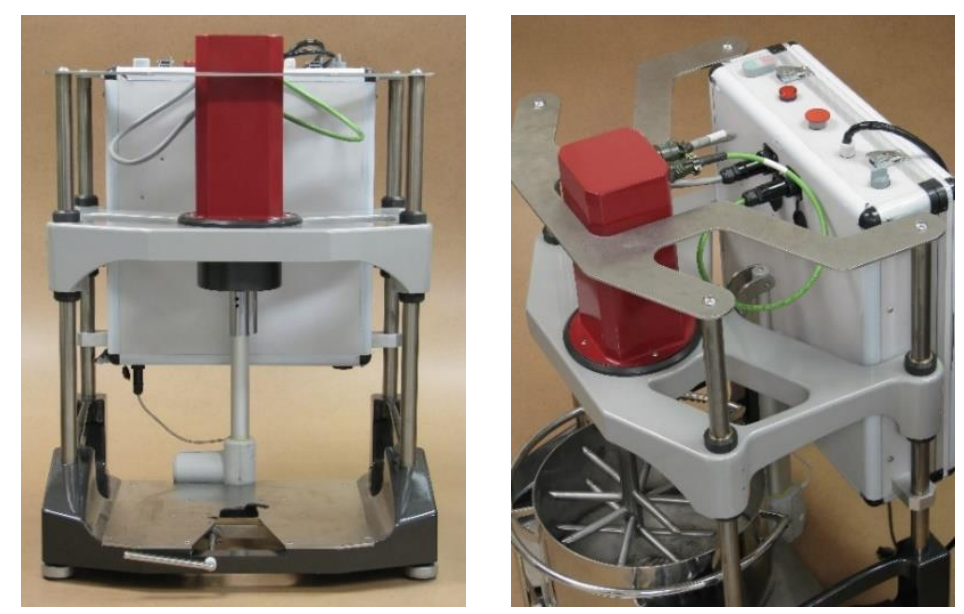

Figura 4.2: Reômetro utilizado na pesquisa (Foto: Mario Takeashi).

Este reômetro é do tipo rotacional podendo ser tanto de tensão controlada (controlase a tensão cisalhante e determina a taxa cisalhante resultante) quanto de taxa controlada (controla-se a taxa cisalhante e determina a tensão cisalhante resultante) e a medição é realizada utilizando o método Searle, ou seja, o controle da velocidade e a medida do torque é realizada no eixo e o recipiente em que é realizado o ensaio fica fixo. 
No reômetro é possível realizar ensaios tanto no eixo central quanto no eixo planetário. Além disso, é possível realizar o ensaio em dois recipientes com capacidade máxima de 17 e 8 litros. Normalmente as argamassas são analisadas no recipiente de menor volume, enquanto que os concretos no de maior volume. Na Tabela 4.1 são apresentadas as especificações deste reômetro.

Tabela 4.1: Especificação do reômetro utilizado na pesquisa.

\begin{tabular}{lc}
\cline { 2 - 2 } & Reômetro \\
\hline Velocidade de rotação no eixo central (rpm) & $0-143$ \\
Velocidade de rotação no eixo planetário (rpm) & $0-550$ \\
Torque no eixo central (N.m) & $0-147$ \\
Torque no eixo planetário (N.m) & $0-38$ \\
Volume de amostra (L) & 8 e 17 \\
\hline
\end{tabular}

A geometria utilizada para os ensaios foi inspirada na geometria utilizada no moinho de atrito. Existem duas geometrias, sendo uma para cada recipiente, conforme Figura 4.3 e a única diferença entre elas é o comprimento das haletas.

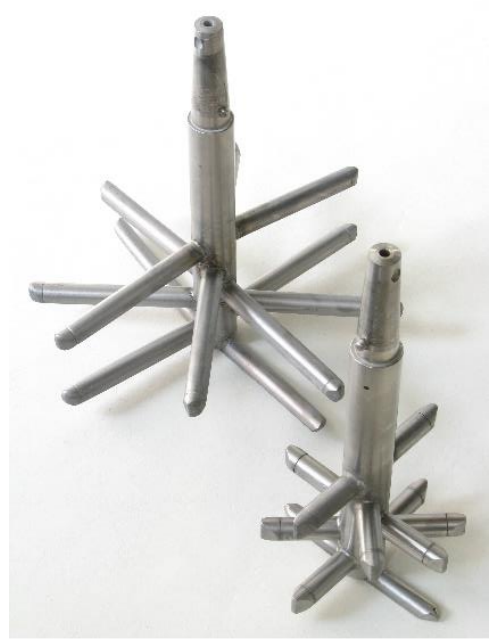

Figura 4.3: Geometrias existentes para utilização no reômetro utilizado na pesquisa (Foto: Mario Takeashi).

\subsection{Potencial uso do reômetro servo controlado}

A utilização do servoconversor e do servo motor no reômetro permite controle preciso da velocidade e do torque do motor. Tanto o controle da velocidade quanto do torque proporciona a abertura de um vasto leque de potenciais ensaios a serem realizados no reômetro, apresentado na Figura 4.4. Mas para realizar tais ensaios é preciso melhorar a forma como é feito o controle da taxa e da tensão, porque atualmente é realizado por comunicação serial. A saída serial do servoconversor permite apenas 
valores truncados, como entrada de parâmetro, diminuindo a precisão no controle do ensaio. Para melhorar a precisão é necessário realizar o controle pela entrada analógica.

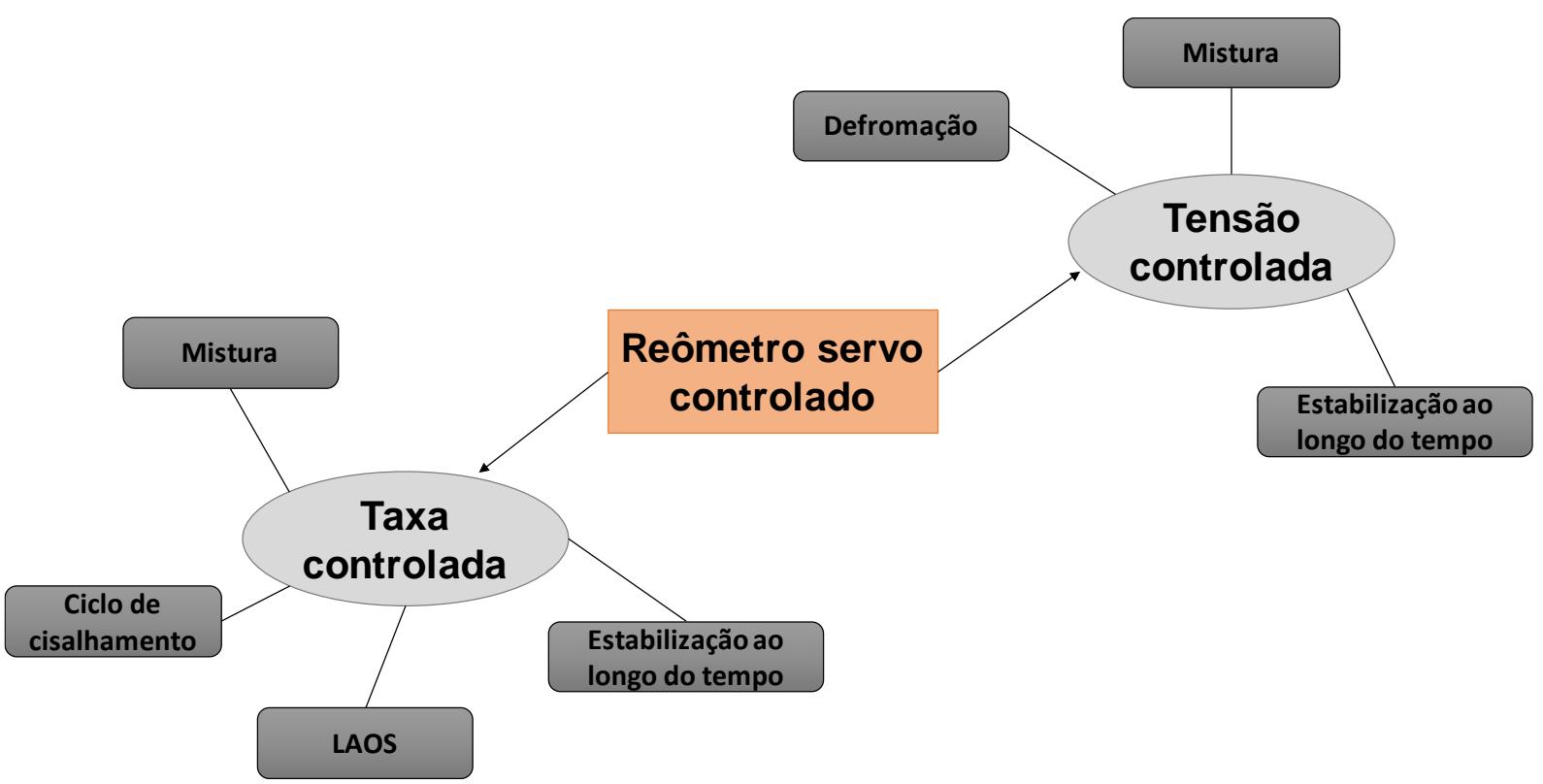

Figura 4.4: Exemplos de possíveis ensaios a ser realizado em um reômetro servo controlado'.

No reômetro em estudo é muito comum a utilização de dois ensaios controlando a taxa de cisalhamento: ensaios de mistura e de ciclo de cisalhamento. Estas técnicas possibilitam a quantificação dos esforços produzidos durante a mistura, bem como a compreensão do perfil reológico do material em diversas rotações.

\subsection{Sistema elétrico}

O princípio para um bom funcionamento do reômetro está no controle preciso do torque e da velocidade do motor. Para isso, são necessários três elementos básicos: um motor, um servoconversor (drive) e um ou mais aparelhos de feedback, conforme Figura 4.5. O feedback existe para retroalimentar o servoconversor, e, assim, controlar de forma precisa a velocidade, posicionamento e o torque do motor.

\footnotetext{
${ }^{1}$ LAOS - Large Amplitude Oscillatory Shear
} 


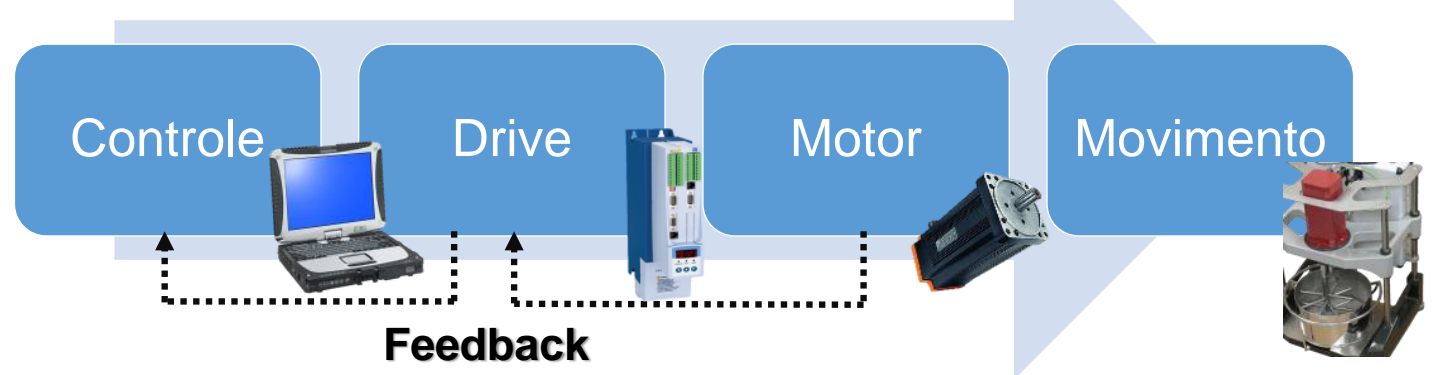

Figura 4.5: Diagrama do funcionamento de um reômetro servo controlado.

\subsubsection{Definição de um servoconversor}

O servoconversor (drive) é definido como o circuito de acionamento do servomotor, em que é possível definir diversos parâmetros e aquisitar dados de interesse. Entre o servoconversor e o servomotor existe um aparelho de feedback, que permite um controle preciso do posicionamento, velocidade e torque (ELLIS, 2004). O conjunto de servomotor e servoconversor é definido como servoacionamento.

A indústria da automação é um setor multibilionário e o servoacionamento faz parte de uma pequena fração desta indústria. Geralmente o servoacionamento encontram aplicações em diferentes campos da indústria, como por exemplo robôs industriais, linhas de transporte, sistemas de posicionamento entre outros (ELLIS, 2004).

A maneira mais simples de identificar as características de um servoconversor é a habilidade de controlar o seu posicionamento, tendo uma resposta rápida. Normalmente, os servomotores são solicitados para trabalhar em ciclos que possuem taxas altas na mudança de velocidade ou posicionamento.

O servoconversor precisa de um aparelho de feedback para controlar o posicionamento, velocidade e torque do motor. Geralmente, esse aparelho é um resolver ou um encoder.

Resolvers e Encoders são muito diferentes, mas têm a mesma finalidade em muitas aplicações. Em aplicações rotativas, ambos são usados para detectar a velocidade, direção e posição do eixo de rotação. Eles funcionam como transdutores, transformando o movimento mecânico em informação eletrônica. Esta informação eletrônica é o feedback para dispositivos eletrônicos que controlam o movimento 
mecânico. O feedback é uma ligação vital que fecha o circuito de controle para melhorar o desempenho do sistema (ELLIS, 2004).

\subsubsection{Servomotor}

A principal característica de um servomotor é a capacidade de controlar precisamente o torque. Idealmente, o torque deveria apresentar alta sensibilidade e independer do posicionamento do motor ou da velocidade de rotação.

Os servomotores mais precisos apresentam um decaimento no nível do torque à medida que a velocidade de rotação aumenta. Esta redução é causada por diversos fatores, como atrito com o ar e os rolamentos. Em motores com escova, muitas vezes o comutador limita a quantidade de corrente utilizada para altas velocidades. Em motores sem escova, tal efeito ocorre de maneira similar devido ao controlador de corrente. Todos esses fatores causam um decaimento do torque ao aumentar a velocidade de rotação (CENG, 2000).

\section{a) Níveis de torque}

A saída do torque eletromagnético ( $\left.T_{E}\right)$ do servomotor é medida de duas maneiras: pico e contínuo. O pico é o torque máximo que o motor gera em um curto intervalo de tempo, geralmente um ou dois segundos. E o contínuo indica a quantidade de torque que o motor pode gerar em um período de tempo indeterminado. Tais fatores estão diretamente relacionados com a temperatura do motor. O motor não é 100\% eficiente e parte da eficiência é perdida pelo calor gerado. Alta temperatura no motor irá degradá-lo, por isso é interessante proteger o motor limitando o seu trabalho em temperaturas ideais. Além disso, exceder os torques de pico pode desmagnetizar os ímãs de forma permanente (ELLIS, 2004).

Os fabricantes de servomotores fornecem a curva torque-rotação. Estas curvas mostram os níveis de torque ao longo do intervalo de rotação do motor. A Figura 4.6 apresenta um exemplo de curva torque-rotação. A estimativa do torque pode ser somente do motor ou para o sistema (por exemplo, motor e drive). Se a estimativa for para o sistema, deve-se analisar, também, na temperatura limite ideal de trabalho para proteger o motor e o servoconversor. 


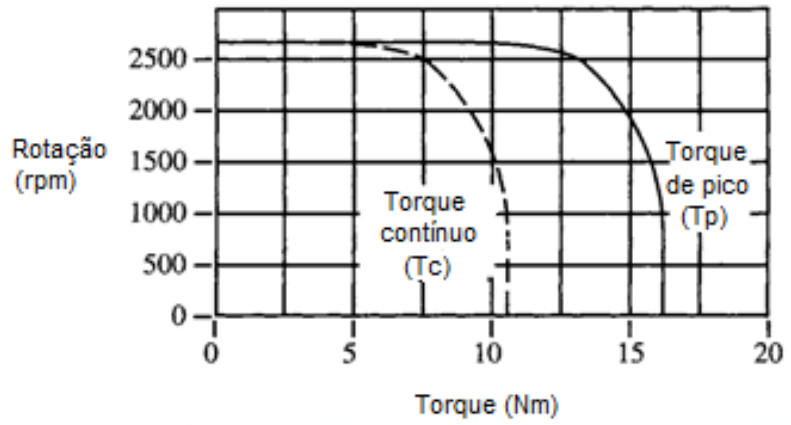

Figura 4.6: Exemplo típico de curva torque-rotação (ELLIS, 2004).

\section{b) Motor sem escova}

Motores elétricos geram torque eletromagnético através de dois mecanismos: bobina e fluxo eletromagnético. Em motores com ímã permanente (CENG, 2000; ELLIS, 2004), o fluxo eletromagnético (ФF) é criado pelos ímãs que estão no estator, conforme ilustrado na Figura 4.7.

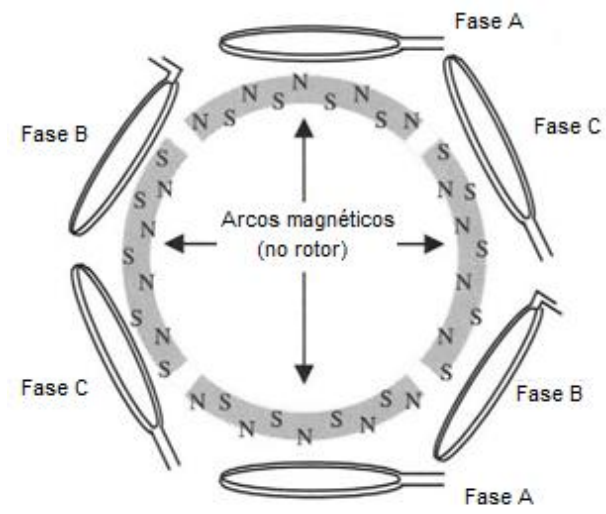

Figura 4.7: Esquemático do fluxo eletromagnético de um motor sem escova (ELLIS, 2004).

O outro fluxo é o fluxo gerado pela bobina $(\Phi т)$. Nos motores sem escova o fluxo é comandado pela corrente que passa pela bobina. Na Figura 4.8 é apresentado um exemplo de um rotor em três situações diferentes rodando em sentido horário. As setas grandes indicam o fluxo criado pela bobina.
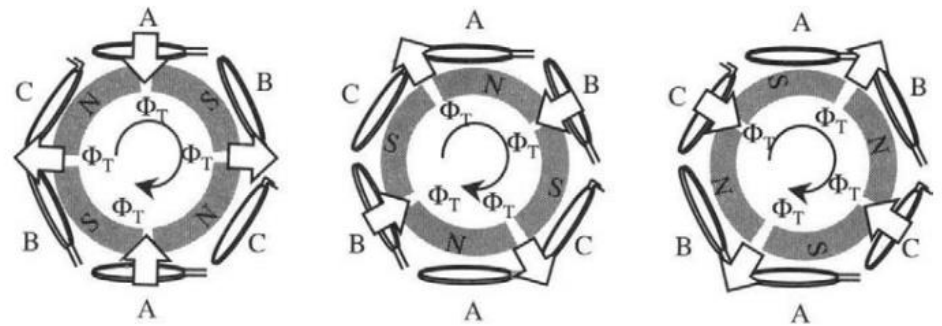

Figura 4.8: Fluxo magnético para as diferentes fases (ELLIS, 2004). 
Vale destacar que os motores sem escova utilizam um comutador eletrônico, que controla o sentido e intensidade da corrente que passa em cada bobina.

Portanto, o torque eletromagnético pode ser calculado a partir da Equação $4.1 \mathrm{e}$ verifica-se que é proporcional ao o fluxo eletromagnético gerado pelos ímãs que estão no estator $\left(\Phi_{F}\right)$, ao fluxo magnético gerado pelas bobinas $\left(\Phi_{T}\right)$ e o ângulo formado pelos dois fluxos ( $\left.\theta_{\mathrm{E}}\right)$ (ELLIS, 2004).

$$
T_{E} \propto \Phi_{T} \times \Phi_{F} \times \sin \left(\theta_{E}\right)
$$

Um motor de quatro polos é apresentado na Figura 4.9: Exemplo de motor de quatro polos (ELLIS, 2004)., com seus fluxos eletromagnéticos gerado pela bobina e seus ímãs. O ângulo formado entre os vetores de fluxo é de $90^{\circ}$ (elétrico), sendo equivalente a 45으 (mecânico) para este motor de quatro polos.

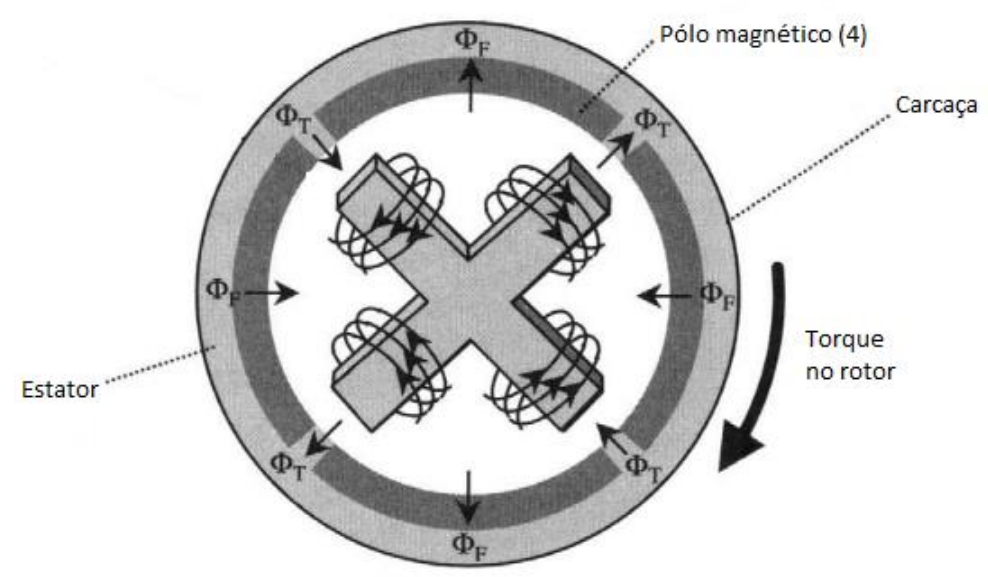

Figura 4.9: Exemplo de motor de quatro polos (ELLIS, 2004).

Como o motor sem escova controla, de maneira independente, a corrente nas bobinas, é possível criar um fluxo com ângulos de pequenos incrementos.

\subsection{Aquisição de dados}

Conforme foi apresentado, o servoconversor além de controlar a velocidade, posicionamento e torque, permite que se faça aquisição de dados de interesse, proteção do próprio sistema, ou aquisição de um parâmetro de interesse, como no caso de reômetros, para a análise do comportamento reológico dos materiais. 


\subsubsection{Sinal}

O termo sinal geralmente é aplicado a algo que transmite informação. Os sinais podem, por exemplo, representar a variação de alguma característica física ao longo do tempo, variação essa que permite representar a informação desejada. Embora os sinais possam ser representados de várias formas, em todos os casos a informação está contida em variações de algum padrão. Os sinais são representados matematicamente como funções de uma ou mais variáveis independentes. Por convenção, o tempo refere-se como a variável independente da representação matemática de um sinal. Outra variável possível é a da frequência.

A variável independente na representação matemática de um sinal pode ser contínua ou discreta. Os sinais de tempo contínuo são definidos como x(t), ou seja, contínuo para intervalo de $-\infty<t<+\infty$. Os sinais de tempo contínuo são frequentemente chamados de sinais analógicos. Os sinais de tempo discreto são frequentemente derivado de um sinal de tempo contínuo, amostrando-se a uma taxa uniforme. Além das variáveis independentes serem contínuas ou discretas, a amplitude do sinal pode ser contínua ou discreta. Os sinais digitais são aqueles para os quais tanto o tempo quanto a amplitude são discretos.

Na Figura 4.10 é representado um exemplo de sinal analógico e digital. Sinais analógicos são aqueles cuja amplitude pode assumir qualquer valor pertencente a um intervalo contínuo de valores. Já um sinal digital caracteriza-se por apresentar amplitudes dentro de um conjunto de valores finito que varia de forma discreta com o tempo, assumindo, habitualmente, dois valores: zero ou um. No caso do reômetro utilizado nesta pesquisa, o sinal aquisitado para a interpretação dos resultados é o analógico.
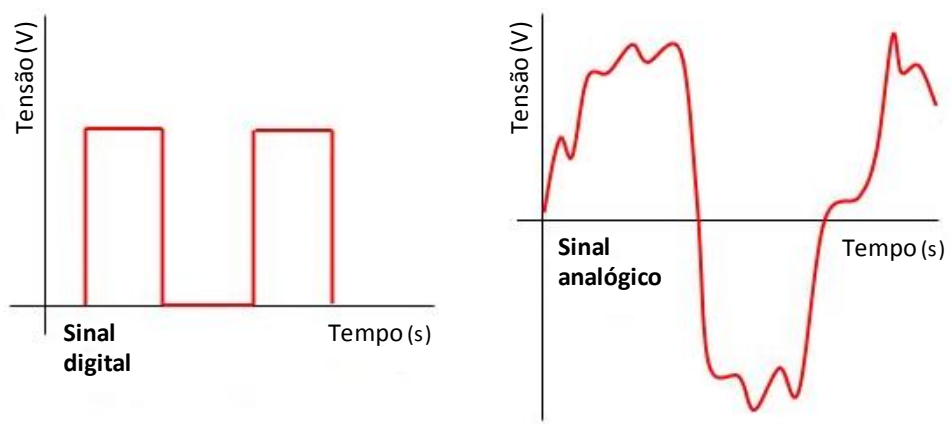

Figura 4.10: Exemplo de sinal analógico e digital. 
O sinal é determinado por diferentes características conforme Figura 4.11. A amplitude é a intensidade da grandeza medida podendo ser voltagem, corrente ou, no caso do reômetro, a tensão. A frequência é a repetição da oscilação por unidade de tempo e a fase diz respeito ao ângulo inicial de oscilação senoidal. Esta é calculada pelo inverso do período.

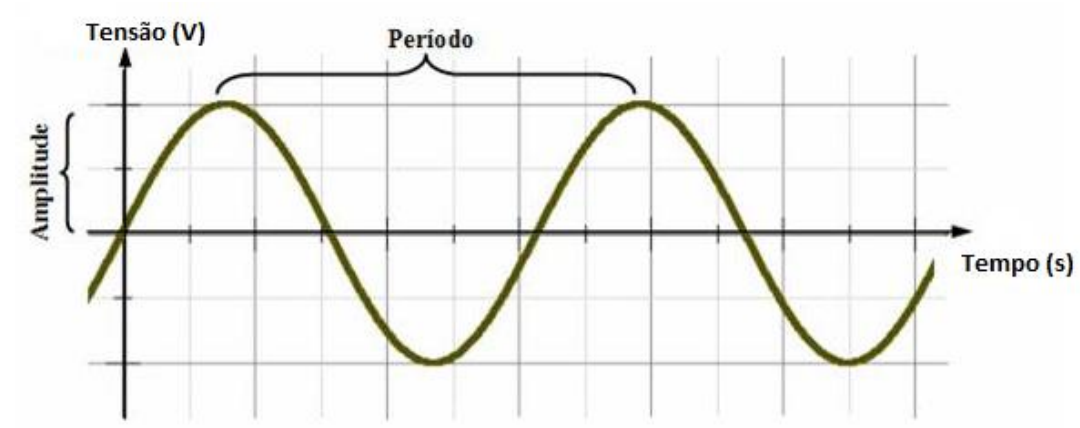

Figura 4.11: Exemplo de uma curva senoidal, destacando a amplitude e o período.

A aquisição do sinal é realizada ao longo do tempo, podendo ser realizados de diferentes taxas de amostras, como por exemplo, 1, 10 ou 10000 amostras por segundo. Vale destacar que a taxa de amostragem afeta o resultado do sinal, por isso é necessário analisar qual a melhor taxa de amostragem.

\subsubsection{Sinais de tempo discreto}

Os sinais de tempo discreto são representações matemáticas de sequência de números espaçadas para um mesmo intervalo de tempo. Uma sequência de $x$ números, em que o n-ésimo número da sequência é indicado por x[n], sendo $\mathrm{n}$ um número inteiro, apresentado na Equação 4.2. Vale observar que [ ] é utilizado para delimitar a variável independente das funções de variável discreta, e ( ) para delimitar a variável independente das funções de variável contínua (OPPENHEIM; SCHAFER, 2009).

$$
x[n]=\{x[n]\}, \quad-\infty<n<+\infty
$$

Na prática, tais sequências são obtidas, frequentemente, a partir de uma amostragem periódica de um sinal analógico $\left(\mathrm{x}_{\mathrm{a}}(\mathrm{t})\right)$. Sendo assim, o valor numérico do $\mathrm{n}$-ésimo número da sequência é igual ao valor do sinal analógico no instante nT, conforme apresentado na Equação 4.3. 


$$
x[n]=x_{a}(\mathrm{nT}), \quad-\infty<n<+\infty
$$

Em que T é o período de amostragem. Normalmente, os sinais de tempo discreto são representados conforme a Figura 4.12.

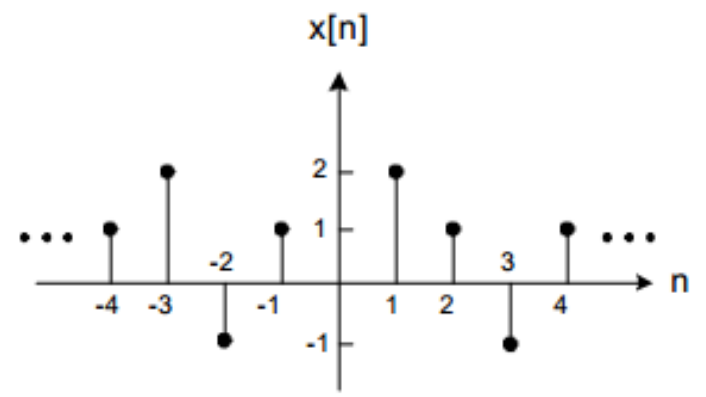

Figura 4.12: Representação gráfica de um sinal de tempo discreto.

Como a representação discreta de um sinal está estritamente ligada ao período de amostragem, observa-se que é preciso conhecer a taxa mínima de amostragem para que se possa reconstruir o sinal original.

\subsubsection{Amostragem}

O processo de amostragem nada mais é que a obtenção de amostras de um sinal contínuo, em instantes de tempo igualmente espaçados. No entanto, certo cuidado deve ser tomado na definição da frequência com a qual as amostras são obtidas. Se tal frequência for muito lenta, a posterior reconstrução do sinal pode não ser mais possível. O limite para que tal processo seja bem-sucedido é definido pelo teorema da amostragem, conhecido como teorema de Nyquist (NYQUIST, 1928) descrito abaixo.

Teorema: seja um sinal $x(t)$ com banda limitada, ou seja, $X(j \omega)=0$ para $|\omega|>\omega_{m}$, onde $\omega_{m}$ representa a máxima frequência do sinal. Neste caso, x(t) pode ser determinado por suas amostras $x(n T)$, onde $T$ é o período de amostragem e $n=0, \pm 1, \pm 2, \ldots$, se $\omega_{s}$ $\geq 2 \omega_{m}$, onde $\omega_{s}$ é a frequência de amostragem.

A taxa de Nyquist é a frequência de amostragem $\omega_{\text {s }}$ maior ou, na pior das hipóteses, igual a duas vezes a frequência do sinal $\omega \mathrm{m}$. Esta conclusão é importante, pois se a taxa de amostragem não estiver dentro desta faixa, o sinal original não poderá ser reconstruído fielmente a partir de suas amostras. A Figura 4.13 apresenta o efeito de diferentes taxas de amostragem. 


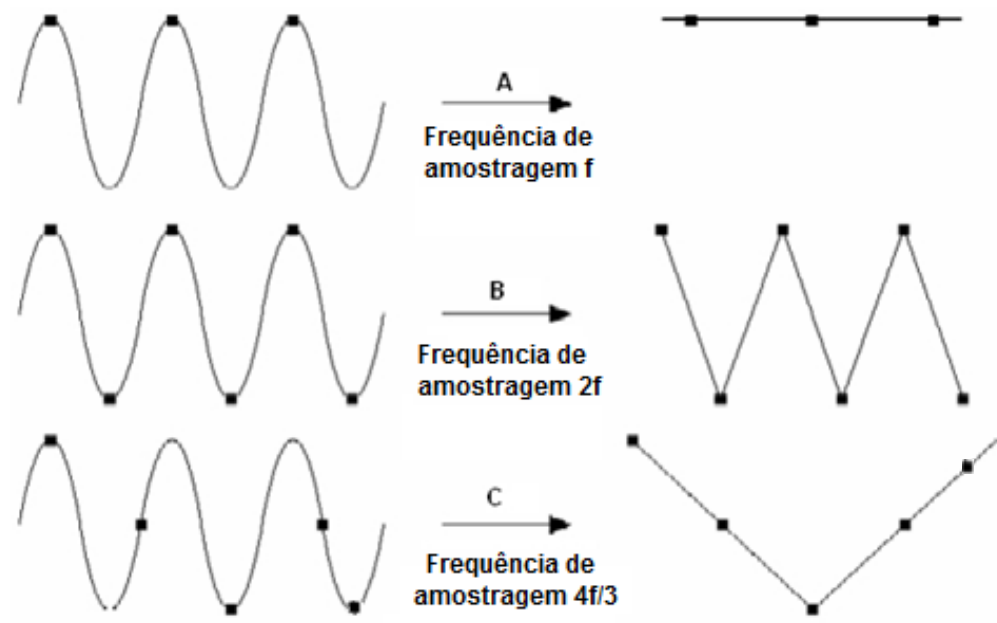

Figura 4.13: Efeito do uso de diferentes taxas de amostragem em um sinal.

Fica claro que ao utilizar uma taxa de amostragem inferior à taxa de Nyquist, não se reproduz fielmente o sinal de origem. No caso $A$, a onda senoidal de frequência f é amostrada com a mesma frequência. Observa-se que a onda reconstruída é diferente do original, ela aparece como uma onda de corrente contínua (CC). E no caso C, a taxa de amostra também é inferior à taxa de Nyquist, o que leva a uma conclusão equivocada do sinal aquisitado. Já o caso $B$, a taxa de amostragem é a taxa de Nyquist. Com esses resultados foi possível reconstruir o sinal original. Aumentando ainda mais a taxa de amostragem será possível reproduzir a forma de onda com maior exatidão.

Caso a taxa de amostragem não satisfaça o teorema da amostragem, temos a ocorrência do efeito de aliasing (Figura 4.14). Este efeito consiste na sobreposição do espectro de $x(t)$, dificultando a recuperação fiel do sinal original.

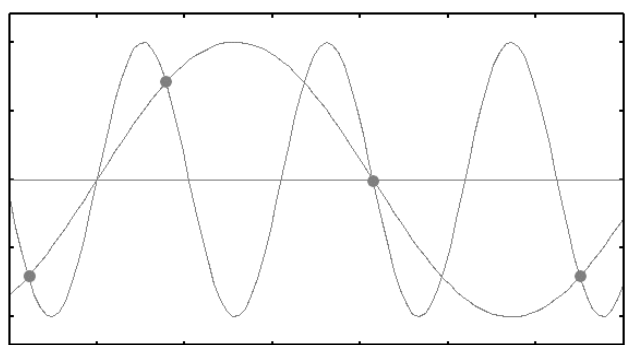

Figura 4.14: Exemplo do efeito de aliasing.

\subsubsection{Transformada de Fourier}

A análise de sinais, comumente, é realizada no domínio da frequência. Neste domínio é possível realizar análises com funções matemáticas com respeito à frequência em 
contraste com o domínio do tempo. A representação no domínio da frequência permite, também, uma análise quanto ao deslocamento de fases.

Existem algumas ferramentas para visualizar o sinal real no domínio do tempo, sendo uma delas o osciloscópio. Já para a análise no sinal no domínio da frequência é necessário um analisador de espectro ou um osciloscópio capaz de realizar uma transformada rápida de Fourier. Um gráfico no domínio do tempo mostra como o sinal oscila ao longo do tempo e um gráfico no domínio da frequência mostra quanto do sinal reside em cada faixa da frequência, conforme a Figura 4.15.

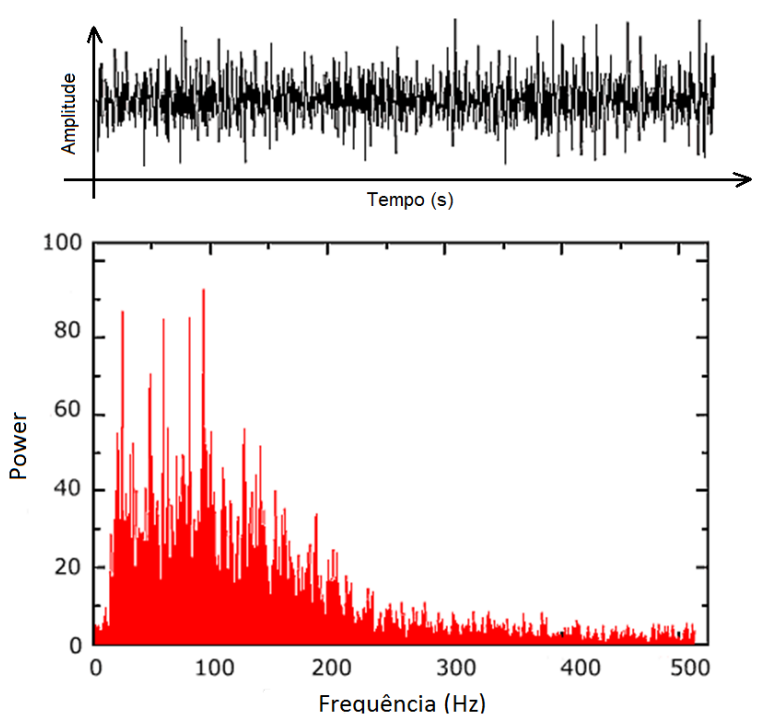

Figura 4.15: Exemplo do mesmo sinal no domínio do tempo e no domínio da frequência.

O estudo de representações de funções genéricas por meio da soma de funções senoidais é conhecido como Análise de Fourier. Originalmente, esta análise procurou representar fenômenos periódicos, através da chamada série de Fourier. Mais tarde, ela se estendeu para os fenômenos não periódicos, através da transformada de Fourier.

Existem diversas representações de Fourier e cada uma é utilizada para uma classe diferente de sinais: periódico contínuo, periódico discreto, não periódico contínuo e não periódico discreto (OPPENHEIM; SCHAFER, 2009).

\subsubsection{Ruído}

O ruído está presente em todas as situações físicas em que as medições são realizadas. Todo sinal elétrico ao propagar-se por um meio de transmissão pode sofrer 
algum tipo de perturbação ou degradação. Assim, as distorções de fase ou ruídos são perturbações de natureza aleatória, causadas por agentes externos ao sistema (HOLMAN, 2012). Experimentos, projetos e procedimentos adequados, em diversas situações, auxiliam na redução deste efeito.

O ruído trata-se de um sinal indesejável, constituído por sinais aleatórios e, por serem aleatórios, esses sinais interferem nos circuitos eletrônicos dificultando a análise dos resultados. Nesse ponto, o ruído torna-se uma adição ao sinal de informação original que tende a alterar seu conteúdo e, na maioria das vezes, não pode ser completamente compreendido. O ruído pode ser gerado por fenômenos naturais como descargas atmosféricas (raios), reações químicas ou pela proximidade de equipamentos elétricos ou eletrônicos, por exemplo, motores, máquinas industriais de grande porte, controladores de potência, etc. O acionamento destes equipamentos pode gerar um pico de consumo na rede elétrica causando uma perturbação nela, adicionando um ruído no equipamento de aquisição.

Para o sucesso na medição, é importante ter o conhecimento a priori do que pode estar disponível nas faixas de frequência do sinal. Por exemplo, ao se realizar a medição da temperatura atmosférica, está subentendido de que a temperatura não irá oscilar em um intervalo de tempo muito pequeno. Portanto, o valor médio da tensão de saída de um termopar inclui apenas as baixas frequências. As frequências mais altas podem ser consideradas como ruídos devido às flutuações ligadas ao termopar. Outro exemplo seria a investigação do ruído audível produzido por uma linha de transmissão de ultra-alta tensão. Uma vez que o ouvido humano reage a sinais acústicos apenas na gama de frequências entre os $20 \mathrm{~Hz}$ e $18 \mathrm{kHz}$, o processamento de saídas do sensor pode ser seguramente limitado a esta gama de frequências.

Essa discussão leva naturalmente a necessidade de filtrar o sinal elétrico, construindo um filtro que passe apenas algumas faixas de frequências do sinal de entrada para melhorar sua análise. As partes não desejadas do sinal podem ser consideradas como ruído, mas, além disso, ruído, também, está presente na banda de frequência de interesse. A filtragem não resolverá todos os problemas, mas fornece um grau significativo de melhoria no experimento.

Além da utilização de filtros, algumas providências básicas para evitar o ruído no equipamento podem ser consideradas. Sempre deve-se manter o aterramento elétrico 
em bom estado de funcionamento e de preferência utilizar um aterramento separado para os aparelhos sensíveis e isolado do neutro da rede elétrica. Outro cuidado é não ligar aparelhos sensíveis na mesma linha de alimentação onde estão ligados aparelhos de maior potência. O ideal é separar uma linha de alimentação, com seu próprio disjuntor para ligar os equipamentos mais sensíveis (DOEBELIN, 1995).

\subsubsection{Filtros}

O termo filtro sugere um sistema que passa certos componentes de frequência de um sinal de entrada e rejeita totalmente todos os outros. O projeto de filtros de tempo discreto corresponde à determinação dos parâmetros de uma função de transferência ou de uma equação de diferenças que aproxima uma resposta ao impulso ou uma reposta em frequência dentro de tolerâncias especificadas (OPPENHEIM; SCHAFER, 2009). Dessa forma, existem diversas alternativas de aceitar ou rejeitar a frequência do sinal, que pode ser resumido em quatro categorias, apresentadas na Figura 4.16.
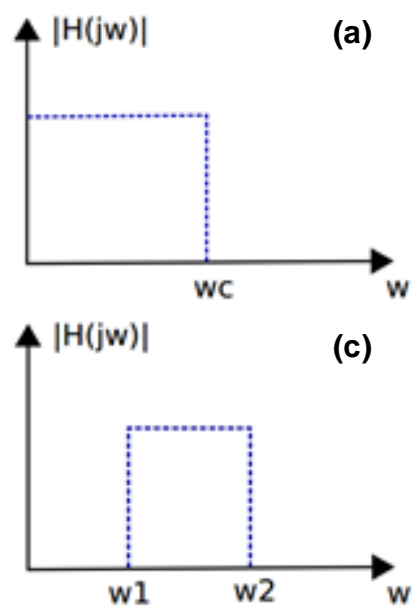

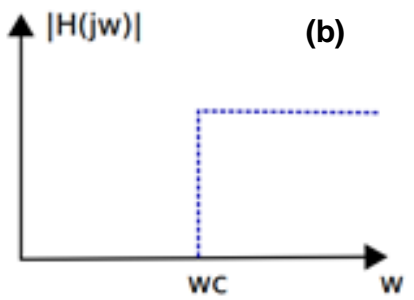

(d)

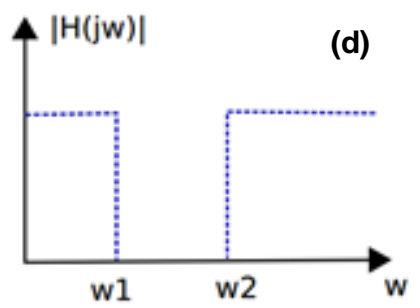

Figura 4.16: Filtros analógicos ideais (a) passa-baixa, (b) passa-alta, (c) passa faixa e (d) rejeita faixa.

Um filtro passa-baixa (Figura 4.16-a) permite a transmissão de sinais com frequências abaixo de um certo valor de corte (wc), enquanto um filtro passa-alto (Figura 4.16-b) permite a transmissão de sinais com frequências acima de um certo valor de corte. Em ambos os casos os dados que estão antes ou após a frequência de corte sofrem pouca ou nenhuma atenuação. Já o filtro de banda (Figura 4.16-c; Figura 4.16-d) permite a transmissão de sinais com frequências de um determinado intervalo, enquanto os sinais abaixo e acima deste intervalo são cortados com pouca ou 
nenhuma atenuação (ANTONIOU, 1993; OPPENHEIM; WILLSKY; NAWAB, 1996; TAYLOR, 1983).

Na prática não é possível realizar um filtro ideal e as transições entre as bandas de passagem e de corte são mais suaves, conforme Figura 4.17.

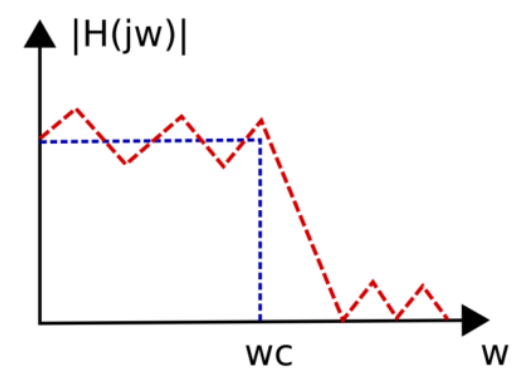

Figura 4.17: Exemplo de filtro real para o caso passa-baixa. Em azul o filtro ideal e em vermelho a resposta real.

Quanto maior a complexidade, ou ordem, do filtro, mais próximo se está da resposta ideal, porém maior e mais complexo será o circuito analógico necessário para realizálo, e, consequentemente, maior será o tempo de resposta (OPPENHEIM; WILLSKY; NAWAB, 1996). Os sistemas de tempo discreto implementados caem em duas categorias básicas: sistemas com respostas ao impulso infinito (em inglês, Infinite Impulse Response (IIR)) e sistemas com respostas ao impulso finito (em inglês, Finite Impuse Response (FIR)). O projeto de filtros IIR implica na obtenção de uma função de transferência aproximada que seja uma função racional de $z$, enquanto o projeto de filtro FIR leva a uma aproximação polinomial.

O projeto de filtros envolve os seguintes estágios: a especificação das propriedades desejadas do sistema, a aproximação das especificações usando um sistema de tempo discreto casual e a realização do sistema (OPPENHEIM; SCHAFER, 2009). Embora essas três etapas certamente não sejam independentes, é necessário focar principalmente na segunda etapa, sendo a primeira altamente dependente da aplicação e a terceira dependente da tecnologia a ser usada para implementação.

Em um ambiente prático, o filtro desejado geralmente é implementado com um hardware digital e/ou um software e normalmente é utilizado para filtrar um sinal que é obtido de um sinal de tempo contínuo por meio de amostragem periódica seguida pela conversão Analógico-Digital (A/D). Por esse motivo, tornou-se comum chamar os filtros de tempo discreto de filtros digitais. 


\subsection{Filtro digital}

O filtro digital é um filtro que processa o sinal analógico, ou seja, ele implementa um algoritmo matemático que opera sobre o sinal $x[n]$ aplicado em sua entrada gerando uma versão filtrada $y[n]$ de $x[n]$. Considerando que o filtro está implementado num Processador Digital de Sinais (PDS) e que o objetivo é processar um sinal analógico $x(t)$, temos (Figura 4.18):

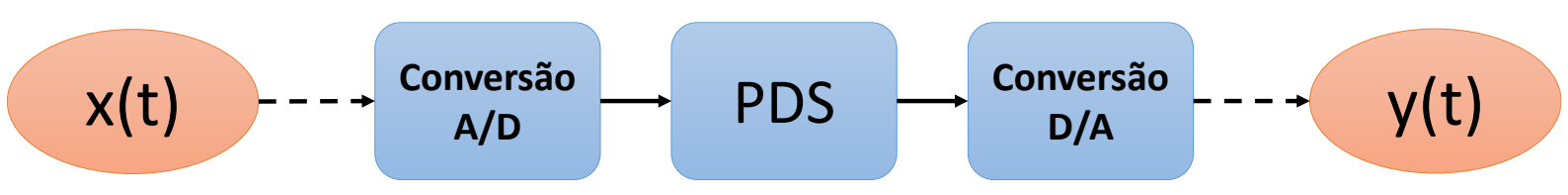

Figura 4.18: Diagrama de bloco do processamento do filtro digital.

O filtro digital apresenta algumas vantagens frente à utilização do filtro analógico, como:

- Filtros digitais podem apresentar fase perfeitamente linear;

- O desempenho dos filtros analógicos depende de componentes do circuito, ou seja, sua resposta é influenciada por mudanças ambientais (temperatura, umidade);

- A resposta em frequência do filtro digital pode ser mais facilmente modificada (caso esteja implementada em software ou hardware programável);

- Com o avanço da tecnologia de fabricação eletrônica, os filtros digitais podem ser implementados em dispositivos cada vez menores e mais econômicos;

- Filtros digitais podem ser utilizados em sinais de frequência muito baixa, como por exemplo, aplicações biomédicas.

No entanto os filtros digitais apresentam algumas desvantagens:

- Considerando as etapas de conversão analógico/digital (A/D) e digital/analógico (D/A) e o processamento propriamente dito, os filtros digitais tem uma velocidade de resposta inferior aos analógicos;

- Os filtros digitais estão sujeitos aos erros inerentes ao processo de quantização na conversão $A / D$ e também aos erros de aproximação devido ao uso de dados discretos. Em filtros recursivos de alta ordem esses fenômenos podem levar à instabilidade. 
Os filtros podem ser classificados em diferentes grupos dependendo dos critérios utilizados. A classe que amplamente é utilizada como filtro de tempo contínuo seletivo em frequência, para o tipo IIR, são Butterworth, Chebshev e elíptico e, para o filtro do tipo FIR, são janela de Kaiser e aproximações ótimas (OPPENHEIM; SCHAFER, 2009).

\subsubsection{Filtro IIR}

Os filtros IIR são filtros simples, que necessitam de um baixo processamento. Isso ocorre, porque se aproximam dos filtros analógicos (OPPENHEIM; WILLSKY; NAWAB, 1996). No projeto de um filtro IIR deve-se considerar a invariância ao impulso como um método para obter um sistema discreto cuja resposta em frequência é determinada pela resposta em frequência de um sistema de tempo contínuo. Para isso, a resposta ao impulso do filtro de tempo discreto é escolhida proporcionalmente a amostras igualmente espaçadas da resposta ao impulso do filtro de tempo contínuo.

Os filtros mais simples de utilizar são do tipo IIR e a seguir são destacados, na Figura 4.19, os filtros clássicos com o perfil da resposta de cada um.
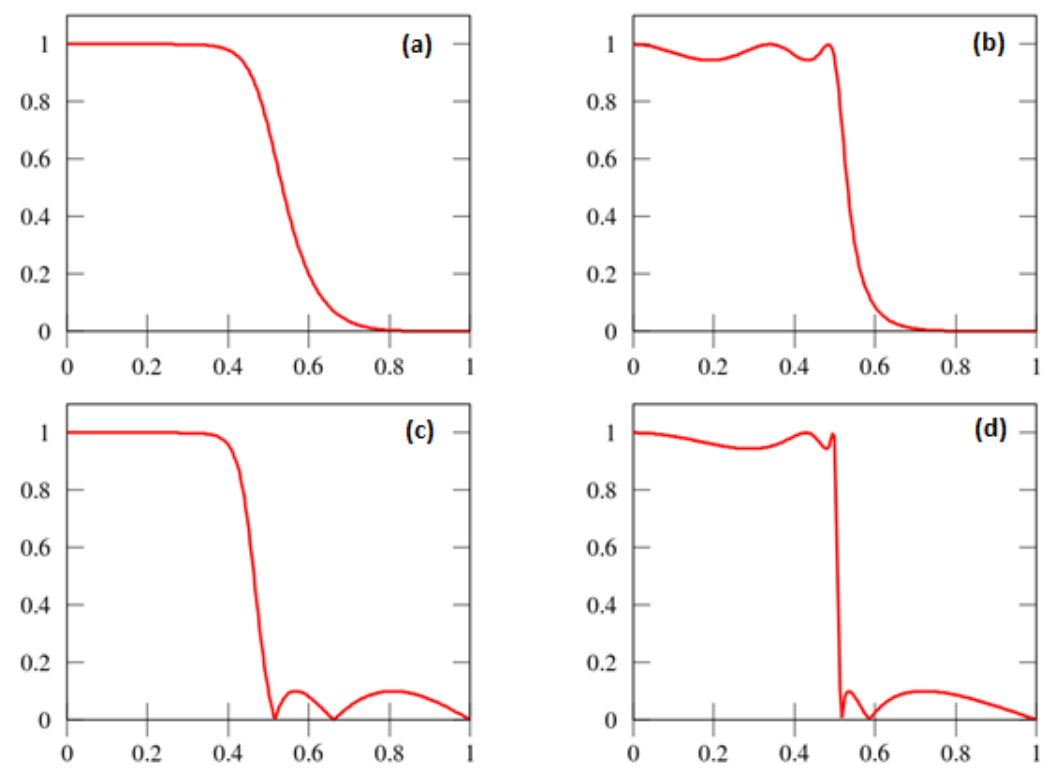

Figura 4.19: Resposta para cada filtro passa-baixa: (a) Filtro Butterworth, (b) Filtro Chebyshev tipo 1, (c) Filtro Chebyshev tipo 2, (d) Filtro Elliptic.

- Butterworth: este filtro fornece uma banda passante muito plana e um ganho monotonicamente decrescente na transição entre a faixa passante e de rejeição. A inclinação da resposta do filtro é menor que o Chebyshev e o Elliptic. 
- Chebyshev ou Chebyshev tipo 1: este filtro fornece uma banda passante com ondulações simétricas e um ganho monotonicamente decrescente na transição entre a faixa passante e de rejeição.

- Chebyshev inverso ou Chebyshev tipo 2: este filtro fornece uma banda passante muito plana e ondulações simétricas na faixa de rejeição.

- Elliptic: este filtro possui ondulações tanto na banda passante quanto na de rejeição. De todos os filtros é o que apresenta a maior inclinação da resposta do filtro.

\subsubsection{Filtro FIR}

O método mais simples para projeto do filtro FIR é conhecido como método de janelamento. Esse método geralmente começa com uma reposta em frequência desejada ideal, que pode ser representado pela Equação 4.4, em que $h_{d}[n]$ é a sequência de resposta ao impulso correspondente.

$$
H_{d}\left(e^{j \omega}\right)=\sum_{n=-\infty}^{\infty} h_{d}[n] e^{-j \omega n}
$$

O fator e $e^{-j \omega n}$ é uma autofunção do sistema, e o valor associado é $\mathrm{H}_{\mathrm{d}}\left(\mathrm{e}^{\mathrm{j} \omega}\right)$. Verifica-se que $H_{d}\left(e^{j \omega}\right)$ descreve a mudança na amplitude complexa de um sinal de entrada exponencial complexo em função da frequência $\omega$. O autovalor $\mathrm{H}_{\mathrm{d}}\left(\mathrm{e}^{\mathrm{j} \omega}\right)$ é a resposta em frequência do sistema e, em geral, pode ser expresso em termos de sua parte real e imaginária.

O fator $h_{d}[n]$ é a sequência de resposta ao impulso correspondente, que pode ser expressa em termos de $\mathrm{H}_{\mathrm{d}}\left(\mathrm{e}^{\mathrm{j} \omega}\right)$, conforme a Equação 4.5 .

$$
h_{d}[n]=\frac{1}{2 \pi} \int_{-\pi}^{\pi} H_{d}\left(e^{j \omega}\right) e^{j \omega n} d \omega
$$

O método mais direto para obter uma aproximação FIR para tais sistemas consiste em um truncamento da resposta ao impulso ideal por meio do processo conhecido como janelamento. Portanto, é necessário verificar a convergência da soma de séries, semelhante ao que ocorre com uma série de Fourier (OPPENHEIM; WILLSKY; 
NAWAB, 1996). Sendo assim, é definido um novo sistema como resposta a partir deste truncamento, conforme Equação 4.6

$$
h[n]=\left\{\begin{array}{lr}
h_{d}[n], & 0 \leq n \leq M \\
0, & \text { caso contrário }
\end{array}\right.
$$

Geralmente, pode-se representar $\mathrm{h}[\mathrm{n}]$ como produto da resposta do impulso desejado por uma janela de duração finita w[n], conforme a equação 4.7.

$$
h[n]=h_{d}[n] w[n]
$$

Cada janela possui diferentes características de forma (relacionada com a largura do lóbulo principal e o nível do lóbulo lateral) e o comprimento (relacionada com a largura do lóbulo principal), conforme a Figura 4.20.

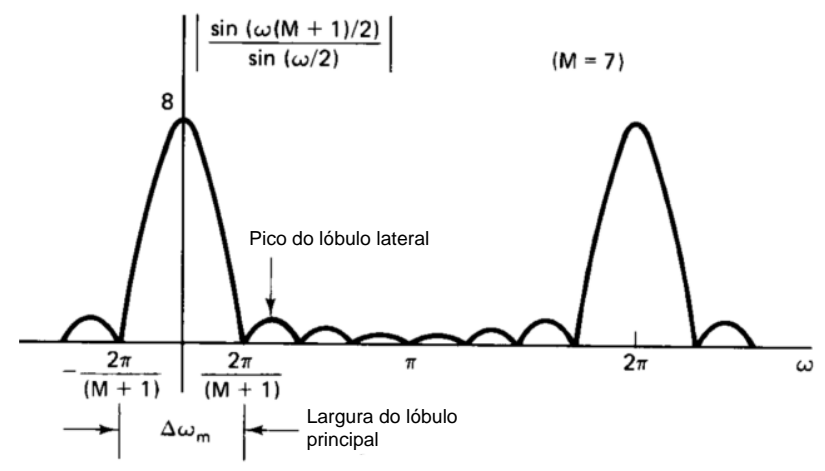

Figura 4.20: Magnitude da transformada de Fourier de uma janela retangular $(M=7)$ (OPPENHEIM; SCHAFER, 2009).

Conclui-se que com o teorema de modulação ou janelamento é dado pela Equação 4.8:

$$
H_{d}\left(e^{j \omega}\right)=\frac{1}{2 \pi} \int_{-\pi}^{\pi} H_{d}\left(e^{j \theta}\right) W\left(e^{j(\omega-\theta)}\right) d \theta
$$

Isto é, $H_{d}\left(e^{j \omega}\right)$ é a convolução periódica da resposta em frequência ideal desejada com a transformada de Fourier da janela. A janela mais simples que existe é a retangular, mas existe vários outros tipos de janelas que podem ser usadas, conforme a Figura 4.21 . 


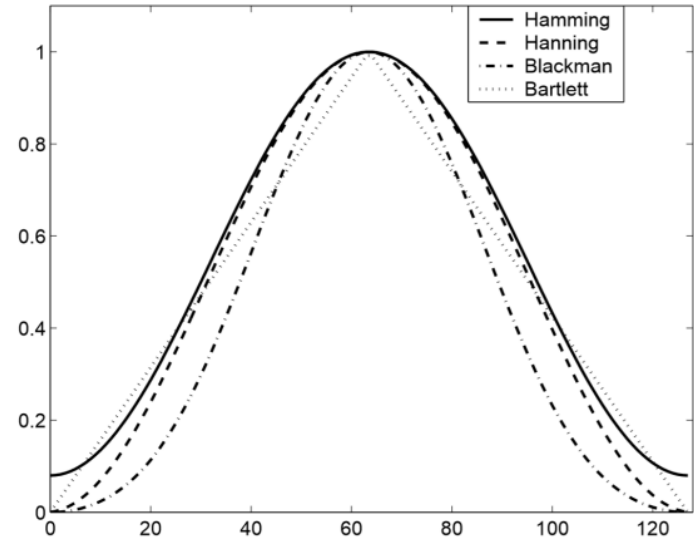

Figura 4.21: Janelas comumente utilizadas.

Como deve-se considerar a forma e duração da janela para o desenvolvimento do filtro, verifica-se que se torna inviável o desenvolvimento deste filtro através de tentativa e erro ao estimar a duração e forma ideal mínima para que haja convergência. Assim, uma formalização simples do método de janelas foi desenvolvido por Kaiser (1974).

O compromisso entre a largura do lóbulo principal e a área do lóbulo lateral pode ser quantificado pela busca da função de janelamento que é maximamente concentrada em torno de $\omega=0$. No entanto as soluções iniciais envolviam cálculos matemáticos complexos. Kaiser (1974) descobriu que uma janela próxima da ótima poderia ser realizada utilizando a função de Bessel modificada de primeira espécie de ordem zero, obtendo a Equação 4.9.

$$
w[n]=\left\{\begin{array}{lr}
\frac{I_{0}\left[\beta\left(1-\left[\frac{n-\alpha}{\alpha}\right]^{2}\right)^{\frac{1}{2}}\right]}{I_{0}(\beta)}, & 0 \leq n \leq M \\
0, & \text { caso contrário }
\end{array}\right.
$$

Sendo $\alpha=\mathrm{N} / 2$ e lo a função de Bessel modificada de primeira espécie de ordem zero. Ao contrário das outras janelas, esta possui dois parâmetros, sendo eles o comprimento $(\mathrm{N}+1)$ e o parâmetro de forma $(\beta)$. Variando esses parâmetros, o comprimento da janela e sua forma podem ser ajustados para trocar amplitude do lóbulo lateral por largura do lóbulo principal. Na Figura 4.22 é apresentado algumas envoltórias das janelas de Kaiser para diferentes parâmetros de comprimento de forma. 

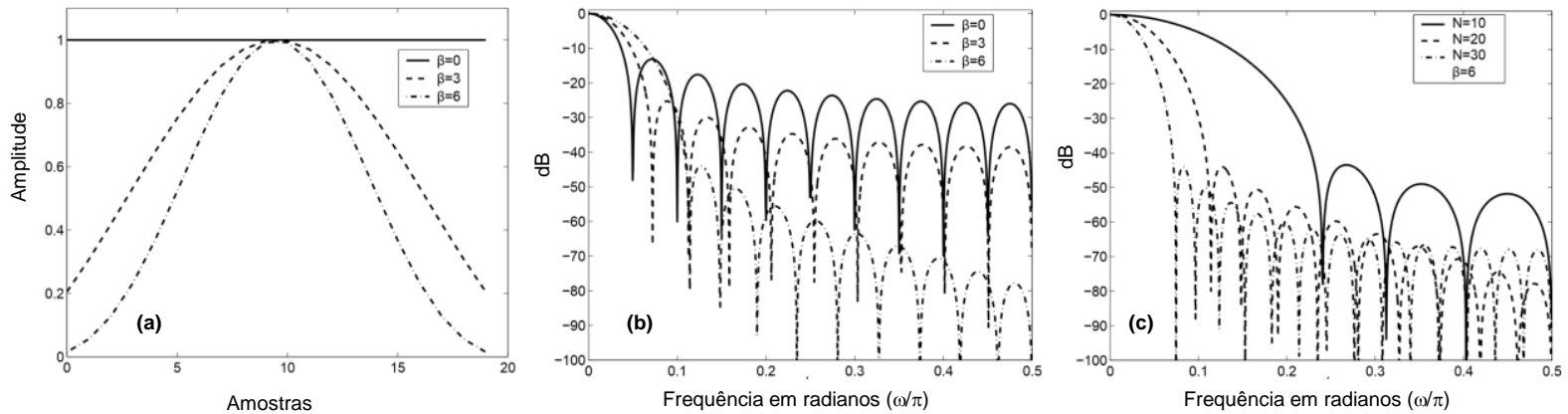

Figura 4.22: (a) Janelas Kaiser para $b=0,3$ e 6 e $N=20$. (b) Transformadas de Fourier correspondentes às janelas em (a). (c) Transformadas de Fourier com $b=6$ e $N=10,20$ e 40 (OPPENHEIM; SCHAFER, 2009).

Pela Figura 4.22-b verifica-se que, mantendo constante o $\mathrm{N}$ e aumentando o $\beta$, a janela decai mais rapidamente, os lóbulos laterais da transformada de Fourier se tornam menores, mas o lóbulo principal se torna mais largo e, também, afeta a amplitude de pico dos lóbulos laterais. Já pela Figura 4.22-c, mantendo constante o $\beta$ e aumentando o $\mathrm{N}$, a janela decai mais rapidamente, o lóbulo principal diminui a largura, mas não afeta a amplitude do pico dos lóbulos laterais.

Vale ressaltar que o projeto de um filtro FIR através do método de janelamento não permite o controle individual sobre os erros de aproximação em diferentes faixas. Além do critério de aproximação levar a um comportamento adverso nas descontinuidades de $H_{d}\left(e^{j \omega}\right)$ (OPPENHEIM; SCHAFER, 2009). Para muitas aplicações, filtros melhores resultam de uma estratégia minimax (minimização dos erros máximos) ou de um critério de erro ponderado na frequência, podendo ser obtido por meio de algoritmos.

Esse tipo de filtro é conhecido com filtro de aproximação ótimo, pois tem o menor erro de aproximação ponderado para o máximo erro $(\delta)$ para as frequências das extremidades das faixas de passagem e de rejeição.

No projeto de um filtro por aproximação ótimo é conveniente considerar primeiro o projeto de um filtro de fase zero, conforme a Equação 4.10.

$$
h_{e}[n]=h_{e}[-n]
$$

A seguir, deve-se inserir um atraso suficiente para torná-lo causal. Consequentemente, deve-se considerar que $h_{e}[n]$ satisfaz a condição da Equação 4.10, tendo assim a resposta em frequência, de acordo com a Equação 4.11. 


$$
A_{e}\left[e^{j \omega}\right]=h_{e}[0]+\sum_{n=1}^{L} 2 h_{e}[n] \cos (\omega n)
$$

Sendo $L=N / 2$ um inteiro e $A_{e}\left(e^{j \omega}\right)$ é uma função real, par e periódica de $\omega$. Um sistema causal pode ser obtido a partir de $h_{e}[n]$ por um atraso de $L=M / 2$ amostras. $O$ sistema resultante tem reposta em frequência segundo a Equação 4.12.

$$
H\left(e^{j \omega}\right)=A_{e}\left(e^{j \omega}\right) e^{-j \omega M / 2}
$$

Na Figura 4.23 é apresentado um diagrama de tolerância para uma aproximação de um filtro passa-baixa com uma função real $A_{e}\left(e^{j \omega}\right)$.

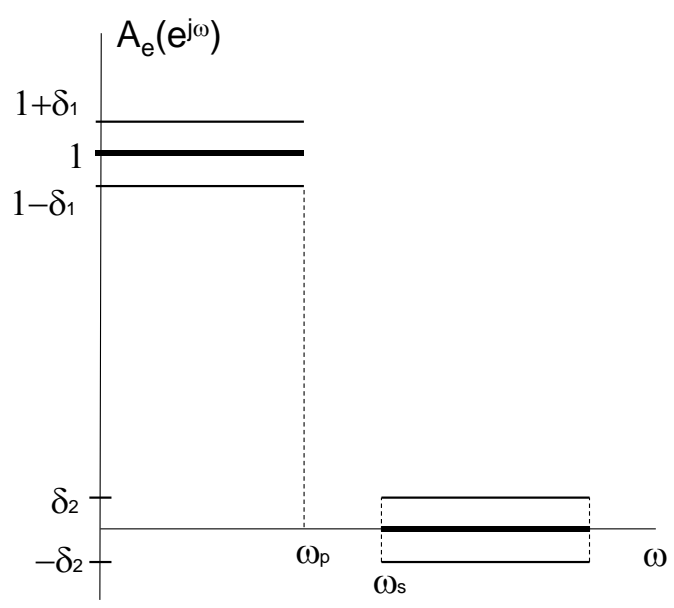

Figura 4.23: Diagrama de tolerância e resposta ideal para filtros passa-baixa.

Este filtro apresenta uma frequência de passagem $(\omega p)$, um erro absoluto máximo de passagem $\left(\delta_{1}\right)$, uma frequência de parada $\left(\omega_{s}\right)$ e um erro absoluto máximo de parada $\left(\delta_{2}\right)$. Diversos pesquisadores desenvolveram seus algoritmos para estimar, de forma iterativa, os parâmetros $L, \delta 1, \delta 2$, $\omega_{p}$ e $\omega_{\text {s. }}$ Duas abordagens são realizadas: $L, \delta 1$ e $\delta 2$ são fixos e $\omega_{p}$ e $\omega_{s}$ são as variáveis (HERRMANN; SCHUESSLER, 1970) ou L, $\omega_{p}$, $\omega_{s}$ e a razão $\delta_{1} / \delta_{2}$ são fixos e $\delta_{1}$ ou $\delta_{2}$ são as variáveis (MCCLELLAN; PARKS, 1973).

O algoritmo de Parks-McClellan sempre se mostrou mais adequado e confiável, e, por isso, tem se tornado como o método dominante para o projeto de aproximação ótima de filtros FIR. Este algoritmo é mais flexível e computacionalmente mais eficiente 
(OPPENHEIM; SCHAFER, 2009). Na Figura 4.24 é apresentado o fluxograma de funcionamento do algoritmo de Parks-McClellan.

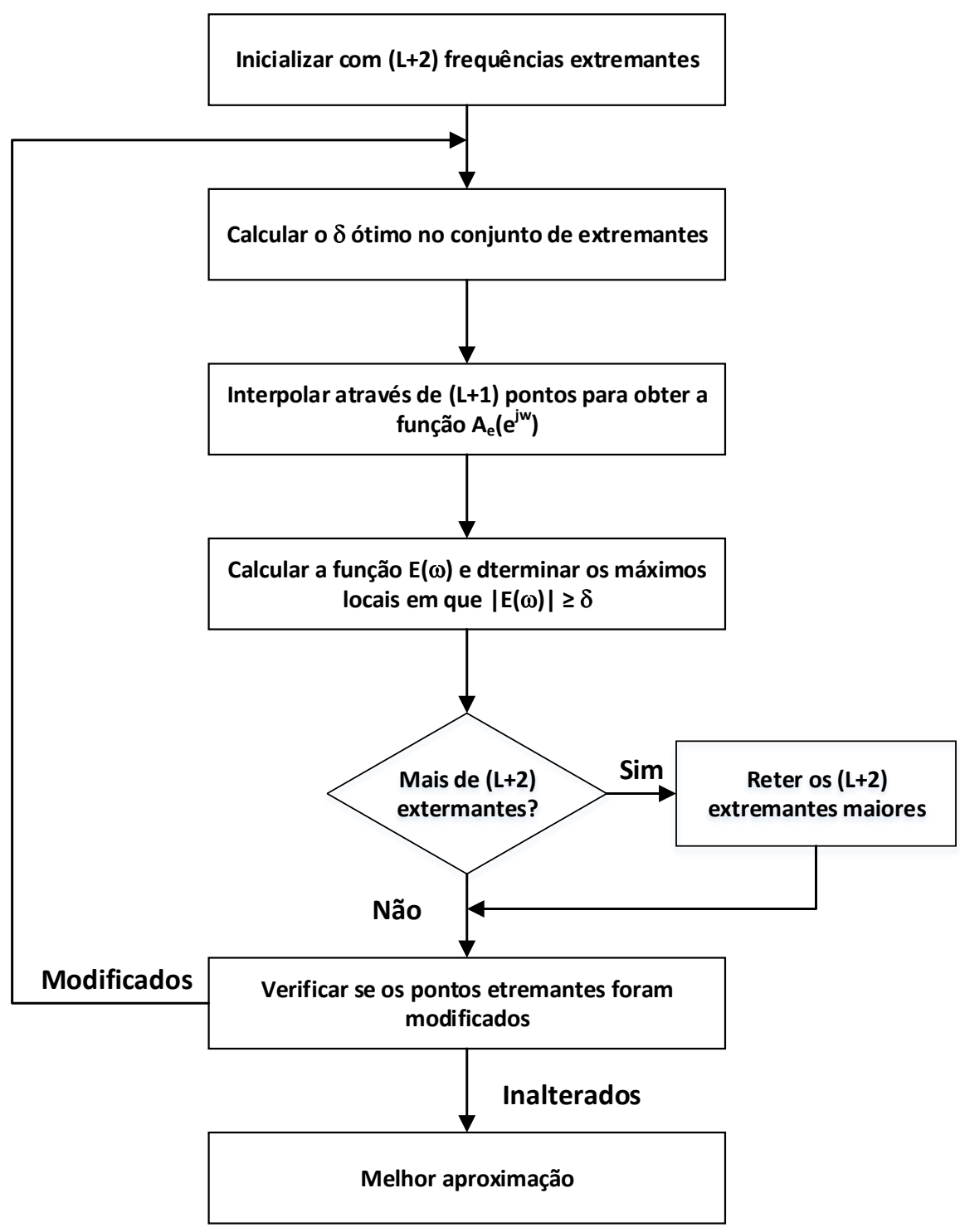

Figura 4.24: Fluxograma do algoritmo de Parks-McClellan (OPPENHEIM; SCHAFER, 2009).

Nesse algoritmo, todos os valores da resposta ao impulso he[n] são implicitamente variados a cada interação para obter a aproximação ótima desejada, mas os valores de $h_{e}[n]$ nunca são calculados explicitamente. Após o algoritmo ter convergido, a resposta ao impulso pode ser calculada a partir de amostras da representação polinomial utilizando a transformada de Fourier discreta.

\subsubsection{Comentários sobre os filtros FIR e IIR}

Ambos os filtros têm suas vantagens e desvantagens, que deve se levar em consideração no projeto do filtro. A escolha entre os filtros FIR e IIR depende da 
aplicação específica e deve considerar as características como: resposta da fase linear, estabilidade e complexidade.

Os filtros FIR apresentam resposta de fase linear. Isso implica que nenhuma distorção de fase é produzida no sinal filtrado. Essa característica é importante em diversas aplicações como por exemplo, no processamento de áudio e de imagem e transmissão de dados. Já na fala, por exemplo, a fase linear não é essencial e por isso pode ser negligenciada, sendo o filtro IIR mais adequado.

Quando um sinal a ser filtrado é analisado desta forma, é fácil decidir qual o tipo de filtro a ser utilizado. Se a característica da fase é essencial, filtros FIR deve ser utilizado, uma vez que apresenta características de fase linear. Caso contrário, quando somente a resposta da frequência que importa, é preferível utilizar os filtros IIR.

Quanto à estabilidade, os filtros FIR são realizados de modo não-recursivo, ou seja, não utilizam a retroalimentação para os cálculos, e assim são sempre estáveis. $O$ mesmo não pode ser garantido para os filtros IIR (TAYLOR, 1983), conforme a Figura 4.25 .

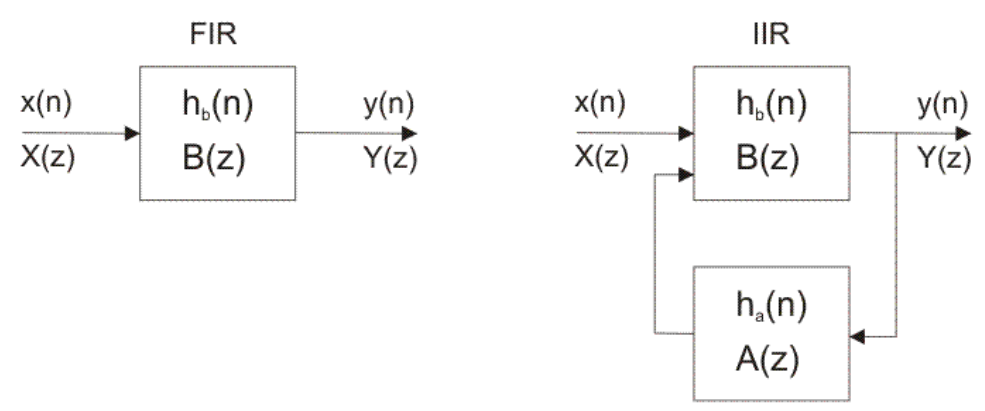

Figura 4.25: Diagrama de funcionamento dos filtros FIR e IIR (TAYLOR, 1983).

Os filtros IIR, em geral, necessitam de menos coeficientes que os FIR para atender a uma mesma especificação de projeto. Um filtro de menor ordem tem menor tempo de execução. Por ser um filtro mais simples, os filtros analógicos podem ser facilmente convertidos em filtros digitais IIR equivalentes (ANTONIOU, 1993; TAYLOR, 1983).

As características básicas de um filtro de resposta ao impulso finita (FIR) são:

- Fase linear característica;

- Filtros de alta ordem (mais complexo);

- Estabilidade. 
As características básicas do filtro de resposta ao impulso infinita (IIR) são:

- Fase não linear característica;

- Filtros de baixa ordem (menos complexo);

- Filtro resultante tem o potencial de se tornar instável.

De modo geral, pode-se usar um filtro IIR sempre que for importante uma resposta bem seletiva no domínio da frequência ou quando for necessário realizar a conversão das especificações de um filtro analógico. E o filtro FIR, quando o número de coeficientes não for grande e especialmente quando a distorção de fase desejada for pequena.

\subsubsection{Especificação do filtro}

Para o desenvolvimento do filtro digital é necessário especificar alguns parâmetros. A seguir será apresentado as etapas para especificação de um filtro passa-baixa, mas este tipo de filtro é facilmente transformado em outros tipos de filtros seletivos em frequência (OPPENHEIM; SCHAFER, 2009).

A Figura 4.26 é uma representação típica dos limites de tolerância associados à e aproximação de um filtro passa-baixa de tempo discreto que idealmente tem um ganho unitário na passagem e ganho nulo na faixa de rejeição.

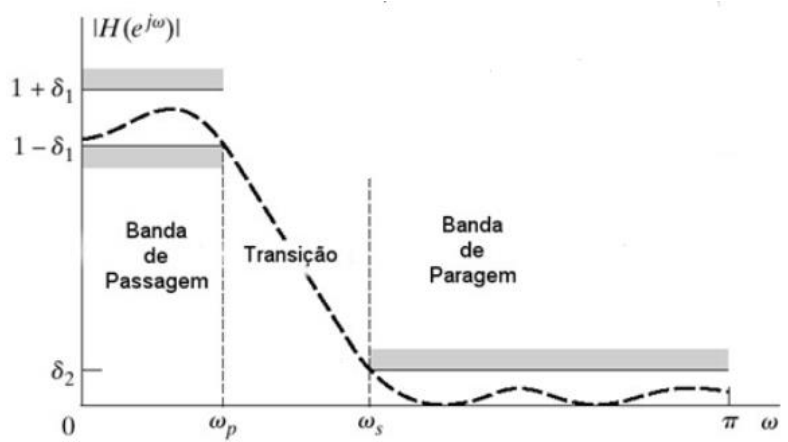

Figura 4.26: Diagrama de tolerância de um filtro passa-baixa.

Como a aproximação não pode ter uma transição abrupta da faixa de passagem para a faixa de rejeição, uma região de transição da frequência da extremidade da faixa de passagem $\omega_{p}$ até o início da faixa de rejeição em $\omega_{s}$ é permitida, sendo a diferença mínima de 0,5 Hz. Caso este valor seja menor, há um aumento da ordem do filtro, o que causa um maior processamento (OPPENHEIM; SCHAFER, 2009). 
Dependendo da forma de aplicação, os limites de tolerância da faixa de passagem podem variar simetricamente em torno do ganho unitário, caso em que $\delta_{1}=\delta_{2}$, ou então pode-se restringir a faixa de passagem de modo a ter ganho máximo unitário, caso em que $\delta_{1}=0$. Na prática, muito dos filtros são especificados para um ganho máximo na faixa de passagem de 0,01 e para a faixa de rejeição um ganho máximo de 0,001 (OPPENHEIM; SCHAFER, 2009).

Na Figura 4.27 são apresentados os parâmetros para filtro tipo passa-baixa e o cálculo pode ser utilizado para os demais tipos de filtros.
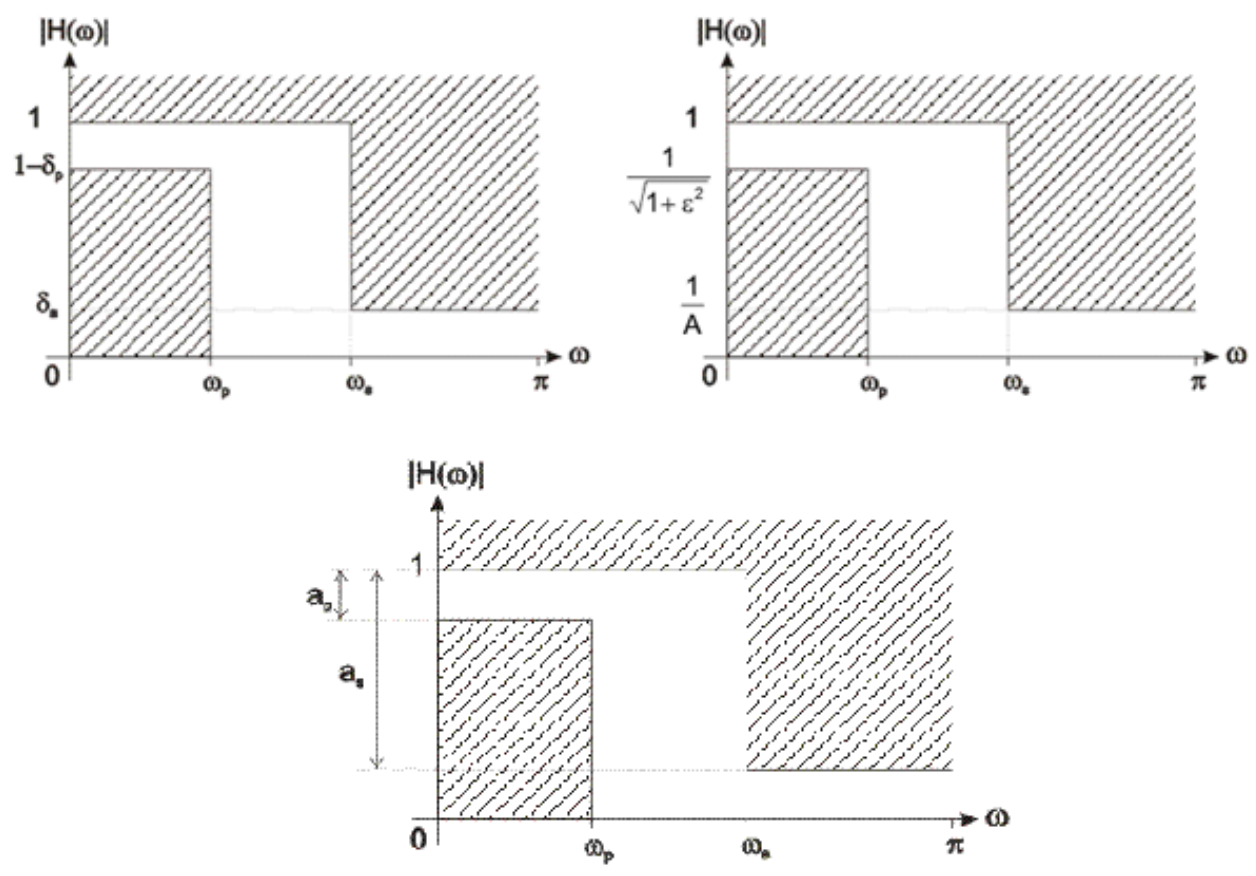

Figura 4.27: Especificação de um filtro passa-baixa (ANTONIOU, 1993; TAYLOR, 1983).

As equações que relacionam esses parâmetros são apresentadas a seguir:

$$
\begin{gathered}
\delta_{p}=1-10^{-\frac{a_{p}}{10}}=1-\frac{1}{\sqrt{1+\varepsilon^{2}}} \\
\varepsilon=\frac{\sqrt{\delta_{p}\left(2-\delta_{p}\right)}}{1-\delta_{p}}=\sqrt{10^{\frac{a_{p}}{10}}-1} \\
a_{p}=-20 \log \left(1-\delta_{p}\right)=10 \log \left(1+\varepsilon^{2}\right)
\end{gathered}
$$

No qual:

- $\quad \omega p$ é frequência de corte da banda passante; 
- $\omega_{s}$ é a frequência de corte da banda de parada;

- $\delta_{p}$ são as ondulações máximas de banda passante;

- $\delta$ m são as atenuações mínimas da banda de parada;

- A é o parâmetro de atenuação da banda de parada;

- ap é a máxima ondulação da banda passante $(\mathrm{dB})$;

- as é atenuação mínima da banda de parada;

- $\varepsilon$ é o parâmetro de atenuação da banda passante.

Os filtros, na prática, são especificados conforme Figura 4.26, mas são apresentados quanto à restrição da resposta e da fase além de sua estabilidade. Por isso, para o caso dos filtros IIR e FIR é necessário realizar a transformada Z (círculo unitário) e verificar o local dos polos.

\subsubsection{Transformada Z}

A análise da estabilidade de filtros digitais, invariantes no tempo é efetuada usando a transformada Z. A principal razão para isso é que após a aplicação da transformada $Z$, as equações de diferenças que caracterizam os filtros digitais são transformadas em equações algébricas que são geralmente mais fáceis de resolver.

Assim como a transformada de Laplace e Fourier, a transformada $Z$ possui uma inversa, conhecida como transformada $Z$ inversa. $A$ aplicação da transformada $Z$ em um sinal de tempo discreto $(x(n T))$ passa a representar o sinal função racional $(X(Z))$, onde z é uma variável complexa. Após o processamento do domínio $z$, obtém-se um resultado $(\mathrm{Y}(\mathrm{z}))$ e aplica-se a transformada $\mathrm{Z}$ inversa a este resultado para obter $\mathrm{o}$ sinal processado.

A transformada $Z$ é definida pela equação 4.16:

$$
F(z)=\sum_{n=-\infty}^{\infty} f(n T) z^{-n}
$$

Além disso, é possível mudar para a coordenada polar, em que o número complexo deve ser expresso segundo a equação 4.17.

$$
z=r e^{j \omega}
$$


No plano $z$, a transformada $Z$ é representada por um círculo unitário, conforme a Figura 4.28.

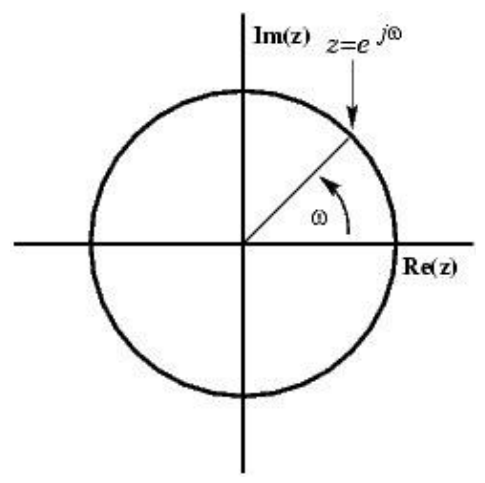

Figura 4.28: Representação do plano z.

A transformada $Z$ é de extrema importância para desenvolvimento de um filtro digital. A localização dos polos indica a estabilidade do filtro. Os polos da função de transferência do filtro devem estar localizados no interior do círculo para obter um filtro estável, conforme indicado na Figura 4.29.

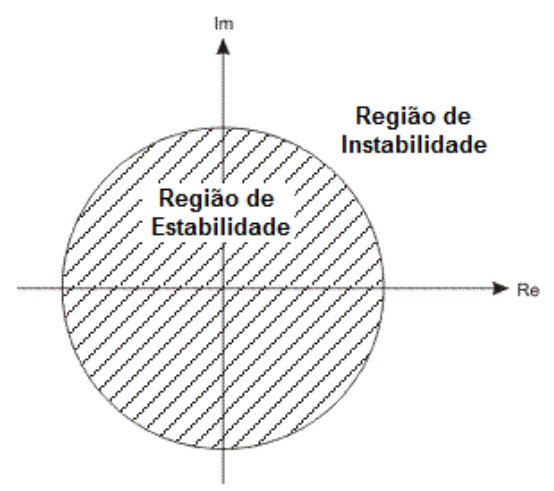

Figura 4.29: Região de estabilidade e instabilidade dos polos no plano z.

\subsection{Suavização e dados espúrios}

Em todo processo de medição existe certa oscilação do sinal medido. Além do processo de filtragem para reduzir ou atenuar o ruído, existe o processo de suavização ou detecção de dados espúrios (outliers). Há diferentes tipos de suavizações ou métodos para detectar outliers. O próprio método de suavização auxilia a detectar possíveis dados espúrios e excluí-los, de maneira que não afete o resultado final. 


\subsubsection{Suavização}

A média móvel é a suavização mais simples de uso e de compreensão (DONNELLY, 2006; LEVIE, 2004). Apesar da sua simplicidade, a suavização de média móvel é ideal para uma tarefa comum: reduzir o ruído aleatório gerado para sinais medidos ao longo do tempo. No entanto, a média móvel pode produzir distorções significativas e reduzir a intensidade do sinal, com a subsequente perda de pequenos sinais adjacentes e este efeito aumenta com o aumento do número de pontos a ser utilizado para o cálculo da média.

A suavização Savitzky-Golay é baseada no método dos mínimos quadrados polinomial (SAVITZKY; GOLAY, 1964). Tipicamente, tanto um polinômio de ordem grande ou moderada permite um elevado nível de suavização sem atenuação dos dados brutos. Por contraste, o método de filtragem Savitzky-Golay é melhor do que a média móvel, porque tende a preservar os recursos de dados, tais como a altura do pico e largura, os quais são normalmente atenuados pela suavização de média móvel.

Outra suavização muito utilizada é o LOESS e o LOWESS. O termo "LOESS" é derivado do termo Local Regression enquanto que o termo "LOWESS" é derivado do termo Locally Weighted Scatterplot Smooth (CLEVELAND, 1979, 1981; CLEVELAND; DEVLIN, 1988). Os dois métodos utilizam uma regressão linear ponderada localmente para suavizar os dados.

O processo de suavização é considerado local porque, como no método da média móvel, cada ponto suavizado é determinado pelos pontos da vizinhança e os pontos a serem utilizados são definidos por um intervalo impostos pelo usuário. O processo é considerado ponderado porque existe uma função que ponderada cada ponto contido no intervalo. Além disso, é possível utilizar uma função robusta fazendo com que o resultado tratado seja menos influenciado pelos espúrios.

\subsubsection{Dados espúrios}

Na estatística, um dado espúrio ou outlier é um ponto de observação que se encontra distante das demais observações (GRUBBS, 1969; MOORE; MCCABE, 2002). Um outlier, normalmente, pode ocorrer devido à variabilidade aleatória na medição ou pode indicar um erro experimental, sendo este último caso, muitas vezes excluído do conjunto dos dados (BOX; HUNTER; HUNTER, 2005; GRUBBS, 1969). 
Quando um pesquisador experiente observa um desvio claro em um dado experimental ele pode excluir os dados espúrios sem recorrer a testes estatísticos. No entanto, em muitos experimentos ainda é difícil identificar os dados espúrios, sendo necessário utilizar técnicas estatísticas para auxiliar a tomar decisões para identificar e excluir tais dados.

Como o outlier se comporta de maneira aleatória, não existe fórmula matemática adequada que o represente. Determinar se uma observação é um dado espúrio é um exercício subjetivo. Existem vário métodos para detectar outliers, podendo ser por método gráfico ou baseado em modelos estatísticos (GRUBBS, 1969; HODGE; AUSTIN, 2004). Métodos baseados em modelos estatísticos são comumente empregados, neste caso, assume-se que os dados possuem uma distribuição normal, e para a identificação "do dado improvável" é utilizado a média e o desvio padrão da amostra. A seguir são apresentados alguns critérios para identificar outliers de uma amostra:

- Critério de Dixon

- Critério de Chauvenet;

- Critério de Rosner;

- Critério de Iglewicz e Hoaglin;

- Critério de Grubb.

Em todos os casos é realizado um teste de hipótese, baseando na média, desvio padrão da amostra e o grau de significância, para identificar se o dado analisado é ou não um outlier. 


\section{PLANEJAMENTO EXPERIMENTAL}

Este trabalho foi dividido em três grupos: estudo do sinal, validações e desenvolvimento de software de pós-processamento e de acessórios. Na Figura 5.1 é apresentado o fluxograma referente às atividades desenvolvidas em cada grupo.

Estudo do sinal

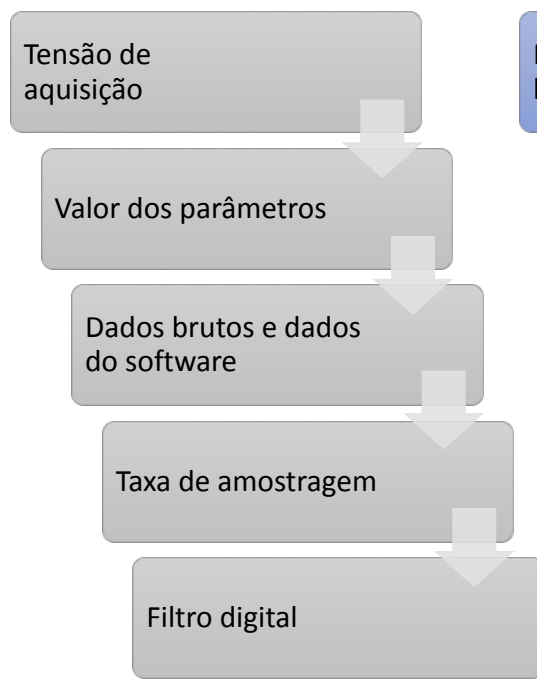

Validações

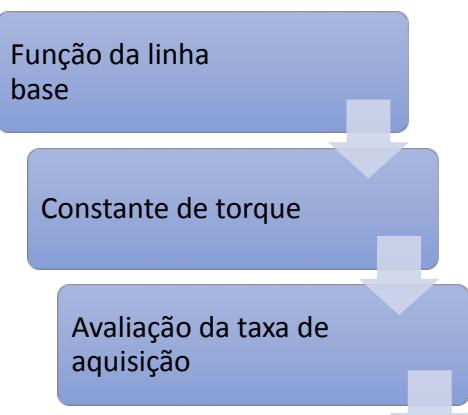

Ensaio com silicone

de diferentes

viscosidades
Ensaio de diferentes suspensões
Desenvolvimento

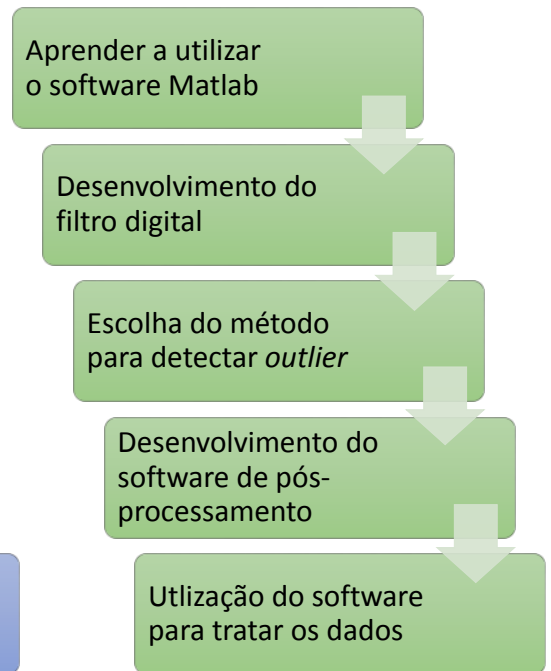

Figura 5.1: Fluxograma das etapas para desenvolvimento do trabalho.

A etapa de estudo de sinal, refere-se à definição da melhor configuração do servoconversor para que o sinal aquisitado apresente um nível de ruído aceitável. Considerando ainda na qualidade do dado, foi realizada comparação do dado bruto com o dado gerado pelo software SCl-R (programa de controle e aquisição do reômetro), uma vez que este software realiza um tratamento prévio. Além disso, foi executada uma análise da taxa de amostragem, uma vez que se esta for inferior à frequência de Nyquist pode levar à interpretação equivocada do resultado, conforme apresentado anteriormente, e, também, foi desenvolvido um filtro digital para reduzir e ou eliminar o ruído gerado pela leitura.

$\mathrm{Na}$ etapa de validação, foi realizado um estudo da linha base do ensaio, com o intuito de estudar os fatores que afetam o sinal, como por exemplo, temperatura, geometria de mistura, rotação do motor. Também, definiu-se a constante de torque do reômetro, utilizando um equipamento semelhante a um dinamômetro. Após todas essas verificações, foi analisada a sensibilidade do reômetro ao realizar um ensaio com água e também com silicone com diferentes viscosidades. 
Já na etapa de desenvolvimento foi desenvolvido um software para o pósprocessamento dos dados aquisitados durante o ensaio.

\subsection{Materiais}

A seguir serão apresentados os materiais utilizados para o desenvolvimento da pesquisa.

\subsubsection{Servoconversor e servomotor}

Para o estudo do reômetro utilizou-se um servoconversor da WEG modelo SCA-05 24/48 e um servomotor da WEG modelo SWA 56-7,0-30.

O servomotor possui um torque máximo de 7,0 N.m e ampla faixa de rotação, variando de 0 a 3000 rpm. A curva característica de torque máximo $x$ rotação do servomotor é fornecida pelo fabricante, conforme a Figura 5.2. Este motor é do tipo sem escova e possui baixo nível de ruído e vibração.

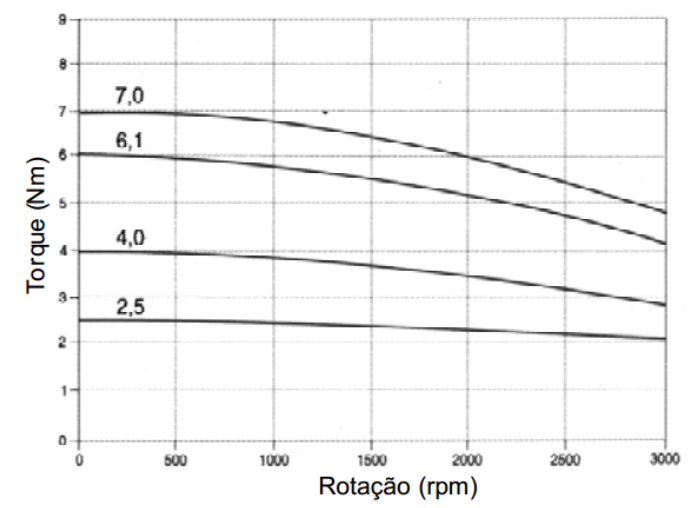

Figura 5.2: Curva característica do servomotor SWA 56-7,0-30.

Este modelo possui entradas e saídas analógicas e digitais, possibilitando a aquisição de parâmetros como tensão e corrente, e, também, o controle do motor como o de posicionamento, torque e rotação.

\subsubsection{Placa de aquisição}

O sinal da corrente medido na saída analógica do servoconversor foi aquisitado por placas de dois modelos: Advantech modelo USB-4711A e National Instruments USB 6009. Na Tabela 5.1 é apresentada uma comparação relevante das características de cada modelo. 
Tabela 5.1: Comparação das placas Advantech e National Instruments.

\begin{tabular}{ccc}
\hline & $\begin{array}{c}\text { Advantech } \\
\text { modelo USB- } \\
\text { 4711A }\end{array}$ & $\begin{array}{c}\text { National } \\
\text { Instruments USB } \\
\mathbf{6 0 0 9}\end{array}$ \\
\hline Resolução de entrada (bits) & 12 & 14 \\
Taxa máxima de amostragem (kS/s) & 150 & 48 \\
Entradas e saídas digitais & 16 & 12 \\
Resolução do contador (bits) & 32 & 32 \\
\hline
\end{tabular}

Cada modelo utilizou um programa de aquisição distinto. A placa da Advatech utilizou o próprio programa do reômetro (SCI-R), enquanto que a da National Instruments utilizou o LabVIEW. O intuito desta comparação foi verificar se o sinal aquisitado pelo software SCl-R era compatível com o real, uma vez que existe uma suavização do sinal aquisitado pelo software SCI-R.

\subsubsection{Freio a disco}

Para estudar o torque do reômetro, desenvolveu-se um dinamômetro de fricção. aparato consiste basicamente em uma célula para medir o torque, uma pinça de freio e um disco, que impede o movimento quando acionado. Na Figura 5.3 é apresentado o esquema de como será o aparato para medir o torque do reômetro.
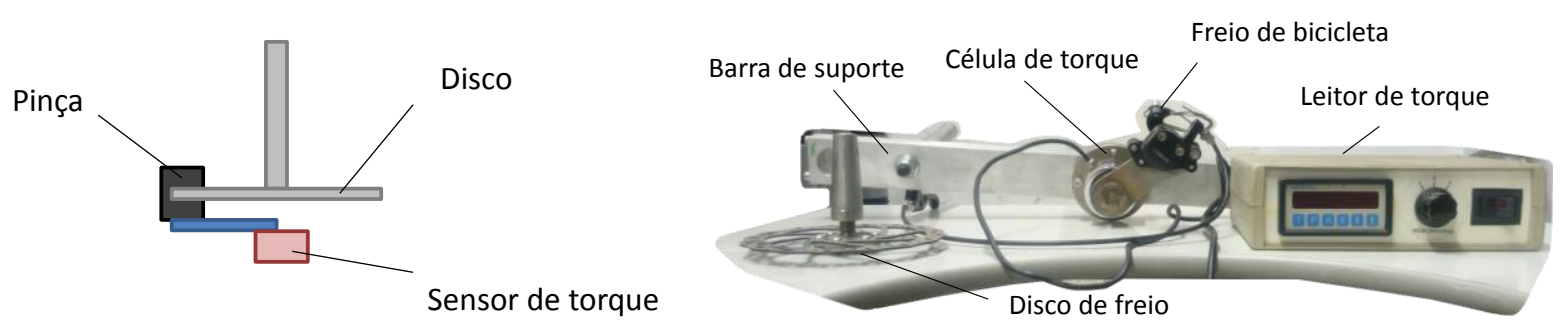

Figura 5.3: Esquema do freio dinâmico e conjunto construído.

\subsubsection{Software}

Para o desenvolvimento desta pesquisa utilizou-se o software Matlab 2012b, para o desenvolvimento do programa de tratamento e análise de dados. Além disso, utilizouse o software LabView e o SCI-R para a aquisição do sinal elétrico do servoconversor. Tanto o Matlab quanto o LabView, possuem licença de uso concedida à USP. Já para o tratamento de imagem utilizou-se o software GIMP e o ImageJ, ambos softwares livres. 


\subsubsection{Esfera de vidro}

Os materiais granulares utilizados foram esferas de vidro de diferentes diâmetros característicos em tamanhos discretos.

- $1,00 \mathrm{~mm}$ a $1,7 \mathrm{~mm}$, denominada fração $[1,18-1,7]$;

- $1,7 \mathrm{~mm}$ a 2,8 mm, denominada fração [1,7-2,8];

- $4,00 \mathrm{~mm}$ a $4,75 \mathrm{~mm}$, denominada fração [4,0-4,75].

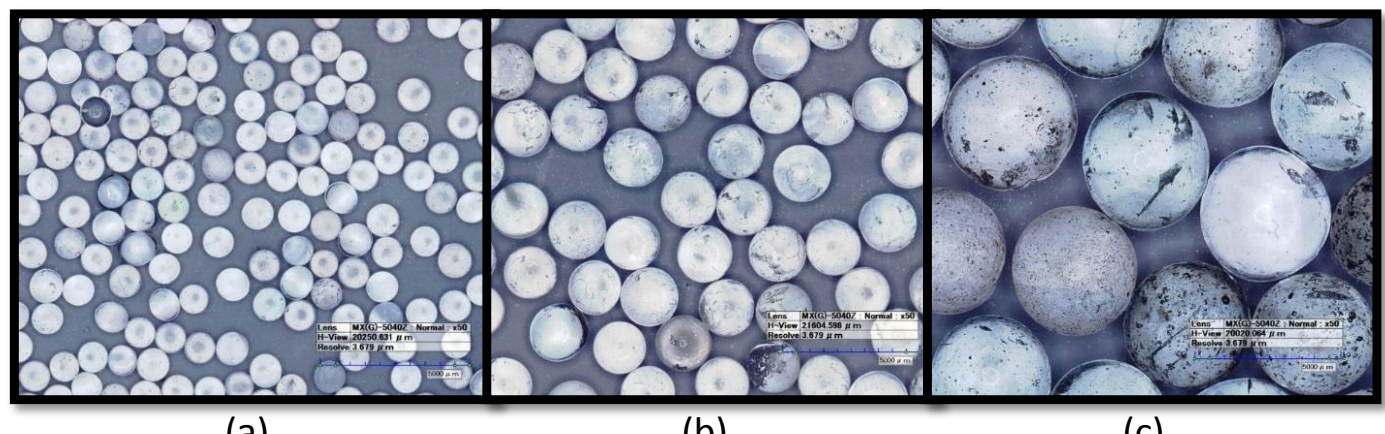

(a)

(b)

(c)

Figura 5.4: Imagens obtidas em microscópio digital modelo 3D Hirox KH-7700 (HIROX Co. Ltd., Japão): (a) fração [1,18-1,7]; (b) fração [1,7-2,8]; (c) fração [4,0-4,75].

\subsubsection{Argamassa de cal}

Formulou-se uma argamassa utilizando Cal hidratada CHIII Itaú da Votorantim e uma areia natural. Como a areia estava úmida por estar estocada ao relento, antes da utilização foi acondicionada em bandejas e seca em estufa por 24 horas à $105^{\circ} \mathrm{C}$. O traço da argamassa foi de 1:3:1,5 em massa.

\subsubsection{Silicone}

Os silicones utilizados foram da marca Dow Corning. São polímeros de média densidade fabricados para ter escoamento essencialmente linear com viscosidades cinemáticas médias variando de 50 a 10000 cSt.

Para este trabalho foram utilizados os silicones com viscoisade de 100, 1000 e 10000 cSt, suas principais características são apresentadas na Tabela 5.2.

Tabela 5.2: Dados dos silicones de acordo com fabricante.

\begin{tabular}{cccc}
\cline { 2 - 4 } & $\mathbf{1 0 0} \mathbf{~ c S t}$ & $\mathbf{1 0 0 0} \mathbf{~ c S t}$ & $\mathbf{1 0 0 0 0} \mathbf{~ C S t}$ \\
\hline $\begin{array}{c}\text { Densidade a } \mathbf{2 5}{ }^{\circ} \mathbf{C} \\
\left(\mathbf{g} / \mathbf{c m}^{\mathbf{3}}\right)\end{array}$ & 0,964 & 0,970 & 0,971 \\
\hline $\begin{array}{c}\text { Tensão superficial } \\
\text { (dynes/cm) }\end{array}$ & 20,9 & 21,1 & 21,2 \\
\hline
\end{tabular}




\subsection{Métodos}

A seguir serão apresentados os métodos utilizados para o desenvolvimento da pesquisa.

\subsubsection{Aquisição do sinal elétrico}

A aquisição da corrente foi realizada utilizando a saída analógica do servoconversor. $\mathrm{Na}$ saída analógica existem diversos parâmetros que podem ser aquisitados, como por exemplo, tensão de cada fase, corrente, velocidade e posicionamento.

\subsubsection{Caracterização física}

A caracterização física é importante para avaliar a distância de separação entre as partículas, determinar a porosidade de empacotamento do solo e auxiliar na correta interpretação dos resultados dos ensaios reológicos, sendo realizado os seguintes ensaios: distribuição granulométrica, densidade real e área superficial específica.

A determinação da distribuição granulométrica foi realizada por meio da difração de raios laser (Helos/Sucell - Sympatec $\mathrm{GmbH}$ - detecção de 0,1 a $350 \mu \mathrm{m}$ ). Já para a caracterização dos materiais particulados grossos foi utilizado o equipamento de Análise Dinâmica de Imagens (QICPIC - Sympatec GmbH), acoplado com a unidade dispersora por gravidade GRADIS e a unidade alimentadora VIBRI/L. A câmera utilizada tem uma lente com resolução de 100 pixels/mm e captação de imagens a uma taxa de $25 \mathrm{~Hz}$.

A densidade real foi determinada por picnometria de gás hélio utilizando equipamento MultiPycnometer (Quantachrome Instruments). E a área superficial específica através do equipamento Belsorp-max da marca McrotacBEL que utiliza o modelo de BET (BRUNAUER; EMMETT; TELLER, 1938). A área superficial específica é determinada a partir da adsorção física de camadas de moléculas de gás sobre a superfície do sólido.

Para a determinação da densidade de empacotamento dos sistemas particulados apresentados neste trabalho utilizou-se o equipamento GeoPyc 1360, da Micromeritics, na opção de "T.A.P. Density", cujo resultado equivale à massa unitária 
compactada do sistema particulado ensaiado. O equipamento dispõe de algumas opções de configurações que alteram o ensaio, sendo estas:

- Tamanho da célula, sempre cilíndrica com algumas opções de diâmetro. Foram utilizadas células de 50,8 mm e 25,4 mm de diâmetro;

- Pressão de compactação aplicada pelo pistão a cada ciclo, padronizado em $20 \mathrm{kPa}$;

- Número de ciclos de compactação realizados em cada ensaio, no caso, 7;

- Número de ciclos de preparação, realizados antes dos ciclos de ensaio, cujos dados são descartados, no caso, 6 ciclos.

Durante o procedimento experimental do equipamento, a célula em que a amostra está contida é rotacionada e agitada em pequenos passos, enquanto o pistão se desloca aos poucos, diminuindo o volume útil da célula, até o ponto em que a amostra é compactada com a força pré-determinada. O ensaio completo consiste em uma série de repetições deste ciclo de compactação, entre as quais há um pequeno alívio do sistema, permitindo novo arranjo das partículas. O resultado principal obtido com o ensaio é a média das repetições do volume aparente compactado do sistema, calculado com precisão a partir da distância percorrida pelo pistão, que é comparada com o resultado de um ensaio de referência feito com a célula vazia, realizado previamente.

Com a razão entre a massa da amostra e o volume obtido chega-se à massa unitária compacta do sistema. A partir deste resultado é possível determinar a densidade relativa de empacotamento do sistema particulado, ao dividi-lo pela densidade real dos grãos. A repetibilidade do resultado é satisfatória, dada a automatização do processo, desde que sejam controlados os efeitos das variáveis de ensaio citadas acima.

\subsubsection{Caracterização reológica}

Para caracterização reológica das suspensões foi utilizado o reômetro servo controlado do tipo planetário, construído na Escola Politécnica da Universidade de São Paulo. Utilizaram-se alguns programas com diferentes rotações e cada programação de ensaio utilizada será apresentada no capítulo de análise dos resultados. 


\section{ANÁLISE DOS RESULTADOS}

A seguir serão apresentados os resultados desenvolvidos neste trabalho, divididos em estudo de sinal, validações, software de tratamento, ensaios de mistura e ciclo. Esta ordem é consequência da necessidade de conhecer a fundo o equipamento. Por isso, buscou-se compreender primeiramente o sinal obtido pelo servoconversor e, assim, fazer as validações do equipamento.

Com o equipamento validado, procurou-se desenvolver um software para análise dos resultados obtidos para que na sequência, fossem realizados ensaios de mistura e ciclo.

\subsection{Estudo do sinal}

Por se tratar de um equipamento cujo resultado depende do sinal aquisitado, é interessante iniciar a estratégia de redução de ruídos por aqueles oriundos dos circuitos eletrônicos. Para isso, vê-se necessário, primeiramente, compreender os parâmetros existentes no servoconversor. A redução do ruído, também, pode ser feita a partir da utilização de filtros e isolamento dos cabos de aquisição.

É apresentado, a seguir, o passo a passo das etapas e resultados estudados para compreender o sinal elétrico e reduzir o ruído. Vale destacar que para todos os resultados apresentados até o item 6.1.4 foi utilizado a placa de aquisição da National Instruments e o software LabVIEW, porque a placa de aquisição e o software de controle e aquisição do reôemetro (SCI-R) não permite o ajuste de taxa de amostragem. Além disso, o software SCI-R já realiza pré-tratamento, não permitindo análise dos dados brutos.

\subsubsection{Parâmetro de aquisição}

$\mathrm{Na}$ saída analógica do servoconversor existem diversas variáveis que podem ser aquisitadas, por exemplo, tensão proporcional à corrente, velocidade e posicionamento do motor. Para o reômetro, o interessante é analisar a tensão, uma vez que ela é proporcional ao torque (CENG, 2000).

Os servoconversores e inversores de frequência contêm circuitos que podem gerar interferência eletromagnética (EMI), por isso é necessário utilizar um cabo blindado 
para reduzir o ruído oriundo deste tipo de interferência. Por isso, utilizou-se cabo blindado para garantir a integridade dos dados aquisitados, minimizando os efeitos do ruído.

De acordo com o manual do usuário do servoconversor, para a saída analógica, existem dois parâmetros de tensão de interesse: referência de corrente (REF) e a corrente proporcional ao torque (lq). Anteriormente, a aquisição era realizada pela tensão de referência. Neste trabalho, avaliaram-se as duas variáveis com o intuito de escolher aquela que apresenta resultados mais satisfatórios.

O ensaio foi realizado com o motor rodando em vazio, ou seja, sem estar acoplado ao redutor planetário. Foram realizados ensaios variando a rotação entre 25 e 3000 rpm para verificar o efeito da rotação nos diferentes tipos da tensão aquisitada, conforme a Figura 6.1.

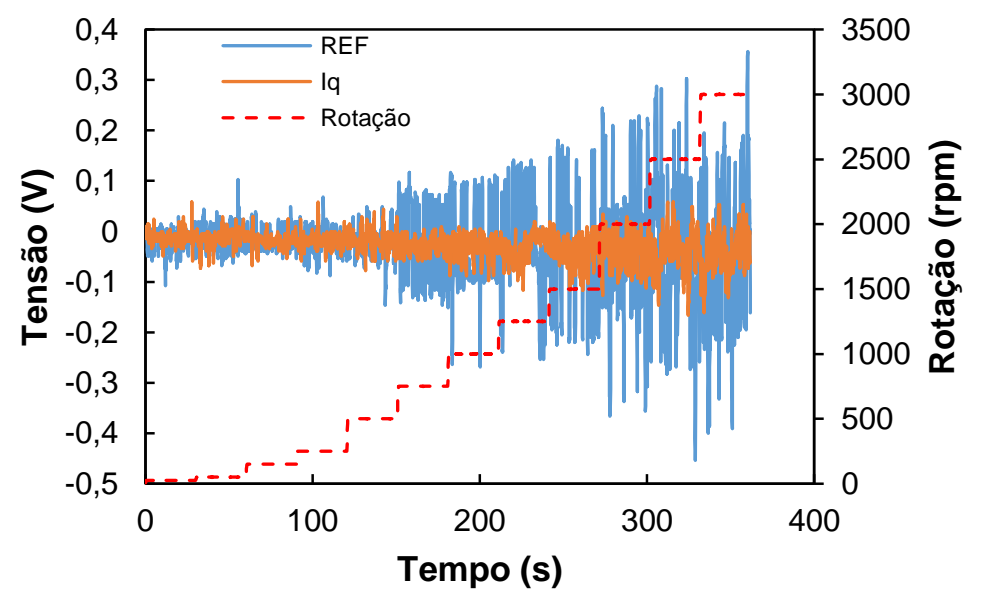

Figura 6.1: Resultado comparando a aquisição de REF e lq.

Observa-se que existe uma grande diferença na oscilação entre tensões aquisitadas. A linha em azul (REF) refere-se ao parâmetro utilizado anteriormente (tensão de referência) e a linha laranja (lq), à corrente proporcional ao torque. Em motores elétricos à medida que se aumenta a rotação, aumenta-se também a tensão, e, consequentemente a corrente, conforme a Figura 6.2. 


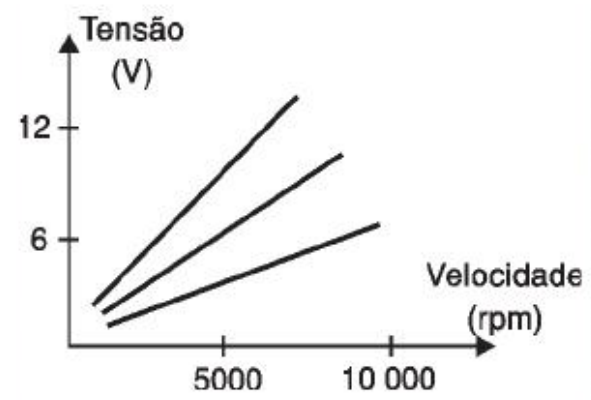

Figura 6.2: Curva típica de motor elétrico.

A referência de corrente (REF) aquisita a corrente do equipamento como um todo, por isso apresenta grandes oscilações à medida que se aumenta a velocidade do motor. Já a corrente proporcional ao torque (lq) é uma tensão exclusiva do motor, por isso apresenta menor oscilação se comparado à referência. No entanto, em ambos os casos, as oscilações aumentam à medida que há o aumento da tensão, e, consequentemente, da corrente do equipamento uma vez que esse necessita para aumentar a velocidade do motor, conforme a Figura 6.2, apresentada anteriormente.

Ao se comparar, a média de cada patamar de rotação, obtém-se o seguinte resultado apresentado na Figura 6.3

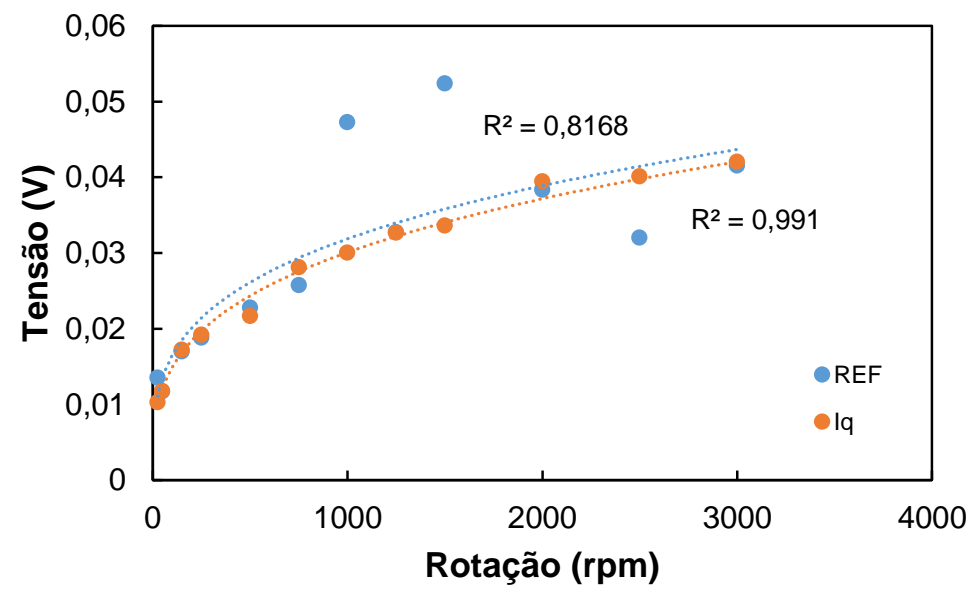

Figura 6.3: Curva tensão $x$ velocidade de rotação do motor.

Observa-se que de fato ao aumentar a velocidade do motor, aumenta-se a tensão. Ambos os parâmetros de aquisição apresentam a mesma tendência, mas o sinal de aquisição REF apresenta maiores oscilações, porque o sinal REF é o sinal aquisitado do equipamento como um todo, já a lq é um sinal exclusivo do motor, sendo um sinal menos ruidoso, conforme apontado anteriormente. 
Com os resultados analisados, definiu-se qual parâmetro será utilizado: corrente proporcional ao torque (lq). Existem outros parâmetros como offset e ganho (Figura 6.4), ambos os casos, os valores não foram alterados porque o ganho apenas é um fator de multiplicação no sinal aquisitado e o offset é um valor somado ao sinal, sendo o valor resultante aquisitado na saída analógica do servoconversor.

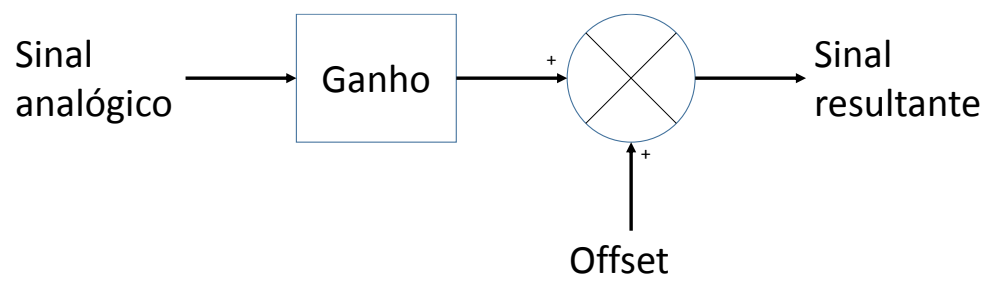

Figura 6.4: Representação do parâmetro ganho e offset do sinal analógico.

Uma vez definida o parâmetro de aquisição (lq), buscou-se avaliar o efeito do motor e redutor no desempenho da tensão, conforme a Figura 6.5. Foi utilizado a mesma programação de ensaio com variação de rotação de 25 a 3000 rpm.
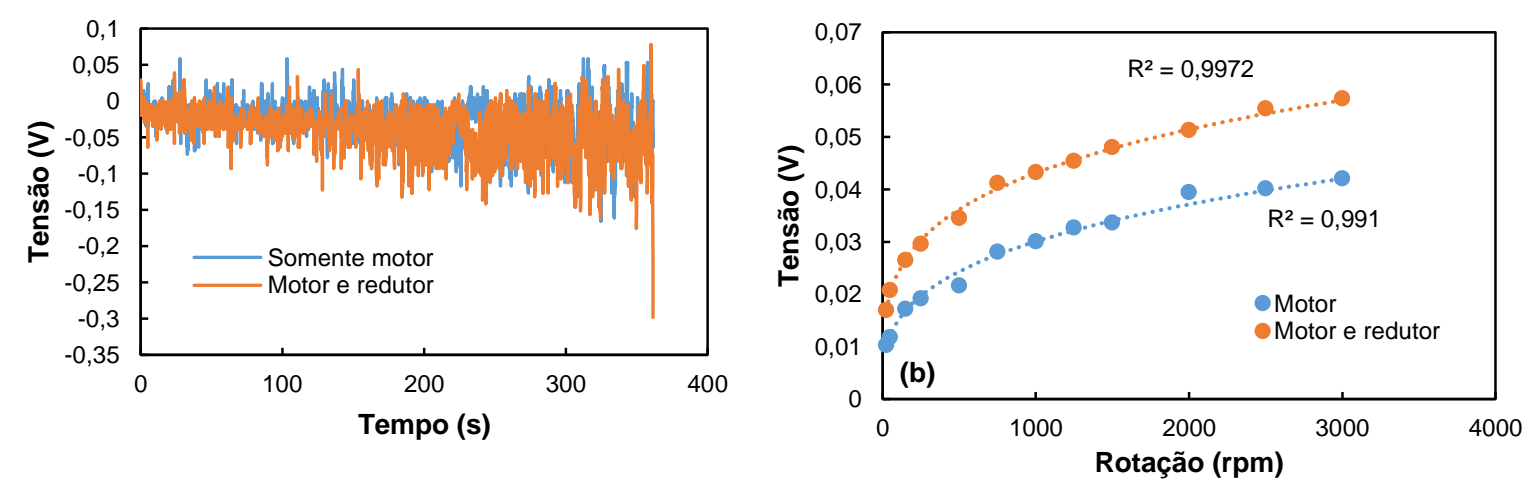

Figura 6.5: (a) Comparação entre as tensões do motor sem e com o redutor e (b) Comparação das médias do motor sem e com o redutor.

Visualmente observa-se que ao acoplar o redutor ao motor os níveis de torque não aumentam significativamente (Figura 6.5-a). No entanto, o sinal apresenta um ganho, ao comparar a média do sinal em cada patamar de rotação (Figura 6.5-b). Tal resultado era de se esperar, uma vez que ao acoplar o motor ao redutor, as engrenagens apresentam um atrito e um esforço necessário do motor para iniciar o movimento. Por isso, existe uma diferença entre a tensão somente do motor e do motor com o redutor. 


\subsubsection{Taxa de amostragem}

Sabe-se que a taxa de amostragem é um fator importante, não apenas para a questão de aquisição de dados, mas também em relação ao tamanho final do arquivo. Quanto maior a taxa de amostragem, maior será o arquivo gerado após o ensaio. Por isso, vê-se necessário definir uma taxa de amostragem que atenda tanto a representação do sinal aquisitado quanto do tamanho final do arquivo.

Para analisar as diferentes taxas de amostragem, decidiu-se realizar alguns testes com diferentes taxas de amostragem. Para o estudo, utilizou-se uma frequência de amostragem de 1, 10, 25, 50 e 100 amostras por segundo e uma rotação do motor de 5 rpm, apresentado na Figura 6.6.
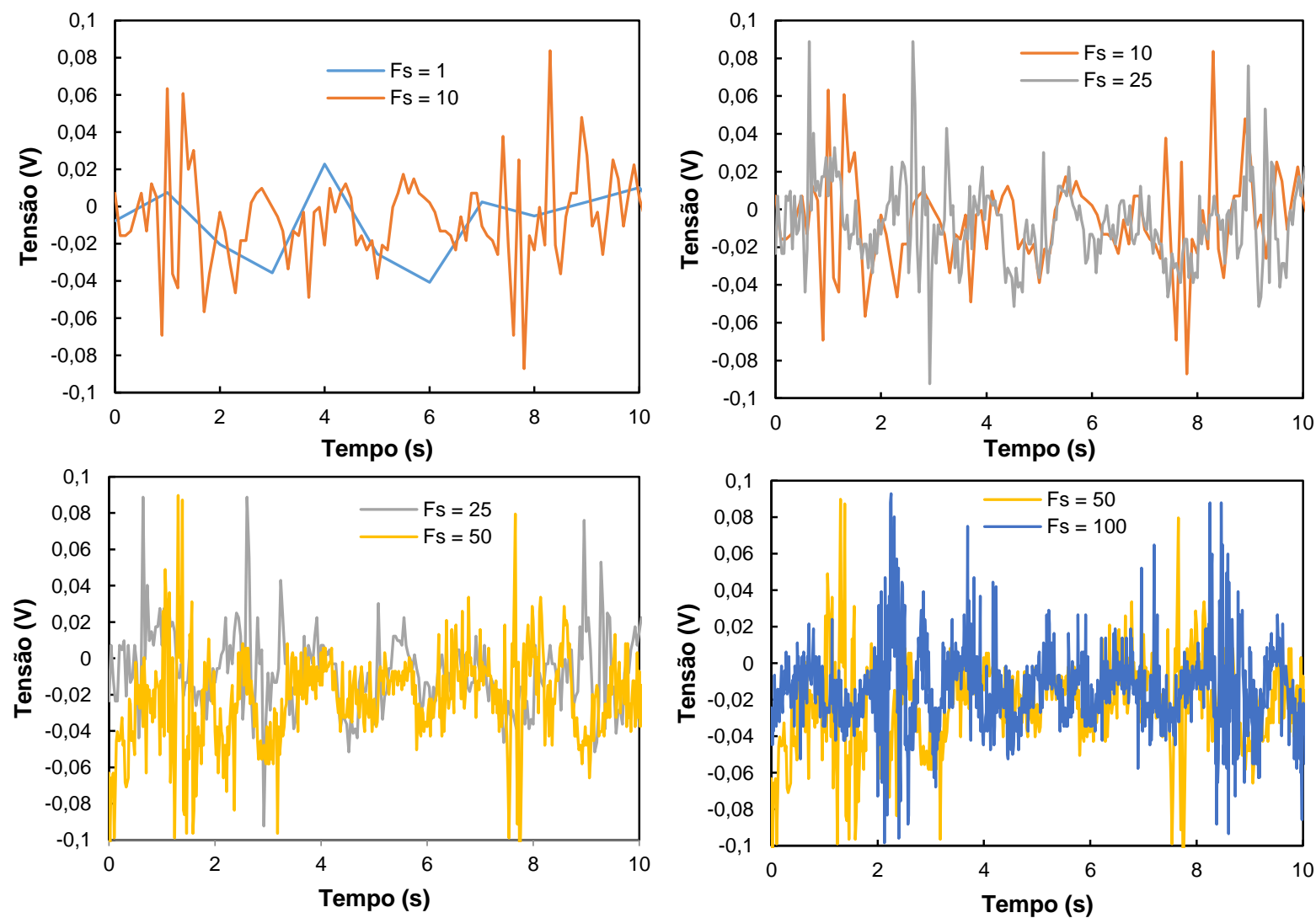

Figura 6.6: Comparação entre a taxa de amostragem de (a) 1 e 10 amostras/segundo (b) 10 e 25 amostras/segundo (c) 25 e 50 amostras/segundo e (d) 50 e 100 amostras/segundo.

Pela Figura 6.6-a, observa-se que os resultados são distintos para as diferentes taxas de amostragem. Isto indica que a taxa de uma amostra por segundo não está adequada para a aquisição e análise dos dados. Por isso, comparou-se uma taxa de amostragem de 10 e 25 amostras por segundo (Figura 6.6-b). 
Ao aumentar a taxa de 10 para 25 amostras por segundo observa-se que ainda assim as curvas aquisitadas não são semelhantes, sendo necessária uma taxa de amostragem superior a 25 amostras por segundo. Por isso foi realizado outro teste com taxa de amostra de 50 e 100 amostras por segundo, conforme a (Figura 6.6-c-d).

Assim, verifica-se que taxas acima de 25 amostras por segundo apresentam pequena diferença entre as curvas aquisitadas, fazendo-se adequada uma taxa de amostragem superior a 25 amostras por segundo.

\subsubsection{Transformada de Fourier}

O sinal elétrico pode ser convertido do domínio do tempo para o da frequência através de uma função matemática conhecida como transformada de Fourier. Esta transformada decompõe o sinal em componentes senoidais e converte o resultado para o domínio da frequência.

Para este ensaio, foi utilizado uma rotação constante de $50 \mathrm{rpm}$ desacoplado ao redutor planetário, com uma taxa de amostragem de 1000 amostras por segundo. Além disso, a placa de aquisição utilizada foi da National Instruments, utilizando o software LabVIEW. O resultado é apresentado na Figura 6.7.

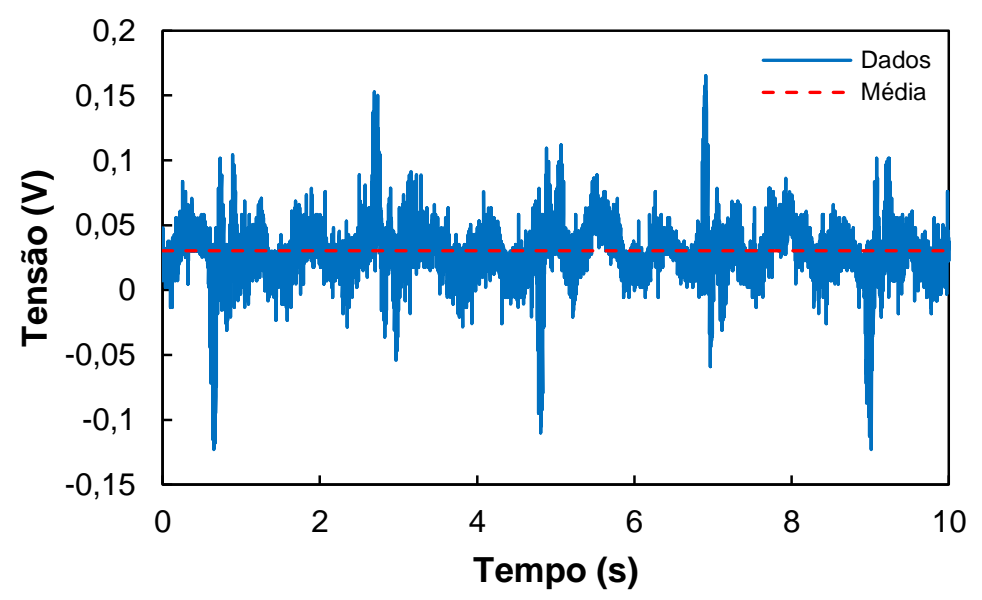

Figura 6.7: Resultado do sinal aquisitado para uma rotação de $50 \mathrm{rpm}$.

Pelo resultado verifica-se que o sinal é periódico, mas ruidoso. Por isso é necessário utilizar a transformada de Fourier e passar para o domínio da frequência. Ao mudar de domínio é possível verificar em que frequência está presente o ruído, conforme a Figura 6.8 . 


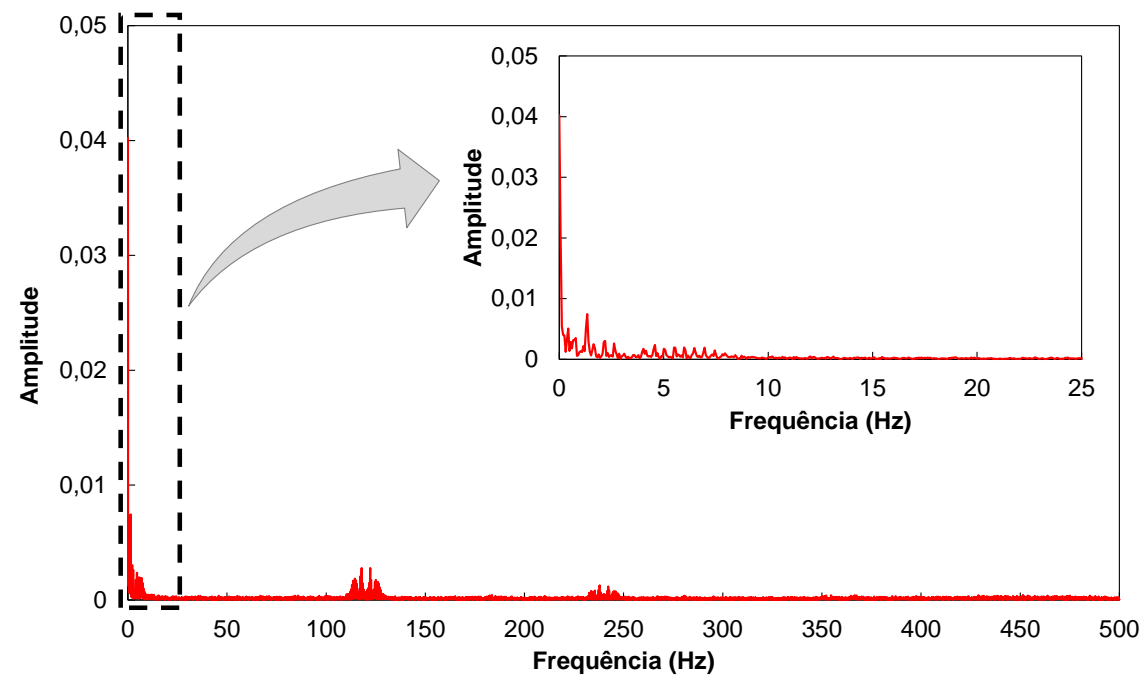

Figura 6.8: Alteração do domínio do tempo para frequência, utilizando a transformada de Fourier e um detalhe do sinal entre a frequência 0 e $25 \mathrm{~Hz}$.

Analisando as frequências mais baixas entre 0 e $25 \mathrm{~Hz}$ (Figura 6.8), é possível verificar que o sinal de interesse é até $10 \mathrm{~Hz}$. As frequências a cima deste valor são consideradas ruído elétrico. Neste caso, o filtro ideal para atenuar o ruído é do tipo passa-baixa, permitindo a passagem das frequências abaixo da frequência de corte e atenuando a amplitude das frequências superiores à frequência de corte. Portanto, é necessário um filtro passa-baixa com frequência de corte de $10 \mathrm{~Hz}$. Pela transformada de Fourier, verifica-se que existe ruído próximo da frequência de $100 \mathrm{~Hz}$ e também em torno de $250 \mathrm{~Hz}$. Sendo necessário um filtro para cortar estas frequências.

Como apontado anteriormente, a taxa de Nyquist é a frequência mínima necessária para que se possa reproduzir o sinal aquisitado. No caso a frequência mínima é de 20 $\mathrm{Hz}$, fato que já foi observado no estudo da taxa de amostragem. Lembrando que este valor é um valor teórico, sendo necessário em alguns casos uma taxa superior à taxa proposta por Nyquist.

\subsubsection{Comparação entre as placas de aquisição}

Como o programa SCI-R já aplica uma espécie de tratamento nos dados, decidiu-se comparar os dados brutos com os dados obtidos pelo programa. Para obter os dados brutos, utilizou-se uma placa da National Instruments juntamente com o software LabVIEW.

Para a comparação dos dados utilizou-se uma rotação de 5, 250, 1000 e 2250 rpm. Para a placa da National Instruments utilizou-se uma taxa de aquisição de 1000 
amostras por segundo e na Advantech, uma taxa de 10 amostras por segundo. Foi utilizada uma taxa inferior para a placa da Advantech devido a uma limitação do programa SCI-R. Os resultados dos ensaios são apresentados na Figura 6.9.
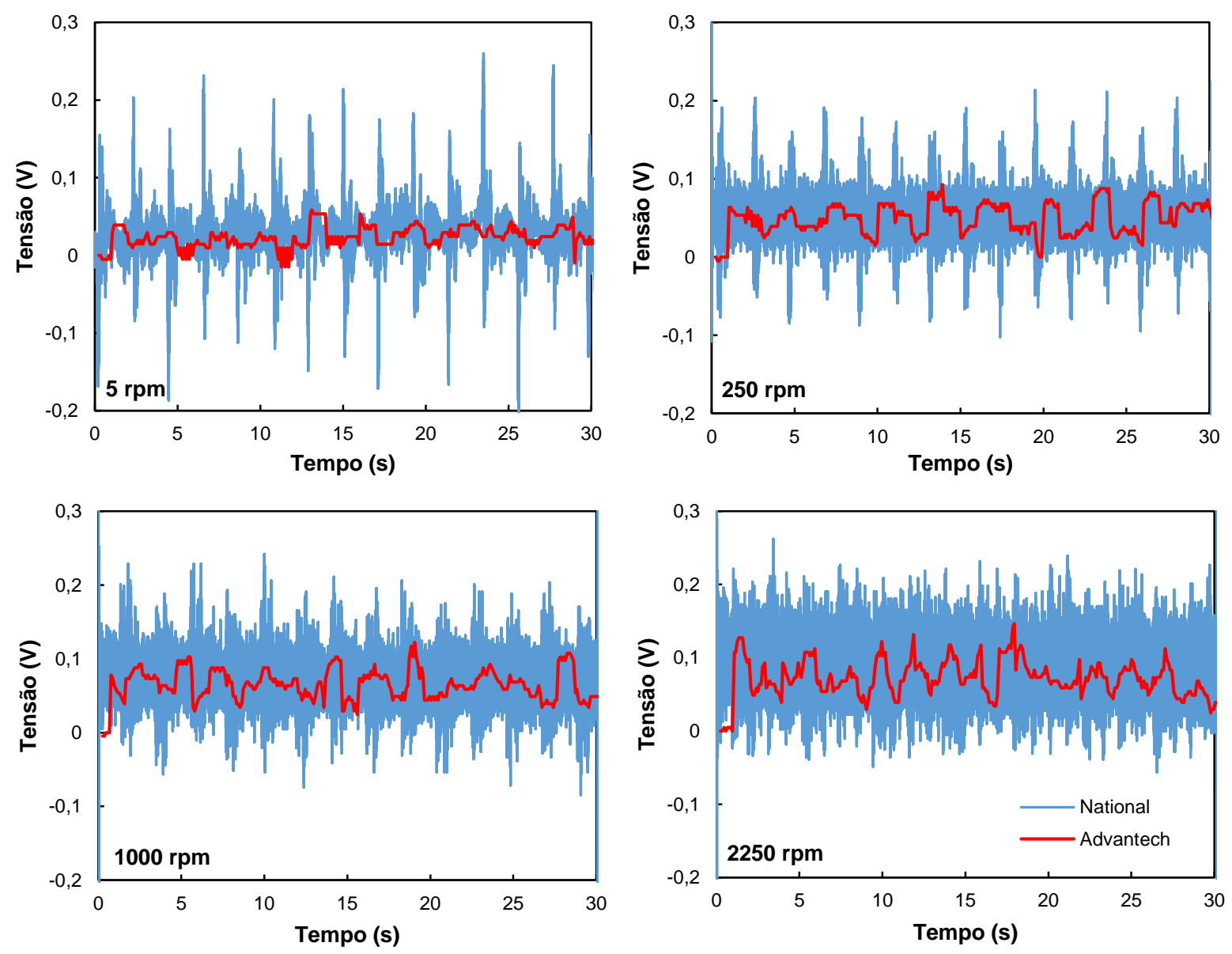

Figura 6.9: Comparação entre o sinal aquisitado entre as placas National e Advantech para diferentes velocidades de rotação.

Primeiramente, é possível observar que o ruído do sinal aumenta à medida que se aumenta a rotação do motor. Isto ocorre porque, em altas rotações, é demandado uma tensão maior, aumentando assim, a intensidade do sinal e, consequentemente, - ruído. Observa-se que na média, as duas placas apresentam resultados semelhantes. Vale destacar que para os instantes iniciais os valores de tensão na placa da Advantech são iguais à zero, devido ao pré-tratamento dos dados executado pelo programa. Além disso, observa-se que para iniciar a rotação, existe um pico na corrente do motor, no entanto a placa da Advantech não percebe tal pico.

Na Figura 6.10 são apresentados com detalhe os resultados entre 10 e 15 segundos. 

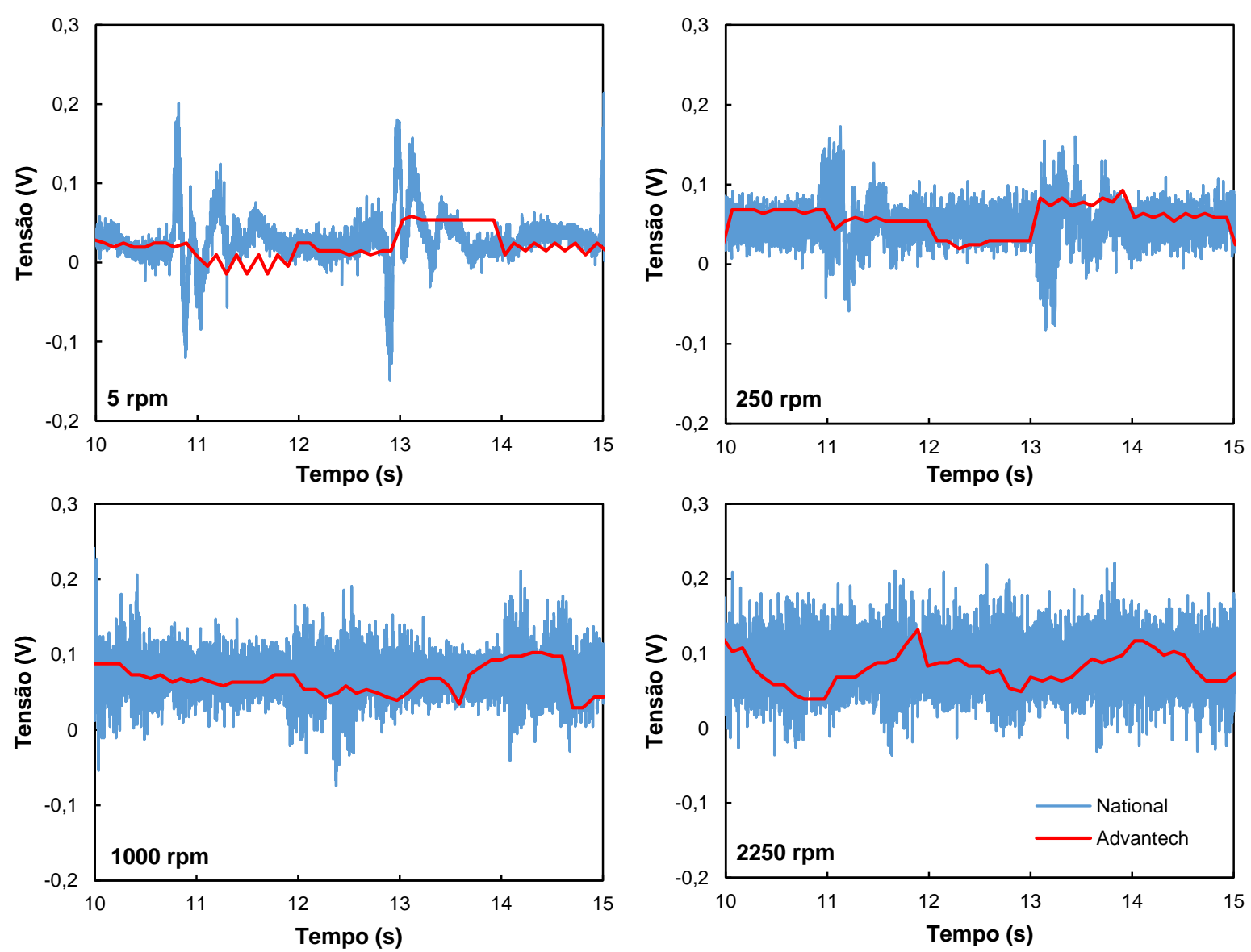

Figura 6.10: Detalhe com o tempo entre 10 e 15 segundos.

Os resultados são diferentes entre as duas placas. Existe uma defasagem da resposta, como se pode observar na rotação de 5 rpm. O pico da primeira onda, em torno de 11 segundos, só é percebido pela placa da Advantech 2 segundos após e o mesmo fenômeno é observado para a rotação de 250 rpm. Já para as rotações maiores, não se observa tal fenômeno com clareza.

\subsection{Calibração e validações}

Definido os valores e os parâmetros de aquisição, é necessário realizar a calibração e alguns testes de validação do equipamento.

Para a calibração, foi realizado um teste com um torquímetro e um freio para o torque dinâmico, e, assim, obter uma curva característica do equipamento, correlacionando a tensão com o torque efetivo.

Além disso, foram realizados ensaios para validar a repetibilidade da linha base do equipamento, avaliar a sensibilidade do equipamento realizando ensaios com água e 
silicones de diferentes viscosidades e, também, testes com uma argamassa simples (areia e cal) para definir o volume de material necessário.

\subsubsection{Constante de torque do reômetro}

Para definir a constante de torque do reômetro, utilizou-se um torquímetro da marca KStool e desenvolveu-se um dinamômetro de fricção, utilizando um freio de bicicleta como elemento de fricção. A medição do torque foi realizada com um sensor de torque desenvolvida pela empresa Newval. Em ambos os casos o princípio de funcionamento é semelhante.

A medida foi realizada utilizando um sensor de torque e o princípio de como foi calculado é apresentado pelo diagrama de corpo livre, conforme a Figura 6.11.

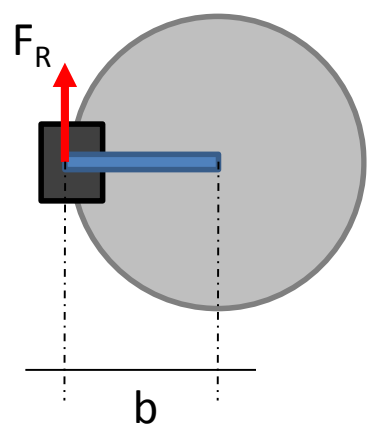

Figura 6.11: Diagrama de corpo livre.

Para os testes com o torquímetro, impõe-se velocidade de 0 rpm para o motor e utilizou-se o torquímetro com diferentes valores de torque para obter a curva característica. Foi realizado o teste tanto no eixo central quanto no planetário. Além disso, as medições foram realizadas tanto no sentido horário quanto anti-horário. Os resultados são apresentados na Figura 6.12. 


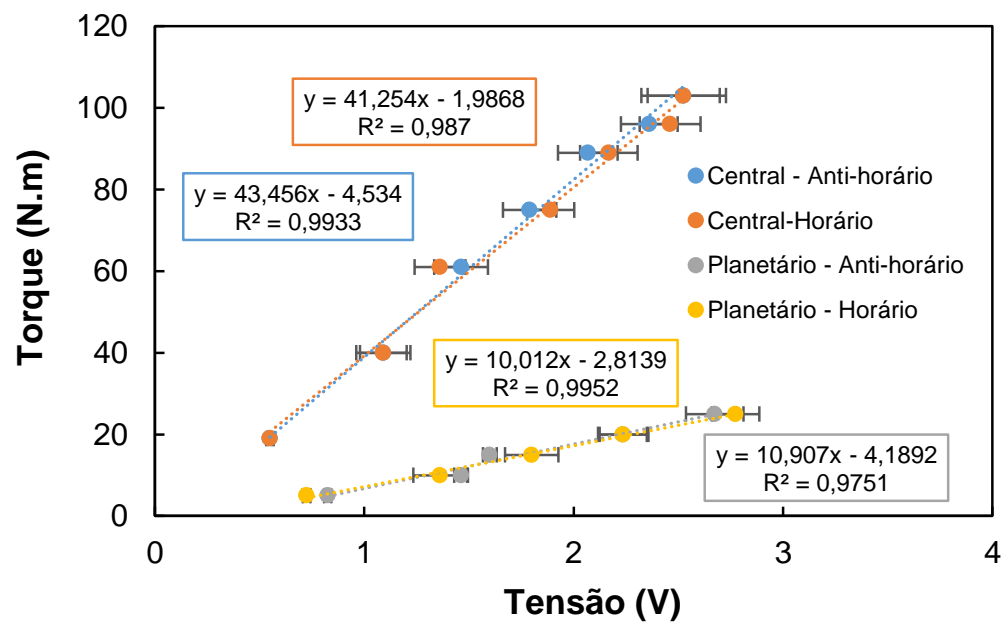

Figura 6.12: Curva de correlação entre o torque e a tensão diferenciando sentido de giro e posição do eixo.

Pelo resultado verifica-se que em ambos os casos, eixo central e planetário, a curva de correlação independe do sentido de giro. Verifica-se então que a constante de torque para ensaio realizado no eixo central é de aproximadamente 42 e quando realizado no eixo planetário é de 10.

Foi realizado um teste, também, utilizando o dinamômetro de fricção, para realizar os testes em outras rotações. No entanto, para este ensaio, foi possível apenas realizar as medições no eixo central.

Para o dinamômetro de friç̧ão, realizou-se testes com 5 rotações: 25, 250, 750 e 1250 rpm. Avaliou-se tanto no sentido horário quanto anti-horário. Os resultados são apresentados na Figura 6.13.

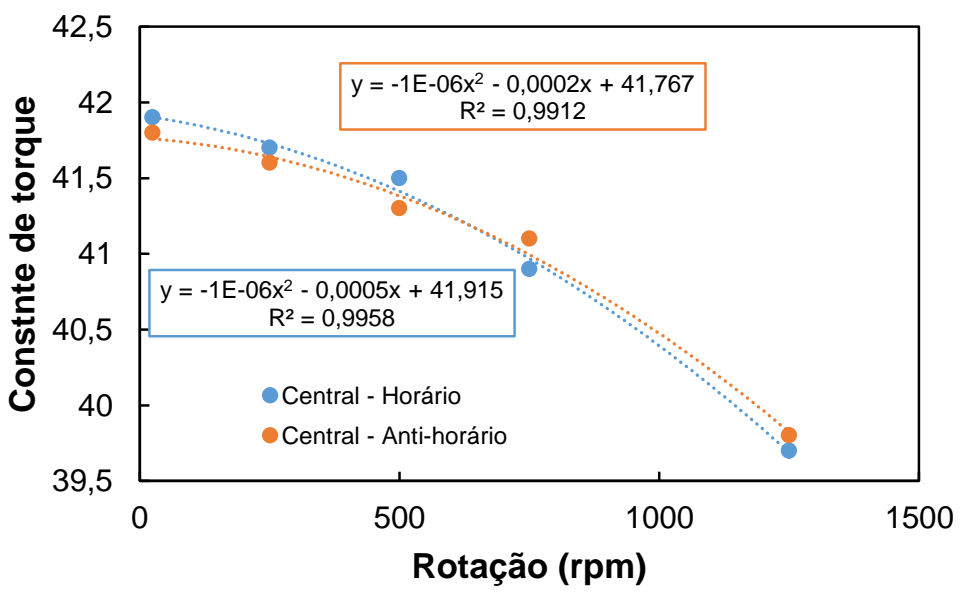

Figura 6.13: Correlação da constante de torque em diferentes rotações. 
Observa-se que a constante de torque tem um decaimento à medida que se aumenta rotação do motor. Isto ocorre porque a medida que o motor aumenta a rotação o seu rendimento decai e, consequentemente, o torque diminui (ELLIS, 2004).

Se as constantes forem multiplicadas pela tensão máxima de aquisição $(3,5)$ e divididas pela redução, para obter o torque máximo no motor, obtém-se o resultado conforme a Figura 6.14.

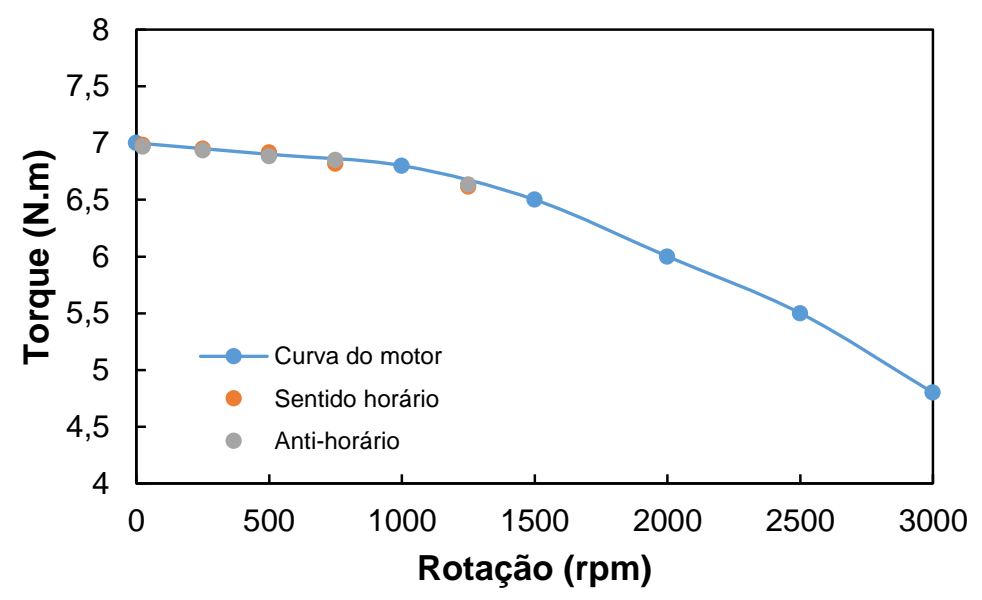

Figura 6.14: Comparação entre o torque medido com o torque real em função da rotação.

Observa-se que tanto as constantes medidas no torquímetro quanto pelo dinamômetro de fricção apresentam valores próximos. No entanto, verifica-se que existe um decaimento do valor da constante em função do tempo, que só foi possível observar utilizando o dinamômetro de fricção.

\subsubsection{Linha base e repetibilidade do ensaio}

Antes ou depois do ensaio, deve-se executar um procedimento padrão conhecido como linha base. Neste procedimento, visa obter os torques relacionados com os atritos internos e inércia do conjunto mecânico e a geometria de ensaio. Posteriormente ao ensaio, esta linha base é subtraída, de modo que se tenha nos resultados finais exclusivamente os torques necessários para gerar o cisalhamento no material.

Para esta etapa, repetiu-se diversas vezes alguns ensaios em que a rotação variava de 25 a 3000 rpm. Realizou-se 7 tipos de testes em ordem aleatória: 12 patamares de aceleração ou de desaceleração; ciclo contínuo em 12 patamares de aceleração e 12 
patamares de desaceleração; ciclo invertido em 12 patamares de desaceleração e 12 patamares de aceleração; 5 patamares de aceleração ou desaceleração rápida e rotações individuais nos mesmos 12 patamares do ciclo contínuo. Em todos os ensaios, cada patamar teve uma duração de 30 segundos. O resultado é apresentado na Figura 6.15

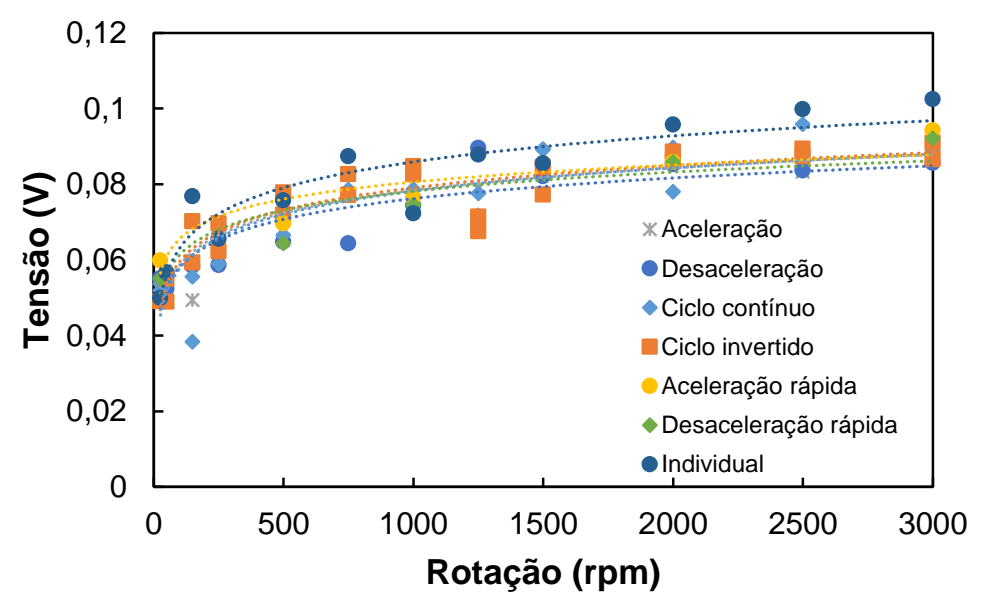

Figura 6.15: Média do sinal elétrico para cada patamar de ensaio.

Verifica-se, visualmente, que apenas o ensaio com patamares individuais apresentou valores de tensão majoritariamente acima dos demais. Ainda não se sabe o motivo de tal comportamento.

Observa-se que os dados se aproximam da função de potência e o coeficiente de determinação $\left(\mathrm{r}^{2}\right)$ é apresentado na Tabela 6.1 .

Tabela 6.1: Comparação entre os coeficientes de determinação dos ensaios de repetibilidade da linha base.

\begin{tabular}{lc}
\hline \multicolumn{1}{c}{ Ensaio } & $\mathbf{r}^{\mathbf{2}}$ \\
\hline Aceleração & 0,878 \\
Desaceleração & 0,804 \\
Ciclo contínuo & 0,773 \\
Ciclo invertido & 0,847 \\
Aceleração rápida & 0,846 \\
Desaceleração rápida & 0,840 \\
Individual & 0,856 \\
\hline
\end{tabular}

Observa-se que em todos os casos os resultados foram satisfatórios, uma vez que todos apresentaram um coeficiente de determinação superior a 0,75. 
A razão de se obter uma função da linha base é que, futuramente, no momento da calibração, o equipamento calcule essa função e após a realização do ensaio com amostra, já desconte automaticamente a linha base do resultado medido. Isto tornando o equipamento mais robusto e menos suscetível a erros do usuário.

\subsubsection{Teste de volume da amostra}

Os ensaios reológicos realizados em reômetros são afetados por diversos fatores, como por exemplo, temperatura, propriedades físico-químicas do material, condições de mistura entre outros.

A reometria de mistura compreende os fenômenos desde o contato do líquido com os materiais sólidos secos até homogeneização da mistura. A reometria rotacional pode ser utilizada para obter valores de torque durante o tempo de mistura. Diferentes autores utilizam direta ou indiretamente da técnica de reometria de mistura para caracterizar o comportamento de sistemas sólido líquido (CAZACLIU; ROQUET, 2009; PILEGGI, 2001). Dos reômetros apresentados, muitos permitem essa quantificação através da utilização do movimento planetário.

O processo de mistura consiste na combinação de dois materiais, podendo por exemplo, ser de um pó seco com um líquido, formando uma suspensão. No momento em que é adicionado o líquido em um sistema de partículas, há a formação de aglomerados devido as forças de van der Waals e à formação de uma camada de líquido em sua superfície, favorecendo a capilaridade. A medida em que se adiciona mais água, as partículas se afastam uma das outras e essas forças são atenuadas. A função do processo de mistura é auxiliar a quebra dos aglomerados (PILEGGI, 2001).

A quantidade de partículas recobertas pelo líquido vai aumentado à medida que o líquido é adicionado ao sistema, causando um aumento no esforço no processo de mistura. A resistência atinge um valor máximo, até que as forças de van der Waals e capilares deixam de ser influentes devido à distância entre as partículas e, consequentemente, há uma queda no esforço para realizar a mistura do material, conforme Figura 6.16. Maiores quantidades de líquido favorecem o afastamento das partículas, reduzindo o esforço necessário para mistura. 


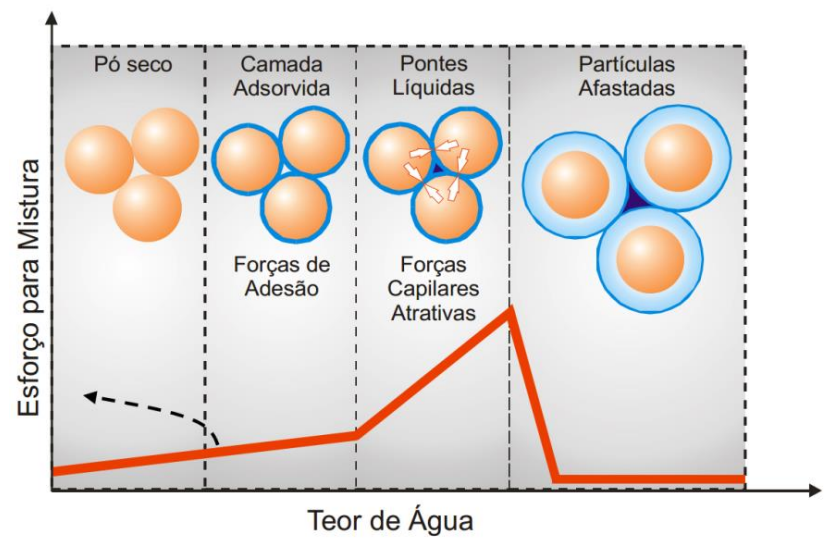

Figura 6.16: Representação esquemática das camadas adsorvidas de ligação e das pontes líquidas de ligação entre três partículas imersa em um meio líquido (PILEGGI, 2001).

Acompanhando valores de torque é possível obter uma estimativa da quantificação da energia dissipada durante o processo. Segundo Cazacliu e Roquet (2009), com melhor compreensão das energias de mistura é possível controlar adequadamente o processo.

França (2012) realizou um estudo sobre o processo de mistura utilizando um reômetro semelhante ao utilizado nesta pesquisa. Em seu trabalho, constatou-se que o tempo de mistura, taxa de adição de água e velocidade de mistura são ferramentas valiosas para a compreensão do comportamento de suspensões em reometria de mistura. No entanto, não foi avaliado a efeito do volume de material a ser analisado. Por isso, realizou-se ensaios com uma argamassa simples de cal e areia (1:3:1,5 em massa) para avaliar sua influência no resultado. As principais características das matériasprimas são apresentadas na Figura 6.17.

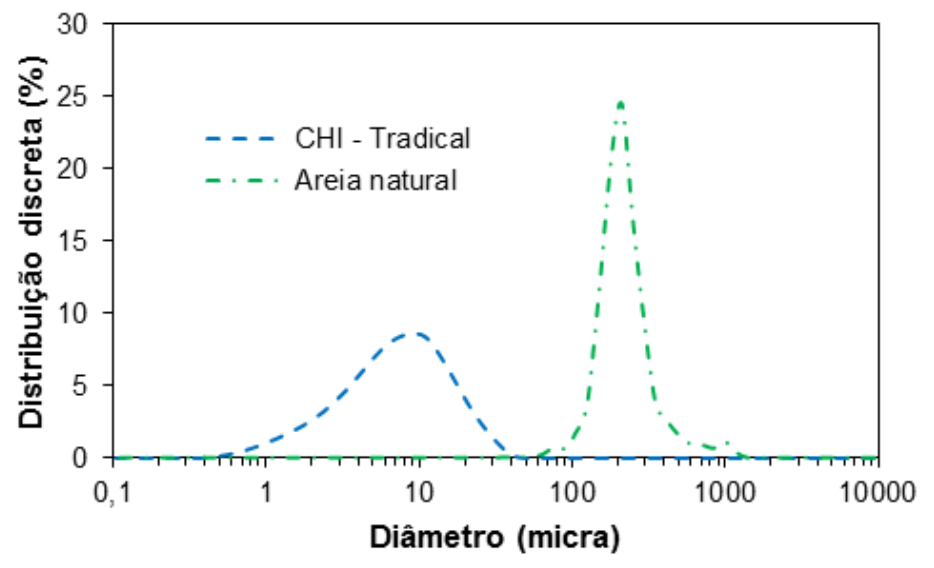

Figura 6.17: Distribuições granulométricas das matérias-primas empregadas na formulação da argamassa. 
Na Tabela 6.2 são apresentadas a densidade real e a área superficial especifica de cada material.

Tabela 6.2: Propriedades físicas das matérias-primas.

\begin{tabular}{l|cc}
\hline \multicolumn{1}{c|}{ Propriedade } & CHI & Areia Natural \\
\hline Densidade real $\left(\mathrm{m}^{2} / \mathrm{g}\right)$ & 2,62 & 2,60 \\
Área Superficial Específica $\left(\mathrm{g} / \mathrm{cm}^{3}\right)$ & 14,5 & 0,4 \\
\hline
\end{tabular}

Para o estudo em questão, realizou-se uma programação de ensaio com uma rotação constante de 90 rpm no eixo planetário com rotação no sentido anti-horário e a água foi adicionada com uma vazão constante de 45,7 g/s. Foram avaliados sistemas com 1,2; 2,5; 3,7 e 5,0 litros (correspondente a 15, 31,25, 46,25, 62,5 \% do volume total da cuba) de suspensão com concentração volumétrica de 0,6 . A água foi adicionada no instante 10 segundos. O resultado é apresentado na Figura 6.18.

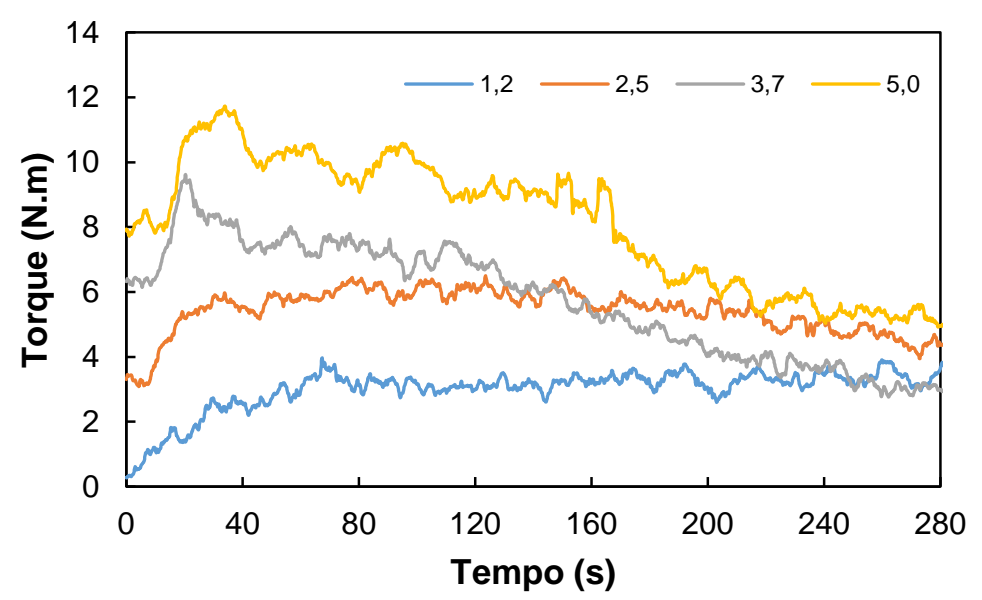

Figura 6.18: Resultado do ensaio de mistura para diferentes volumes de preenchimento da cuba.

Verifica-se que a partir do momento em que a água entra em contato com as partículas, há um aumento do torque, devido à aglomeração, e a medida que se adiciona água há uma redução do torque, porque as partículas já estão afastadas uma das outras. Pelo resultado fica claro que o volume de material afeta o resultado. Isso ocorre porque o esforço necessário para realizar a mistura aumenta à medida que aumenta a quantidade de material na cuba. Ao se normalizar o resultado, dividindo o torque pelo volume de material, obtém-se o seguinte resultado (Figura 6.19). 


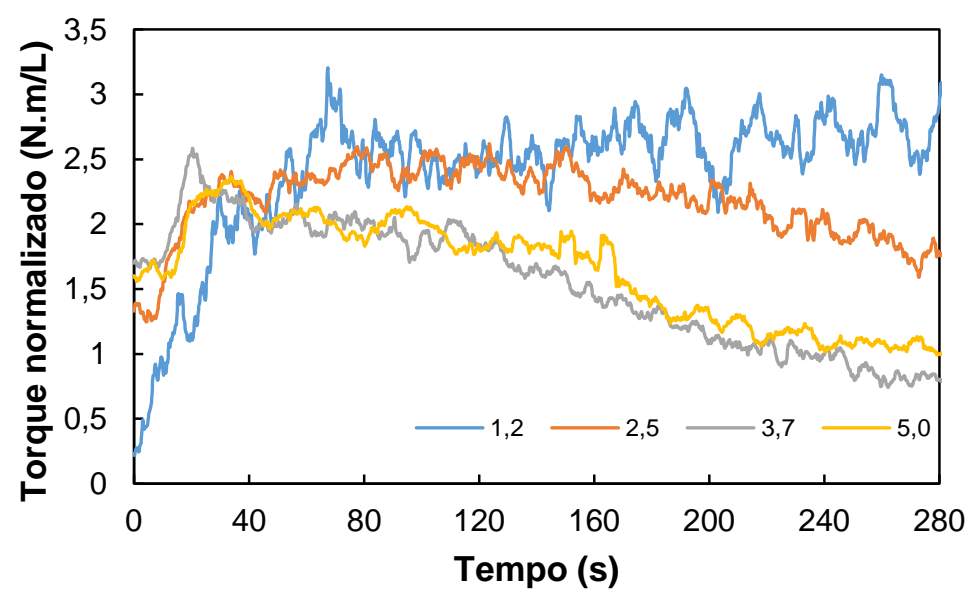

Figura 6.19: Torque normalizado para diferentes volumes de preenchimento da cuba.

Observa-se que a partir de 3,7 litros o acréscimo do volume não altera o valor do torque normalizado. Isso ocorre porque a partir deste volume, toda a geometria está em contato com o material. Pelo resultado, pode-se concluir que o valor mínimo necessário de preenchimento da cuba é de 3,7 litros. Além disso, verifica-se que para um volume pequeno, 1,2 litros, há oscilação do torque, por exemplo, entre o instante 180 e 220 segundos. Isto ocorre porque a geometria não está em contato com toda o material, ocasionando momentos de vazio e momentos em contato com o material.

Vale a pena ressaltar que a geometria ficou com uma distância de $2 \mathrm{~mm}$ do fundo da cuba, resultando no volume de 3,7 litros para cobrimento de toda a geometria. Caso a distância fosse maior, o volume necessário para cobrimento da geometria seria maior.

Após mistura e homogeneização do material, a avaliação do comportamento reológico pode ser realizada submetendo-o a ciclo de cisalhamento. Aplicando aceleração e desaceleração controlada, é possível estimar valores de torque de escoamento e viscosidade aparente e cálculo da área de histerese para análise de perfil reológico.

Durante o cisalhamento, pode ocorrer a quebra estrutural dos materiais que sofrem aglomeração, como o caso das pastas cimentícias. Desta forma é preciso considerar a história de cisalhamento da amostra na análise dos dados, o qual inclui o teste em si (BANFILL et al., 2006). 
A área de histerese corresponde à diferença entre a área das curvas de aceleração e desaceleração, correspondendo ao balanço entre a energia armazenada e energia dissipada no sistema durante o ciclo (JAYASREE; KRISHNAN; GETTU, 2011).

A energia fornecida à mistura durante o ciclo de cisalhamento favorece à quebra de eventuais aglomerados que não foram rompidos durante a mistura (FERNÀNDEZALTABLE; CASANOVA, 2006), implicando em grandes áreas de histerese (OLIVEIRA et al., 2003).

Assim, a partir do perfil reológico de torque em função da rotação avalia-se a área de histerese e o estado de dispersão. A influência da mistura no comportamento reológico pode ser estabelecida quando o material é submetido aos ciclos de cisalhamento (PILEGGI et al., 2001a, 2001b).

Por isso, foi realizado um ensaio de ciclo de cisalhamento para verificar a influência do volume de material, conforme Figura 6.20. As setas indicam o sentido da aceleração e desaceleração do motor. Os valores de rotação no eixo são referentes à rotação no eixo planetário.

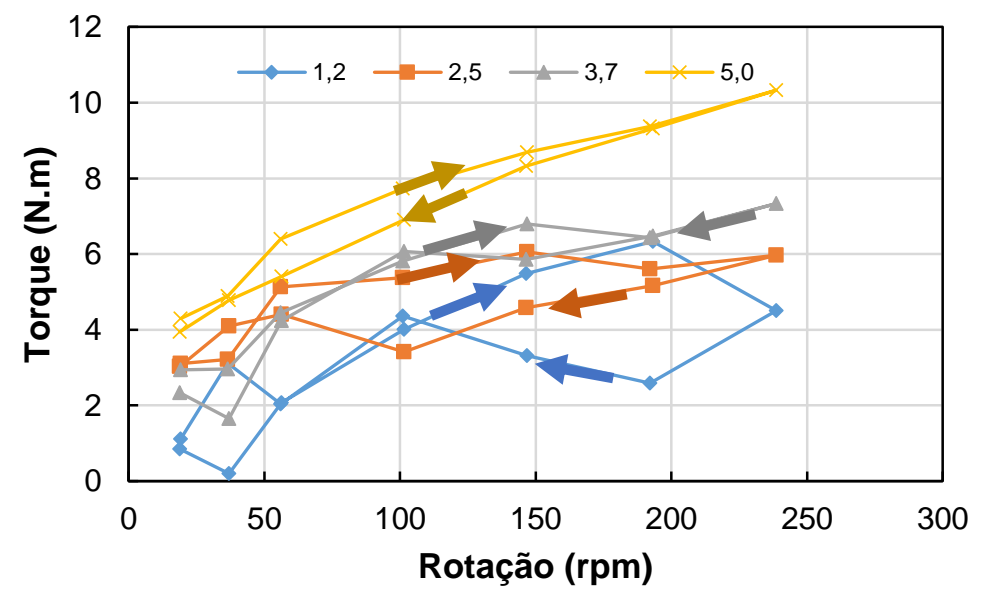

Figura 6.20: Resultado do ciclo de cisalhamento para os diferentes volumes de preenchimento da cuba.

Pelos resultados observa-se que existe influência do volume no resultado. Assim como na mistura, ao aumentar o volume de material, o esforço é maior e, consequentemente, os níveis de torque.

Observa-se também que há uma grande área de histerese para os pequenos volumes de material, conforme a Figura 6.21. 


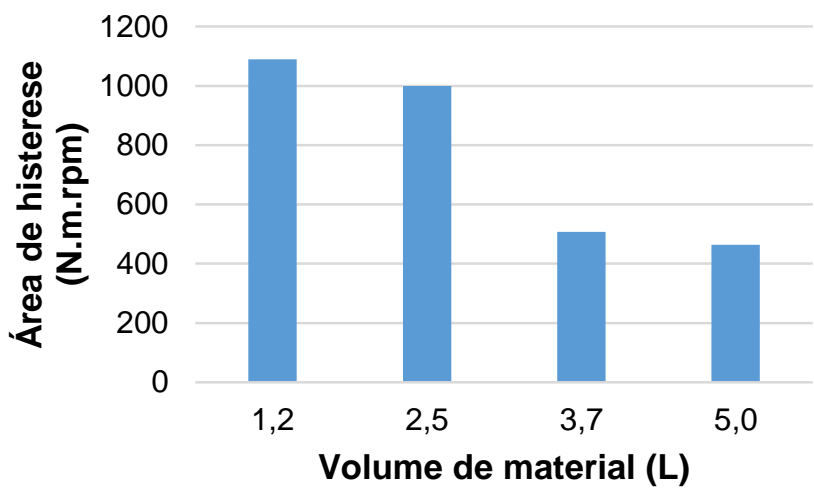

Figura 6.21: Comparação entre as áreas de histerese para os diferentes volumes de preenchimento da cuba.

O decréscimo na área de histerese se deve ao fato da quantia de material na cuba. Como o ensaio atingiu altas velocidades, para os ensaios com pouco volume o material ficava aderido à parede da cuba, formando um vazio na região central da cuba, influenciando no resultado final. E a partir do instante em que a geometria estava completamente recoberta (volume de 3,7 litros), observa-se que há um decaimento na área de histerese e aumento do valor de torque, porque toda a geometria está em contato com o material.

Assim como no ensaio de mistura, ao normalizar o torque pelo volume, verifica-se que a partir de 3,7 litros o resultado torna-se independente do volume, conforme a Figura 6.22 .

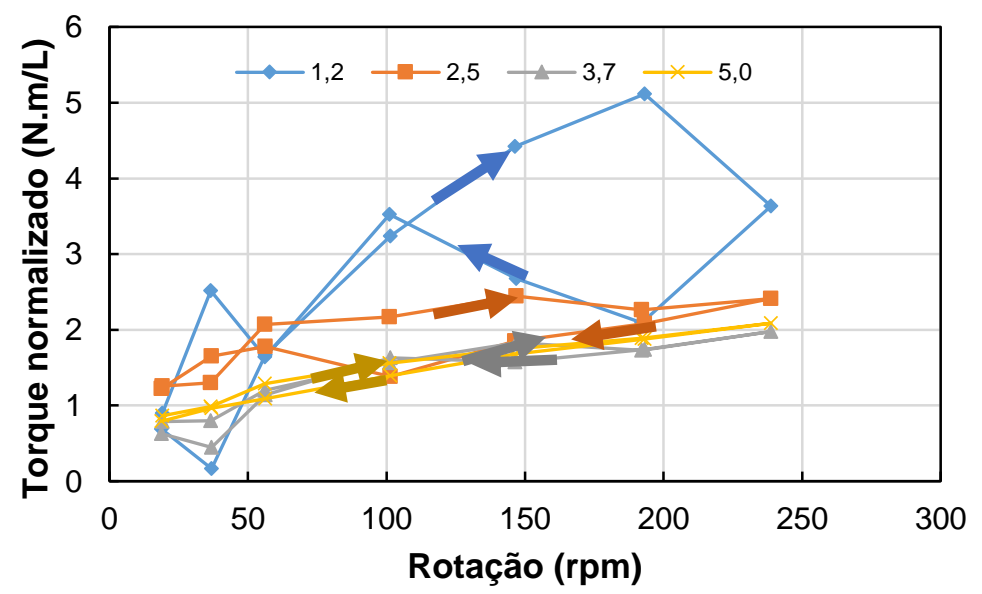

Figura 6.22: Torque normalizado para o ensaio de ciclo de cisalhamento para diferentes volumes de preenchimento da cuba.

A partir dos resultados analisados, definiu-se que todos o ensaio a serem realizados neste trabalho deverá recobrir, pelo menos, todas as haletas da geometria. 


\subsubsection{Sensibilidade do equipamento}

Após definir o volume de material necessário para realizar ensaios no reômetro independentes do volume, partiu-se para avaliação da sensibilidade do equipamento. Para isso, realizaram-se testes com material de viscosidade conhecida, três silicones de viscosidades distintas, 100, 1000 e 10000 cSt. A programação de ensaio do ciclo de cisalhamento foi a mesma utilizada anteriormente. O resultado do ensaio é apresentado na Figura 6.23. Para cada ensaio foi realizado quatro repetições, com o intuito de avaliar a repetibilidade do ensaio.

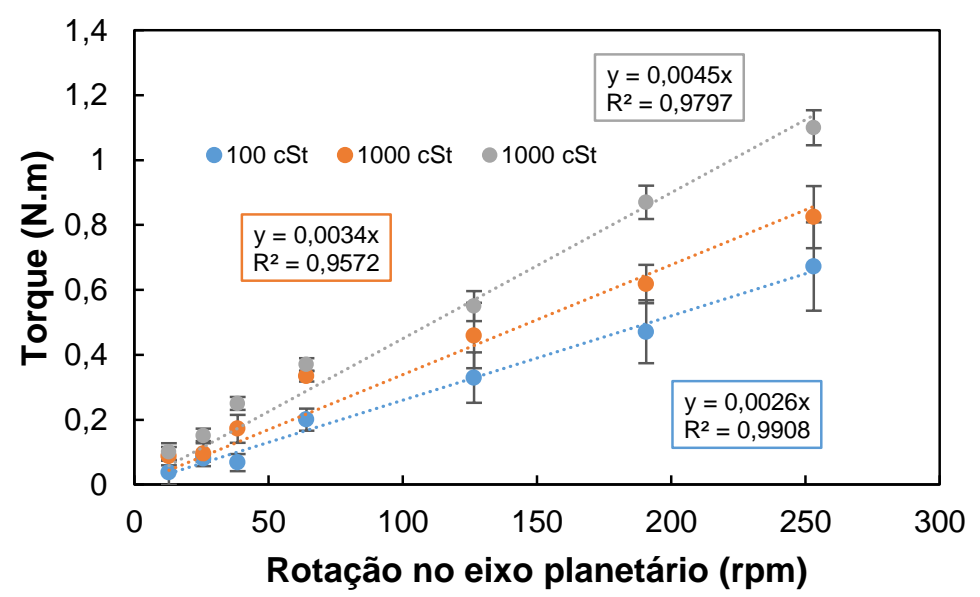

Figura 6.23: Resultado do ensaio com silicone de diferentes viscosidades.

Pelos resultados observa-se que o equipamento apresenta sensibilidade, podendo fazer ensaios com diversos materiais. No entanto, para a geometria utilizada, os materiais com menor viscosidade (100 e $1000 \mathrm{cSt}$ ) as barras de erro se intercalam, verificando assim, que esta geometria não é adequada para materiais com baixa viscosidade, devida, provavelmente, à turbulência gerada pela geometria.

Para avaliar o regime de escoamento de um fluido, utiliza-se um número adimensional conhecido como número de Reynolds, verificando se o fluido está em regime laminar ou turbulento. Sinnott e Towler (2012) estudaram o número de Reynolds em um recipiente cilíndrico utilizando uma geometria simples com uma haleta para mistura de produtos químicos e chegando a Equação 6.1.

$$
R e=\frac{\rho N D^{2}}{\mu}
$$


Em que D é o diâmetro da geometria $(m), N$ é a velocidade de rotação da geometria (rps), $\rho$ é a densidade do fluido $\left(\mathrm{kg} / \mathrm{m}^{3}\right)$ e $\mu$ é a viscosidade do fluido (Pa.s). Ao utilizar esta equação para a geometria utilizada e com os diferentes silicones, obtém-se o resultado apresentado na Figura 6.24.

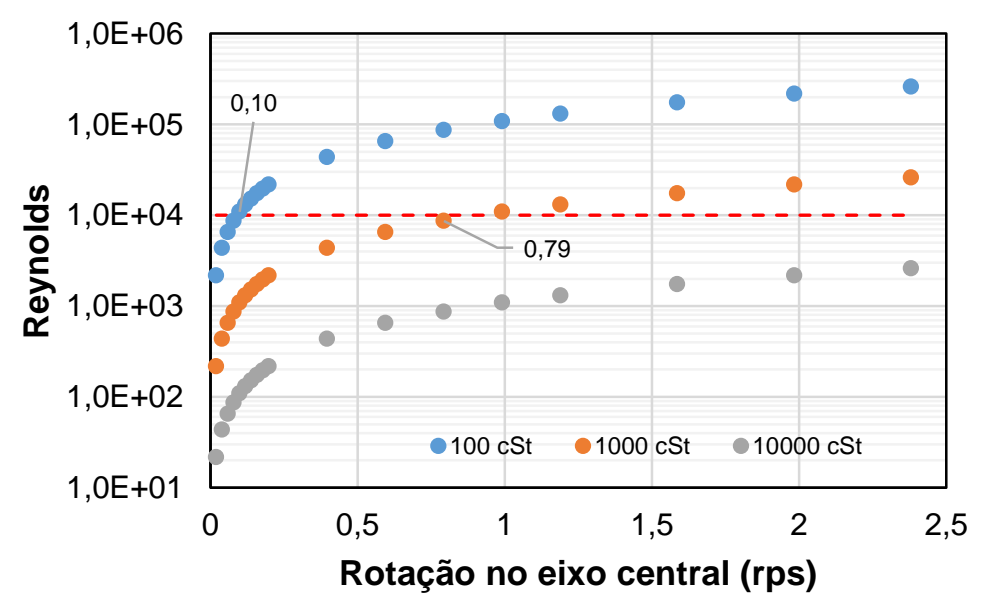

Figura 6.24: Número de Reynolds para diferentes viscosidades.

Segundo Sinnott e Towler (2012), para um Reynolds acima de 10000, o fluido está em regime turbulento. Verifica-se que para os fluidos 100 e 1000 cSt em uma dada velocidade, o fluido está em regime turbulento. Para um silicone de 100 cSt, a velocidade para permanecer em regime laminar deve ser inferior a 0,1 rps e para 0 silicone de 1000 cSt a velocidade máxima para permanecer no regime laminar é de aproximadamente 0,8 rps.

Vale ressaltar que este número de Reynolds é apenas uma aproximação, uma vez que a geometria utilizada não é a mesma utilizada por Sinnott e Towler (2012). Além disso, para o cálculo considerou-se que a geometria estava no eixo central do reômetro. Caso a geometria esteja no eixo planetário, a turbulência causada deve ser maior.

O aumento do número de Reynolds indica a existência de turbulência no fluido, causando perturbação no fluxo e oscilações nas medições, verificando-se assim, oscilações nos resultados.

Foi realizado um ensaio com os silicones, em que foi aplicado uma rotação constante no motor de 32, 630 e 1890 rpm (0,025, 0,5 e 1,5 rps no eixo central, respectivamente) e geometria acoplada no eixo central. Optou-se pelo eixo central devido à formula 
utilizada para o cálculo do número de Reynolds. O resultado para o silicone de 100 cSt é apresentado na Figura 6.25.
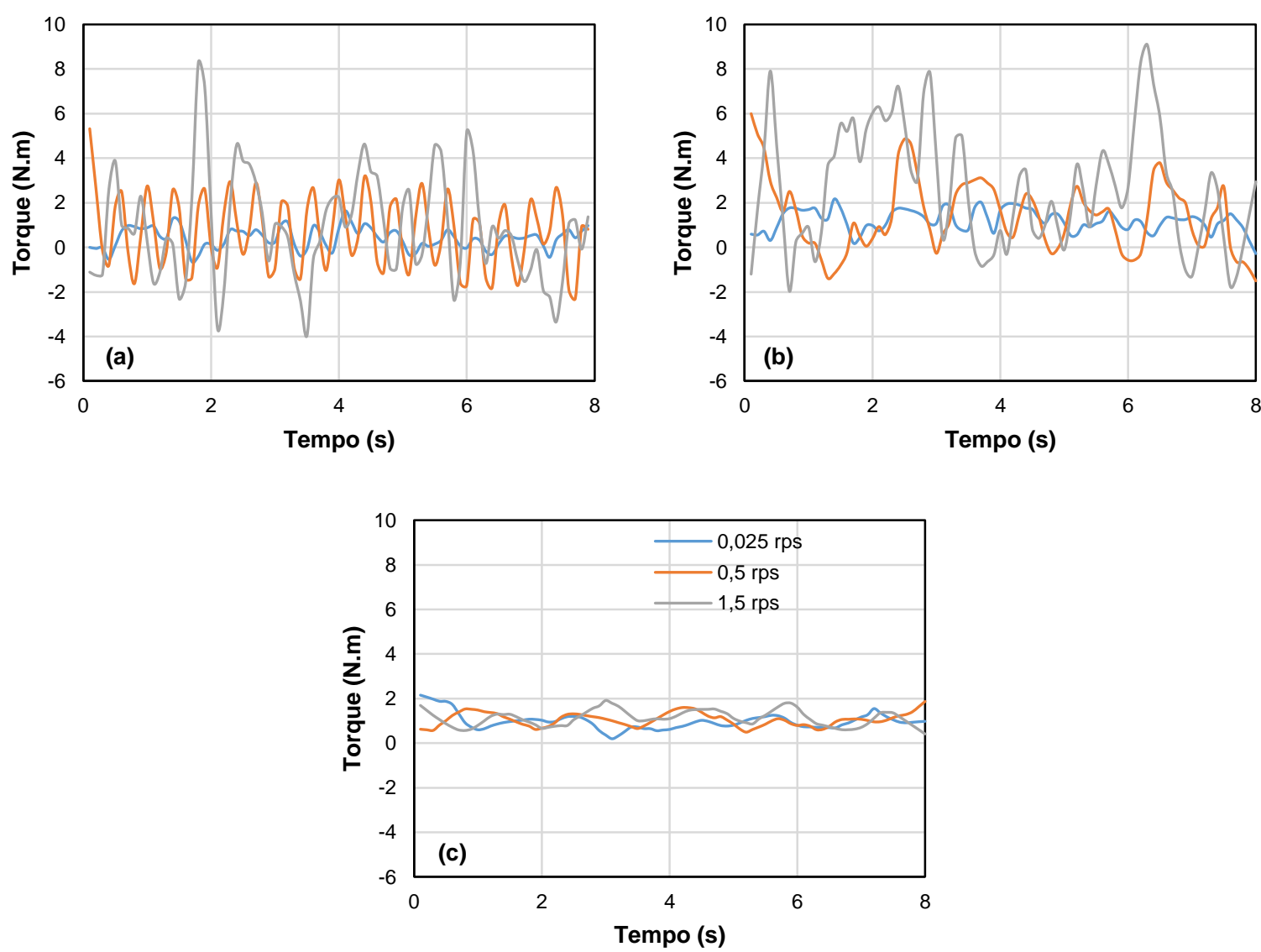

Figura 6.25: Ensaio para rotação constante com o silicone de (a) 100 cSt (b) 1000 cSt e (c) 10000 cSt.

Pela Figura 6.25-a verifica-se que para a rotação mais baixa $(0,025$ rps) o silicone ainda está em regime laminar e pelo sinal obtido verifica-se que seu valor permanece praticamente constante. No entanto, para as demais velocidades o regime passa para o turbulento, como foi observado pela Figura 6.24 , no qual a partir de 0,1 rps o fluido estará em regime turbulento. Devido ao regime turbulento gerado pela geometria, verifica-se grande oscilação do sinal aquisitado, principalmente para as rotações mais elevadas, que pode levar a interpretações equivocadas sobre o material.

Ao analisar a mesma situação para o silicone de 1000 cSt (Figura 6.25-b), é esperado que somente para a rotação mais elevada o fluxo seja turbulento. Pela Figura 6.24 espera-se que a partir da rotação de 0,8 rps o fluxo seria turbulento. No entanto, verifica-se que há uma oscilação grande já na rotação de 0,5 rps. Isto ocorre porque 
a fórmula proposta considera um outro tipo de geometria, mais simples. Utilizou-se esta fórmula apenas para um efeito comparativo.

E por fim para o ensaio com o silicone de 10000 cSt (Figura 6.25-c), verifica-se que para este caso, também, existe oscilação do sinal. No entanto, a oscilação não é grande como nos demais casos. Isto ocorre porque o fluxo gerado pela geometria com o silicone de maior viscosidade não é turbulento, permanecendo apenas em regime laminar ao longo do ensaio.

Vale ressaltar que a oscilação é oriunda do próprio sinal, mas quando o material a ser analisado está em regime turbulento, verifica-se uma maior oscilação. Portanto, devese atentar ao material e a geometria utilizada para a pesquisa, porque o fluxo gerado pela geometria pode levar a interpretações equivocadas.

\subsection{Software de tratamento dos dados}

No item anterior, foram apresentados problemas referentes à aquisição e ao ruído do sinal. Uma vez amenizado a questão de ruídos, alterado o parâmetro de aquisição e, também, aumentado a taxa de amostragem que requer mais tempo e custo para tratamento e análise dos dados, viu-se como necessidade e oportunidade o desenvolvimento de um software para tratamento dos dados obtidos pelo programa SCI-R, desenvolvido pela empresa Ragnar Solution.

Nesta pesquisa, a ferramenta computacional para a análise e tratamento dos dados foi desenvolvida a partir do software Matlab. Mas antes do desenvolvimento do software, procurou-se compreender quais eram suas principais necessidades, sendo elas destacadas a seguir:

- Filtrar os dados, para remover ruídos;

- Detectar outliers do ensaio;

- Realizar o tratamento de ensaios de mistura e ciclo;

- Aproximar os dados a modelos reológicos.

O intuito do software RheoView é de auxiliar o usuário a tratar os dados obtidos no reômetro. A Figura 6.26 ilustra como o tratamento é executado. Como foi apresentado anteriormente, é comum realizar ensaios de mistura e de cisalhamento e cada tipo de ensaio recebe o tratamento diferente, que será apresentado no decorrer do capítulo. 

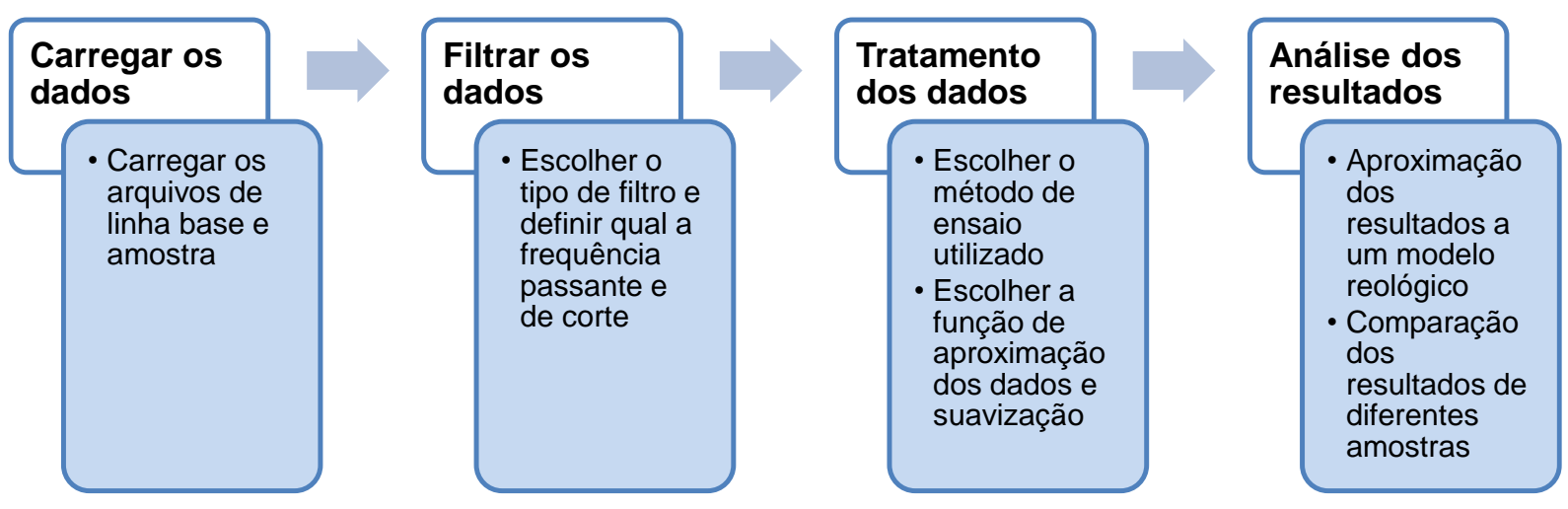

Figura 6.26: Fluxograma das etapas do RheoView.

No RheoView, é possível filtrar os dados, suavizá-los, aproximá-los a uma função, comparar resultados de diferentes ensaios e aproximar os resultados tratados à um modelo reológico. Todas estas etapas são apresentadas a seguir.

\subsubsection{Outliers}

As observações que apresentam um afastamento dos resultados medidos ou inconsistência são conhecidas com dados espúrios ou outliers. Diversos pesquisadores buscaram técnicas para identificar os outliers (BOX; HUNTER; HUNTER, 2005). Mas antes de decidir o que deve ser feito com os dados indesejados é necessário ter conhecimento das possíveis causas que levam ao seu aparecimento. Os valores extremos podem ser considerados como manifestações da variabilidade aleatória inerente aos dados, ou apenas um erro no cálculo durante o recolhimento dos dados e até mesmo uma anotação precipitada pelo operador.

O estudo de outlier é realizado em três fases. A primeira fase é de suma importância, pois é realizada a identificação de potenciais dados espúrios utilizando métodos subjetivos, sendo, normalmente, realizada a identificação por análise gráfica ou por observação direta, quando o número de dados é pequeno. Em seguida, são realizados testes de hipótese com os resultados apontados como outliers. Neste caso é utilizado um critério para aceitar ou rejeitar o dado como um dado indesejado. E por fim é necessário decidir se realmente o dado discordante é indesejado ou não.

Existem inúmeros critérios para testar outliers. Em todos eles, é desenvolvido o cálculo numérico amostral estatístico e compara-se com um valor crítico baseado na teoria de amostras aleatórias, para decidir se existe ou não uma observação considerada 
como um outlier. Para o programa RheoView foi utilizado o critério de Grubbs. Este teste detecta outliers que não pertencem a uma distribuição normal, em que são testados os valores máximos e mínimos dos dados em questão. Como resultado temse que a amostra pertence ou não à população. O funcionamento do critério de Grubbs é apresentado do Apêndia A.

\subsubsection{Filtragem dos dados}

Pelo estudo do sinal, verificou-se que o sinal apresenta ruído, principalmente ao aumentar a velocidade de rotação do motor. Por isso, vê-se necessário remover o ruído, ou seja, ter uma resposta bem seletiva do domínio da frequência. Pelo estudo de amostragem verificou-se que o ideal é utilizar um filtro digital passa-baixa.

No software Matlab, existem diversos filtros digitais, podendo ser do tipo IIR ou FIR. Para o desenvolvimento do trabalho optou-se, inicialmente, por utilizar o filtro do tipo IIR, por ser mais simples. No toolbox de Signal Processing do Matlab é possível utilizar os filtros clássicos Butterworth, Chebyshev tipo 1, Chebyshev tipo 2 e Elliptic.

Realizou-se um ensaio com rotação constante do motor em $100 \mathrm{rpm}$ com uma taxa de amostragem de 25 amostras/segundo, para avaliar os quatro tipos de filtro. Como parâmetros para o filtro passa-baixa, foram utilizadas frequência passante de 1,25 Hz e frequência de parada de $2,0 \mathrm{~Hz}$, também um valor de ganho máximo na faixa de rejeição em decibéis de $60 \mathrm{~dB}$.

Para o desenvolvimento do filtro utilizou-se a função fdesign.lowpass para especificação e design do mesmo. Na função design escolhe-se qual tipo de filtro será escolhido. Os resultados dos diferentes filtros são apresentados na Figura 6.27.
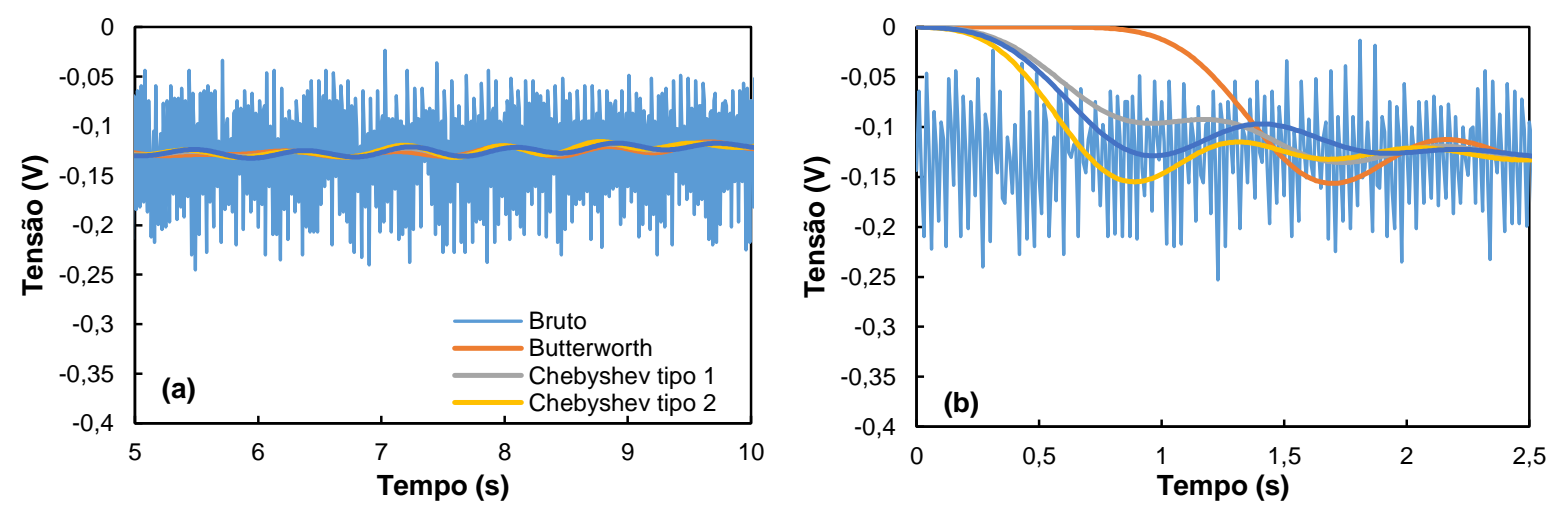

Figura 6.27: Resultado dos diferentes filtros do tipo IIR com motor andando em vazio (a) Detalhe do filtro entre os instantes 5 e 10 segundos e (b) tempo de resposta do filtro. 
Pela Figura 6.27-a, observa-se que os filtros removem o ruído do sinal aquisitado e na Figura 6.27-b verifica-se que todo filtro tem um tempo de resposta e que em todos os casos, com exceção do Butterworth, os filtros apresentaram um tempo de resposta inferior a 0,5 segundos. O Butterworth foi o único que apresentou um tempo maior de resposta (aproximadamente 1 segundo), isto ocorre porque este filtro é o mais simples de todos, sendo necessário um tempo maior para 0 seu processamento (OPPENHEIM; SCHAFER, 2009).

Vale ressaltar que esse teste foi realizado com o motor rodando no vazio e por isso, na sequência, realizou-se teste em que se manteve rotação constante de 5 rpm no motor e segurou a geometria com as mãos para aumentar o torque medido pelo equipamento e o resultado é apresentado na Figura 6.28.

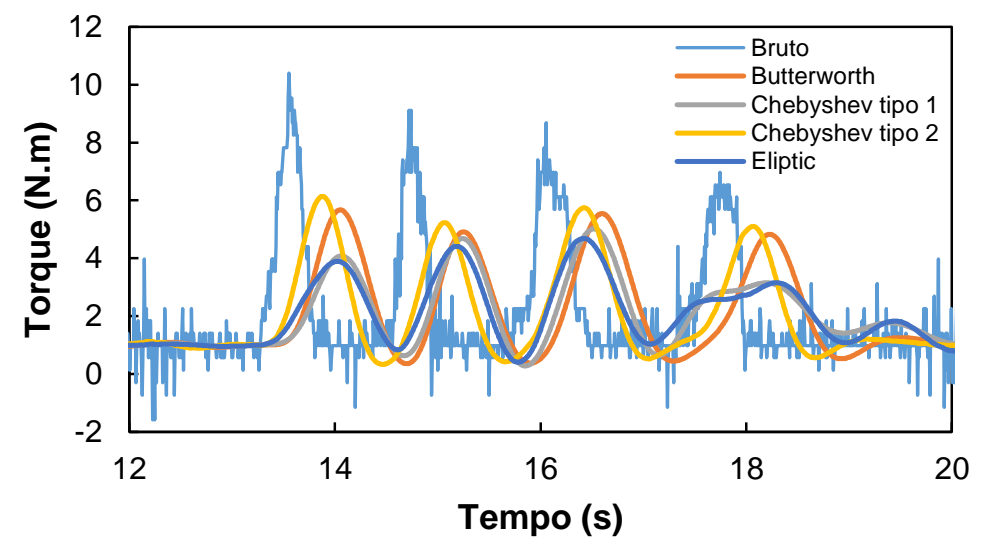

Figura 6.28: Aplicação dos filtros IIR no ensaio.

Como o filtro do tipo IIR apresenta uma fase não-linear e pode ser instável, o resultado pode sofrer alteração após a aplicação do filtro (OPPENHEIM; SCHAFER, 2009), como pode-se observar na Figura 6.28. Por conta disso, buscou-se desenvolver um filtro do tipo FIR, por apresentar uma fase linear e ser mais estável. A função utilizada para a construção do filtro é apresentada no Anexo A. O resultado do filtro é apresentado na Figura 6.29. 


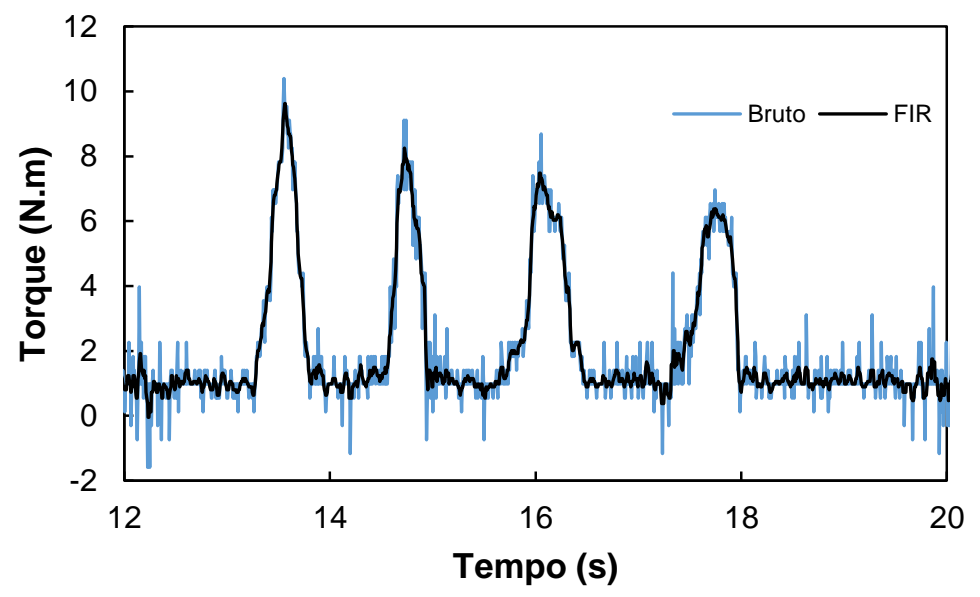

Figura 6.29: Aplicação do filtro FIR.

Este filtro apresenta-se adequado para ser utilizado no programa. Portanto, no programa será implementado o filtro FIR para tratamento dos dados. No Anexo B será apresentado um comparativo entre os filtros destacados anteriormente para interpretação dos resultados obtidos no ensaio reológico.

\subsubsection{Suavização dos dados}

Após o desenvolvimento do filtro, viu-se que ainda assim o sinal apresentava oscilação. Por isso utilizou-se as funções de suavização do Matlab, que são apresentadas a seguir. $\mathrm{O}$ detalhe do funcionamento de cada método é apresentado no Anexo A.

\section{a) Média móvel}

A média móvel suaviza os dados substituindo cada ponto pela média dos pontos vizinhos. Os pontos a serem utilizados são definidos por um intervalo imposto pelo usuário. Este processo é equivalente a uma filtragem passa-baixa com a resposta suavizada.

\section{b) Suavização Savitzky-Golay}

A suavização Savitzky-Golay é uma técnica que pode ser aplicada a um conjunto de pontos cuja finalidade é a suavização deles. Isto é possível utilizando um processo conhecido por convolução, em que sucessivos subconjuntos de dados adjacentes são aproximados por uma função polinomial de baixo ou alto grau através do método de mínimos quadrados lineares. O método, baseando em cálculos matemáticos (GUEST; 
GUEST, 2012; WHITTAKER; ROBINSON, 1924), foi popularizado em 1964 por Abraham Savitzky e Marcel J. E. Golay, que publicaram tabelas de coeficientes de convolução para vários polinômios e diferentes tamanhos de subconjuntos (SAVITZKY, 1989; SAVITZKY; GOLAY, 1964). Alguns erros nas tabelas foram corrigidos (STEINIER; TERMONIA; DELTOUR, 1972) e o método foi estendido para o tratamento de dados em 2 e 3 dimensões. Normalmente, este método necessita de espaçamento uniforme dos dados, mas com o algoritmo matemático que existe no Matlab é possível utilizar este método mesmo que os dados não apresentem espaçamento uniforme.

\section{c) Suavização por regressão local}

Este método foi proposto por Cleveland (1979) e aprimorado por Cleveland e Devlin (1988). A suavização é diferente para cada método: LOWESS utiliza um polinômio de ordem um, enquanto que o LOESS utiliza um polinômio de ordem dois. Em ambos os casos, o polinômio é gerado utilizando o método dos mínimos quadrados ponderado, ou seja, aplica-se um maior peso aos pontos que estão mais próximos da resposta que está sendo estimada e menor peso aos pontos mais distantes.

\subsubsection{Ajuste de curva}

Este método consiste em encontrar uma função que possivelmente se ajuste a uma série de pontos, envolvendo interpolação e suavização. Além disso, é possível realizar uma inferência estatística através de uma análise de regressão, por exemplo, para verificar se a função aproximada está adequada.

O programa RheoView utiliza esta função de ajuste de curva porque, muitas vezes, os dados obtidos da amostra e linha base não coincidem. Em alguns casos, o arquivo gerado pelo software SCI-R apresenta intervalo de aquisição diferente ou as matrizes não possuem o mesmo tamanho.

No Matlab, deve-se utilizar a função fit para permitir a aproximação do resultado a alguma função. A seguir são destacadas funções existente no programa. Vale ressaltar que é possível o usuário definir uma função genérica para aproximação do resultado obtido.

i. Aproximação polinomial;

ii. Aproximação exponencial; 

iii. Aproximação da série de Fourier;
iv. Aproximação Gaussiana;
v. Ajuste por segmento;
vi. Aproximação por soma de seno.

Para o programa optou-se por utilizar o ajuste por segmento (smooth spline) porque é uma opção que se ajusta ao resultado com facilidade, principalmente se os dados apresentam ruído elevado.

\subsubsection{Tratamento dos resultados}

Após todo o tratamento ser realizado, com etapas de filtragem, suavização e ajuste da curva, é necessário tratar o resultado. O tratamento difere para o ensaio de mistura e de ciclo de cisalhamento. A seguir apresenta-se como é realizado o tratamento para cada tipo de ensaio.

\section{a) Mistura}

O tratamento do ensaio de mistura se inicia com a subtração da linha base do resultado do material analisado. A análise do resultado é realizada verificando a curva de mistura, ou seja, "torque x tempo".

Com este ensaio, é possível obter diversas informações sobre o material, como por exemplo, torque máximo de mistura, energia necessário para realizar a mistura, torque médio final, entre outros. Além disso, é possível analisar a energia de mistura necessária para homogeneizar o material.

\section{b) Ciclo de cisalhamento}

Assim como ocorre no ensaio de mistura, o primeiro passo é descontar a linha base do resultado do material a ser analisado. No ensaio de cisalhamento, geralmente são realizados patamares com diferentes velocidades e com duração de 8 segundos. $A$ escolha no tempo de duração de cada patamar depende do tipo de material que está sendo analisado, sendo necessário realizar um estudo prévio para sua definição. No entanto, no ensaio de ciclo de cisalhamento, a análise do resultado é realizada em relação ao "torque x rotação", diferente da mistura. Logo, o seu ponto de interesse corresponde a um único valor de torque para certa rotação. 
Dessa forma, o problema surge com relação à qual dado utilizar para realizar a análise do resultado. Segundo Steffe (1996), o ensaio realizado em uma taxa de cisalhamento constante, para materiais que apresentam um comportamento reológico dependente do tempo, pode ter o aumento ou decaimento da tensão de cisalhamento, conforme Figura 6.30.

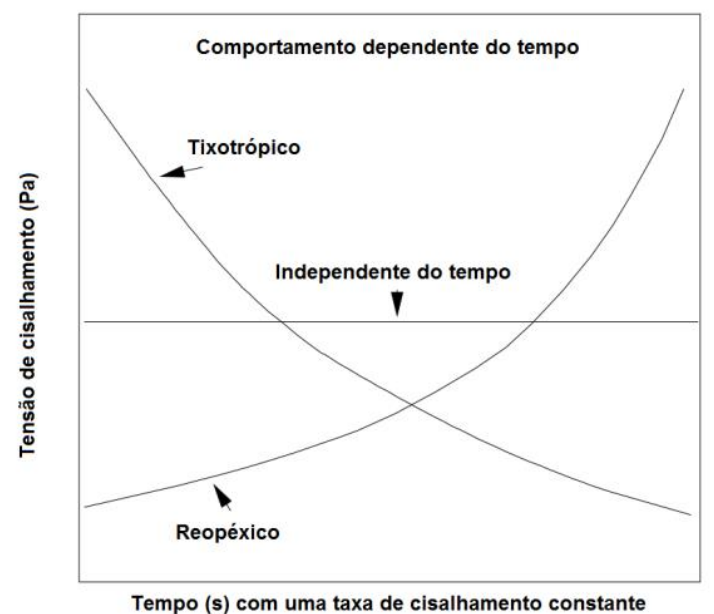

Figura 6.30: Comportamento dos fluidos dependente e independente do tempo (STEFFE, 1996).

Este fenômeno é observado em ensaios com mudanças de patamares, como os ensaios de ciclos realizados neste reômetro. Segundo Steffe (1996), para este tipo de ensaio, se o fluido apresentar um comportamento dependente do tempo, em cada patamar, a tensão pode aumentar ou diminuir, conforme a Figura 6.31.

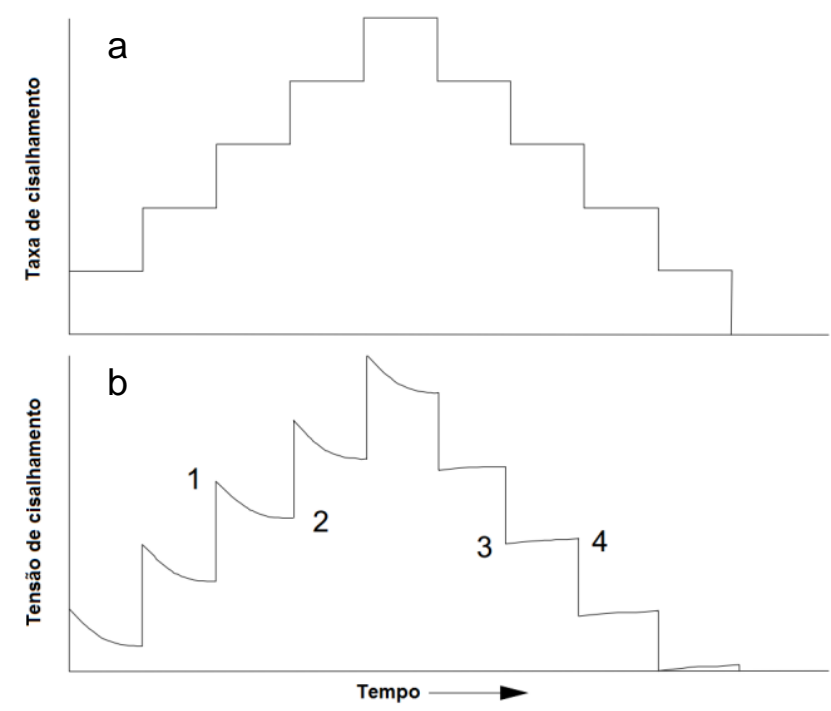

Figura 6.31: Comportamento de um material tixotrópico para ensaio com patamares: (a) programação de ensaio e (b) resposta do material (STEFFE, 1996). 
Por conta dos motivos apresentados acredita-se que a média do torque de todos os pontos do mesmo patamar levaria a interpretações equivocadas. Como o sinal aquisitado apresenta oscilações, como foi apresentado nos itens anteriores, escolher apenas um ponto dos dados da amostra e um ponto da linha base, também seria um erro. Por isso, no software RheoView escolheu-se realizar a média dos últimos pontos. Após o tratamento, obtém-se o perfil reológico do material possibilitando o cálculo da viscosidade aparente do material e da área de histerese.

\subsection{Comportamento reológico de suspensões com esferas rígidas com extensão granulométrica entre 1 e $4 \mathrm{~mm}$ e matriz apolar}

Após a compreensão do sinal, calibração e validação do equipamento e 0 desenvolvimento do software para o tratamento dos dados, pode-se realizar ensaios reológicos com o equipamento. Para esta pesquisa, realizaram-se ensaios com suspensões de esferas graúdas rígidas, com diferentes granulometrias e silicones com diferente viscosidade.

O comportamento de fluxo das suspensões é controlado pelo equilíbrio entre interações hidrodinâmicas e termodinâmicas, dependendo da dimensão das partículas e do meio em que elas estão inseridas (GENOVESE, 2012; PUSEY; VAN $M E G E N, 1986)$. As partículas apresentam uma tendência natural à aglomeração, a qual aumenta com a redução do seu tamanho. As interações termodinâmicas incluem principalmente repulsão/atração eletrostática e estérica, a força de atração de van der Walls e forças capilares na presença de um líquido. No entanto, para o estudo em questão será considerado esferas rígidas em meio apolar para avaliar o efeito da fração de volumétrica e tamanho, descartando forças eletrostáticas de carga e as de van der Walls, tendo apenas interação interparticular de natureza capilar.

Estudo de dispersão com esferas rígidas são modelos de sistema idealizados em que não há interação entre as partículas, a menos que elas estejam em contato. Mas mesmo para um sistema simples pode apresentar um comportamento reológico complexo. Para o estudo em questão, foi realizado ensaio de mistura, para avaliar o efeito do teor de sólidos, granulometria próxima da monomodal e viscosidade da matriz, bem como o perfil reológico da suspensão através do ensaio de ciclo de 
cisalhamento. Além disso, foi realizado um estudo da eficiência de mistura da geometria utilizada no reômetro.

Na Figura 6.32 é apresentada a distribuição granulométrica das esferas de vidro utilizada neste estudo.

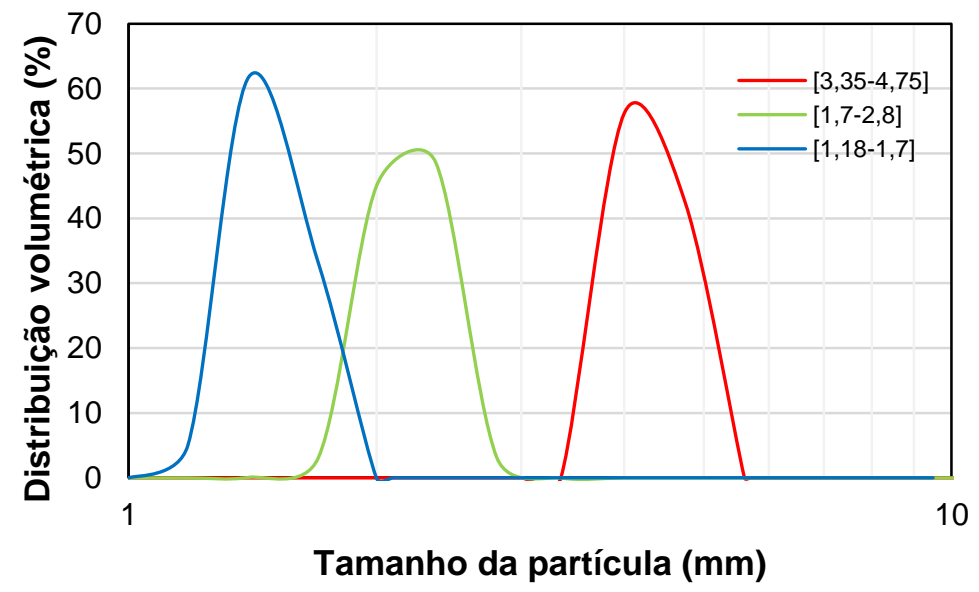

Figura 6.32: Distribuição granulométrica das frações de esferas de vidro utilizadas.

Verifica-se que são frações granulométricas com distribuições distintas, se aproximando a uma distribuição monomodal. Há uma sobreposição na fração [1,7$2,8]$ e $[1,18-1,7]$.

Além disso, foi realizada uma análise da forma das esferas de vidro tanto para o parâmetro de esfericidade quanto para o de relação de aspecto conforme ilustrado na Figura 6.33.
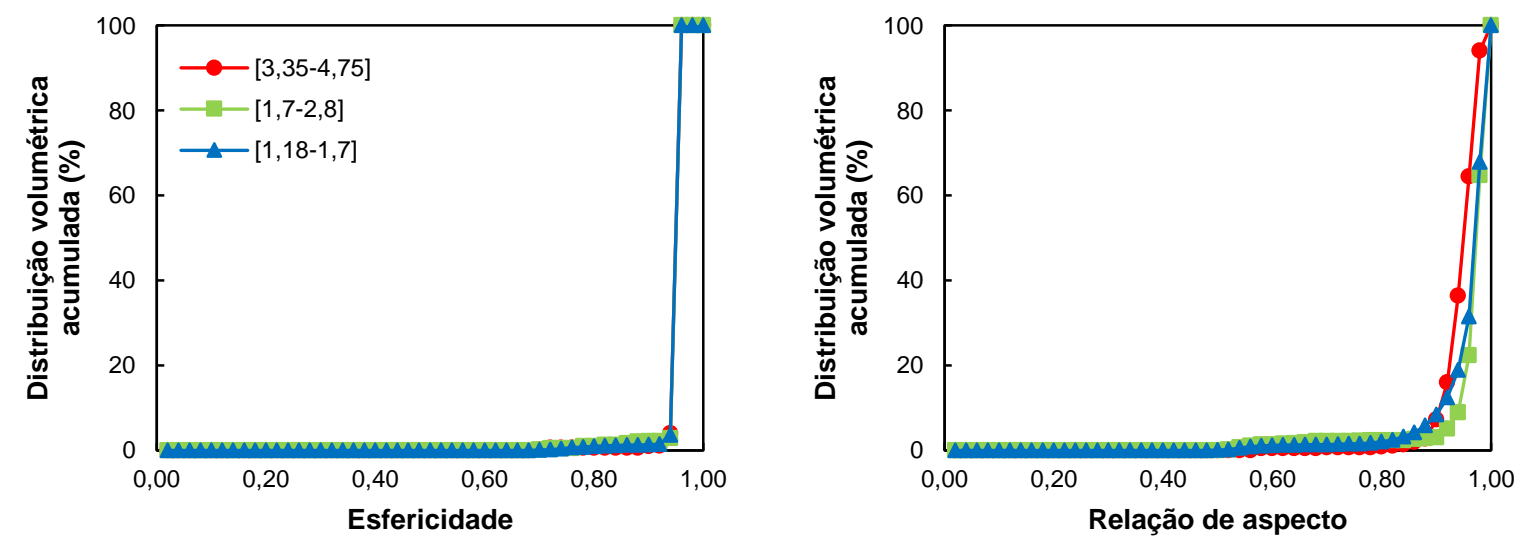

Figura 6.33: Distribuição acumulada do fator de forma "esfericidade" e "relação de aspecto" das frações de esfera de vidro utilizadas. 
Pelos resultados observa-se que as esferas utilizadas na pesquisa são próximas de esferas perfeitas, uma vez que a esfericidade e a relação de aspecto são superiores à 0,9 . Buscou-se utilizar partículas mais próximas do formato esférico para que a perturbação gerada pelo fluxo fosse minimizada.

$\mathrm{Na}$ Tabela 6.3 apresentam-se os resultados de densidade de empacotamento em sistemas monomodais de cada uma das amostras das esferas. Estes resultados foram obtidos através do ensaio no GeoPyc 1360.

Tabela 6.3: Valores de densidade de empacotamento para sistemas com cada uma das frações das esferas de vidro utilizadas

\begin{tabular}{cc}
\hline Fração & Densidade de empacotamento (\%) \\
\hline$[1,5-2,2]$ & $66,10 \%$ \\
{$[2,0-2,36]$} & $65,70 \%$ \\
{$[4,0-4,45]$} & $63,20 \%$ \\
\hline
\end{tabular}

Pode-se observar que o empacotamento diminui ligeiramente à medida que o tamanho das esferas aumenta.

Como matriz líquida foram utilizados silicones para compor a suspensão, variando a viscosidade de 100, 1000 e 10000 cSt. As suspensões foram preparadas com teor volumétrico de sólidos de $60 \%$ e $70 \%$. Optou-se por estes teores porque com $60 \%$ as partículas estariam totalmente recobertas e separadas por uma pequena camada de liquido enquanto que para o teor de $70 \%$ as partículas estariam próximas umas das outras.

Foram realizados ensaios de mistura e ciclo de cisalhamento para as suspensões. Além disso, foi avaliada a eficiência de mistura da geometria utilizada no reômetro. Para o ensaio de mistura, foi utilizada a programação apresentada na Figura 6.34.

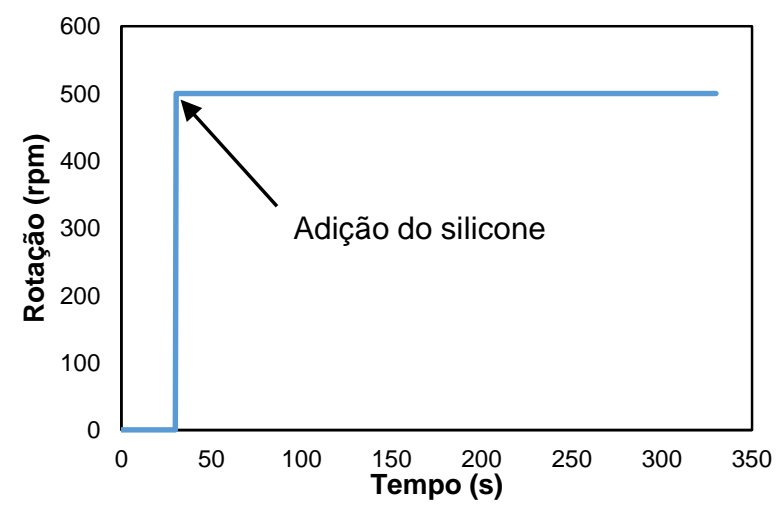

Figura 6.34: Programação utilizada para o ensaio de mistura. 
Foi utilizado o volume de 4 litros de suspensão para este ensaio, cobrindo assim, todas as haletas da geometria e o silicone foi adicionado no instante em que se inicia a rotação de 500 rpm do motor, em 30 segundos.

Todos os resultados apresentados a seguir foram tratados utilizando o programa RhoeView. Foram seguidas todas as etapas apresentadas no item 6.3. Nos resultados apresentados na Figura 6.35 e Figura 6.36, a legenda é composta por três códigos, o primeiro número representa a viscosidade da matriz utilizada, em cSt, em seguida o teor utilizado, concentração volumétrica, e por fim a granulometria utilizada, em mm, sendo 1 referente à fração [1,5-2,2], 2 à fração [2,-2,36] e 4 à fração [4,0-4,45].

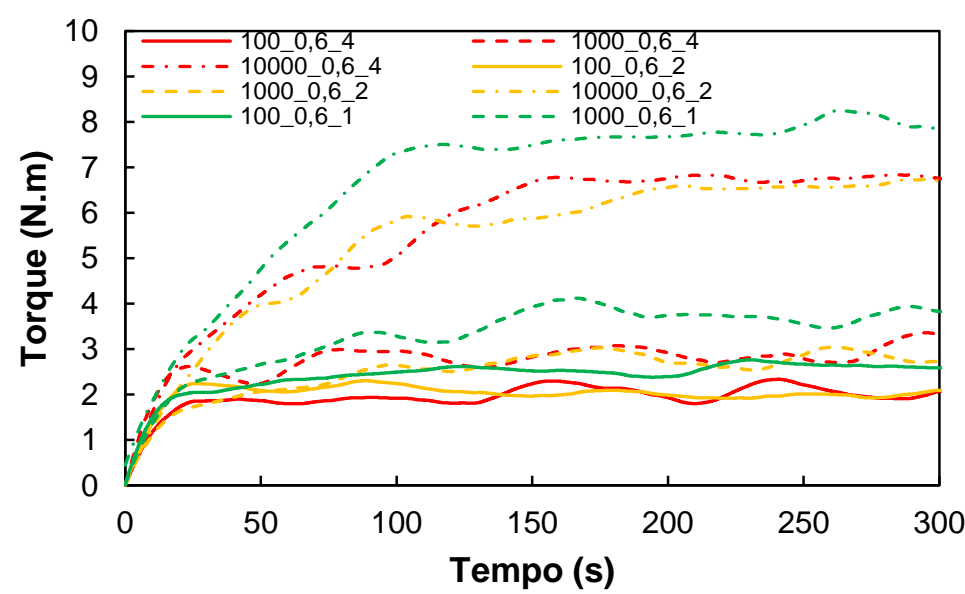

Figura 6.35: Resultado do ensaio de mistura para o teor de $60 \%$.

O comportamento de mistura de sistemas de partículas tem sido alvo de diversos estudos ao longo dos anos devido a sua elevada importância para diversos setores da tecnologia. Pode-se observar que a partir do instante que o silicone entra em contato com as partículas há um aumento dos níveis do torque. Procurou-se adicionar o silicone com a mesma vazão, no entanto, para o silicone de maior viscosidade (10000 cSt) não foi possível.

Observa-se que a curva de mistura não se assemelha com a apresentada na Figura 6.18, devido à dimensão e a natureza das partículas e do fluido. As interações termodinâmicas são negligenciadas para partículas com diâmetro superior a $1000 \mu \mathrm{m}$, que não favorece a aglomeração das partículas (NIENOW; EDWARDS; HARNBY, 1997). As forças atuantes são de capilaridade, devido à proximidade entre as partículas e as forças hidrodinâmicas, devido à dimensão da partícula. Como não há aglomeração, não se verifica um pico na curva de mistura. 
Pela curva de mistura verifica-se que há uma grande influência da viscosidade da matriz no processo de mistura. Quanto maior a viscosidade maior o torque final de mistura. Além disso, observa-se que a suspensão composta pela fração [1,5-2,2] sempre apresentou um torque superior se comparado com as demais distribuições granulométricas. Isto se deve ao fato da força capilar, que, normalmente, induz ao aumento da resistência do sistema, que tem um papel importante em processos tecnológicos e em fenômenos naturais (DUAN; BERGGREN, 2010; REIS et al., 2010).

A existência de capilaridade pode ser relacionada com o conceito de MPT, parâmetro que pode ser calculado para cada suspensão em função do teor de sólidos e do diâmetro médio das partículas, com o auxílio dos resultados de empacotamento. Os resultados de MPT para as suspensões em análise são apresentados na Tabela 6.4.

Tabela 6.4: Valores de MPT para cada suspensão preparada, em função do teor de sólidos e da fração de esferas utilizada

\begin{tabular}{ccc}
\hline \multirow{2}{*}{ Fração } & \multicolumn{2}{c}{ MPT $(\boldsymbol{\mu} \mathbf{m})$} \\
& $\mathbf{6 0 \%}$ & $\mathbf{7 0 \%}$ \\
\hline$[1,5-2,2]$ & 41,53 & $-50,91$ \\
{$[2,0-2,36]$} & 72,46 & $-105,05$ \\
{$[4,0-4,45]$} & 90,05 & $-270,33$ \\
\hline
\end{tabular}

Os valores negativos indicam que não há liquido o suficiente para recobrir a partícula e separar uma da outra, ou seja, estão em contato.

Simons e Fairbrother (2000) estudaram sobre a energia de ruptura necessária para romper um menisco formado entre duas partículas esféricas. Em continuidade, Pitois, Moucheront e Chateau (2001) estudaram o efeito da capilaridade e da viscosidade do fluido, obtendo a seguinte Equação 6.2, verificando que a energia necessária para o rompimento do menisco é a somatória da energia de ruptura referente as forças capilares $\left(\widetilde{W}_{c a p}\right)$ e a energia de ruptura das forças viscosas $\left(\widetilde{W}_{\text {visco }}\right)$. Na presença apenas da influência da força capilar deve-se considerar apenas a força capilar sendo desprezado o efeito da força viscosa. Se o fluido em questão apresenta viscosidade mais elevada, o efeito da força viscosa é predominante.

$$
\widetilde{W}_{\text {total }}=\widetilde{W}_{c a p}+\widetilde{W}_{\text {visco }}
$$

Segundo Pitois, Moucheront e Chateau (2001) $\widetilde{W}_{c a p}=f(\theta, V, R)$ e $\widetilde{W}_{\text {visco }}=$ $f(V, R, D, \eta, v, \sigma)$, em que $\theta$ é o ângulo de contato formado entre o sólido e o líquido, 
V é o volume do menisco, $\mathrm{R}$ é o raio da esfera, $\mathrm{D}$ é a distância de separação entre as partículas, $\eta$ é a viscosidade do fluido, $v$ é a velocidade relativa da esfera e $\sigma$ é a tensão superficial. Além disso, a distância de ruptura depende do número capilar $(C a=\eta v / \sigma)$, verificando um aumento à medida que se aumenta a viscosidade do fluido.

Para verificar o efeito da capilaridade realizou-se ensaio com um teor de sólido de $70 \%$, em que as partículas estão em contato, favorecendo ainda mais a formação dos meniscos. A seguir, na Figura 6.36, é apresentado a curva de mistura para as suspensões com teor de sólido de $70 \%$.

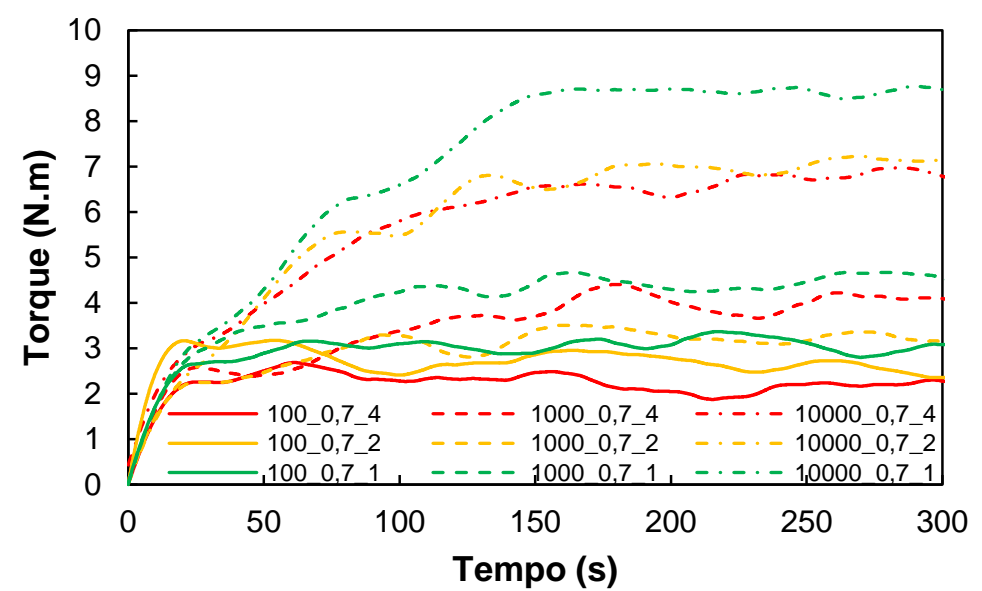

Figura 6.36: Resultado do ensaio de mistura para o teor de $70 \%$.

Pode-se verificar que há uma mudança no torque médio no fim da mistura, se comparado com o teor de $60 \%$. Este aumento se deve ao fato das partículas estarem mais próximas umas das outras, favorecendo assim a formação dos meniscos, e consequentemente, a força capilar. Além disso, ao diminuir o diâmetro da esfera, a quantidade de partículas aumenta exponencialmente, conforme a Figura 6.37.

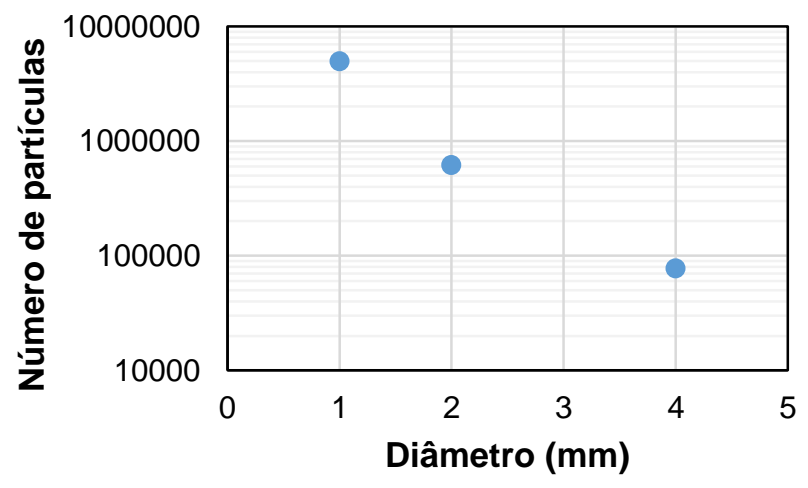

Figura 6.37: Quantidade de esferas em função do diâmetro. 
O aumento do número de esferas favorece o acréscimo no número de contato entre elas, favorecendo as forças capilares. Além disso, quanto maior o diâmetro menor o efeito da capilaridade (PITOIS; MOUCHERONT; CHATEAU, 2001; SIMONS; FAIRBROTHER, 2000; SIMONS; SEVILLE; ADAMS, 1994). Por isso, há uma diferença maior entre os torques finais de mistura para a esfera de $1 \mathrm{~mm}$, se comparado as demais esferas. Além do efeito da capilaridade, por possuir menos fluido ao redor da partícula, há o aumento do atrito entre elas, causando o aumento do torque e, consequentemente, a energia de mistura.

No ensaio de mistura, além da curva de mistura, analisou-se a eficiência de mistura da geometria utilizada. Para isso, as esferas foram pintadas em cinco cores diferentes, colocadas em camadas e, no término do ensaio, foram recolhidas três alíquotas, representada esquematicamente na Figura 6.38.
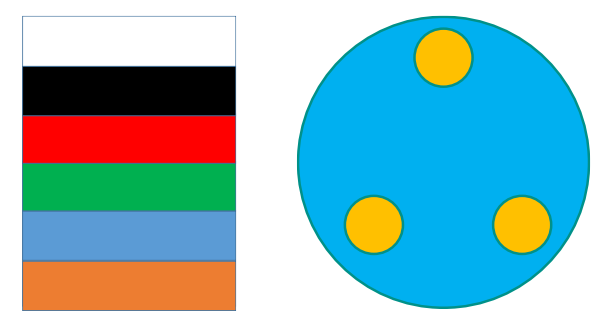

Figura 6.38: Esquemático da distribuição das camadas e dos locais para recolhimento das alíquotas representado pelos círculos amarelos.

Cada alíquota foi fotografada para efetuar a contagem das partículas. Iniciou-se com um pré-tratamento da imagem utilizando o software GIMP, no qual foi possível diminuir a saturação da imagem e isolar a cor desejada. Em seguida utilizou-se o software ImageJ com um plugin chamado de Nucleus Counter para realizar a contagem. Este plugin é utilizado para a contagem de células em laboratórios de medicina. A Figura 6.39 apresenta um exemplo simplificado de como foi realizado este processo. No caso de partículas da mesma cor estar em contato uma da outra, o próprio plugin aplica um tratamento, uma vez que um parâmetro de ajuste é referente à dimensão máxima e mínima da partícula, e assim, detecta que a partícula está em contato uma da outra.

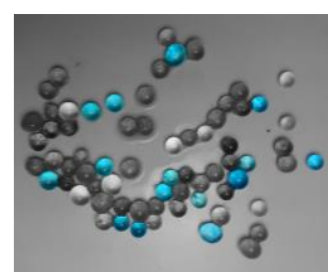

GIMP

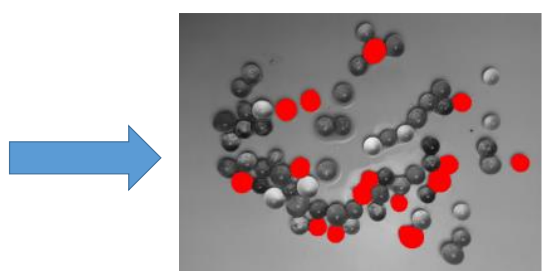

Image

Figura 6.39: Processo simplificado para contagem das esferas. 
Na Figura 6.40 é apresentada a média da contagem das partículas das suspensões compostas por diferentes granulometrias e viscosidades e com teor de sólidos de $60 \%$.
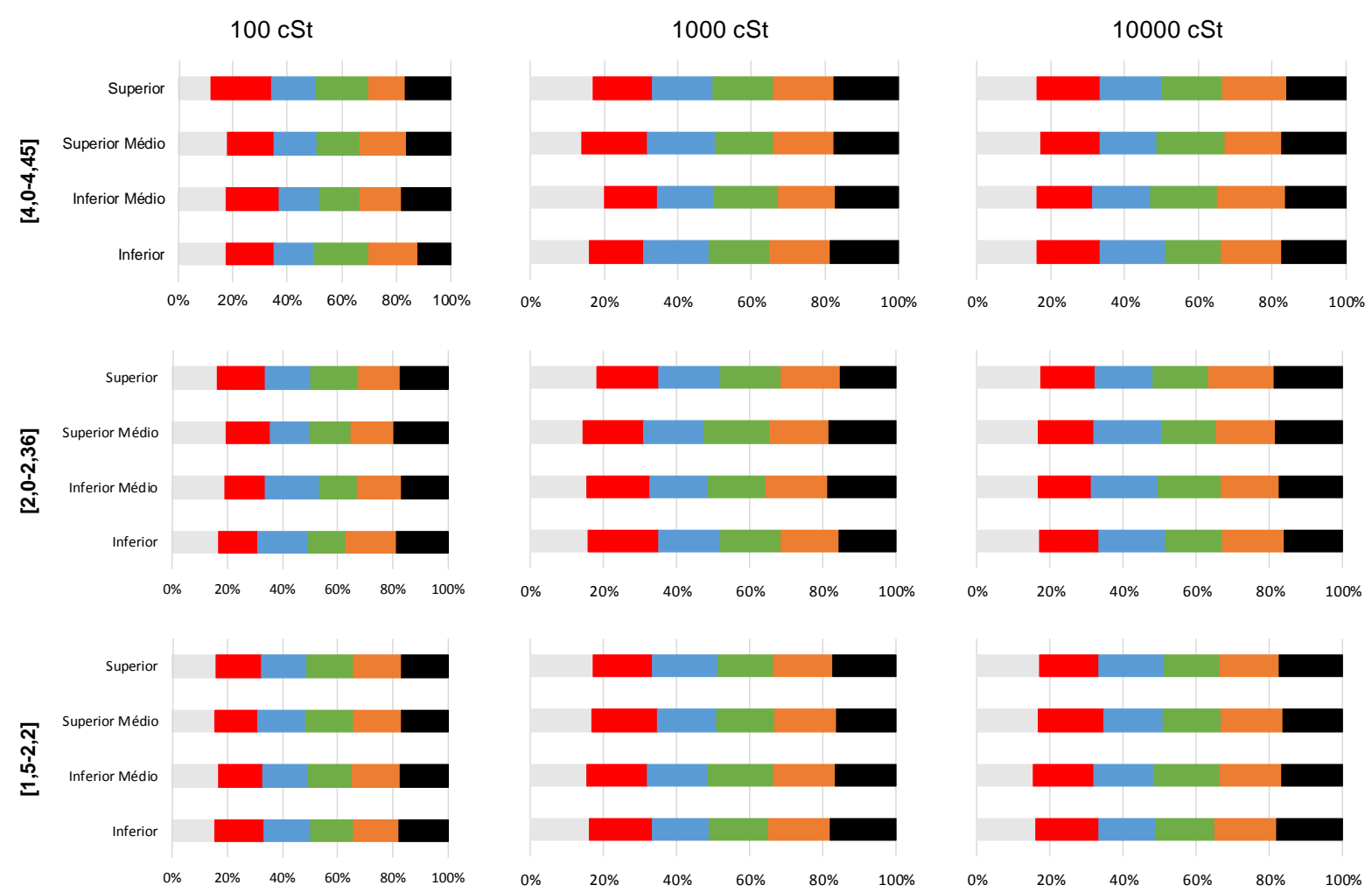

Figura 6.40: Porcentagem média de cada esfera em cada camada, para as diferentes distribuições granulométricas e viscosidades, com o teor de sólidos de $60 \%$. Cada cor representa a cor da esfera.

Pelo resultado conclui-se que o tempo de mistura foi adequado, uma vez que as distribuições das esferas são semelhantes em todas as camadas. O mesmo ocorre para o teor de $70 \%$, conforme a Figura 6.41 . 

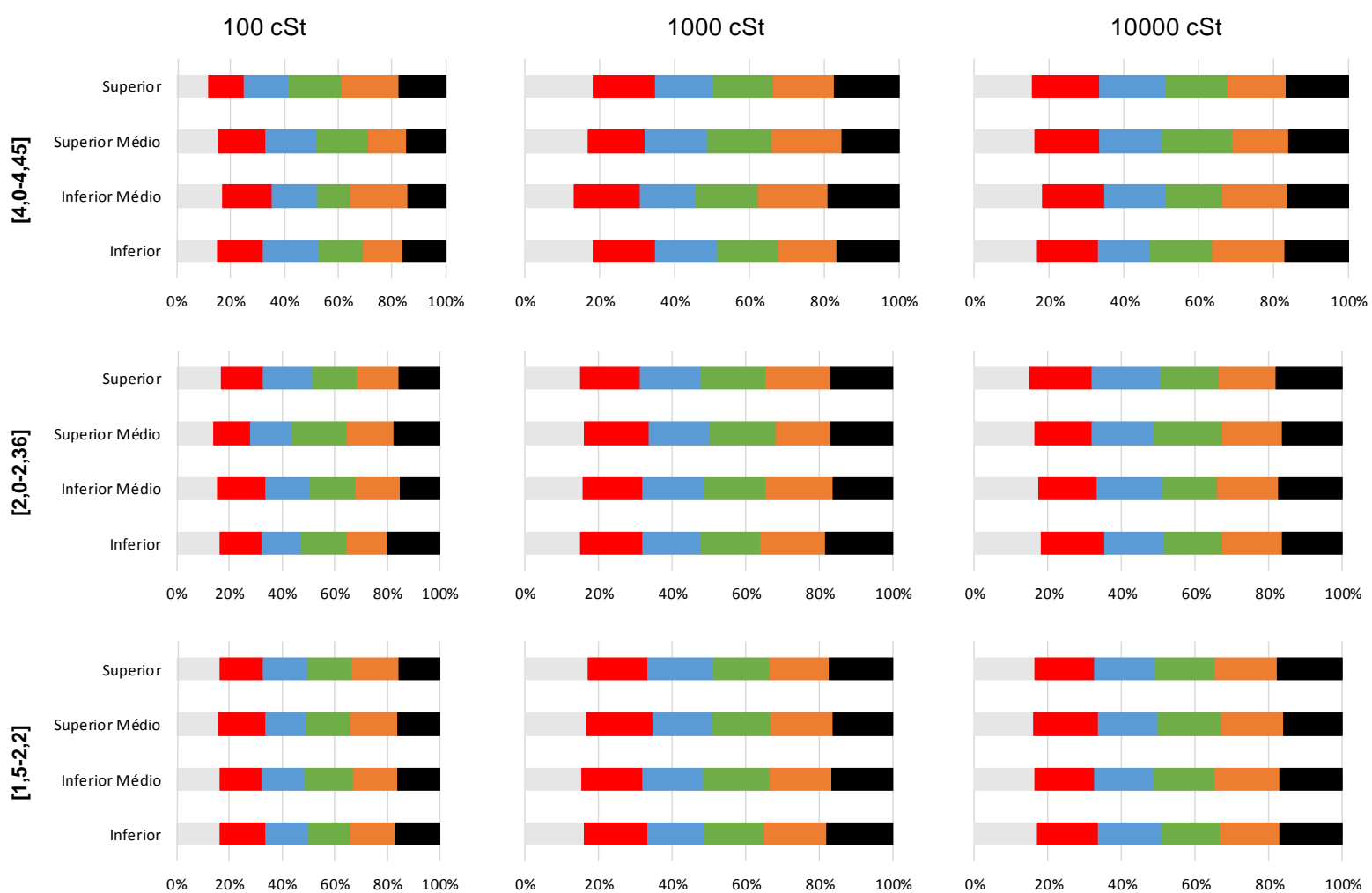

Figura 6.41: Porcentagem média de cada esfera em cada camada, para as diferentes distribuições granulométricas e viscosidades, com o teor de sólidos de $70 \%$. Cada cor representa a cor da esfera.

Para o estudo em questão, em ambos os teores, o tempo de mistura foi adequado. Vale ressaltar que a mistura foi adequada, uma vez que não houve aglomeração das partículas e a viscosidade da matriz não dificultou a mobilidade das partículas. É possível reduzir o tempo de mistura, no entanto, é necessário realizar novos ensaios com tempo de mistura reduzido.

Após o ensaio de mistura foi realizado um ensaio de ciclo de cisalhamento da suspensão e na Figura 6.42 é apresentada a programação utilizada.

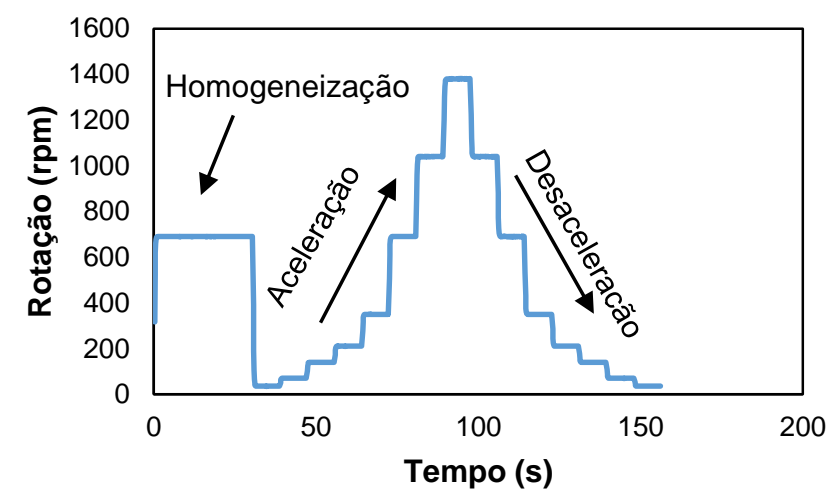

Figura 6.42: Programação utilizada para o ensaio de ciclo de cisalhamento. 
A seguir a Figura 6.43 apresenta o resultado do ciclo de cisalhamento para o teor de sólido de $60 \%$, com as diferentes viscosidades e frações granulométricas. A sigla da legenda segue a mesma descrição dos resultados do ensaio de mistura. Todos os resultados apresentados são referentes a curva de desaceleração.

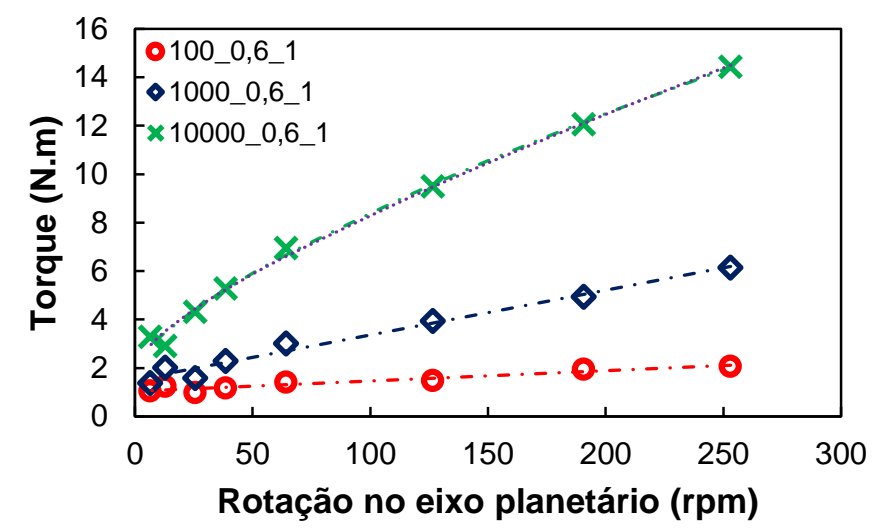

Figura 6.43: Resultado do ciclo de cisalhamento para a fração [1,5-2,2].

Verifica-se que o perfil reológico desta suspensão é afetado pela viscosidade da matriz. Para as suspensões compostas pelo silicone de 100 e 1000 cSt, o perfil reológico foi aproximado por um fluido de Bingham enquanto a suspensão de 10000 cSt por um fluido de Casson (verde claro) e Herschel-Bulkley (roxo). Em todos os casos o $r^{2}$ foi superior a 0,95 .

A mudança do comportamento de um fluido de Bingham para um pseudoplástico se deve ao fato do aumento das forças viscosas e, consequentemente, a necessidade de maior energia para romper os meniscos entre as partículas, visto pela mudança da inclinação da reta. Na Figura 6.44 é apresentado os resultados para as suspensões com as frações [2-2,36] e [4,0-4,45].
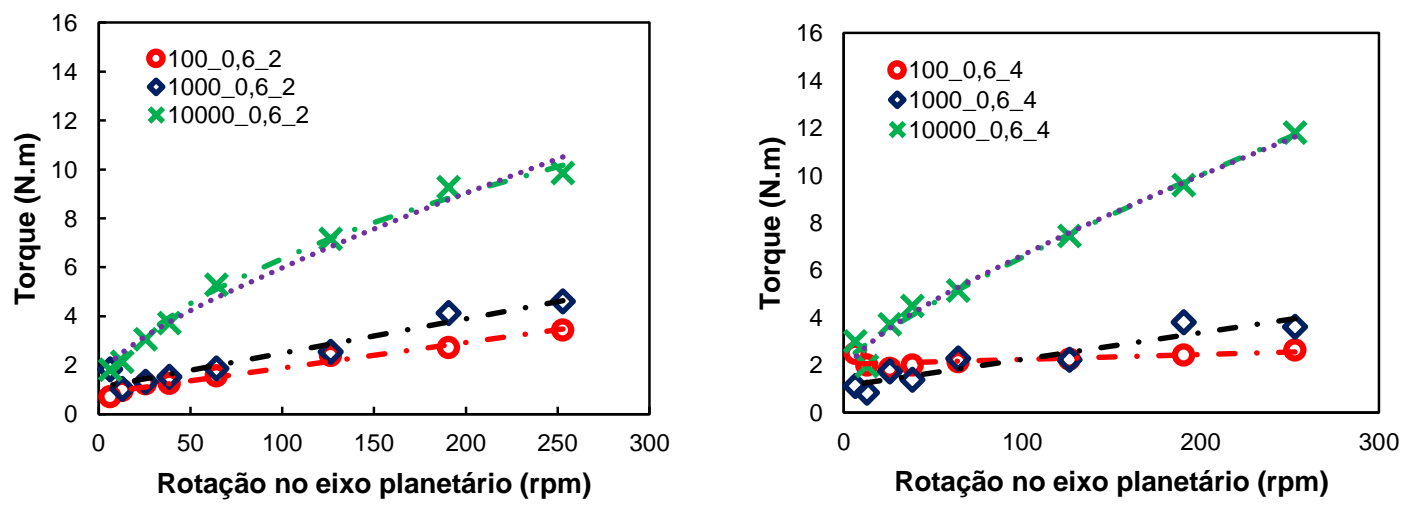

Figura 6.44: Resultado do ciclo de cisalhamento para a fração [2-2,36] e [4,0-4,45]. 
O mesmo fenômeno apontado anteriormente ocorreu para estas suspensões. No entanto, para a fração [4,0-4,45] composta pela viscosidade de 100 cSt apresentou um $r^{2}$ inferior a 0,5. Isso ocorre devido ao efeito parede, dificultando a mobilidade das esferas no início do movimento da raquete, uma vez que pode haver esferas entre o espaçamento raquete-cuba. Por conta disso, há oscilação dos valores medidos de torque em baixas rotações.

Na Figura 6.45 é apresentado o resultado para o teor de $70 \%$.
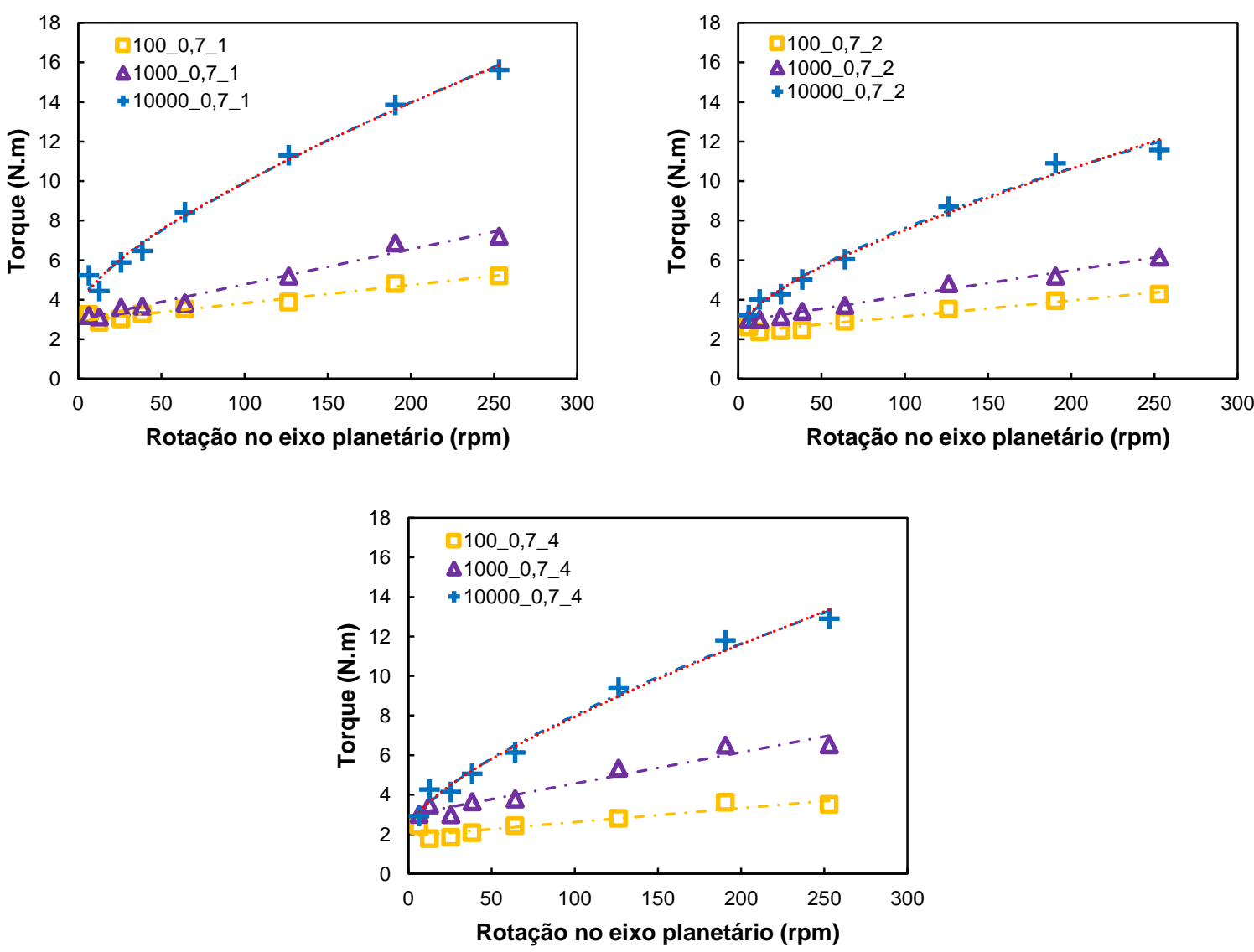

Figura 6.45: Resultado do ciclo de cisalhamento para a fração [1,5-2,2], [2-2,36] e [4,0-4,45].

Novamente é possível observar a predominância do comportamento de um fluido de Bingham para as suspensões compostas pelo silicone de 100 e 1000 cSt e para de 10000 cSt o comportamento de um fluido de Casson (azul claro) e Herschel-Bulkley (vermelho).

A redução do fluido ao redor da partícula favorece a formação dos meniscos e também $\mathrm{o}$ atrito entre elas durante o movimento. O que causa uma diferença entre o resultado do teor de $60 \%$ para o de $70 \%$. 
Todos os ensaios foram realizados com um volume constante de 4 litros, atendendo ao quesito que foi apontado no item 6.2.3. O equipamento mostrou-se adequado e sensível, uma vez que apresentou diferença nos valores dos torques medidos. $O$ programa RheoView mostrou-se adequado para remoção dos outliers, filtragem e tratamento dos dados. Além disso, demonstrou-se adequado na aproximação dos modelos reológicos. 


\section{CONCLUSÃO}

Como já destacado, diversos pesquisadores desenvolveram reômetros para análise de materiais de construção civil, focando principalmente em concretos e argamassas. Para esta pesquisa utilizou-se o reômetro desenvolvido por Rafael G. Pileggi, por possibilitar a investigação do sinal elétrico.

O reômetro em questão é composto basicamente por um servomotor, servoconversor e um conjunto redutor planetário. Para a execução dos ensaios, utilizaram-se sempre patamares de rotações definidas e mediu-se a tensão. As placas de aquisição da Advantech e da National Instruments aquisitaram sinais elétricos pela saída analógica do servoconversor.

O primeiro passo foi identificar qual o melhor parâmetro de aquisição do sinal, sendo que o servoconversor disponibiliza dois tipos de tensões, a de referência e a corrente proporcional ao torque. Pelos resultados observou-se que a tensão proporcional ao torque se apresenta mais satisfatória, principalmente nas altas rotações porque há menos oscilação. Além disso, a tensão proporcional ao torque é uma tensão exclusiva do motor, enquanto que a de referência mede a tensão do equipamento como um todo. Por isso a tensão proporcional ao torque é menos ruidosa e, portanto, foi escolhida como aquela a ser aquisitada para posterior análise dos ensaios.

Ainda que menos ruidosa, assim como qualquer sinal elétrico, há ruído. Para remover a interferência eletromagnética, utilizou-se um cabo blindado, obtendo assim, um sinal menos ruidoso possível.

Utilizando cabo blindado, foi realizada a aquisição do sinal da tensão do motor e passaram-se os dados aquisitados do domínio do tempo para o domínio da frequência, utilizando a transformada de Fourier. Assim, pode-se identificar em quais frequências existia ruído e qual a taxa de aquisição mínima necessária para garantir a integridade do sinal. Verificou-se que seriam necessárias taxa de aquisição de no mínimo 20 amostras por segundo e utilização de um filtro passa-baixa para remover os ruídos de alta frequência.

O software SCI-R de aquisição já presente no equipamento utiliza a placa de aquisição da Advantech e realiza pré-tratamento nos dados. Para verificar a autenticidade dos resultados, comparou-se os dados tratados com os brutos. Para isso, utilizou-se uma 
placa de aquisição da National Instruments e o software LabVIEW. Verificou-se que na média os resultados são semelhantes. No entanto, nos instantes iniciais, a tensão aquisitada pela Advantech fica nula devido ao pré-tratamento. Além disso, não é sensível às mudanças de rotação, como observada na placa da National Instruments. Observou-se também que existe uma defasagem na resposta do sinal, que pode afetar o resultado final. Verifica-se assim a necessidade de realizar alterações no software SCI-R para se obter um resultado fiel. Dessa forma, optou-se pela aquisição do sinal bruto do equipamento favorecendo a compreensão dos fenômenos envolvidos durante o ensaio.

Foram realizados testes de calibração e validação do equipamento. Primeiramente obteve-se a constante de torque do equipamento, utilizando um torquímetro para obter o torque estático e um freio a disco para obter o torque dinâmico do equipamento. Verificou-se que a constante de torque se altera para as diferentes rotações. Em paralelo, foi realizada análise da repetibilidade da linha base do equipamento, obtendo assim, uma função da linha base.

O volume de amostra foi avaliado. Verificou-se que volumes a partir de 3,7 litros de material são suficientes para que o resultado seja independente do volume. Vale ressaltar que o volume 3,7 litros é o mínimo para cobrir todas as haletas da geometria, quando posicionadas a $2 \mathrm{~mm}$ do fundo. Caso a distância do fundo seja maior será necessário um volume maior de material. Além disso, buscou-se avaliar a sensibilidade de leitura do torque através do ensaio de fluxo com material newtoniano, silicone, de diferentes viscosidades. O resultado final foi satisfatório, uma vez que apresentou o perfil reológico esperado. No entanto, quanto menor a viscosidade do fluido, menor será a velocidade necessária imposta para obter um regime turbulento dentro do recipiente o que desfavorece o ensaio reológico, pois a perturbação gerada afeta as medições.

Foi desenvolvido um software de tratamento de dados, o RheoView. Nele foi implementado um filtro digital, suavizações e funções para auxiliar o tratamento e compreensão dos dados. Existe a possibilidade de tratar os ensaios padrões: mistura e ciclo de cisalhamento. O software apresentou-se adequado. Para o ensaio de mistura é possível obter informações importantes, como por exemplo, torque final de mistura e energia de mistura. Já para o ensaio de ciclo de cisalhamento é possível realizar a aproximação do resultado a um modelo reológico. 
Após os testes de validação e calibração acima citados e, também, o desenvolvimento do software para auxiliar a análise dos resultados, avaliou-se o comportamento reológico de suspensões composta por esferas rígidas próximas de monomodais e silicones de diferentes viscosidades. Foi possível observar a variação do comportamento reológico, tanto no ensaio de mistura, quanto no de ciclo de cisalhamento, mostrando mais uma vez a sensibilidade do equipamento. Além disso, observou-se que a geometria utilizada é eficiente no processo de mistura, comprovado pelo teste de contagem de esferas pelas três alíquotas recolhidas na cuba estratificadas em quatro camadas.

Todos os resultados foram tratados utilizando o software RheoView, que atendeu as necessidades de análise de mistura e ciclo de cisalhamento. A aproximação dos dados experimentais aos modelos reológicos condiz com os fenômenos físicos envolvidos.

Entende-se que todo o desenvolvimento para compreensão e interpretação do sinal elétrico pode ser adotada como metodologia de análise do sinal de outros equipamentos. 


\section{REFERENCIA BIBLIOGRÁFICA}

ANTONIOU, A. Digital filters: Analysis, design, and applications. Second ed. [s.I.] McGraw-Hill, 1993.

BANFILL, P. F. G. et al. Comparison of concrete rheometers: International tests at LCPC. Nantes, França: NIST, out. 2000.

BANFILL, P. F. G. The rheology of fresh cement and concrete - A review. Porceedings of the 11th International Cement Chemistry Congress. Anais... In: $11 \mathrm{TH}$ INTERNATIONAL CEMENT CHEMISTRY CONGRESS. Durban: 2003

BANFILL, P. F. G. et al. Rheology of low carbon fibre content reinforced cement mortar. Cement \&amp; Concrete Composites - CEMENT CONCRETE COMPOSITES, v. 28, n. 9, 2006.

BARNES, H. A. Shear-Thickening ("Dilatancy") in Suspensions of Nonaggregating Solid Particles Dispersed in Newtonian Liquids. Journal of Rheology (1978-present), v. 33, n. 2, p. 329-366, 1 fev. 1989.

BARNES, H. A. The yield stress-a review or "таvта $\rho \varepsilon 1$ "-everything flows? Journal of Non-Newtonian Fluid Mechanics, v. 81, n. 1-2, p. 133-178, 1 fev. 1999.

BARNES, H. A.; HUTTON, J. F.; WALTERS, K. An introduction to rheology. Amsterdam; New York: Elsevier: Distributors for the U.S. and Canada, Elsevier Science Pub. Co., 1989.

BEAUPRÉ, D. Rheology of high performance shotcrete. British Columbia: University of British Columbia, 1994.

BOX, G. E. P.; HUNTER, J. S.; HUNTER, W. G. Statistics for experimenters: design, innovation, and discovery. [s.I.] Wiley-Interscience, 2005.

BRUNAUER, S.; EMMETT, P. H.; TELLER, E. Adsorption of gases in multimolecular layers. Journal of the American Chemical Society, v. 60, n. 2, p. 309-319, 1938.

CAZACLIU, B.; ROQUET, N. Concrete mixing kinetics by means of power measurement. Cement and Concrete Research, v. 39, n. 3, p. 182-194, mar. 2009.

CENG, P. M. BS. MS. PH D. F. Industrial Brushless Servomotors. 1 edition ed. Oxford: Newnes, 2000.

CHANDER, S. Challenges in characterization of concentrated suspensions. Colloids and Surfaces A: Physicochemical and Engineering Aspects, v. 133, n. 1, p. 143150, 1998.

CHENG, D. C.-H. Yield stress: A time-dependent property and how to measure it. Rheologica Acta, v. 25, n. 5, p. 542-554, 1 set. 1986.

CHEREMISINOFF, N. P. Encyclopedia of Fluid Mechanics: Slurry flow technology. [s.l.] Gulf Publishing Company, 1986. v. 5 
CLEVELAND, W. S. Robust Locally Weighted Regression and Smoothing Scatterplots. Journal of the American Statistical Association, v. 74, n. 368, p. 829836, 1979.

CLEVELAND, W. S. LOWESS: A Program for Smoothing Scatterplots by Robust Locally Weighted Regression. The American Statistician, v. 35, n. 1, p. 54, 1 fev. 1981.

CLEVELAND, W. S.; DEVLIN, S. J. Locally Weighted Regression: An Approach to Regression Analysis by Local Fitting. Journal of the American Statistical Association, v. 83, n. 403, p. 596-610, 1988.

CYR, M. Contribution à la caractérisation des fines minérales et à la compréhension de leur rôle joué dans le comportement rhéologique des matrices cimentaires. [s.I.] INSA de Toulouse, Université de Sherbrooke, 17 dez. 1999.

DOEBELIN, E. O. Engineering experimentation: planning, execution, reporting. [s.l.] ernest otto doebelin, 1995.

DONNELLY, D. The fast fourier transform for experimentalists, part V: filters. Computing in Science \&amp; Engineering, n. 1, p. 92-95, 2006.

DUAN, H.; BERGGREN, K. K. Directed Self-Assembly at the $10 \mathrm{~nm}$ Scale by Using Capillary Force-Induced Nanocohesion. Nano Letters, v. 10, n. 9, p. 3710-3716, 8 set. 2010.

ELLIS, G. Chapter 15 - Basics of the Electric Servomotor and Drive. In: ELLIS, G. (Ed.). . Control System Design Guide (Third Edition). Burlington: Academic Press, 2004. p. 303-339.

FAY, R. W. Process and apparatus for continuously measuring slump, 2 nov. 1982. Disponível em: <http://www.google.com/patents/US4356723>. Acesso em: 10 fev. 2015

FERNÀNDEZ-ALTABLE, V.; CASANOVA, I. Influence of mixing sequence and superplasticiser dosage on the rheological response of cement pastes at different temperatures. Cement and Concrete Research, v. 36, n. 7, p. 1222-1230, 2006.

FRANÇA, M. S. DE. Comportamento de mistura de sistemas cimentícios multifásicos reativos. text-[s.l.] Universidade de São Paulo, 12 dez. 2012.

GENOVESE, D. B. Shear rheology of hard-sphere, dispersed, and aggregated suspensions, and filler-matrix composites. Advances in Colloid and Interface Science, v. 171-172, p. 1-16, mar. 2012.

GRUBBS, F. E. Sample Criteria for Testing Outlying Observations. The Annals of Mathematical Statistics, v. 21, n. 1, p. 27-58, mar. 1950.

GRUBBS, F. E. Procedures for Detecting Outlying Observations in Samples. Technometrics, v. 11, n. 1, p. 1-21, 1 fev. 1969. 
GUEST, P. G.; GUEST, P. G. Numerical Methods of Curve Fitting. [s.I.] Cambridge University Press, 2012.

HACKLEY, V. A.; FERRARIS, C. F. The use of nomenclature in dispersion science and technology. Gaithersburg, Md.: Washington, DC: U.S. Dept. of Commerce, Technology Administration, National Institute of Standards and Technology ; For sale by the Supt. of Docs., U.S. G.P.O., 2001.

HERRMANN, O.; SCHUESSLER, W. Design of nonrecursive digital filters with minimum phase. Electronics Letters, v. 6, n. 11, p. 329-330, maio 1970.

HODGE, V. J.; AUSTIN, J. A survey of outlier detection methodologies. Artificial Intelligence Review, v. 22, p. 2004, 2004.

HOLMAN, J. P. Experimental Methods for Engineers. [s.I.] McGraw-Hill/Connect Learn Succeed, 2012.

HU, C. Rhéologie des bétons fluides. [s.I.] Ecole Nationale des Ponts et Chaussées, 27 jan. 1995.

$\mathrm{HU}, \mathrm{C}$. et al. Validation of BTRHEOM, the new rheometer for soft-to-fluid concrete. Materials and Structures, v. 29, n. 10, p. 620-631, 1 dez. 1996.

JAYASREE, C.; KRISHNAN, J. M.; GETTU, R. Influence of superplasticizer on the non-Newtonian characteristics of cement paste. v. 44, n. 5, p. 929-942, 2011.

KAISER, J. F. "Nonrecursive Digital Filter Design Using the 10 - sinh Window Function,". Proceedings of 1974 IEEE International Symp. on Circuits and Systems. Anais... In: 1974 IEEE INTERNATIONAL SYMP. ON CIRCUITS AND SYSTEMS. San Francisco: 1974Disponível em: <https://www.researchgate.net/publication/246973293_Nonrecursive_Digital_Filter_D esign_Using_the_10_-_sinh_Window_Function>. Acesso em: 19 fev. 2016

KOEHLER, E. P.; FOWLER, D. W. Development of a Portable Rheometer for Fresh Portland Cement Concrete. Tese de mestrado-Austin, Texas: International Center for Aggregates Research - The University ofTexas, ago. 2004.

LEVIE, R. DE. Advanced Excel for Scientific Data Analysis. Corrected edition ed. Oxford ; New York: Oxford University Press, 2004.

MACOSKO, C. W. Rheology: Principles, Measurements, and Applications. [s.I.] Wiley, 1994.

MARTYR, A. J.; PLINT, M. A. 8 - Dynamometers and the measurement of torque. In: MARTYR, A. J.; PLINT, M. A. (Eds.). . Engine Testing (Third Edition). Oxford: Butterworth-Heinemann, 2007. p. 144-169.

MCCLELLAN, J. H.; PARKS, T. W. A unified approach to the design of optimum FIR linear phase digital filters. IEEE Transactions on Circuit Theory, v. v.20, p. 697-701, nov. 1973. 
MESCHYAN, S. R. Experimental rheology of clayey soils. Rotterdam [Netherlands]; Brookfield [Vt.]: A.A. Balkema, 1995.

MOORE, D. S.; MCCABE, G. P. Introduction to the Practice of Statistics, 4th Edition. 4th edition ed. New York: W. H. Freeman, 2002.

NIENOW, A. W.; EDWARDS, M. F.; HARNBY, N. Mixing in the Process Industries. 2nd. ed. [s.l.] Butterworth-Heinemann, 1997.

NYQUIST, H. Certain Topics in Telegraph Transmission Theory. American Institute of Electrical Engineers, Transactions of the, v. 47, n. 2, p. 617-644, abr. 1928.

OLIVEIRA, I. R. et al. Dispersão e empacotamento de partículas: Princípios e aplicações em processamento cerâmico. $2^{\mathrm{a}}$ ed. São Paulo: Fazendo Arte Editorial, 2000.

OLIVEIRA, I. R. DE et al. Dispersion and setting control of ultra-low cement refractory castables in the Al2O3-SiC-SiO2-C system. Cerâmica, v. 49, n. 309, p. 17-22, mar. 2003.

OPPENHEIM, A. V.; SCHAFER, R. W. Discrete-Time Signal Processing. 3 edition ed. Upper Saddle River: Prentice Hall, 2009.

OPPENHEIM, A. V.; WILLSKY, A. S.; NAWAB, S. H. Signals and Systems. 2 edition ed. Upper Saddle River, N.J: Prentice Hall, 1996.

PILEGGI, R. G. Ferramenta para o estudo e desenvolvimento de concretos refratários. Doutorado em Ciência e Engenharia de Materiais-São Carlos: Universidade Federal de São Carlos, 2001.

PILEGGI, R. G. et al. How mixing affects the rheology of refractory castables. Part 1. American Ceramic Society Bulletin, v. 80, p. 38, 2001 a.

PILEGGI, R. G. et al. How mixing affects the rheology of refractory castables. Part 2. American Ceramic Society Bulletin, v. 80, p. 38, 2001b.

PILEGGI, R. G. et al. New mixer rheometer for granular suspensions. Proceedings of 10th Annual European Rheology Conference. Anais... In: 10TH ANNUAL EUROPEAN RHEOLOGY CONFERENCE. Nantes: 2015

PITOIS, O.; MOUCHERONT, P.; CHATEAU, X. Rupture energy of a pendular liquid bridge. The European Physical Journal B - Condensed Matter and Complex Systems, v. 23, n. 1, p. 79-86, set. 2001.

POWERS, T. C. The properties of fresh concrete. [s.I.] Wiley, 1968.

POWERS, T. C.; WILER, E. M. A device for studying the workability of concrete. Proceedings of 1941 Ameria society for testing and materials. Anais... In: 1941 AMERIA SOCIETY FOR TESTING AND MATERIALS. 1941

PUSEY, P. N.; VAN MEGEN, W. Phase behaviour of concentrated suspensions of nearly hard colloidal spheres. Nature, v. 320, n. 6060, p. 340-342, 27 mar. 1986. 
REIS, P. M. et al. How Cats Lap: Water Uptake by Felis catus. Science, v. 330, n. 6008, p. 1231-1234, 26 nov. 2010.

SAVITZKY, A. A Historic Collaboration. Analytical Chemistry, v. 61, n. 15, p. 921A923A, 1 ago. 1989.

SAVITZKY, A.; GOLAY, M. J. E. Smoothing and Differentiation of Data by Simplified Least Squares Procedures. Analytical Chemistry, v. 36, n. 8, p. 1627-1639, 1 jul. 1964.

SCHRAMM, G. Reologia e reometria: fundamentos teóricos e práticos. [s.l.] Artliber Ed., 2006.

SIMONS, S. J. R.; FAIRBROTHER, R. J. Direct observations of liquid binder-particle interactions: the role of wetting behaviour in agglomerate growth. Powder Technology, v. 110, n. 1-2, p. 44-58, 1 maio 2000.

SIMONS, S. J. R.; SEVILLE, J. P. K.; ADAMS, M. J. An analysis of the rupture energy of pendular liquid bridges. Chemical Engineering Science, v. 49, n. 14, p. 23312339, jul. 1994.

SINNOTT, R. K.; TOWLER, G. Chemical Engineering Design, Second Edition: Principles, Practice and Economics of Plant and Process Design. 2 edition ed. Boston, MA: Butterworth-Heinemann, 2012.

STEFFE, J. F. Rheological Methods in Food Process Engineering. [s.I.] Freeman Press, 1996.

STEINER, T. Continuous control of fresh concrete using the FCT101 tester. Production Methods and Workability of Concrete. Anais... In: INTERNATIONAL RILEM CONFERENCE. Londres: 1996

STEINIER, J.; TERMONIA, Y.; DELTOUR, J. Smoothing and differentiation of data by simplified least square procedure. Analytical Chemistry, v. 44, n. 11, p. 1906-1909, 1 set. 1972.

SZECSY, R. E. Concrete Rheology. Tese de doutorado-Chicago, IL: University of Illinois at Urbana Champaing, 1994.

TATTERSALL, G. H.; BANFILL, P. F. G. The rheology of fresh concrete. [s.I.] Pitman Advanced Publishing Program, 1983.

TAYLOR, F. J. Digital filter design handbook. [s.I.] Marcel Dekker, Inc., 1983.

TEUBERT, J. Ermittlung eines Zementabhängigen Grenzwasserzementwertes als Kenngröße für Sichtbeton. Betonstein-Zeitung, v. 11, p. 654-659, nov. 1969.

TORRES, D. DOS R. et al. Impacto da rota de incorporação de ar nas propriedades de materiais formulados com cimento Portland. Ambiente Construído, v. 14, n. 2, p. 141-152, jun. 2014. 
TYRACH, J. Rheologische Charakterisierung von zementären Baustoffsystemen. Dissertação de doutorado-Alemanha: Universität ErlangenNürnberg, abr. 2001.

VALENCIA, G. A. et al. Effect of superplasticizer on mortars with recycled fine aggregates. Proceedings of III International Rilem Conference on Progress of Recycling in the Built Enviroment. Anais... In: III INTERNATIONAL RILEM CONFERENCE ON PROGRESS OF RECYCLING IN THE BUILT ENVIROMENT. São Paulo: 2015

WALLEVIK, O. H.; GJORV, O. E. Development of a Coaxial Cylinder Viscometer for Fresh Concrete. In: Properties of Fresh Concrete: proceedings of the Rilem Colloquium. Hanover: Chapman \& Hall, 1990. p. 213-224.

WHITTAKER, E. T.; ROBINSON, G. The Calculus Of Observations. [s.I.] Blackie And Son Limited, 1924.

WHORLOW, R. S. Rheological Techniques. 1st edition ed. Chichester Eng. : New York: John Wiley \& Sons Inc, 1980.

WONG, G. S. et al. Portland-Cement Concrete Rheology and Workability: Final Report. Vicksburg, MS: [s.n.]. 


\section{ANEXO A - Programa RheoView}

O programa RheoView, foi desenvolvido no software Matlab utilizando a ferramenta GUI (Graphical User Interfaces). O programa foi desenvolvido utilizando um programa principal (main), que chama as demais funções do programa, conforme ilustrado na Figura 9.1.

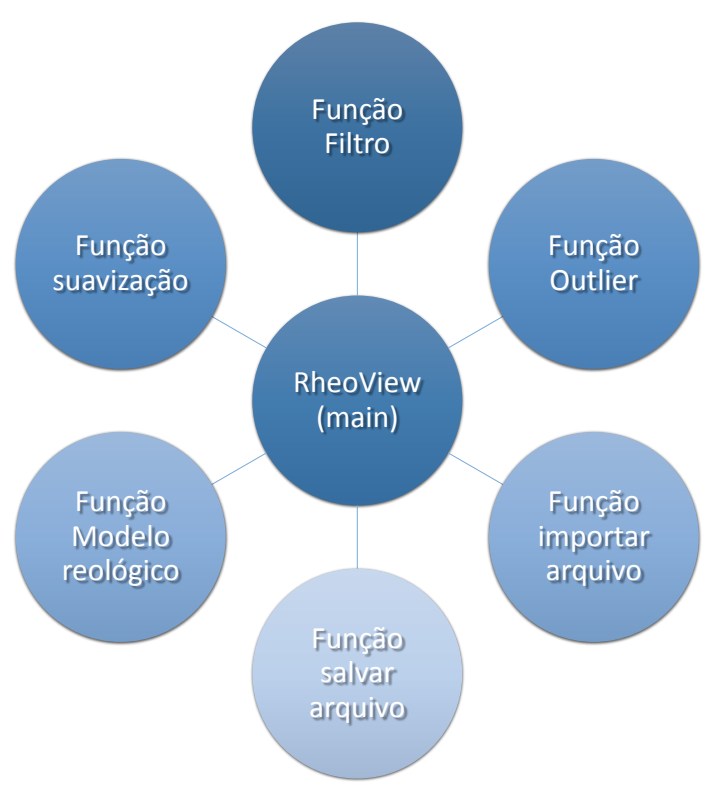

Figura 9.1: Arquitetura do programa

A utilização desta alternativa, reduziu o tempo de processamento e funcionamento do programa. As funções para importar o arquivo e salvar o arquivo são funções do próprio Matlab e por isso não serão apresentadas aqui no anexo. As demais serão apresentadas a seguir.

O programa é divido em três abas (dados, tratamento e análise). A aba dados, serve para carregar os dados brutos, tanto da linha base quanto da amostra. Ao carregar o arquivo, é aplicado a função filtro e outlier nos dados brutos, para remover o ruído e os dados indesejados. Além disso, para a linha base, existe um check-box chamado LBS, que permite utilizar a função da linha base ao invés do arquivo linha base. Vale ressaltar que cada equipamento possui a própria linha base, sendo necessário então adaptar cada programa para o respectivo reômetro que será utilizado. Na Figura 9.2 é apresentado a aba dados. 


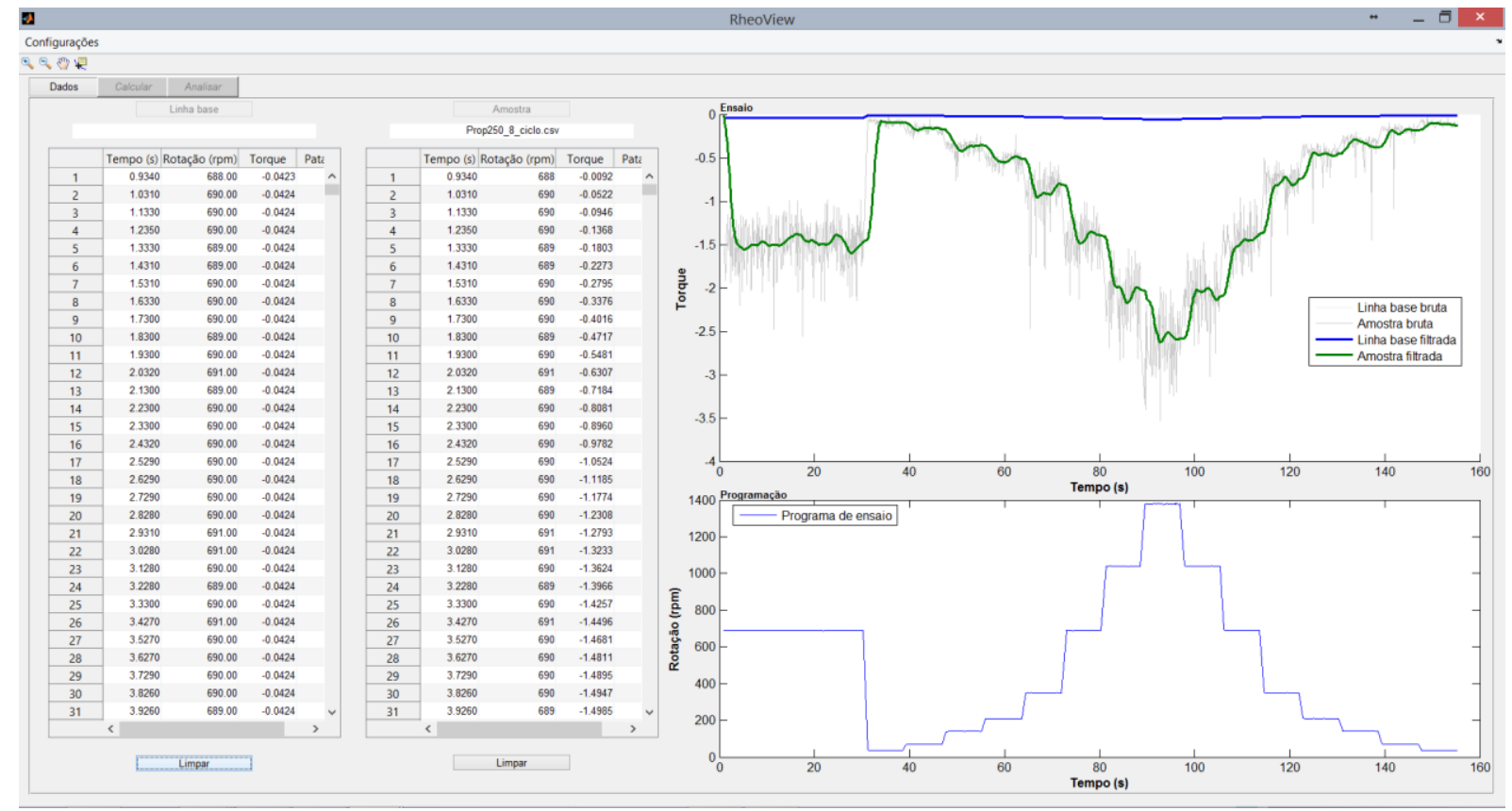

Figura 9.2: Aba dados com os dados da amostra e da linha base já filtrado.

A aba tratamento é o local onde se realiza os inputs do ensaio, como por exemplo, escolha do eixo em que foi acoplado a geometria (planetário ou central), como apresentado na Figura 9.3.

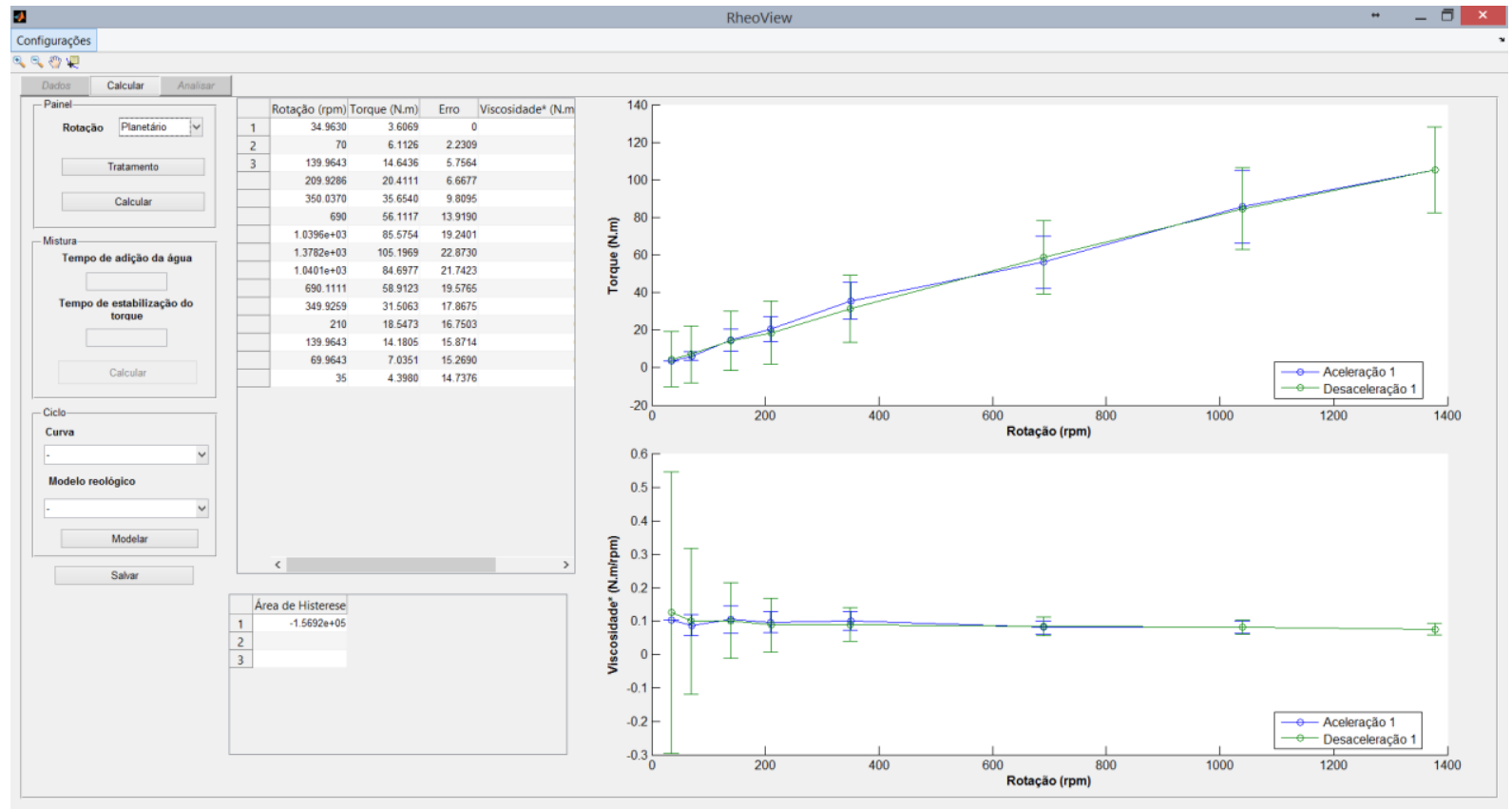

Figura 9.3: Aba calcular, com um exemplo do tratamento para o ensaio de ciclo de cisalhamento.

Mas antes de realizar o cálculo é preciso realizar a escolha do que é necessário realizar com cada etapa de ensaio. Assim é feito a escolha do que se deseja realizar 
com os n's patamares de mesma rotação, ou seja, no patamar de mesma rotação é possível exclui-lo da análise, realizar uma média dos pontos finais ou considerar o patamar inteiro, conforme apresentado na Figura 9.4. Nesta etapa também pode-se realizar a suavização dos dados.

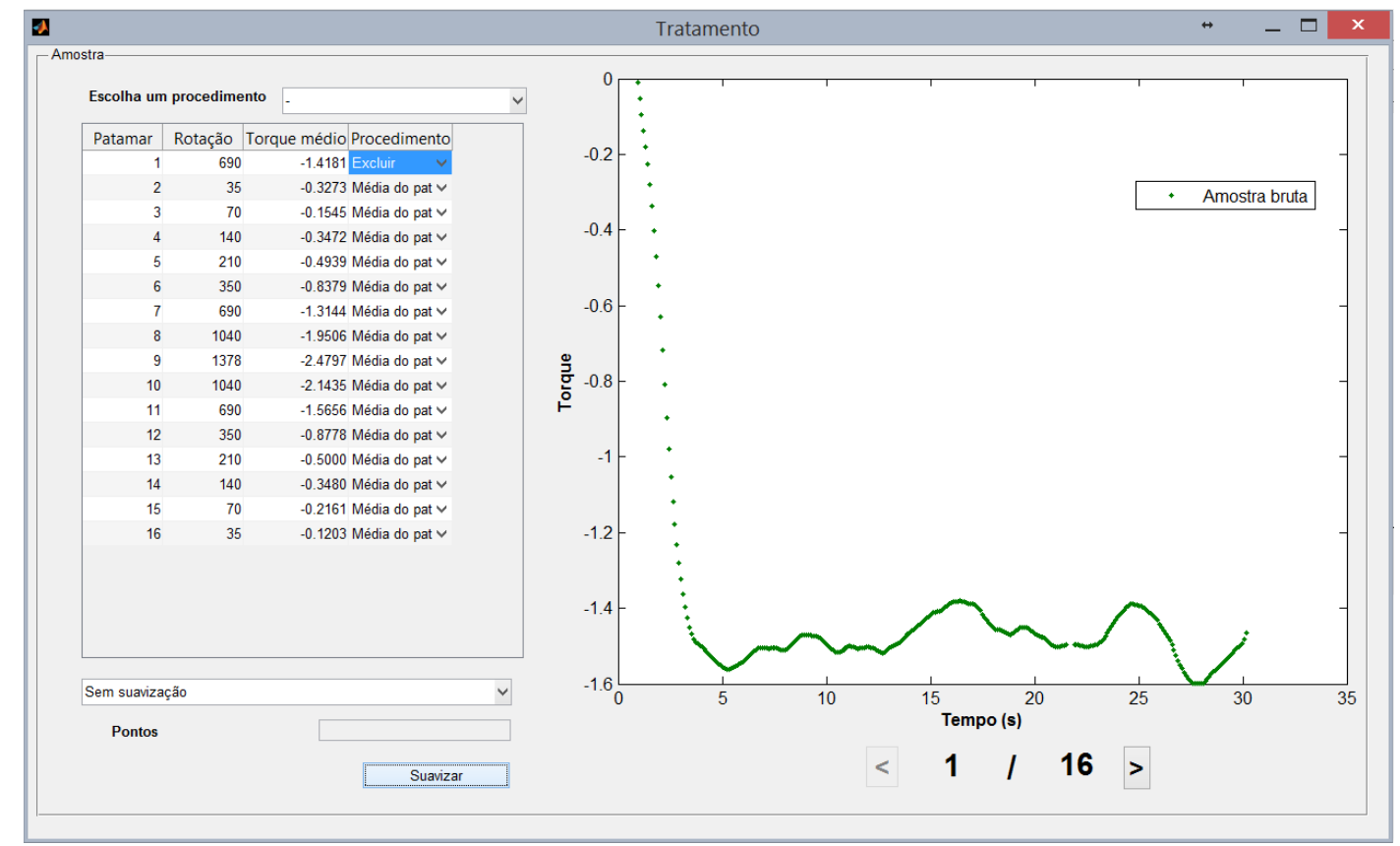

Figura 9.4: Etapa para tratamento de cada etapa do ensaio.

Se o ensaio realizado foi de mistura, é possível quantificar os principais parâmetros, como energia de mistura, torque máximo e torque médio final. Se for o ensaio de ciclo de cisalhamento é possível aplicar algum modelo reológico. Ao salvar o dado tratado e gerado dois arquivos (.mat e .xls) ambos salvam o resultado tratado e os dados brutos.

Já a aba de análise permite carregar os n's ensaios e compará-los com uma maior facilidade e por isso ao salvar o dado tratado existe o arquivo .mat. Na Figura 9.5 é apresentada a aba de análise. 


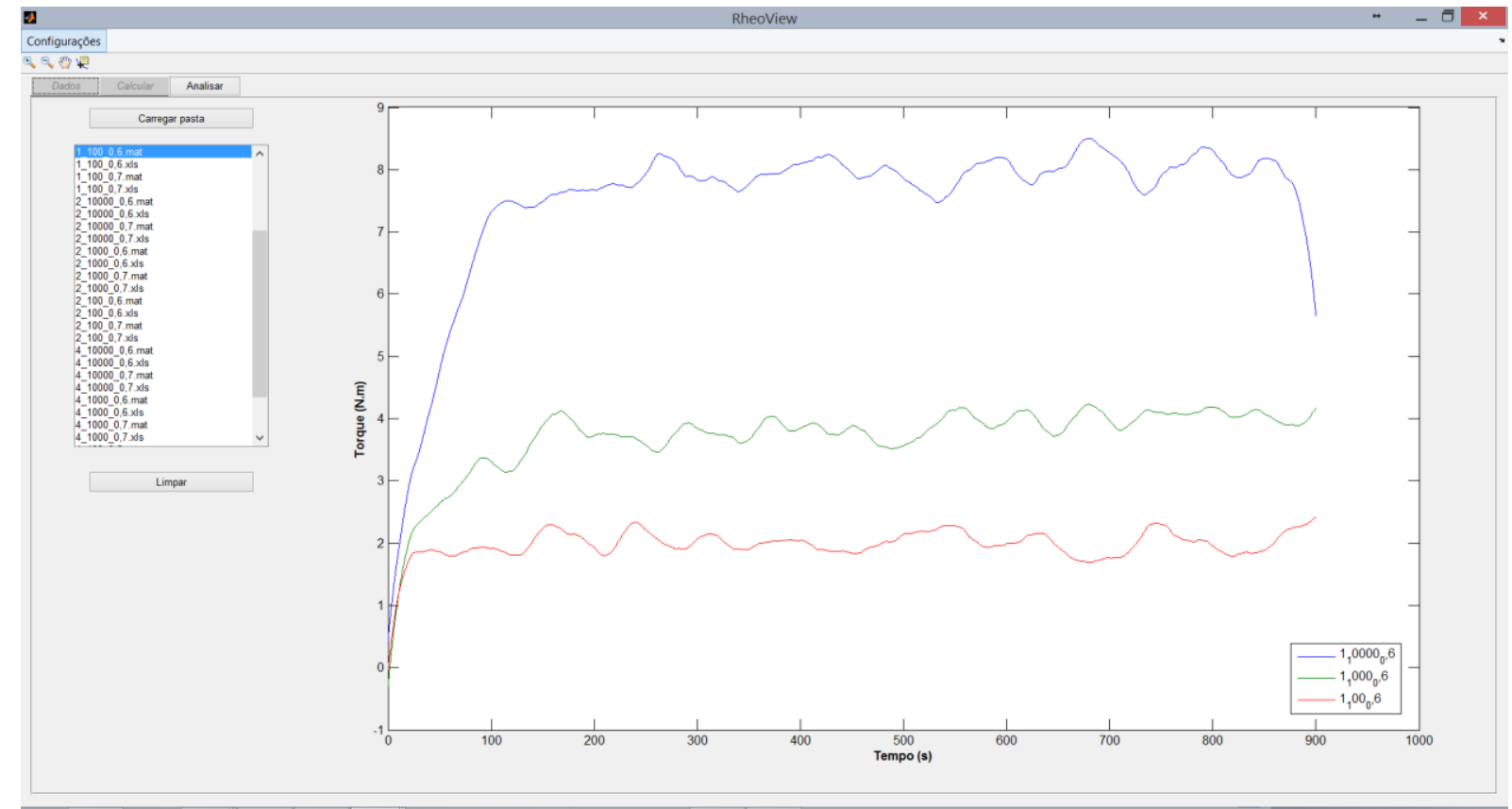

Figura 9.5: Aba análise, elaborada para comparar os ensaios realizados.

Além das abas apresentadas anteriormente, existe um menu para configuração do programa, em que são definidos alguns parâmetros do programa como constante de torque e os parâmetros do filtro.

\subsection{Função outlier}

Foi utilizado o critério de Grubbs para detectar dados espúrios. Este teste é baseado na diferença da média da amostra e os dados mais extremos, considerando o desvio padrão (GRUBBS, 1950), conforme a equação 9.1.

$$
Z=\frac{\left|x_{i}-\bar{x}\right|}{s}
$$

Em que $x_{i}$ é uma observação da amostra, $\bar{x}$ é a média amostral e s é o desvio padrão da amostra. E como critério e adotado a seguinte hipótese estatística:

$$
\left\{\begin{array}{c}
H_{0}: x_{i} \text { é uma observação considerada valor extremo } \\
H_{1}: x_{i} N \text { Ão é uma observação considerada valor extremo }
\end{array}\right.
$$

Rejeita-se a hipótese $H_{0}$ com nível de significância $\alpha$, se Z>Zc. No qual Zc é um valor crítico baseado na distribuição de $Z$ que se encontra na tabela conforme os valores de $\alpha$ unicaudais (GRUBBS, 1969). 


\subsection{Função filtro}

O filtro desenvolvido foi do tipo FIR, por ser mais estável e apresentar uma fase linear, garantindo assim uma robustez do filtro. No entanto, este filtro é de alta ordem, ou seja, mais complexo e por isso tem um tempo de resposta um pouco mais lento. Por conta disso, utilizou-se um outro filtro para compensar esse atraso.

Para o desenvolvimento deste filtro, utilizou-se a função firpmord, que é um algorítimo que foi desenvolvido por James McClellan e Thomas Parks em 1972 (MCCLELLAN; PARKS, 1973). Como parâmetros para o filtro passa-baixa, foi utilizado uma frequência passante de $1,25 \mathrm{~Hz}$ e frequência de parada de $2,0 \mathrm{~Hz}$ e para 0 desenvolvimento foi usado a função filter. Na Figura 9.6 é apresentado a resposta da magnitude e da fase do filtro.

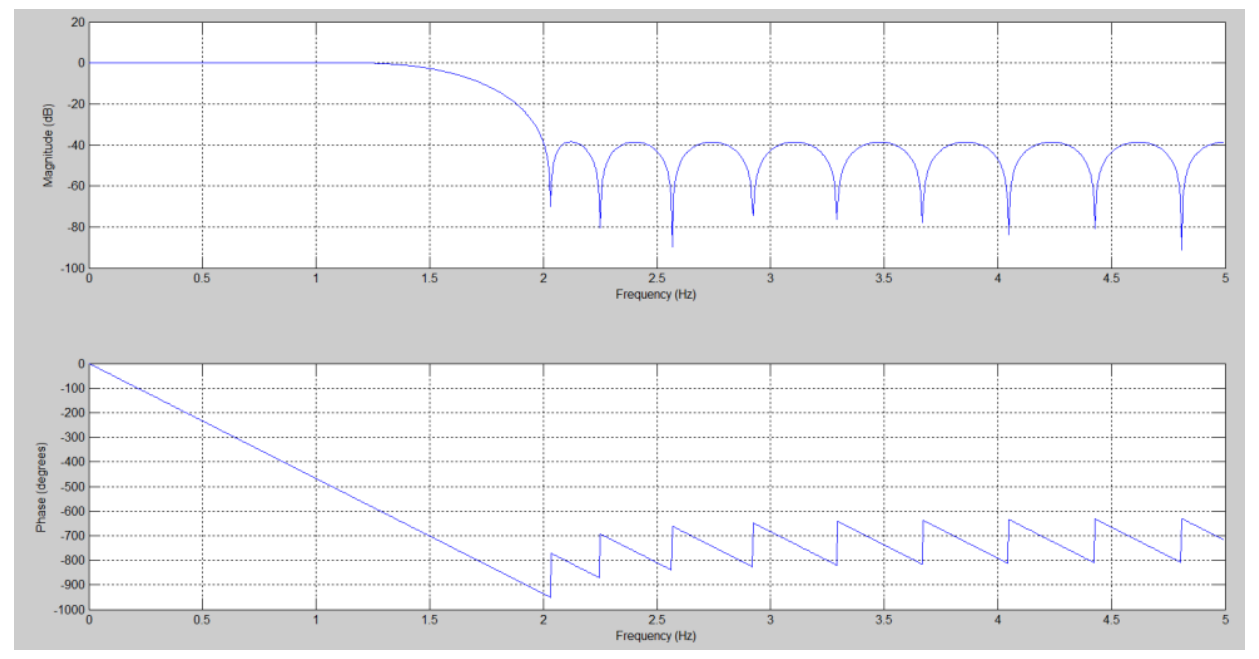

Figura 9.6: Resposta da magnitude e da fase do filtro.

Verifica-se que o filtro desenvolvido apresenta uma fase linear até a frequência de parada. Além disso, o sinal só é atenuado a partir da frequência de $2,0 \mathrm{~Hz}$, como podese observar na resposta da magnitude. $O$ sinal antes da frequência passante não é alterado. Também foi avaliado a estabilidade do filtro, conforma a Figura 9.7. 


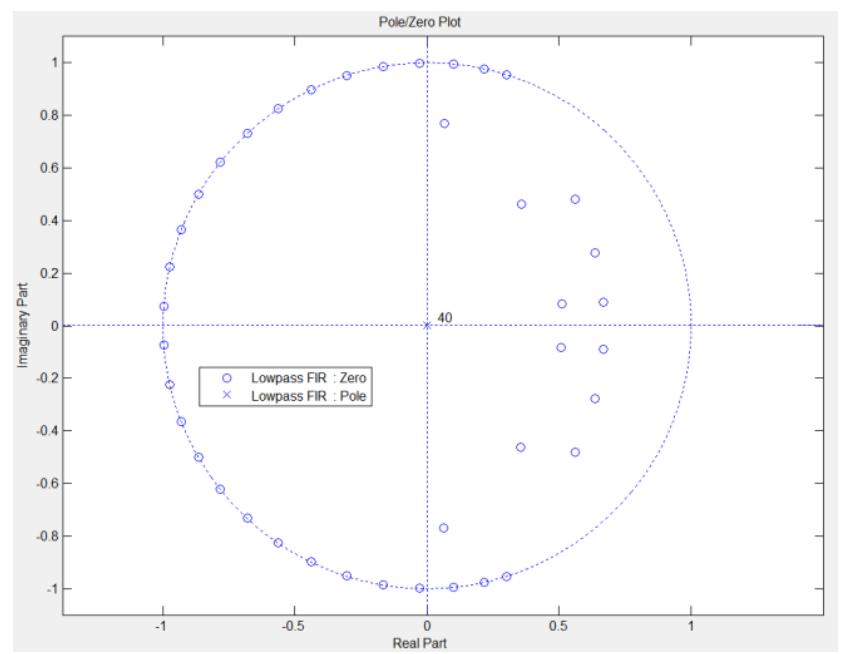

Figura 9.7: Diagrama de polos e zeros para a transformada z.

Pode-se verificar que o filtro é estável, uma vez que todos os polos e zeros estão no interior da circunferência.

Outro fator importante que deve ser avaliado é o tempo de resposta, uma vez que cada filtro possui um tempo de resposta ao impulso. Na Figura 9.8 é apresentado o tempo de resposta do filtro desenvolvido.

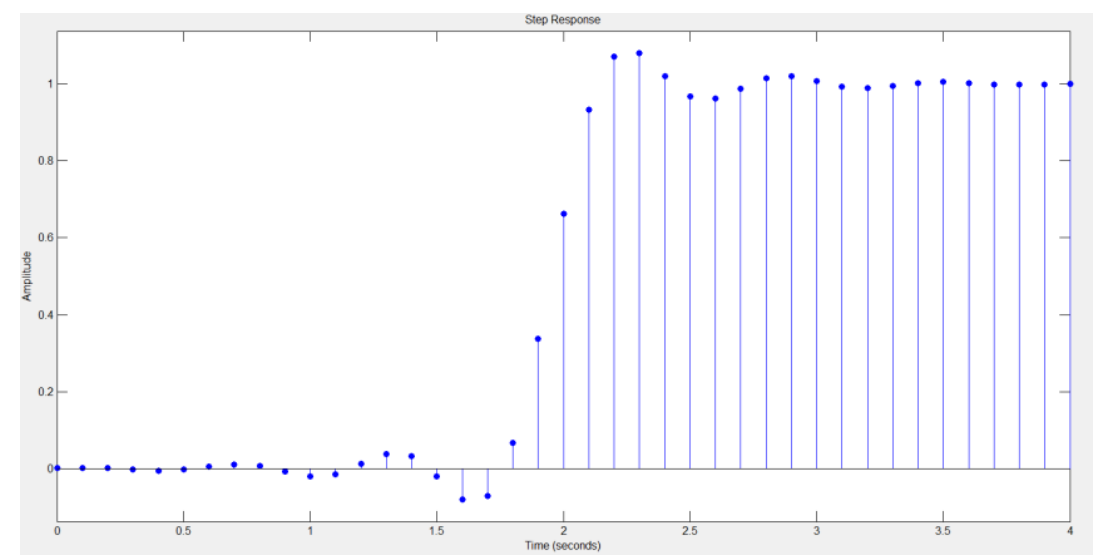

Figura 9.8: Tempo de resposta do filtro

Verifica-se que o tempo de resposta do filtro é de 2 segundos, sendo um valor alto. Por isso, utilizou-se a função filtfilt para reduzir este tempo, e o resultado é apresentado na Figura 9.9. 


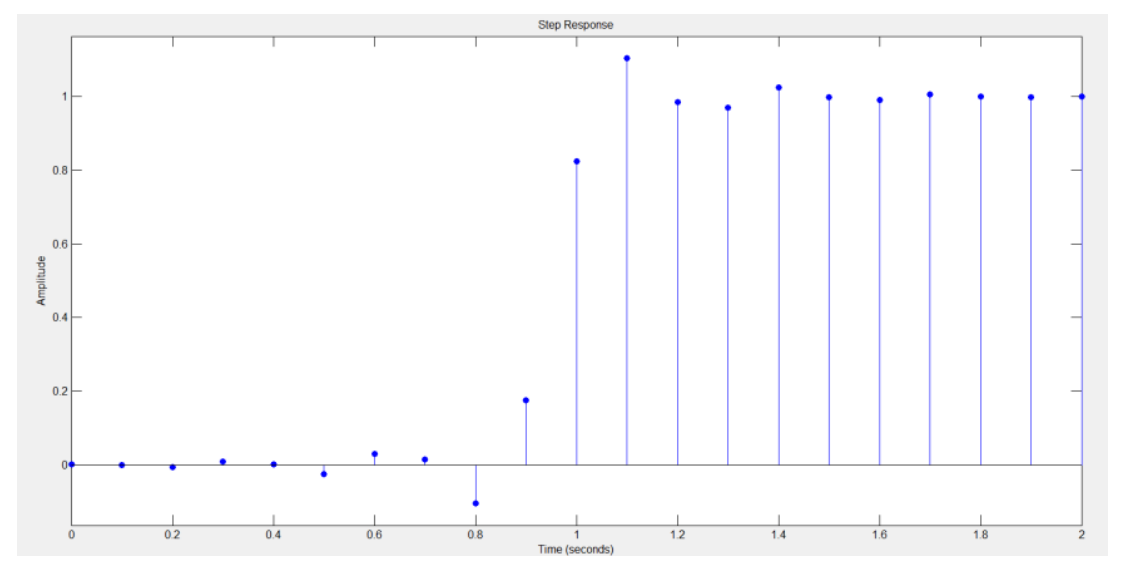

Figura 9.9: Novo tempo de resposta.

Ainda assim, o tempo de resposta do filtro é alto. Isso ocorre porque a faixa de transição, entre frequência de passagem e frequência de parada, é muito próxima, e, por isso, não é possível reduzir muito o tempo de resposta do filtro.

\subsection{Função suavização}

Para a utilização desta função é necessário utilizar o comando smooth, escolher qual método deseja (Média móvel (moving), Savitzky-Golay, Regressão local (loess, lowess) e Regressão local robusta (rlowess, rloess) e o intervalo desejado a ser considerado.

\subsubsection{Média móvel}

A média móvel segue a função dada pela Equação 9.2.

$$
y_{s}(i)=\frac{1}{2 N+1}(y(i+N)+y(i+N-1)+\cdots+y(i-N)
$$

Onde y(i) é o valor bruto, $y_{s}(i)$ é o valor suavizado e o índice i é referente ao i-ésimo ponto, $\mathrm{N}$ é o número de pontos da vizinhança que serão utilizados para o cálculo. 

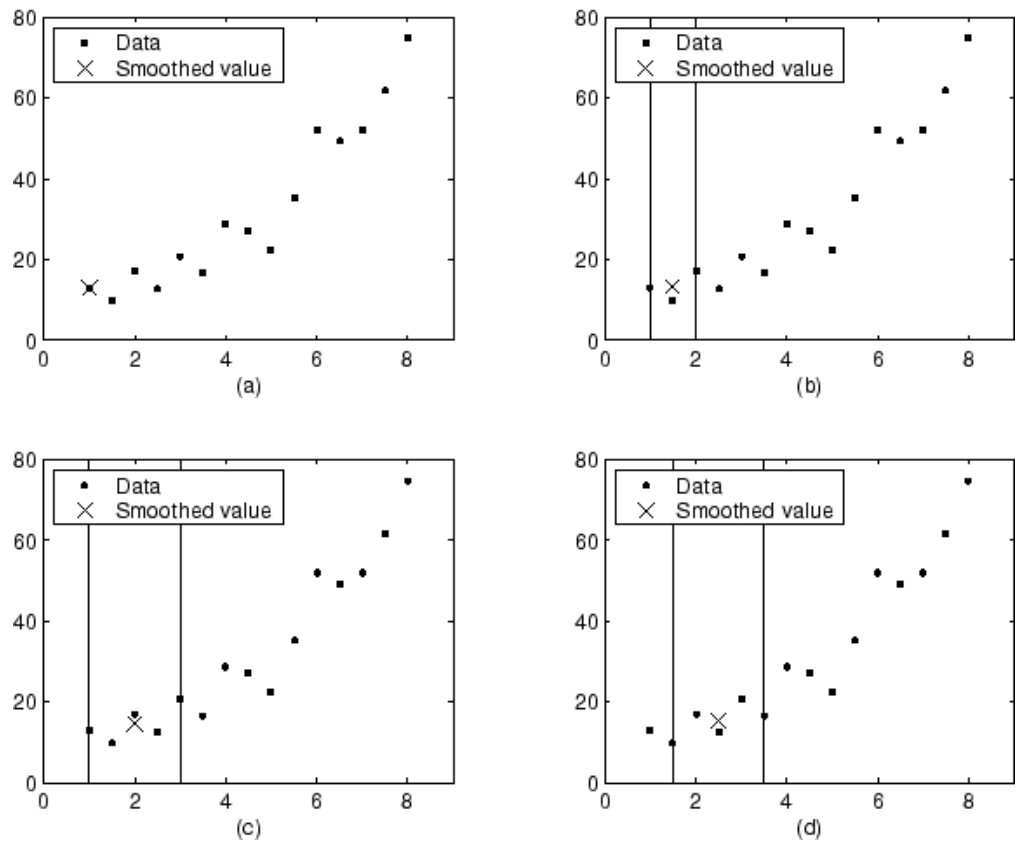

Figura 9.10: Indica que o primeiro ponto (a) não é analisado porque dado o intervalo utilizado não dá para realizar o cálculo. $O$ segundo ponto (b) é analisado através da média dos dois pontos mais próximo. Já o (c) e (d) indicam como é calculado a média dos próximos pontos, utilizando cinco pontos, para realizar a suavização. ${ }^{2}$

Vale ressaltar que este método segue as seguintes regras:

- O intervalo de dados a ser utilizado deve ser ímpar;

- O dado a ser suavizado tem que estar no centro deste intervalo (Figura 9.10c);

- Para os pontos de dados que não podem acomodar o número especificado de vizinhos, adota-se um intervalo capaz de realizar a média, seguindo as regras dos itens anteriores (Figura 9.10-b);

- Os pontos iniciais e finais não serão suavizados por falta de dados a ser utilizado para o cálculo (Figura 9.10-a).

\subsubsection{Savitzky-Golay}

Este método segue as seguintes regras:

- O intervalo de dados a ser utilizado deve ser ímpar;

- O grau do polinômio deve ser menor que o intervalo de dados utilizado para análise; 
- Não é necessário que os dados tenham espaçamento uniforme.

A Figura 9.11 a seguir apresenta dados de uma curva teórica Gaussiana que foi adicionada ruído e algumas tentativas de utilizar a suavização de Savitzky-Golay. Pode-se observar que a curva apresenta diferentes larguras no pico. Para a suavização utilizou-se um intervalo igual a $5 \%$ dos dados.
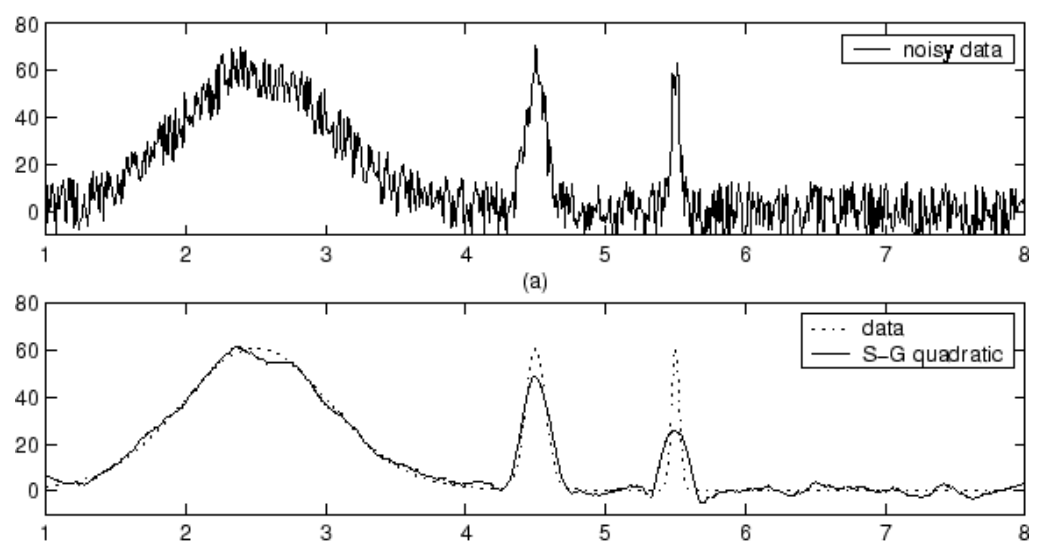

(b)

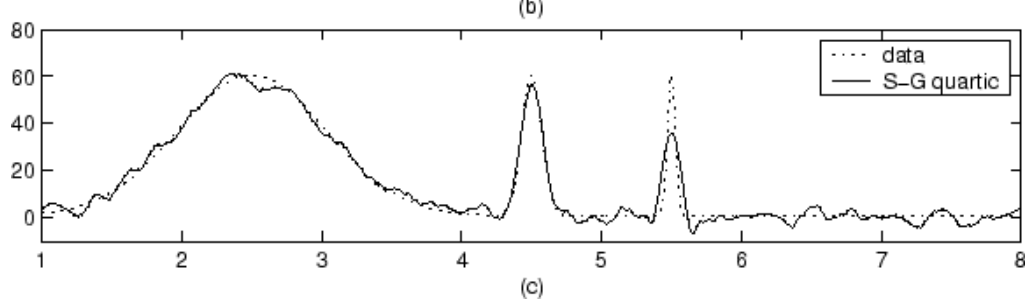

Figura 9.11: (a) Curva teórica com ruído adicionado, (b) suavização com polinômio de ordem dois e (c) de ordem quatro. Para facilitar a comparação dos dados removeu-se o ruído da curva teórica em (b) e (c). ${ }^{3}$

A Figura 9.11-b apresenta os dados filtrados utilizando um polinômio de ordem dois. Observa-se que este método não é adequado quando a largura do pico é estreita, pois não consegue se aproximar do resultado real. E a Figura 9.11-c apresenta os dados filtrados utilizando um polinômio de ordem quatro. Em geral, quanto maior a ordem do polinômio, o dado suavizado se adequa mais aos picos com pequena largura, mas para picos de maiores larguras o ruído interfere no dado tratado, distorcendo o resultado final.

\subsubsection{Regressão local}

Este método segue as seguintes regras:

\footnotetext{
${ }^{3}<$ http://www.mathworks.com/help/curvefit/smoothing-data.html> Acessado em15/02/2015
} 
- Pode se especificar o intervalo como a porcentagem do total de número de dados. Por exemplo, para um intervalo de 0,1 , utilizam-se intervalos com 10\% dos dados.

- O intervalo de dados a ser utilizado pode ser par ou ímpar;

\section{Método de regressão local robusto}

A regressão local utiliza os seguintes passos para calcular os dados tratados:

1. A ponderação da regressão é calculada para cada ponto dentro do intervalo de cada dado. A função ponderada $\left(w_{i}\right)$ é dada pela função tri-cúbica apresentada a seguir.

$$
w_{i}=\left(1-\left|\frac{x-x_{i}}{d(x)}\right|^{3}\right)^{3}
$$

Onde $x$ é o valor predito associado à resposta que será suavizada, $x_{i}$ é o ponto da vizinhança mais próximo de $x$ que foi definido pelo intervalo e $d(x)$ é a distância entre os pontos medidos na abscissa.

O ponto a ser suavizado tem o maior peso e é o que mais influência na suavização e os dados fora do intervalo possuem um peso igual a zero e não influenciam na suavização. Se os dados a serem tratados apresentam a mesma quantidade de pontos em ambos os lados da vizinhança, a função de ponderação será simétrica. No entanto, se for diferente a ponderação não será a mesma, ou seja, não será simétrica (Figura 9.12). Para os pontos inicias até os pontos que não ficam simétricos de acordo com o intervalo, a função de ponderação fica truncada e os valores inicias ficam com o maior valor e utilizase somente os dados do lado direito e isto se repete para os últimos dados, porém do lado esquerdo. Já para os valores intermediários a ponderação é aplicada de forma simétrica e sem truncamento. 


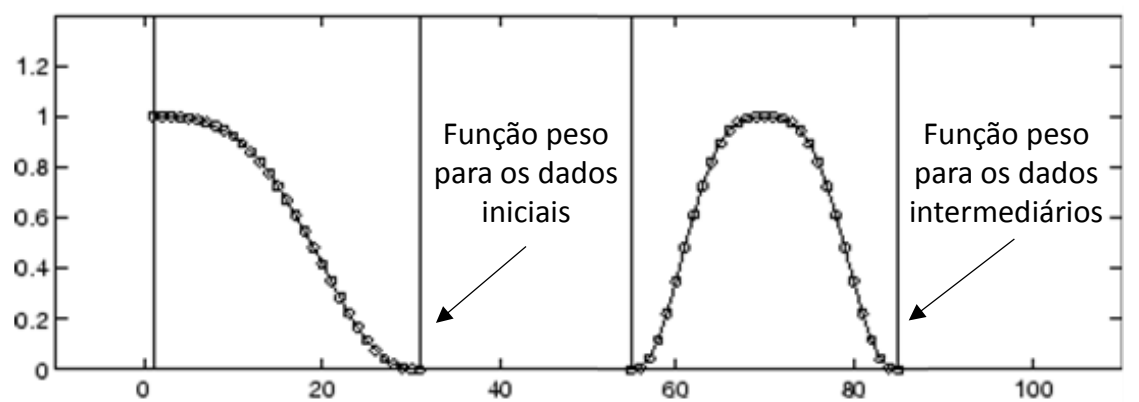

Figura 9.12: Exemplo de cálculo da função de ponderação para os pontos iniciais e intermediários. $^{4}$

2. É realizada uma aproximação por métodos dos mínimos quadrados utilizando uma regressão linear ponderada. Para o LOWESS utiliza-se um polinômio de ordem um e para o LOESS utiliza-se um polinômio de ordem dois.

3. O valor suavizado é dado pela regressão ponderada no ponto de interesse.

Deve-se destacar que, diferente da média móvel, o intervalo nunca muda para o cálculo do ponto de interesse (Figura 9.13).
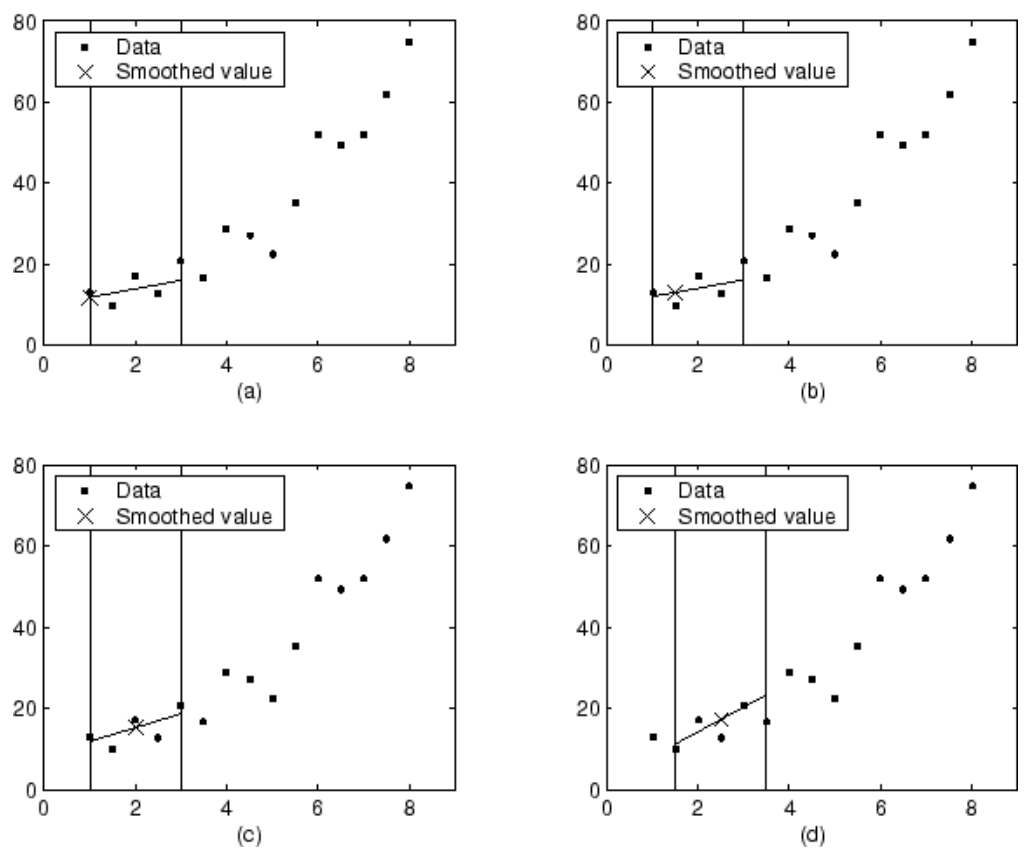

Figura 9.13: Exemplo de cálculo dos pontos de suavização dos dados através do método LOWESS. $^{5}$

A Figura 9.13-a e Figura 9.13-b utilizam uma função de ponderação assimétrica enquanto que a Figura 9.13-c e Figura 9.13-d utilizam uma função simétrica.

\footnotetext{
$4<$ http://www.mathworks.com/help/curvefit/smoothing-data.html> Acessado em15/02/2015

${ }^{5}<$ http://www.mathworks.com/help/curvefit/smoothing-data.html> Acessado em15/02/2015
} 
O método LOESS utiliza o mesmo procedimento e a única diferença é que a função de suavização seria gerada a partir de uma função polinomial de segunda ordem.

\section{Método de regressão local robusto}

Se os dados apresentarem espúrios, os valores da suavização podem-se distorcer e não refletir o comportamento da maioria dos dados vizinhos. Para superar este problema, pode-se usar o método de regressão local robusto, que sofre menos influência dos espúrios na suavização.

No software Matlab existe a função robusta para os dois métodos LOWESS e LOESS. Neste método, além do cálculo da função de ponderação apresentada anteriormente, realiza-se um novo cálculo de uma função ponderada robusta, que não sofre tanta influência dos dados espúrios. A suavização robusta segue os seguintes passos:

1. É calculado a suavização conforme o procedimento descrito anteriormente para verificar o resíduo dos dados;

2. Em seguida, é calculado a ponderação robusta $\left(w_{i}\right)$ de cada dado dentro do intervalo. A ponderação é dada pela função a seguir:

$$
w_{i}=\left\{\begin{array}{cl}
\left(1-\left(\frac{r_{i}}{6 M A D}\right)^{2}\right)^{2} & \left|r_{i}\right|<6 M A D \\
0, & \left|r_{i}\right| \geq 6 M A D
\end{array}\right.
$$

Onde ri é o valor residual do i-ésimo ponto caluclado e MAD é o desvio absoluto médio dos resíduos.

$$
M A D=\operatorname{median}(|r|)
$$

O desvio médio absoluto (MAD) avalia o comportamento do resíduo. Se ri é maior que $6 \mathrm{MAD}$ a ponderação é 0 e o ponto é excluído da suavização.

3. É realizado o cálculo, novamente, mas agora utilizando a função de ponderação robusta e é calculado a suavização;

4. Repete-se as duas últimas etapas por cinco vezes.

Na Figura 9.14 é apresentado os resultados comparando a suavização utilizando o procedimento LOWESS e o robusto (RLOWESS). Para este cálculo utilizou-se um intervalo de 11 pontos. 

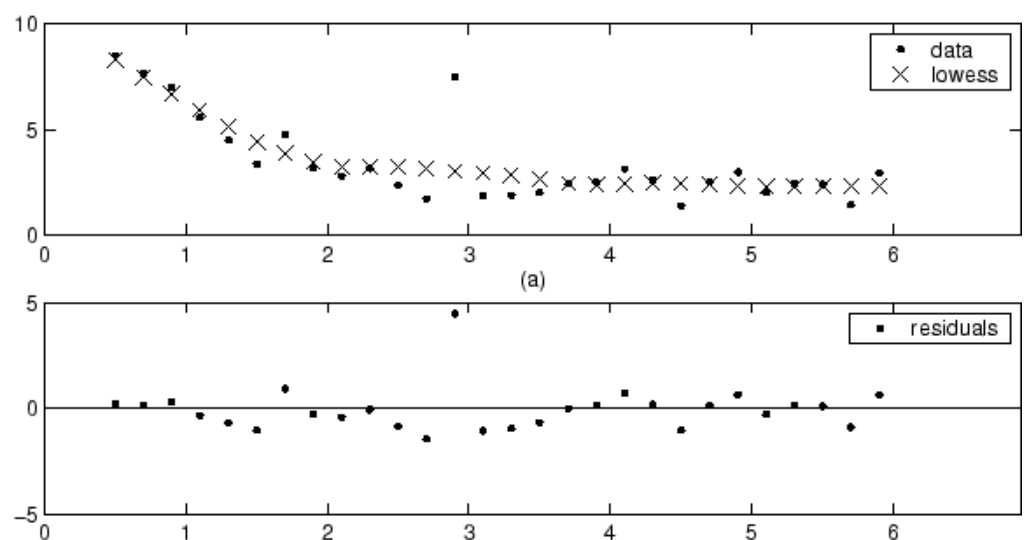

(b)

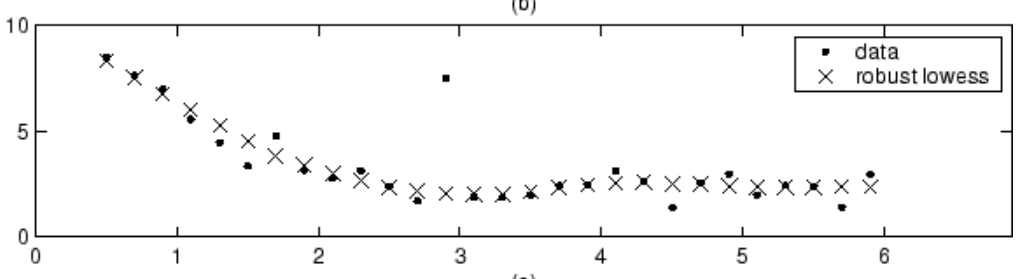

(c)

Figura 9.14: (a) suavização utilizando o método LOWESS (b) resíduo entre o dado original e dado suavizado. (c) suavização utilizando o método RLOWESS. ${ }^{6}$

Pode-se observar que o espúrio influencia no cálculo da suavização dos pontos vizinhos enquanto que para o método robusto este espúrio não influencia.

No programa, fica a critério do usuário escolher o método de suavização, bem como o intervalo de pontos a ser utilizado.

\subsection{Função ajuste da curva}

Para execução desta função, é necessário utilizar o comando no Matlab conhecido como fit e definir qual tipo aproximação será desejada:

i. Aproximação polinomial;

ii. Aproximação exponencial;

iii. Aproximação da série de Fourier;

iv. Aproximação Gaussiana;

v. Ajuste por segmento;

vi. Aproximação por soma de seno.

Para o programa foi utilizado o ajuste por segmento. Este modelo utiliza alguns parâmetros para o seu cálculo, sendo eles: parâmetro de suavização $(p)$, coeficiente 
de ponderação $\left(w_{i}\right)$ e um coeficiente de ajuste específico para os parâmetros anteriores (s). Se não for especificado nenhum parâmetro, todos assumem o valor de 1. A equação é apresentada a seguir:

$$
y=p \sum_{i} w_{i}\left(y_{i}-s\left(x_{i}\right)\right)^{2}+(1-p) \int\left(\frac{d^{2} s}{d x^{2}}\right)^{2} d x
$$

O parâmetro de suavização (p) possui o valor entre 0 e 1. Nota-se que para o valor de $p=1$, nos leva a uma função do primeiro grau, com uma aproximação de mínimos quadrados e para $p=0$ nos leva a uma interpolação cúbica do resultado.

\subsection{Função modelo reológico}

Esta função permite uma aproximação dos modelos reológico mais comum, sendo eles: Newton, Bingham, Lei de potência, Herschel-Bulkley e Casson. Para realizar a aproximação, utilizou-se a mesma função do ajuste da curva (fit). Mas o tipo utilizado foi de acordo com os modelos. 


\section{ANEXO B - Comparativo dos filtros}

Neste anexo são apresentados resultados tratados de ensaio de mistura e de ciclo de cisalhamento utilizando os diferentes filtros apresentados no item 6.3.2 (página 81). Para o ensaio de mistura utilizou-se uma argamassa e para o de ciclo de cisalhamento um concreto auto adensável. O intuito deste estudo é analisar o efeito causado pela má utilização de um filtro para a interpretação dos resultados.

Para o ensaio de mistura utilizou-se o mesmo procedimento apresentado no item 6.4 (página 87). Apenas foi utilizado um tempo menor de mistura de 330 segundos. $\mathrm{Na}$ Figura 10.1 é apresentado o resultado bruto obtido do ensaio de mistura.

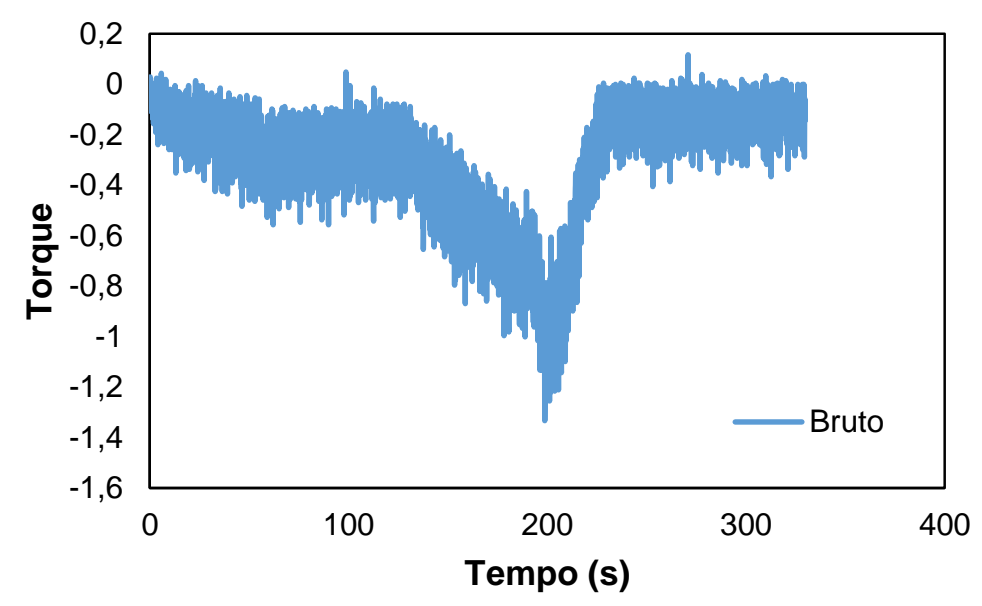

Figura 10.1: Resultado bruto para o ensaio de mistura (rotação do motor em $690 \mathrm{rpm}$ ) de uma argamassa.

Observa-se que esta curva é uma curva característica de um ensaio de mistura, porque no instante em que se adiciona a água no sistema, no instante 120 segundos, há um acréscimo nos níveis de torque até atingir um torque máximo e em seguida há o decaimento em módulo, indicando que a quantidade de água adicionada no sistema foi o suficiente para separar as partículas uma das outras. Aplicando os filtros estudados: Butterworth, Chebshev tipo 1 e 2, Eliptic e FIR, no dado anterior obtém-se o resultado apresentado na Figura 10.2. 


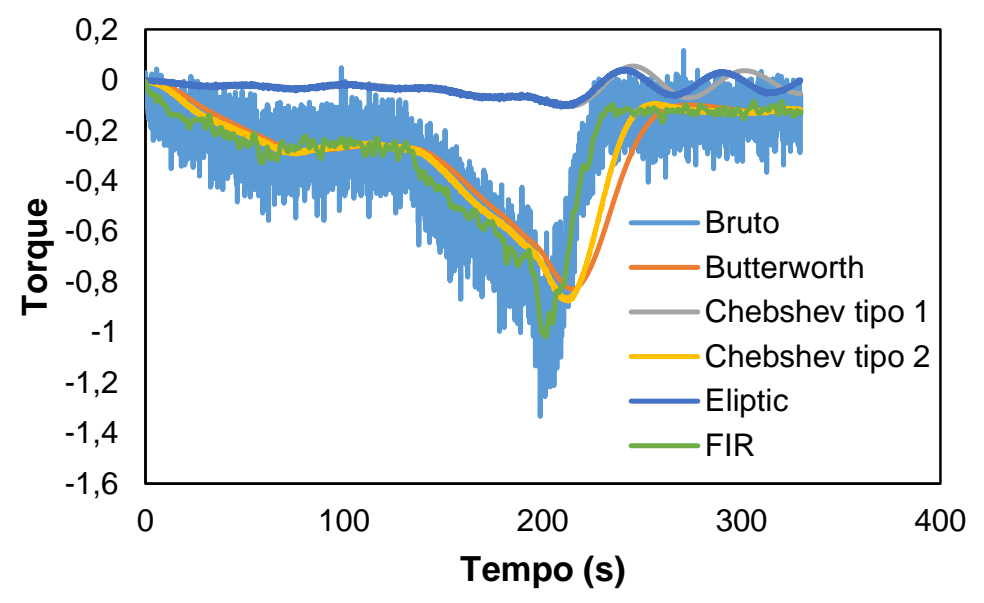

Figura 10.2: Comparativo do dado tratado para os diferentes tipos de filtros.

Verifica-se que os filtros Chebshev tipo 1 e Eliptic não são satisfatórios, uma vez que distorcem por completo o resultado. Já os filtros Butterworth e o Chebshev tipo 2 são melhores se comparado aos anteriores, mas apresentam pequena distorção e também atraso no resultado por conta do tempo de resposta do filtro. O filtro FIR escolhido para a filtragem dos dados é aquele que se apresenta mais adequado, porque os dados são filtrados sem distorcer do resultado bruto obtido. A seguir é apresentado um comparativo do torque máximo, em módulo, e do instante em que ocorre para os diferentes filtros, conforme a Figura 10.3. Lembrando que o torque máximo para cada filtro corresponde ao valor mais próximo do torque máximo do resultado bruto.

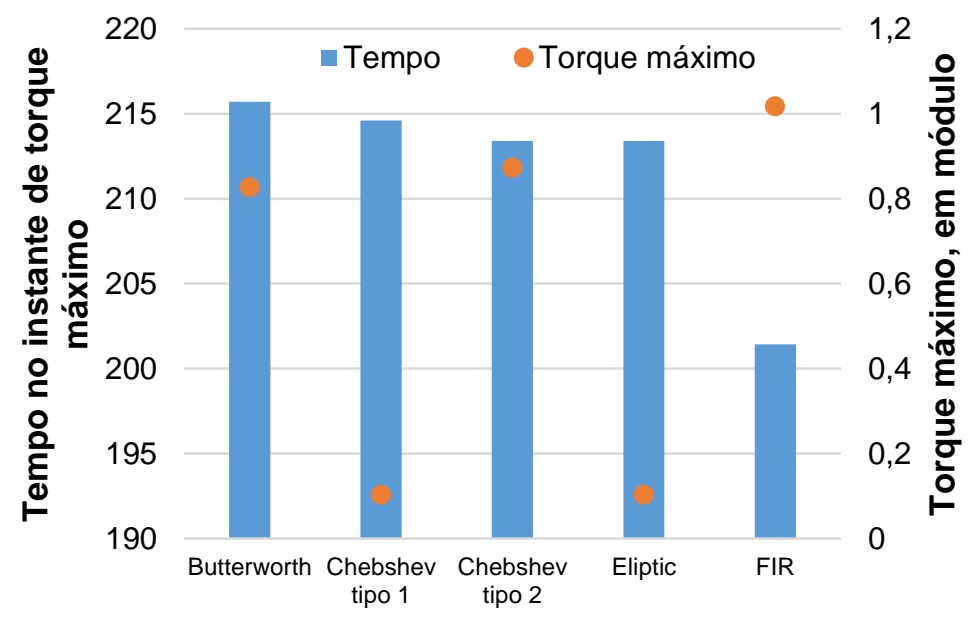

Figura 10.3: Instante em que ocorre este fenômeno e torque máximo de mistura para os filtros estudados no tratamento do mesmo dado bruto. 
Pelo resultado pode-se observar que o instante em que ocorre o torque máximo, para os filtros Butterworth, Chebshev tipo 1, Chebshev tipo 2 e Eliptic são próximo, com uma diferença máxima de aproximadamente 2 segundo. Verifica-se que há uma diferença notável no torque máximo entre os filtros. No entanto, o resultado se difere razoavelmente do real. Nitidamente, há uma diferença no instante em que ocorre o torque máximo e isso ocorre por conta do tempo de resposta do filtro. Além disso, o valor de torque máximo é diferente devido à má filtragem. O filtro FIR se apresentou adequado para utilizar no processo de filtragem.

Além do ensaio de mistura, realizou-se ensaio de ciclo de cisalhamento com um concreto auto adensável, em que o procedimento foi idêntico ao do item 6.4 (página 87). Na Figura 10.4 é apresentado o resultado bruto do ciclo de cisalhamento. Inicialmente realizou-se pré-homogeneização do material com duração de 30 segundos na rotação de 690 rpm no motor.

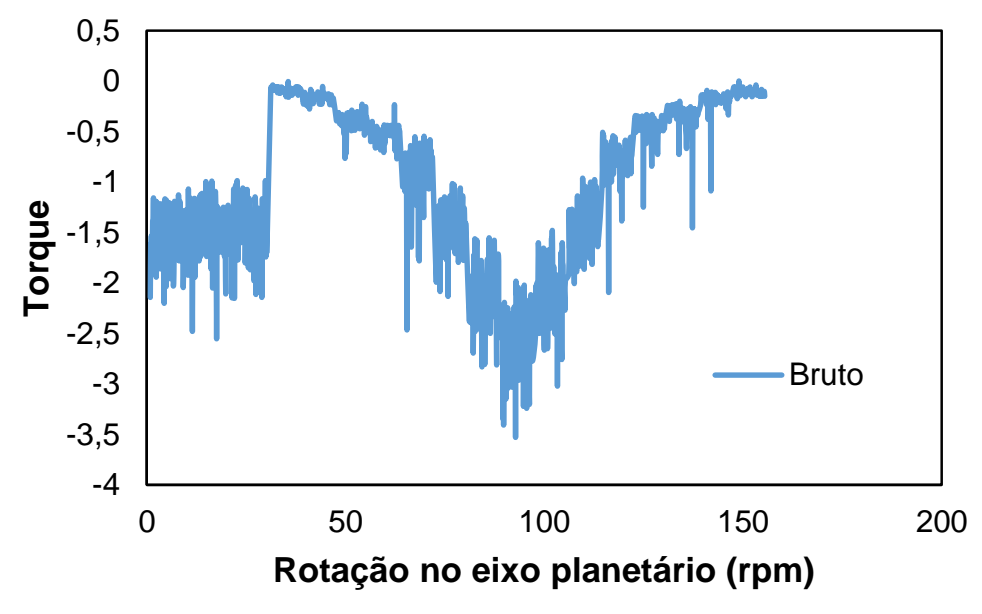

Figura 10.4: Resultado bruto para o ensaio de ciclo de cisalhamento com pré-homogeneização.

Observa-se que esta curva é característica de um ensaio de ciclo de cisalhamento em que a resposta do torque é influenciada pela rotação que está sendo aplicada ao material. Aplicando os filtros estudados: Butterworth, Chebshev tipo 1 e 2, Eliptic e FIR, no dado anterior obtém-se o resultado apresentado na Figura 10.5. 


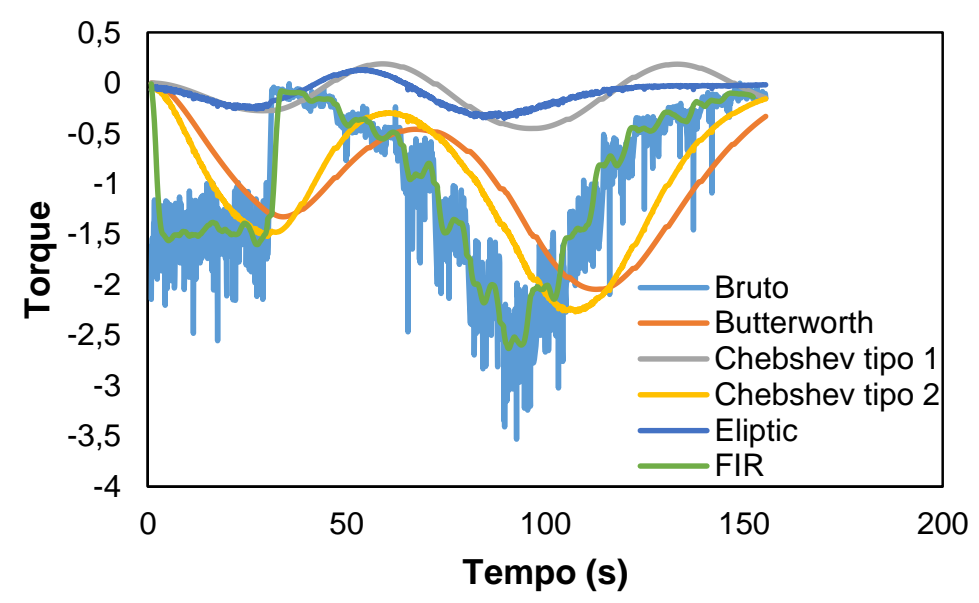

Figura 10.5: Comparativo do dado tratado para os diferentes tipos de filtros de um mesmo dado bruto de ensaio de ciclo de cisalhamento.

Assim como observado no ensaio de mistura, os filtros Chebshev tipo 1 e Eliptic não são satisfatórios, pois há grande divergência do resultado real. Já os filtros Butterworth e Chebshev tipo 2 seguem a tendência do resultado mas apresentam considerável defasagem, como observado anteriormente no tratamento do ensaio de mistura. Além disso, para os filtros discutidos anteriormente, sua resposta é afetada devido ao pequeno intervalo de cada patamar (8 segundos). O filtro FIR apresentou-se satisfatório, pois há a filtragem dos dados sem distorcer do resultado bruto obtido no ensaio. Comumente o resultado de ciclo de cisalhamento é analisado pelo gráfico de rotação $x$ torque, que é apresentado na Figura 10.6.

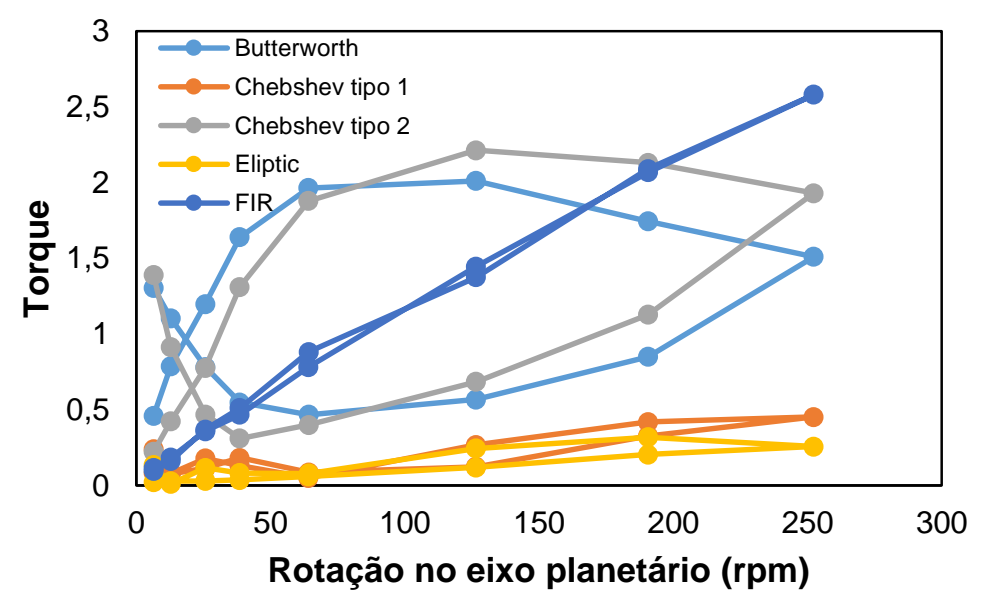

Figura 10.6: Perfil reológico resultante do tratamento de diferentes filtros para o mesmo material. 
Verifica-se que o processo de filtragem afeta o resultado final, alterando o perfil reológico do material. O resultado mais próximo do real é apresentado pelo filtro FIR, sendo um perfil de um fluido newtoniano. Se utilizado o filtro Chebshev tipo 1 e Eliptic o resultado final fica próximo de um fluido newtoniano, mas com uma inclinação muito mais baixa. Já para os filtros Butterworth e Chebshev tipo 2, que a princípio se assemelhava a curva dos dados brutos, mas com uma defasagem, apresenta um resultado completamente diferente. Além de apresentar um perfil reológico diferente do real, exibe, também, uma área de histerese muito grande, que levaria a interpretações equivocadas do material.

Por conta dos resultados apresentados anteriormente, adotou-se a utilização do filtro FIR. 